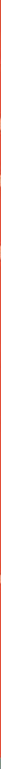

Interdisciplinary Research in Gender

\title{
FORCED MIGRATION IN THE FEMINIST IMAGINATION
} TRANSCULTURAL MOVEMENTS

Anna Ball

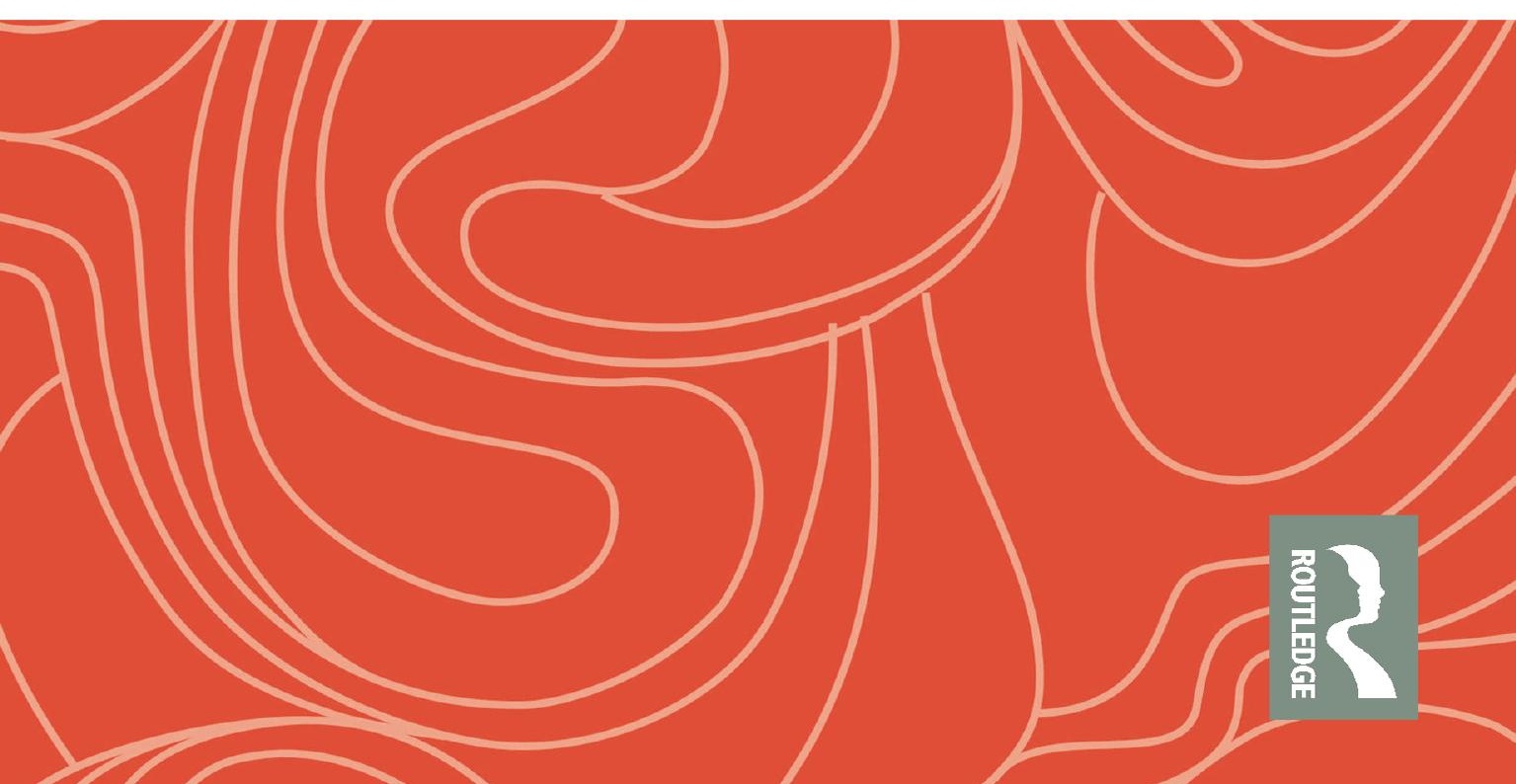


"This book provides a much needed critical engagement with an entire field of multi-media work that has appeared in order to specifically document, represent and facilitate an understanding of the experiences of forced migration. Anna Ball's intervention shows us how to construct creative and compassionate responses and as such it is a crucial book - a necessary book.”

-Anastasia Valassopoulos, Senior Lecturer in World Literatures, University of Manchester, U.K.

"This powerful book examines the forced migration of women as a gendered experience. Its original transcultural approach demonstrates the migration of women not as single transnational experiences, but as part of larger global trends about the perception of women that are influenced not only by the particular migratory path, but also by attitudes and knowledge towards other migratory places and experiences. Dr Ball compellingly weaves together the primary reading of text with larger theoretical questions about author intentionality, political currents, patterns of female engagement, the significance of maternity in establishing women's 'acceptability' and 'need', and larger national and international questions about human rights crises, medical and political responsibility for refugees, and the politics of images in changing narratives about refugees from 'terrorists' to 'victims'. It is a 'must read' for scholars of women and gender studies, and those interested in labor and forced migration."

-Rachel Sylvia Harris, Associate Professor of Comparative and World Literature, University of Illinois, USA

"This is a wonderful book! Deeply inspiring, essential reading and a major intervention in transcultural feminist approaches to forced migration. It will have resonance far beyond academia in reinvigorating feminist responses through the transcultural feminist imagination defined and practiced in the book."

-Maggie O’Neill, Professor in Sociology and Criminology, University College Cork, Ireland 

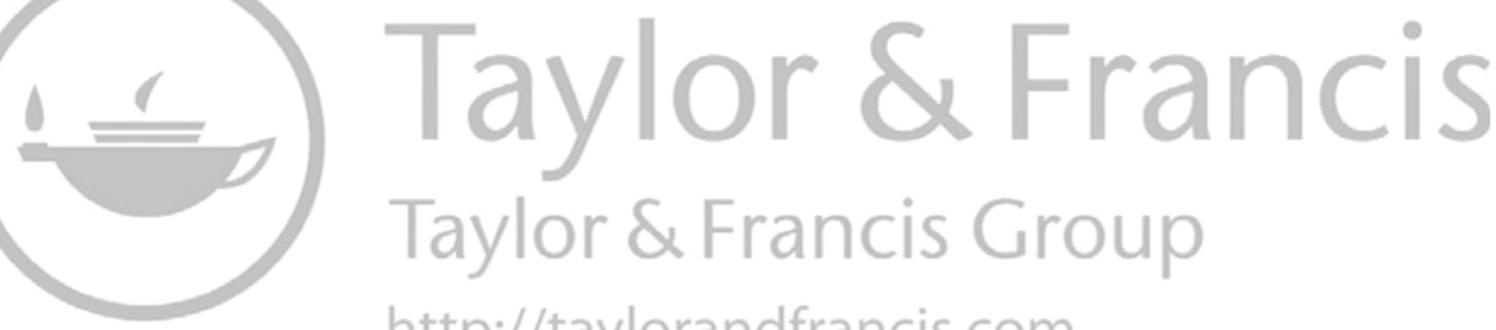
http://taylorandfrancis.com 


\section{Forced Migration in the Feminist Imagination}

Forced Migration in the Feminist Imagination explores how feminist acts of imaginative expression, community-building, scholarship, and activism create new possibilities for women experiencing forced migration in the twenty-first century.

Drawing on literature, film, and art from a range of transnational contexts including Europe, the Middle East, Central America, Australia, and the Caribbean, this volume reveals the hitherto unrecognised networks of feminist alliance being formulated across borders, while reflecting carefully on the complex politics of cross-cultural feminist solidarity. The book presents a variety of cultural case studies that each reveal a different context in which the transcultural feminist imagination can be seen to operate - from the 'maternal feminism' of literary journalism confronting the European 'refugee crisis' to Iran's female film directors building creative collaborations with displaced Afghan women; and from artists employing sonic creativities in order to listen to women in U.K. and Australian detention to LGBTQ+ poets and video artists articulating new forms of queer feminist community against the backdrop of the hostile environment.

This is an essential read for scholars in Women's and Gender Studies, Feminist and Postcolonial Literary and Cultural Studies, and Comparative Literary Studies, as well as for those operating in the fields of Gender and Development Studies and Forced Migration Studies.

Anna Ball is Associate Professor of Postcolonial Feminisms, Literatures, and Cultures at Nottingham Trent University, U.K. Working across literary, filmic, and artistic mediums, her research operates at the intersection of postcolonial feminist literary and cultural studies, and focusses primarily on the gendered politics of mobility, agency, and cultural expression at stake within sites of political instability in the Middle East and among its resulting global flows of forced migrants. She held a Leverhulme Research Fellowship in 2018-2019 in support of this work. Firmly committed to transcultural feminist community-building, she also engages in collaborative cultural work that enables those within forced migrant communities to explore their creative agency. 
Interdisciplinary Research in Gender

Freewomen, Patriarchal Authority and the Accusation of Prostitution

Stephanie Lynn Budin

Spatialities in Italian American Women's Literature

Beyond the Mean Streets

Eva Pelayo Sañudo

Women's Suffrage in Word, Image, Music, Stage and Screen

The Making of a Movement

Edited by Christopher Wiley and Lucy Ella Rose

Intersectional Feminist Readings of Comics

Interpreting Gender in Graphic Narratives

Edited by Sandra Cox

Caffie Greene and Black Women Activists

Unsung Women of the Black Liberation Movement

Kofi Charu Nat Turner

Forced Migration in the Feminist Imagination

Transcultural Movements

Anna Ball

The Misogynistic Backlash to Women-Strong Films

Dana Schowalter, Shannon Stevens, and Daniel Horvath

Feminist Existentialism, Biopolitics, and Critical

Phenomenology in a Time of Bad Health

Talia Welsh

For more information about this series, please visit: https://www.routledge. com/Interdisciplinary-Research-in-Gender/book-series/IRG 


\title{
Forced Migration in the Feminist Imagination \\ Transcultural Movements
}

Anna Ball

\author{
Routledge \\ 贯 Taylor \& Francis Group \\ LONDON AND NEW YORK
}


First published 2022

by Routledge

2 Park Square, Milton Park, Abingdon, Oxon OX14 4RN

and by Routledge

605 Third Avenue, New York, NY 10158

Routledge is an imprint of the Taylor \& Francis Group, an informa business

(C) 2022 Anna Ball

The right of Anna Ball to be identified as author of this work has been asserted by her in accordance with sections 77 and 78 of the Copyright, Designs and Patents Act 1988.

The Open Access version of this book, available at www.

taylorfrancis.com, has been made available under a Creative

Commons Attribution-Non Commercial-No Derivatives 4.0 license.

No part of this book may be reprinted or reproduced or utilised in any form or by any electronic, mechanical, or other means, now known or hereafter invented, including photocopying and recording, or in any information storage or retrieval system, without permission in writing from the publishers.

Trademark notice: Product or corporate names may be trademarks or registered trademarks, and are used only for identification and explanation without intent to infringe.

British Library Cataloguing-in-Publication Data

A catalogue record for this book is available from the British Library

Library of Congress Cataloging-in-Publication Data

A catalog record has been requested for this book

ISBN: 978-0-367-34381-1 (hbk)

ISBN: 978-1-032-11096-7 (pbk)

ISBN: 978-0-429-32540-3 (ebk)

DOI: $10.4324 / 9780429325403$

Typeset in Sabon

by codeMantra 
This book is dedicated to the members of PAMOJA Women Together at Nottingham and Nottinghamshire Refugee Forum, with thanks, friendship, and respect, and to my daughters, Clara and Elspeth, with love. May you all find joy in your journeys through life. 

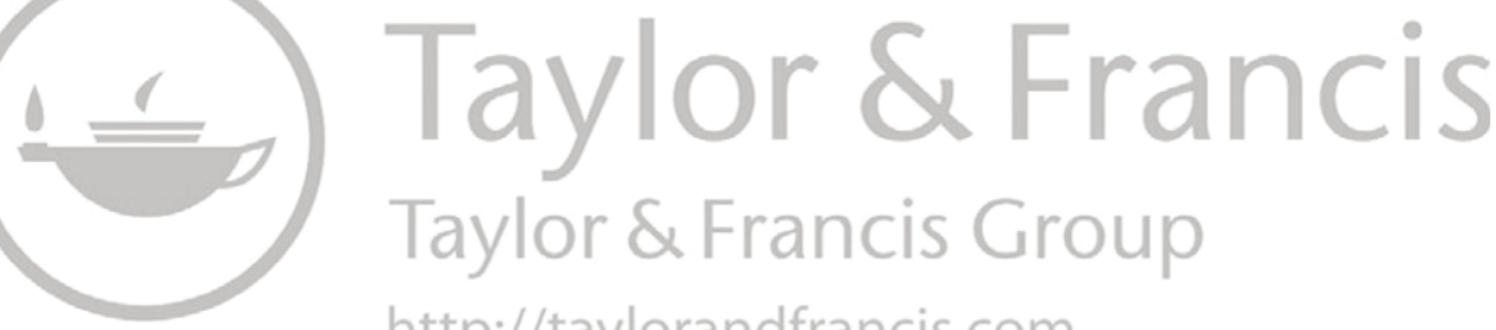
http://taylorandfrancis.com 


\section{Contents}

List of figures $\quad$ xi

Acknowledgements xiii

Preface: walking with the river $\quad \mathrm{xV}$

1 Moving women, moving stories: forced migration in the transcultural feminist imagination

2 An expectant figure: encountering the 'refugee crisis' through literary maternal feminism

3 Feminisms in conflict: decolonising Afghan women's displacement through the Iranian cinematic gaze

4 Sounding out dissent: learning to listen to women in detention through sonic creativities

5 No straightforward journey: traversing queer feminist territories through a poetics of crossing

Conclusion: creative mobilisations 

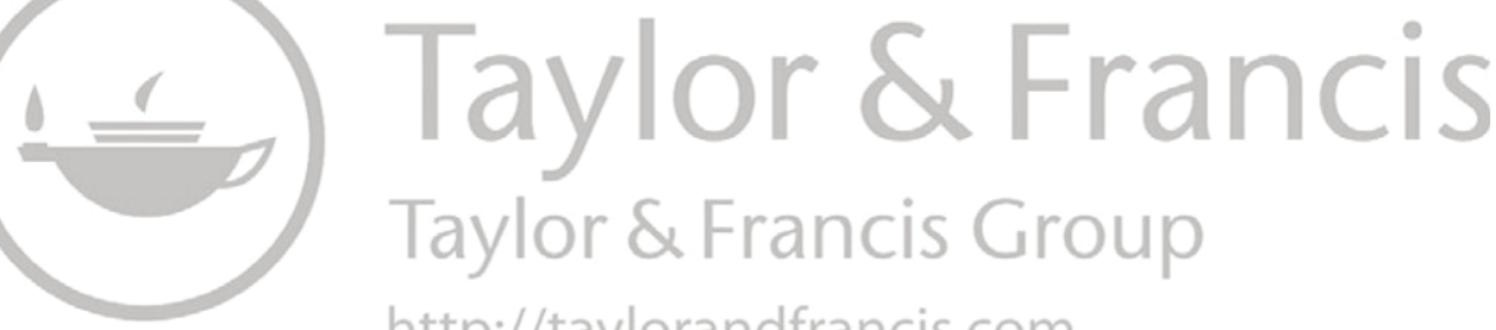
http://taylorandfrancis.com 


\section{Figures}

1.1 Still from The End of carrying All by Wangechi Mutu, 2015. Three-screen animated video (colour, sound). 9 minutes 27 seconds loop. Edition of 3

1.2 Feminist activists protesting at the Tijuana border, Mexico

2.1 Humanitarian midwife 'Jet' makes 'tentative first contact' with a pregnant refugee and is invited into the private and concealed space of her tent. Image from Threads from the Refugee Crisis, Kate Evans, Verso 2017

3.1 Still from 'God, Destruction and Construction' by Samira Makhmalbaf. Short film contribution to Alain Brigand, 11.09.01, September 11th, A Film (2002)

3.2 Director Samira Makhmalbaf (left) and protagonist Nogreh, played by Agheleh Rezaie (right), align their gazes on set in At Five in the Afternoon (2002). Still from At Five in the Afternoon, dir. Samira Makhmalbaf

3.3 Still of Sonita in her video 'Brides for Sale', featured in Rokhsareh Ghaem Maghami, dir., Sonita (2016)

4.1 Protestors create a 'wall of sound' around Yarl's Wood, Bedfordshire

4.2 Still from Hear Her Singing, Charwei Tsai, 2017

5.1 Photograph of Sarah Hegazi taken at the Mashrou' Leila concert in Cairo, 2017

5.2 Still from One Emerging from a Point of View by Wu Tsang (2019)

6.1 Hayv Kahraman, Search, 2016, oil on linen, $96 \times 73$ inches. (C) Hayv Kahraman 

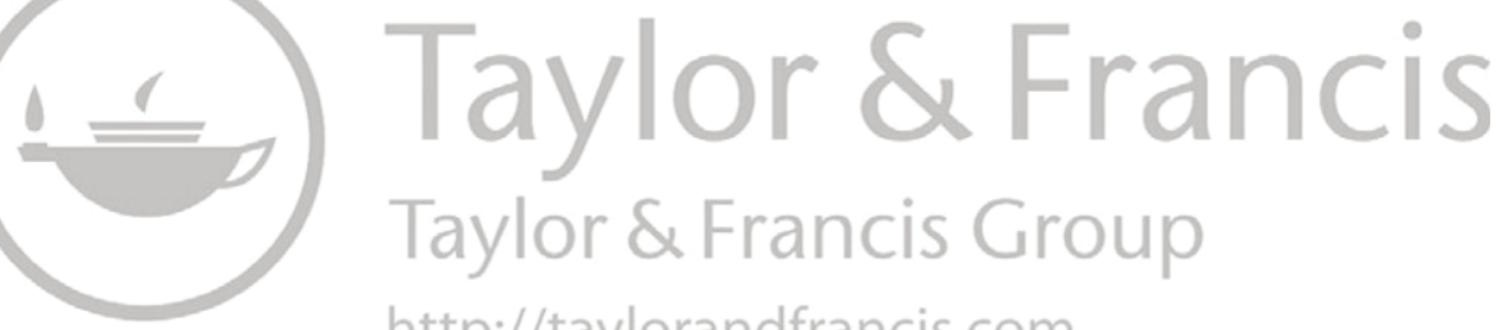
http://taylorandfrancis.com 


\section{Acknowledgements}

This book is a product of the immense hospitality, generosity, and care that has been extended to me by many individuals and organisations over the past six years. My thanks are due, first and foremost, to those who have welcomed me into their communities during this time, offering their insights, imaginations, and creative abilities as sources of inspiration. Notably, thank you to Nottingham and Nottinghamshire Refugee Forum, and, in particular, to all at the PAMOJA Women Together Group - especially Veronica, Ola, Salani, Ghidey, Viola, and Jarrai (surnames omitted for privacy). Special thanks are due to Hannah Ziolek, Viviane Bizimana, and Lizzie Haines for their support during our collaborative projects. Thank you, too, to Survivor Alliance for the deeply moving collaborative opportunities we have shared and to those who work both regionally and nationally on Refugee Week, which has offered a platform for many of the debates and creative activities that have circulated around the writing of this book. A particular thank you to Natelle Morgan-Brown, April Chung, Kevin Price, Dave Hewitt, Margaret Levin, and Alexia Ball for their energy and solidarity over the years. I am also deeply grateful to Mirriam for the wisdom and creativity that she has shared with me and with the Refugee Week team. I wish to offer special thanks to Camilla Reeve, editor of Palewell Press, for her goodwill, integrity, and industrious labour during the creation of The World Is for Everyone - the outcome of much of our collaborative work with PAMOJA.

I am extremely grateful to the Leverhume Trust for supporting the Research Fellowship that enabled me to complete much of this book in 20182019, and to Nottingham Trent University for providing sabbatical leave in 2017-2018. At Nottingham Trent University, I have benefitted from the insights and support of colleagues, including Olga Bailey, Martin O'Shaughnessy, Jenni Ramone, Nicole Thiara, Amy Rushton, Sarah Newport, Jenny Wustenberg, Natalie Braber, Phil Leonard, Nahem Yousef, and Andrew Thacker. My PhD students, meanwhile, have been outstanding conversants and, on numerous occasions, teachers: a particular thank you to Allan Njanji for his intelligent insights into the politics of forced migrants' representation; to Margaret Ravenscroft for her energetic engagements with 
the politics of refugee women's cultural production; to Tom LockwoodMoran for his insights into queer Caribbean cultures; to Nat Muller for her encyclopedic knowledge of Middle Eastern art; and to Veronika Schuchter for her feminist solidarity. Thank you, too, to Betty Cribb, who conducted a wonderful research placement on this project, focussing particularly on sourcing materials relating to Hayv Kahraman. Within the wider academic community, I have found inspiring allies in colleagues and mentors, including Roger Bromley, Lindsey Moore, Patrick Williams, Anastasia Valassopoulos, miriam cooke, Anna Bernard, and Wen-Chin Ouyang. My thanks to each them for the various forms of support and solidarity they have offered over the years.

I am deeply indebted to the wonderful editorial team at Routledge. A particular thank you to Alexandra McGregor for her enthusiasm for this volume and to Eleanor Catchpole Simmons for her immense patience as it emerged. Thank you, too, to all of those who have granted copyright permission to reproduce images or quotations from their work, many of them offering to do so without cost in the service of this project. I am grateful to Wangechi Mutu for the still from The End of carrying All; to Emilio Espejel for his image of the Tijuana border protests; to Kate Evans for the image from her graphic novel Threads; to Chris Bethell for the image from the Yarl's Wood protest; to Charwei Tsai for the still from her video work Hear Her Singing; to New Wave Films for the still from Roksareh Ghaem Maghammi's film Sonita; to Wu Tsang for the still from her work of video art, One Emerging from a Point of View; and to Hayv Kahraman for the still of her painting Search. I am extremely grateful to Staceyann Chin for granting her permission to reproduce quotations from 'Crossfire', 'My Jamaica', 'Know When to Fold', 'Common Truths, or: Why I Love My Pussy', 'Song of Survival', 'Passing', 'Raise the Roof', 'Speech Delivered in Chicago at 2006 Gay Games', 'Tweet This, Motherfucker', 'Tsunami Rising (\#MeToo)', and 'I Have Never Known What We Are', taken from her collection Crossfire: A Litany for Survival (Chicago: Haymarket, 2019).

A project spanning many years such as this one could not emerge were it not for the emotional support of friends and family. A special thank you to the Excellent Women, Cathy Clay and Sarah Jackson, for their friendship during the journey to this book's completion, given all of its ups and downs - and to Rebecca Relton, Alicia Leontieff, Rizwana Lala, Burcu Alkan, Bhavina Scavetta, and Amy Fuller for their vital conversations, distractions, and laughter. Thank you to my family, Jennifer, Stephen, Alex, and Terry for remaining ever-supportive. Above all, though, thank you to Lee Garland for supporting me during this exceptional period. The conception of this book, after all, took place shortly before the birth of our first daughter, Clara - and its writing ends just a week before the birth of our second daughter, Elspeth. Their love, and my love for them, has carried us through it all. 


\section{Preface}

\section{Walking with the river}

The creation of this book has been framed by an ugly word: lockdown. The aggressively biopolitical implications of this term became apparent as I began writing in 2015, when borders across Europe started to close in response to the rapid increase in people fleeing warfare and unrest primarily (or most visibly) in Syria, and a dehumanising rhetoric of anti-migrant sentiment surfaced as a key feature of public discourse. While presented as a fresh 'crisis' for twenty-first-century Europe, however, these developments resonated painfully and urgently with the much longer-standing preoccupations that have driven my transcultural feminist efforts at creative dialogue with that region tenuously and problematically defined as 'the Middle East' over the past several decades - for the emergence of arbitrarily enforced borders and governmentalised transnational hostility are familiar features of this landscape and propel us towards careful scrutiny of the ingrained Orientalist and neocolonial tendencies that drive the construction and exclusion of 'the other' at times when the boundaries of 'the self' are called into question. ${ }^{1}$ The lockdowns of 2015, then, prompted me to consider how postcolonial, decolonial, and transcultural feminist thought might be mobilised afresh in the service of those who found themselves barred not just from their right to sanctuary but also from access to self-representation at a time when narratives of identity and (non)belonging were being weaponised against them. For when faced with such political concretisations of difference, transcultural feminist discourse has a powerful role to play indeed, capable as it has proven itself of enabling alternative voices to those of nationalised, neocolonial, and androcentric discourse to rise above the parapet. By turning down the volume of mainstream media discourse and instead amplifying those voices usually quieted by their location at the interstices of racial, ethnic, national, gendered, and sexual difference, transcultural feminist discourse, it seemed to me, could present the key with which to unlock creative ways of moving through an otherwise rigidly hostile landscape.

Five years later, as I complete these pages, the specter of lockdown has reared before us once again, though in the unexpected form of governmental responses to the catastrophic surge of the COVID-19 pandemic around the world. These lockdowns, though, have revealed not just the absolute 
necessity of home as a space of sanctuary but its uneven biopolitical privilege as such. While those with citizenship of the world's wealthiest countries find themselves supported by furlough schemes, mortgage breaks, and the ability to isolate indoors, those without citizenship have found themselves rendered supremely vulnerable as the pandemic has swept through poorly provided and overcrowded refugee camps around the world, while those seeking asylum have found themselves isolated within inadequate housing and with little social support. The radical inequalities of these lockdowns have been further compounded by gendered positionalities: a report in July 2020 published by Sisters Not Strangers revealed an increase in unsafe and unsanitary living conditions, in destitution, and in the threat or experience of domestic violence for asylum-seeking women during the COVID-19 lockdowns, who find themselves 'among those BAME women most affected by the consequences of the outbreak', positioned as they are at 'the intersection of gender, race, and immigration status, coupled with the trauma of their past experiences'. ${ }^{2}$ The vulnerability of women in such positions became tragically evident with the death of Mercy Baguma in August 2020, who was found deceased in her Glasgow flat in August 2020. Having sought asylum in the U.K., Mercy had been rendered effectively destitute following the expiry of her right to work and had been forced to seek assistance from local charities. She was found near to her baby son who was suffering from malnutrition by the time he was rescued, an estimated three days after his mother's death - a result, her family has suggested, of a bungled arrangement by the Mears Group, a private contractor to the Home Office, which had promised to relocate Mercy and her son though failed to do so, leaving her whereabouts ambiguous to her friends. ${ }^{3}$ Mercy's story is indicative of the extreme precarity of asylum-seeking women's lives and the extent to which it has been exacerbated during lockdown. Yet while the lives of asylum-seeking women have found themselves critically marginalised at governmental level, it is notable that during this time, coalitions led by forced migrant women and their allies have emerged at the forefront of research, grassroots activism, and national advocacy, seeking to promote their interests. ${ }^{4}$ In 2019, for instance, a feminocentric group of 'mothers, wives, partners, sisters and aunts, including members and descendants of the Windrush generation' has joined forces as Families for Justice in order to campaign against the deportation of family members on the grounds of its 'unduly harsh' impact on children within the family in particular. ${ }^{5}$ In the Mediterranean, meanwhile, it is a 30 -foot motor yacht named after the French feminist anarchist Louise Michel, captained by anti-fascist, antiracist, feminist Pia Klemp alongside her 'flat hierarchy' team, which has remained one of the few operational rescue boats willing to respond to the distress signals of 'non-European' vessels during the pandemic. ${ }^{6}$ And on the walls of a New York gallery space, images that seek to imagine not apocalypse but utopia at this most desperate of times have emerged, in the form of portraits shaped in aesthetic and ethos by conversations held with 'young 
women of the new diaspora' - those who have been variously forced to migrate from North Africa and the Middle East in the past decade. ${ }^{7}$ In the face of governmental marginalisation, then, feminocentric and variously defined 'feminist' imaginations have made it their task to create alternative forms of action and representation, shifting the narratives that circulate around forced migrant women in the process of doing so.

Between them, these lockdowns have both yielded and affirmed the core insights that underpin this volume - namely, an understanding of the complex structures of privilege and disenfranchisement that nuance individual experiences of mobility; of the deeply prejudicial ideologies and biopolitical mechanisms according to which border mechanisms are policed; of the political significance of forced migrants' narrativisation to the perpetuation of these ideologies; of the intersectionality of forced migrant experience with gendered, racial, and multiple other positionalities; and, ultimately, of the necessity of inclusive, intersectional, transcultural feminist response as a means to illuminate and to counteract these sources of inequality. My critical approach to tackling these issues will become apparent over the course of this book and is outlined in more detail in Chapter 1. Yet the transcultural feminist motivations that have driven this work have ultimately been guided by voices and experiences positioned far beyond the world of the library. To understand how these alternative perspectives have shaped this path, it is necessary to travel elsewhere for a moment - to a blustery day in April 2017.

We are walking along a river. It is the River Trent, to be more precise - the river that winds its way through the city of Nottingham that all 30 of us on this walk share, despite our very different positions within it. Twenty or so of the women in the group are currently seeking asylum in the U.K., or have been granted it, and are members of the PAMOJA Women Together Group at Nottingham and Nottinghamshire Refugee Forum. The remainder of the women have never had to go through this process, though some of them have experienced different forms of migration. None of our journeys have been the same. Yet here we are, walking together, our movements echoing the path of the river and as we walk, we talk to one another about anything that comes into our minds. Or perhaps the river is talking to us - because many different stories from around the world are rising to its surface. In Eritrea, you go to the river to confide your troubles and to watch them flow away. In Togo, you line out your washing on its banks while the children play. In Sudan, you take coffee and popcorn, and go there to chat with the other ladies. Sometimes, individuals pause to look out across the water, and it may prompt a memory that they choose to share or to experience alone. At other times, it makes people sing - or hide from the wind behind a tree.

Our river walk moves me. There is a release that occurs as we tread this common path, beyond the boundaries of our everyday lives structured by the demands of governmental administration, the pressures of the urban living space. The group sets its own pace and assumes its own leaders; its narrative emerges organically through conversation, a desire to connect 


\section{xviii Preface}

and support, to find out who one another are, beyond the labels that have brought us together on this journey. Linguistic difference collapses in the face of sensory commonality: we teach each other new words and hold out small creatures, fronds of foliage, for one another to examine. It is a moment of movement guided by the path of a natural entity that pays no heed to externally enforced boundaries, and it reveals more about the structures of solidarity and alliance, cross-cultural community, and narrative-building than any of the critical paradigms I have encountered in scholarly writing.

The women with whom I shared this river walk are also those with whom I have worked over the past five years on the creation of photography, poetry, bread, stories, books, and public events. I do not describe this work as research, but rather as shared learning - for through those I have met in this group, I have gained profound insights not simply into the lives and experiences of women who engage in varied forms of forced migration but into the pivotal roles of cross-cultural collaboration and public self-representation in relation to the experience of agency. You will hear reverberations of the PAMOJA women's voices throughout this volume, but they have also produced their own narrative spaces beyond these pages that remain their own. ${ }^{8}$ Instead, it is the model of cross-cultural, feminocentric community-building that I had the pleasure and privilege to experience with them that undergirds the imaginative connections I forge within this volume, and for this, I offer them my profound thanks.

This book is really about our journeys along the river together. It is about how those who experience forced migration might reflect, contradict, or shape the narratives through which they are represented; about how we can move in solidarity and alliance with those who experience forced migration, while forging a respect for difference, individuality, and commonality; and about how we acknowledge the narrative heterogeneity of women's experiences in the landscape of forced migration. And at a profound level, it is about how 'feminist' thought and cultural action - in all of its multiple definitions and manifestations - can shape this kind of transcultural community. Feminist imaginations, this book proposes, can create new kinds of transcultural movement within and in response to the profoundly unequal structures of the global landscape. Each page of this book, then, is an invitation to move a little further with us along the river.

\section{Notes}

1 For further discussion, see Anna Ball and Karim Mattar, eds., The Edinburgh Companion to the Postcolonial Middle East (Edinburgh: Edinburgh University Press, 2018).

2 Sisters Not Strangers Coalition, 'Hear Us: The Experiences of Refugee and Asylum-Seeking Women during the Pandemic', Sisters Not Strangers, July 2020, https://www.refugeewomen.co.uk/wp-content/uploads/2020/08/Hearus-Sisters-Not-Strangers.pdf (last accessed 13th October 2020). 
3 Catriona Stewart, 'Mercy Baguma: Home Office Facing Legal Action', The Herald, 8th October 2020, https://www.heraldscotland.com/news/18777917. mercy-baguma-home-office-facing-legal-action/ (last accessed 13th October 2020).

4 Women for Refugee Women has been particularly active, and indeed is the umbrella organization to which Sisters Not Strangers is connected - itself a nationwide coalition of eight feminocentric asylum-seeker-led organisations advocating support for those women experiencing destitution during the asylum process. See https:/www.refugeewomen.co.uk/campaign/sistersnotstrangers/ for further information (last accessed 14th October 2020).

5 Mark Townsend, 'Women Fight to Help Families Torn Apart by "Racist" Deportation Policy', The Guardian, 3rd January 2020, https://www.theguardian. com/uk-news/2021/jan/03/women-fight-to-help-families-torn-apart-by-racistdeportation-policy (last accessed 1st February 2021).

6 Renewed closures of European borders in the light of the pandemic have made it increasingly challenging for forced migrant populations either to seek asylum or indeed to return home. Lorenzo Tondo and Maurice Stierl, 'Banksy Funds Refugee Rescue Boat Operating in Mediterranean', The Guardian, 27th August 2020, https://www.theguardian.com/world/2020/aug/27/banksy-fundsrefugee-rescue-boat-operating-in-mediterranean (last accessed 13th October 2020).

7 See Nadja Sayej, “It's About Finding a Place”: Stunning Portraits of Women Affected by the Refugee Crisis', The Guardian, 1st September 2020, https:// www.theguardian.com/artanddesign/2020/sep/01/its-about-finding-a-placestunning-portraits-of-women-affected-by-the-refugee-crisis (last accessed 14th October 2020).

8 I discuss this work further in Chapter 1. 

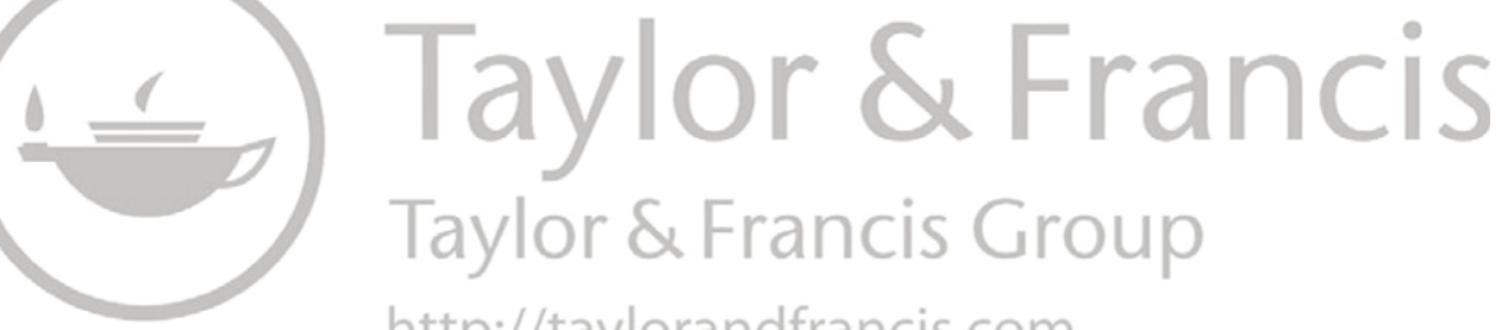
http://taylorandfrancis.com 


\title{
1 Moving women, moving stories
}

\author{
Forced migration in the \\ transcultural feminist \\ imagination
}

When we look to the opening decades of the twenty-first century, we find them filled with the figures of variously moving women. Perhaps most visible are the vast numbers of women who have been displaced by war, climate change, poverty, or social circumstance over the course of the century, testifying to the era's extreme geographical and political flux. Surfacing alongside these women experiencing varied forms of forced migration, though, are those who have found themselves compelled to other forms of movement, notably the political. Here, the 'moving woman' is synonymous with the intersectional feminisms mobilised by women across the globe in response to the gendered, racial and political disenfranchisements that have threaten women's sanctuary within and beyond their homeland. The voices of these moving women, forced migrant and political activist alike, have become a prominent feature of the twenty-first-century landscape as they have sought to channel their moving experiences into creative forms that have, in turn, prompted others to emotive response and critical debate in the sociocultural sphere. Collectively, these voices have inspired a prolific quantity of filmic, literary, and artistic work that simultaneously articulates the cultural complexities of forced migrant women's stories and the imaginative possibilities of transnational feminist perspectives. The spatial, political, and creative movements of women ripple between one another in the twenty-first century, then. Yet in the absence of any sufficiently developed interdisciplinary, cross-cultural, or gender-conscious framework of analysis, the intersection between these twenty-first-century movements has remained largely invisible, the dialogues between women's forced migration, transnational feminist mobilisation, and feminocentric cultural creativity left untraced and unrepresented, and their radical connections unrealised.

It is with a consciousness of these connections that Forced Migration in the Feminist Imagination: Transcultural Movements sets out to create a discursive space in which the geographical, sociopolitical, and cultural networks operating between the variously moving women of the twenty-first century are able to emerge in all of their complexities. At the interstices of these narratives, lives, and imaginations, there is, this volume claims, a deeply moving story to be told. Yet as the following pages also reveal, this 


\section{Moving women, moving stories}

is a terrain that has often been traversed clumsily, even violently, including when approached in 'feminist' terms that have at times paid little heed to the places, roles, experiences, or voices of women who have experienced forms of forced migration themselves. How, then, might it be possible to navigate this vast terrain in a way that moves not just carefully but with the kind of care that offers something beyond the politics of the 'empty gesture' so often visible in gender-blind, if well-meaning, cultural enquiry into twenty-first-century migration ${ }^{1}$ One answer can be found by turning to what I term the 'transcultural feminist imagination' - a realm that has not yet been widely recognised in this century of moving women, but which in fact offers a rich and largely untapped repository of insight, inspiration, and guidance on how it is possible to move differently through this complexly mobile feminocentric landscape. But before presenting anything as reductive as a definition of the 'transcultural feminist imagination', let us first catch a glimpse of it at work in a provocative portrait of a moving woman that prompts many questions about the representational function of forced migrant women and of the transnational feminist movements that intersect with them.

Kenyan-born, transnationally based artist Wangechi Mutu transports us to a surreal and metamorphic terrain of mobile female identity in her 2015 video piece The End of carrying All. ${ }^{2}$ Set in an unidentified landscape that might best be characterised as something between apocalyptic no-man's land and natural utopia, this three-channel, nine-minute twenty-sevensecond video installation focusses on an anonymous woman - played in

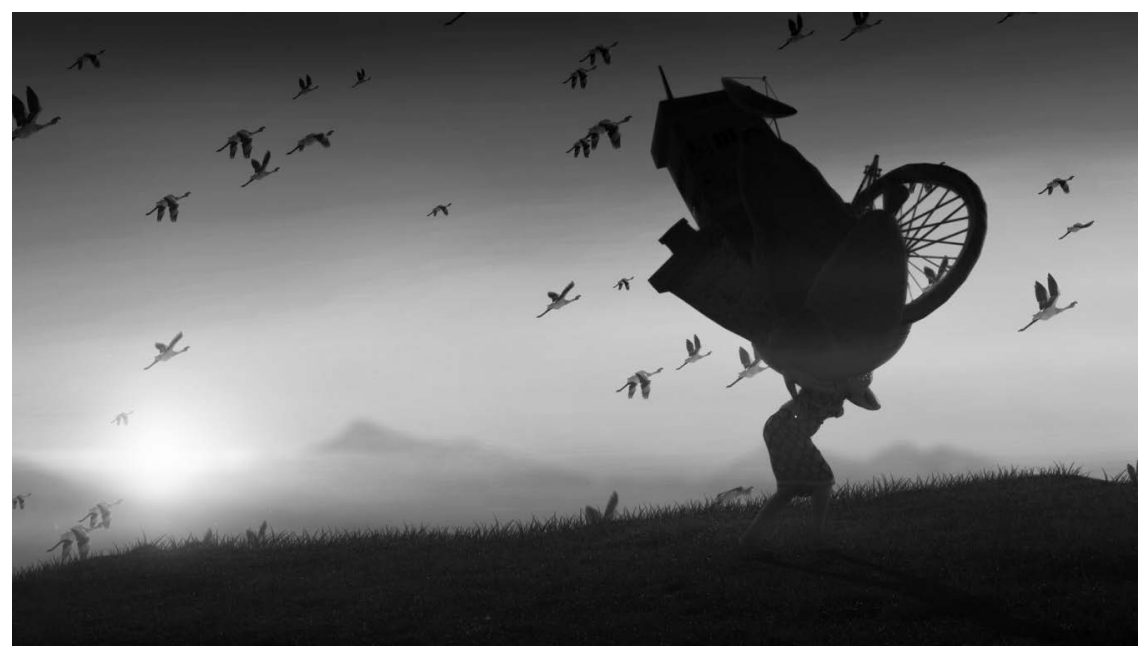

Figure 1.1 Still from The End of carrying All by Wangechi Mutu, 2015. Threescreen animated video (colour, sound). 9 minutes 27 seconds loop. Edition of 3. Courtesy of the Artist, Gladstone Gallery, Susanne Vielmetter Los Angeles Projects, and Victoria Miro Gallery. 
the film by Mutu herself - trekking through a mountainous rural environment, bearing a basket of belongings upon her head. As she walks, unlikely objects of disproportionate scale accumulate in the basket: a huge wheel; a satellite dish; eventually, even a tower block, its windows glinting with signs of collective life. The basket now too heavy to bear, her pace falters, her back stoops, and an extraordinary transformation occurs. The load she carries morphs into molten form, becoming a heaving globule of lava-like substance into which she is subsumed. Still, 'she' squirms forward, simultaneously alien and liquid in form - until, reaching the edge of the mountain, the mass of the former woman flows over the edge and, after disappearing briefly from sight, reappears as a subterranean rupture - a temporary ripple that passes beneath the surface of the mountain, returning her to her point of origin. Her journey seems to be over and the earth regains its composure - but as the video piece ends, it loops back to the start; we witness her troubled passage begin again. The end of carrying it all is, it turns out, in fact just the beginning.

Mutu's work appears, at first glance, to evoke what has become an iconic image of womanhood within the twenty-first-century cultural imagination: that of the forced migrant woman as bearer of the world's burdens; as quintessentially 'moving subject' who evokes powerful affect in those who encounter her image. ${ }^{3}$ Amidst the dehumanised statistics of a transnational landscape ravaged by war, famine, imperialism, capitalism, environmental disaster, and global power imbalances, ${ }^{4}$ moving women have served extensively as humanising and individualising narrative foci - figures who give form and material substance to the otherwise incomprehensible statistics of twenty-first-century global displacement. Stooped and suffering, bearing children, scant belongings, or unimaginable emotional loads, she has trodden an unending path across our screens and pages, trapped in a perpetual feedback loop of cultural response mechanisms - sometimes pitying, sometimes lionising, sometimes vilifying. And as she has made her way through these discourses, 'she' - as individual, as human, as differentiated subject has also lost her form, melding into a seething mass of feminised imagery: of interchangeable victims, heroines, and mothers who, like Mutu's alien form burrowing into the landscape, have become synonymous with the plight of a ravaged, fluctuating earth - absorbed into the very substance of the forced migration narrative in which she features as endless performer.

That this should be the case is in many ways unsurprising. The twentyfirst century has, after all, seen an unprecedented number of people forced from their homes over the course of its several decades, with some 79.5 million people categorised as refugees, asylum seekers, internally displaced, or stateless by the end of 2019 - the highest number on record according to data collated by the United Nations High Commissioner for Refugees (UNHCR). ${ }^{5}$ A consciousness of forced migration has not just duly saturated the cultural imagination, evident in the explosion of literary, filmic, artistic, journalistic, and indeed academic representations of forced 
migrants' stories that have marked the past decade in particular, but also entered into national political consciousness at a profound level, emerging as a powerfully divisive issue within a range of transnational contexts. ${ }^{6}$ Women have often been mobilised to powerful symbolic effect within this discourse, evident, for instance, in the hunger for 'real-life' stories of forced migrant women prevalent in international journalism at the height of the Syrian 'crisis', which sought heightened affect through women's gendered vulnerability. ${ }^{7}$ For those working from transnational, decolonial, and postcolonial feminist positionalities, the gendered dimensions of these discursive mobilisations have been hard to ignore. ${ }^{8}$ While men on the move have frequently been read as active, sometimes threatening, often 'illegitimate' agents in the global drama of border-crossing, women have, in contrast, tended to be read as passive victims of a world in flux - and hence have been pushed to the fore of a humanitarian advocacy narrative that stresses the human cost of forced migration. ${ }^{9}$ In these narratives, though, women tend to figure in primarily symbolic and ultimately reductive terms, their own voices, cultural differentials, and individual narratives elided in the service of a coherently gendered appeal for institutional support that reinforces an image of subaltern female refugee 'powerlessness' and 'need' - a ventriloquised narrative that, as Liisa Malkki notes, echoes throughout the humanitarian imagination, particularly in the 'West'. ${ }^{10}$ Nevertheless, the increased prominence of women within narratives of global displacement also reflects the 'mainstreaming' of gender consciousness that has taken place within Non-Governmental Organisations and other advocacy bodies within the past several decades ${ }^{11}$; a move derived not so much from what some have claimed as the 'feminisation' of forced migration as a twentiethand twenty-first-century phenomenon as from an improved awareness of the complex ways in which forced migration is experienced differently by those occupying the rich spectrum of female identities.

But the prominence of moving women in the twenty-first-century cultural imagination cannot be explained simply through the mainstreaming of gender discourse within the humanitarian realm. Here, The End of carrying All becomes powerfully instructive. For Mutu's work cannot be reduced to a straightforwardly signifying narrative of forced migrant women's experiences. It also, in its stridently and surreally mobile representation of black female identity, locates itself at the cusp of other twenty-first-century movements: of an expanded transnational feminist consciousness that has mobilised women of varied cultures and identifications across the globe in what some have termed the feminist 'fourth wave'; of a struggle for racial equality that has generated feminist networks across the global North and South; and of an enhanced drive towards intersubjectivity that has renewed understandings of cross-cultural, cross-positional feminist solidarity and coalition building. ${ }^{12}$ In its mobilisation of these discourses, Mutu's work prompts a number of questions much more complex than simply asking how her filmic subject narrates the story of women's forced migration. Instead, 
her video work prompts us to ask: what does female mobility signify in her visual imagination? What assertions, reconfigurations, or dissolutions of female identity, experience, and agency take place within this imagined landscape of multiply signifying mobility? What transcultural traversals of imaginative connection, distance, and alliance take place through Mutu's performance of women's journeys other than her own, and indeed, what representational responsibilities might her work therefore evoke by speaking to these loaded discourses from platforms of simultaneous disenfranchisement and privilege? What are the 'realities' and what are the creative potentialities at stake in her visualisation of a severely hostile mobile environment? And not least, how do works such as Mutu's enable femaleidentified subjects and subjectivities to move creatively in ways that release them from their representational burdens? How, in sum, might creativity enable women to shift themselves from beneath the narratives that they, like Mutu's amorphous figure, have been forced to bear, so that they might tell and indeed hear different stories of themselves, and of the world around them - ones that do not reduce them, simply, to the role of 'moving woman'?

These are questions that have not yet been asked of Mutu's works, nor of representations of forced migrant women in the twenty-first-century cultural imagination more broadly. But they are the questions that enable us to identify Mutu's work as indicative of a cultural phenomenon beyond what we might describe as the 'mainstreamed' narrative of women's forced migration. It is part of a larger body of work that displays, in its willingness to ask challenging questions of its central female subjects and of its viewers, not just tokenistic gender consciousness but a transcultural feminist consciousness that actively seeks to interrogate, challenge, and reimagine the terms in which moving women are represented and in which they are able to re-present themselves. The transcultural feminist imagination displayed within The End of carrying All, while manifesting distinctively in Mutu's work, is not a territory exclusive to her artistic practice, however. Indeed, it is a vibrant and flourishing terrain that has emerged as a disparate yet distinctive feature of the twenty-first-century cultural landscape, appearing in geographical and creative locations ranging from Iranian cinema to European journalism; from the Lebanese novel to Jamaican-American poetry; and from Afghan rap music to sound art created with detained immigrants in the U.K. Surfacing across variously asserted 'feminist' positionalities, through a range of cultural and creative practices, and in relation to many different manifestations of 'forced migrant' experience and identity, these discourses have yet to be placed in dialogue, and read as a manifestation of a collective transcultural body of work. Yet it is the contention of this book that allowing these works to resonate with one another across geographical, contextual, disciplinary, and political boundaries constitutes a vital move in the twenty-first-century cultural landscape. For when read in dialogue, these works collectively reveal ways in which we, too, can create, act, and move differently together, across cultures, genders, and territories, 
enabling us to imagine new ways of moving as, or with, or indeed beyond the significations attached to women on the move through what can be defined as 'the transcultural feminist imagination'.

The aim of this opening chapter is to lay out the terms in which the transcultural feminist imagination functions within both the cultural landscape and the remainder of this volume. The initial section, 'Mobilising feminisms: reapproaching women's twenty-first-century movements', presents a case for the necessity of a reinvigorated feminist approach to forced migration in the twenty-first century. It explores the varied ways in which gender-consciousness has been mobilised within the core discourses of Gender and Development Studies and Forced Migration Studies to date and considers the developments required of these discourses in order to address the distinctive landscape of women's twenty-first-century forced migration in which feminist practices, modes of resistance, and activisms have become necessities. The next section, 'Towards a cultural countertopography: into the transcultural feminist imagination', lays out this volume's specific terms of engagement with the core intersecting premises of the 'transcultural' and the 'feminist'. In particular, it explores the necessity of a politically informed and resistant feminism within this landscape and advances the case for the urgency of this approach by positioning the 'transcultural feminist imagination' against the backdrop of existing cultural and academic discourses, which reduce and limit the representational capacities of women within cultural-critical discussions of forced migration. The final section of this chapter, 'Ways ahead: transcultural movements', outlines how these core concepts and premises are applied over the remaining sections of the book and details the specific contexts, creative works, and feminist positionalities at stake within each chapter. Navigating these questions guides us - as critics, scholars, creative practitioners, activists, and as always-moving beings - towards what emerges within these pages as a radically mobile feminism that must be driven by the interests of women who experience forced migration themselves. Yet as we shall also see, the stories that rise from the transcultural feminist imagination ultimately invite us to move far beyond the limiting categories of 'forced migration', 'forced migrant woman', 'feminist activist', and 'feminist ally' that have tended to demarcate highly restrictive boundaries within this landscape. Instead, they generate new forms of movement - geographical, political, cultural, and epistemological - derived from our shared imaginative and creative capacities within the ever-moving terrain of transcultural feminist potentiality.

\section{Mobilising feminisms: reapproaching women's twenty-first-century movements}

The dawn of the twenty-first century has been widely heralded as an era displaying a newly feminised mobility. In her UNHCR Working Paper 
produced at the start of the century, Susan Martin notes that 'one of the most significant trends has been the feminisation of migration streams that had heretofore been primarily male', ${ }^{13}$ while UNHCR data from the cusp of the century identifies 'the face[s] of refugees [as] overwhelmingly those of women and children, as they comprise up to 80 per cent of most refugee populations' ${ }^{14}$ Claims such as this have often been used to present women as the 'forgotten majority' among the rapidly proliferating number of people who have found themselves displaced in the twenty-first century, exceeding 50 million in 2014 - the highest on record since comprehensive statistics on forced displacement have been collected. ${ }^{15}$ As Jane Freedman has been swift to point out, however, the numerical analysis of global mobility is complex and ultimately limited in terms of what it reveals about the forced migration of women. As figures such as those cited above demonstrate all too well, statistics that accurately disaggregate gender identity, that distinguish women from their dependents, and that record and differentiate between different forms of movement (such as economic migration, internal displacement, trafficking, and asylum-seeking: difficult categories to assign definitively to what may be complicated and intersecting modes of mobility) have long been lacking from governmental and NGO-based data gathering. This is an omission that can be explained, at least in part, by 'a lack of interest on the part of governments...in issues concerning gender in the asylum process' ${ }^{16}$ Additionally, the gender demographics of different flows of forced migrant populations may differ significantly between contexts (women constituting, for example, a majority within some refugee camps, but a minority in immigration detention centres), as may the dynamics of who is displaced, versus who goes on to claim asylum - a global minority of whom, according to UNHCR statistics where available, are women. ${ }^{17}$ Working broadly with UNHCR data since 2000, however, it is possible to discern that women make up, on average, half of the world's refugee population, constituting some 25.7 million women and girls in 2018. ${ }^{18}$ If women do not, therefore, constitute a majority of the world's forcibly displaced - and indeed, if the claim to a newly 'feminised' landscape of forced migration in the twenty-first century emerges as an oversimplification of longer-running and more complex trends in global mobility then why, as this volume claims, does a distinctively feminist approach to forced migration prove so necessary? The answer emerges when we turn away from numerical analysis and examine, instead, the gender-conscious movements that have circulated around forced migration in the past two decades - in scholarly, sociopolitical, and cultural realms alike.

Spurred on by the relative invisibility and reductive characterisation of forced migrant women in the sociopolitical sphere, the late twentieth century witnessed a sustained and tenacious drive towards gender-consciousness within Gender and Development and Forced Migration Studies. ${ }^{19}$ Pioneering interventions from Gender and Development scholars such as Doreen Indra argued not simply for the need for increased attention to women 


\section{Moving women, moving stories}

within forced migrant populations but for the need to 'deeply engende[r] knowledge in the study and practice of forced migration', given the place of gender as 'a fundamental organizing principle of everyday life'. ${ }^{20}$ These scholars made it possible "to "see" how the world is shaped by gendered concepts, practices and institutions', ${ }^{21}$ including 'the often unseen androcentric or masculine biases in the way that knowledge has traditionally been constructed in all the disciplines'. ${ }^{22}$ These interventions also resonated with the parallel interventions of feminist geographers such as Doreen Massey and Linda McDowell, who turned their attention to wider manifestations of global movement in order to reveal it as always determined by 'power-geometries' that result in a 'politics of mobility'. ${ }^{23}$ This politics is determined, ultimately, by our embodied positionality, which generates unequal access to and experience of mobility that may by turns be empowering, disempowering, limiting, desired, or enforced. Thus, as Hyndman puts it, 'migration is an embodied expression of desperation and hope in a highly unequal world'. ${ }^{24}$ Through these discourses, women's forced migration surfaces as a phenomenon that demands attention to the ways in which both gendered embodiment and gendered space function in relation to one another, radically complicating understandings of the gendered, spatial, and representational agency experienced by 'the forced migrant woman'.

These intersecting epistemological frameworks have transformed the way in which forced migration has been approached over the course of the late twentieth and twenty-first centuries. While it has been argued that a certain 'gender-blindness' still informs mainstream political scientific approaches to the subject, it has nevertheless laid the foundations for a substantial body of interdisciplinary work that falls under the headings of Refugee or Forced Migration Studies, in which an increasingly sophisticated level of gender-consciousness is in evidence. Within much of this discourse, gender is understood not only as something that 'structure[s] both the causes of ... flight and ...experiences of displacement ${ }^{25}$ but as a 'relational' and 'dynamic' set of structures, shaped by 'axes of power and difference (class, race and ethnicity)' and indeed by forced migrants' shifting social environments ${ }^{26}$ as much as by its relationship to the social scripts assigned to embodied biology. Indeed, gender-conscious analysis is now widely applied to every aspect of forced migration - not only as it manifests

in the lives of both female and male migrants [but also] in the politics and governance of migration, in the workplaces of immigrants, in neoliberal or welfare state policies towards migration or foreign-born nationals, in diasporas, and even in the capitalist world system. ${ }^{27}$

This discourse has, for instance, revealed the ways in which gender shapes people's motivations and abilities to migrate - such as their gendered positioning within social and economic systems. As Jane Freedman notes, 
the sexual division of labour, ...the presence or absence of spatial restrictions to public space and mobility for women... [and] gendered inequalities in the sexual distribution of wealth [are global factors] that $\mathrm{pu}[\mathrm{sh}]$ many women to migrate in order to ensure survival for themselves and their families. ${ }^{28}$

It has also revealed the forms of gender-related persecution that can drive people to flee their countries - such as the threat of female genital mutilation, forced marriage, forced abortion or sterilisation, and persecution on the grounds of sexuality; persecutory laws that discriminate against someone on the basis of their sex or gender; and sexual violence, threatened or enacted. ${ }^{29} \mathrm{~A}$ significant amount of research now also illuminates how gender actively shapes and differentiates the experience of forced migration itself. In particular, sexual violence, sexual coercion, and sex trafficking emerge as prominent features of forced migrant experience for many women during their journeys, and during their residency within refugee camps, or incarceration within immigration detention facilities. ${ }^{30}$ As the UNHCR has put it, 'refugee women are more affected by violence against women than any other women's population in the world. ${ }^{31}$ Indeed, this may be particularly the case for transgender women who, in addition to experiencing discrimination and persecution within their home countries, often face an increased level of violence during their flight. ${ }^{32}$ In other circumstances, conditions specific to the biologically sexed body such as menstruation and pregnancy may also shape the decisions, needs, and experiences of those migrating, while the added responsibility of childcare tends to fall primarily on women during their journeys. ${ }^{33}$ The gendered biases and oversights endemic to asylum systems have also been subjected to vital scrutiny within this discourse. The 1951 Convention Relating to the Status of Refugees (the Geneva Convention) and its 1967 protocol, for instance, have come under intense scrutiny for their androcentrism, evident in their initial failure to recognise gender-related persecution as legitimate grounds for the granting of refugee status or to recognise women - or indeed those of any gendered identification - as 'a particular social group' who may face persecution. ${ }^{34} \mathrm{~A}$ series of guidelines subsequently issued by the UNHCR have since clarified and extended the potential for gendered identity and experience to be recognised as grounds for a 'well-founded fear of persecution'. ${ }^{35}$ Yet a number of scholars have noted the endemic forms of gender discrimination that endure within many nations' aggressively biopolitical asylum regimes - systems that may perpetuate androcentric or even misogynistic bias. We see this, for instance, in the use of gender-insensitive interview techniques by many border regimes, which may demand that women produce deeply traumatic testimonies of experiences potentially deemed 'shameful' or culturally taboo, or which may discourage their ability to testify due to the presence of male interviewers or of their own children in the interview room. ${ }^{36}$ Women's 'failure' to reproduce accounts of their experience that fully evoke their 
physical and mental trauma may subsequently undermine the credibility of their claims - or may even arouse suspicion for the commonality their experiences share with those of other women, who often testify to rape and sexual exploitation. ${ }^{37}$ Indeed, women's individualised claims to asylum may be further undermined by the fact that many women are encouraged to make claims as spouses, and hence dependents - an arrangement that may subsequently lock them into a controlling or abusive situation within the home. ${ }^{38}$ Some studies also reveal endemically patriarchal tendencies within the legislative systems of asylum-granting countries, where women's abilities to perform 'proper' modes of female and feminine identity, as well as to reproduce the expectations of the 'convention refugee', ultimately determine the success of their claims. ${ }^{39}$ Collectively, these insights reveal genderconsciousness as essential to the critical understanding of forced migration.

This shift towards comprehensive analysis of gendered 'power geometries' represents a positive and necessary move. Yet as Jennifer Hyndman also acknowledges, this comprehensive 'en-gendering' has run an interesting course within the field. For while, as she puts it, Refugee Studies has now thoroughly integrated 'gender analysis', she and an increasing number of scholars have come to note that 'feminism is not its forte' [emphasis added] and 'the absence of a sustained ... feminist critique of Refugee Studies is conspicuous'. ${ }^{40}$ Indeed, when reviewing the emergence of genderconsciousness within discursive approaches to forced migration, an interesting ambivalence towards women also becomes apparent. Perhaps most forcefully, Doreen Indra has insisted that foregrounding women may run

[the] risk of quick foreclosure: that gender will be simplistically read as "women" rather than as relations of power, privilege and prestige informed by situated notions of maleness and femaleness; and that "women refugees" will then be comfortably categorized as a comparatively invariant kind of "multiple minority" [...] Systematic neglect of the class, subcultural, and situational variability among women would be an almost automatic consequence. ${ }^{41}$

Given her foundational position within the field, Indra's concerns are valid and necessary, and indeed can be read as initiating a tentative version of what I later explore in terms of a transnational feminist positionality in her call for gender - including its application to women - to be read intersectionally and in a manner resistant to First-World assumptions of homogenised experience. Yet as Jane Freedman has argued more recently, while "what gender looks like" is also not just about women, ... women may be the primary subjects of much research on gender because it is they who suffer the primary consequences of gendered inequalities of power. ${ }^{4}$ While emergent trends in twenty-first-century forced migration should not be viewed as departing from longer-standing patterns of mobility that present 'part and parcel of human experience', ${ }^{43}$ many of the most drastic 
twenty-first-century movements are characterised by what continue to be heavily feminised dynamics, which have also been met with governmental responses displaying particularly misogynistic tendencies that have, in turn, galvanised distinctively feminist forms of protest. This constellation of gendered discourses therefore seems to direct us towards a style of gender-conscious analysis in which the varied positionalities, identities, and experiences of women (a term that itself encompasses a spectrum of definitions, incorporating the biological, the gender-fluid, and the selfidentified ${ }^{44}$ ) are deserving of particular scrutiny, and indeed demand feminist critical response.

Powerfully illustrative here is the emergence of Central America as a site of feminised forced migration. This area has witnessed a fivefold increase in asylum seekers from El Salvador, Honduras, Guatemala, and Mexico since 2008. As the UNHCR notes, 'women and children are often the first to flee' these contexts since they are the ones who find themselves 'fac[ing] alarming rates of escalating, targeted violence and persecution from maras, criminal armed groups, including murder, disappearance, assault, rape, and recruitment of children ${ }^{45}$ - in other words, highly masculinised systems of violence and threat, in which women do not feel their own governments are able to protect them. Women who have made the journey to claim asylum in the U.S. describe the further perpetuation of masculinised violence they experienced during their journeys - including rape and sexual exploitation at the hands of the coyotes (people smugglers) who facilitate their journeys. ${ }^{46}$ Upon reaching the U.S. border, however, they also encounter gendered structures of violence - notably, in the aggressively masculinised form of the 'Minutemen', a group of vigilante anti-immigration activists who employ theatrical forms of threat in order to police the border-crossing. ${ }^{47}$ Once within the U.S. asylum system, women also find themselves subjected to further forms of gender-insensitive trauma - such as the impact of detention upon them and their children who, at the time of the UNHCR's 2015 report, tended to be detained together. ${ }^{48}$ In 2018, however, border detention policies took a further aggressively gendered turn, with the implementation of a 'zero tolerance' policy that demanded prosecution of all undocumented migrants at the U.S. border, resulting in the separation of adults from children - a policy with particularly deleterious effect upon women, who constituted a high number of those travelling with children to the border. The results of this policy have been violently masculinist. It has, according to Arietta Messing and colleagues, perpetuated multiple forms of 'reproductive injustice', including the mistreatment of pregnant migrants who can now be detained, often in poor and stressful conditions and sometimes resulting in miscarriage; a ban on abortion for unaccompanied minors in detention; and the violation of people's rights to parent in a safe environment, due to the enforced separation of adults and children. ${ }^{49}$ Currently, women who wish to avoid separation from their children must adhere to a 'remain in Mexico and await' policy while their 


\section{Moving women, moving stories}

claims are assessed - a situation that forces them into precarious and unsafe living situations in temporary camps in Mexican border towns where the same masculinised forms of violence that they were fleeing continue to operate. ${ }^{50}$ Such heavily gendered dynamics see women distinctly disadvantaged within this landscape, then, demanding urgent feminist scrutiny and response.

Convergent with the heightened hostility that women have been facing as they have moved across these various landscapes of gendered violence, however, are multiple forms of assertively feminocentric and feminist activism which have presented important counter-discourses, alliances, dialogues, and spaces of safety for women engaging in forced migration. U.S. detention centres, for instance, have become common sites of feminist protest and consciousness-raising, ${ }^{51}$ while grassroots movements such as \#NoBanNoWallNoRaids, a cross-cultural community alliance initiated by Latino and Muslim communities in defence of 'communities of color, immigrants and refugees', have allied themselves to feminist networks through their presence at the Women's Marches on Washington and the International Women's Strike in 2017. ${ }^{52}$ Within U.S. academia, feminist attention to the politics of contemporary immigration has also garnered strength, presenting a newly engaged public face to contemporary feminist discourse. ${ }^{53}$ In the realm of socially engaged cultural practice, meanwhile, interventions such as Amy Sara Caroll's The Desert Survival Series - a free mobile phone application presenting poems designed to aid those making the border-crossing, including advice in matters of personal safety - present innovative ways of reaching out and drawing attention to the threats that forced migrant women must navigate. ${ }^{54}$ Grassroots activisms also point towards a resurgence of feminist self-assertion: in the U.S., for instance, migrant women, including those without documentation, have formed alliances such as the Georgia Latino Alliance for Human Rights and the National Domestic Worker's Alliance, which have enabled them to protest against the particular challenges they face. ${ }^{55}$ And across the U.S. - Mexico border, repeated waves of strident feminist protest against gender violence, particularly rape and femicide, have sprung up since 2016, thanks, in part, to the galvanising actions of feminist collectives such as the Tijuana-based Circulo Violeta. While connected to a long-standing heritage of feminist border activism, the protests of recent years - such as the revolución diamantina (glitter revolution) - have directly drawn attention to the Mexican President's failure to protect women from endemic gender violence, while activists' attempts to close the border at Tijuana thus also implicitly linked this gender violence to the driving forces of women's migration. ${ }^{56}$

Operating across varied discourses and across multiple territories, these varied mobilisations of women - not simply as subjects of analysis but also as agents and as allies - not only indicate the need for gendered scrutiny of forced migration but also reveal the necessity of a (re)turn to questions of 


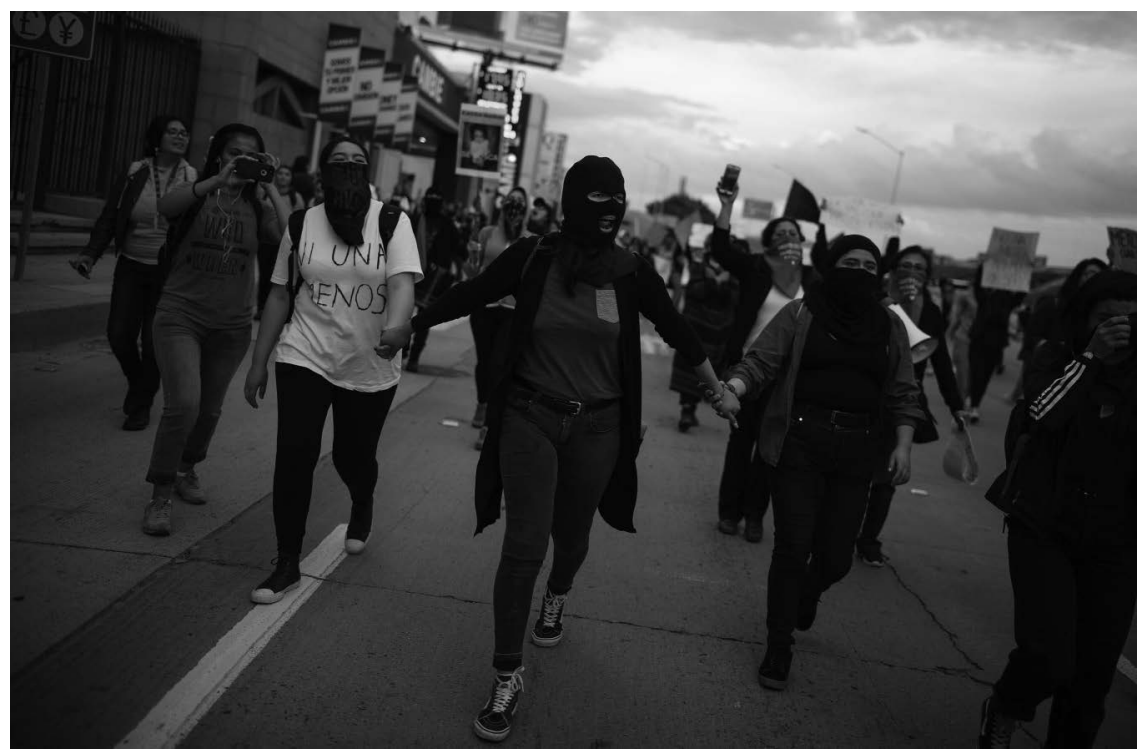

Figure 1.2 Feminist activists protesting at the Tijuana border, Mexico. Photograph by and courtesy of Emilio Espejel.

women's situated, embodied, and 'materialized...agency'. ${ }^{57}$ For these feminist discourses expose a desire not simply for gendered awareness but for societal change. Certainly, this drive towards material intervention has been implicit in previous waves of gender-conscious scholarship on forced migration. Yet it is the contention of this book that twenty-first-century engagement with women's forced migration must acknowledge its intersection with the larger fourth-wave global feminist movement that is currently responding to the mobile and shifting forms of intersectionally gendered, raced, sexualised, and economically determined disenfranchisements circulating around women's mobilities. ${ }^{58}$ These interrelationships have not yet been extensively chartered in Forced Migration Studies to date, which tends to distance itself from overtly feminist or activist stances. Rather than signalling a new trend in women's twenty-first-century forced migration, then, the connections that I forge between social, political, geographical, cultural, activist, and critical feminist movements reveal a new approach to women's forced migration. This approach recognises forced migrant women not simply as subjects of vulnerability and need but as agents, activists, allies, and as the very galvanising force of a necessarily mobile twenty-first-century feminism.

When faced with women's experiences of forced migration, then, we must all mobilise. Yet how to move within, and through, the geographical and indeed discursive boundaries of this world? How, as feminists, is it possible to position ourselves ethically, creatively, and usefully in relation to 
these structures? And indeed, how do these feminist mobilisations resonate with forced migrant women themselves? Answers to these questions begin to emerge when we turn to the distinctive territory that lies at the heart of this book: that of the transcultural feminist imagination.

\section{Towards a cultural counter-topography: into the transcultural feminist imagination}

In 2012, a woman appeared at the U.S.-Mexico border - not in order to cross it but to make it disappear. Clad in a black cocktail dress and elegant footwear, this woman scaled a ladder propped against a fortified portion of the San Diego-Tijuana border fence and began to paint it a delicate shade of sky blue. The fence was positioned in an area called Friendship Park, where people met in order to share meals and link fingers through the gaps in the fence, until 'they applied the third layer of mesh and didn't allow people to touch anymore. ${ }^{59}$ This woman was the Mexican artist Ana Teresa Fernández, who, employing her keen eye for aesthetics, was able to disguise the fence in such a way as to render it indistinguishable from the sky, thus making it 'disappear' for those on the Mexican side. Yet the transgressive potential of this artistic work - which Fernández entitled Erasing the Border - lies just as much in the politically performative power of the artist's own body as it does in the skill of her brushstrokes. Asserting a confident, capable, and self-possessed female agency unafraid to stand, even climb up to the biopolitical mechanisms of the border regime, Fernández presents a potently feminocentric creativity in defiance of national(ist) governmentalities. ${ }^{60}$ In doing so, her gendered erasure of the border evokes a stridently transcultural feminist imagination - a mobilisation of assertively gendered agency that functions at the levels of political critique, imaginative resistance, and creative transformation.

The term 'transcultural feminist imagination' is distinctive to this book, and as such, it is worthy of further explanation. The 'feminist imaginations' at stake here are twofold: first and foremost, they are those of the writers, film-makers, artists, creative practitioners, critics, and activists whose works are explored over the course of the following pages - those who, like Fernandéz, consciously or unconsciously invoke feminist perspectives from which to engage with the political and cultural landscapes of forced migration around them. Secondly, though, they are the acts of imaginative critical work that emerge in each of the chapters, as I seek out freshly feminist possibilities through engagement with these works. Crucially, however, the feminisms explored within this volume are identified as 'transcultural', and this standpoint proves essential when addressing the discourse of forced migration. In many senses, this 'transculturalism' is closely linked to transnationalism - a stance that has influenced much globally conscious feminist discourse through its awareness of the 'politics of location', through which it becomes possible to identify 'the grounds for historically specific 
differences and similarities between women in diverse and asymmetrical relations, creating alternative histories, identities and possibilities for alliances. ${ }^{61}$ Transnational consciousness enables us to comprehend feminism as a situated, contested, and context-dependent entity that in fact consists of a plurality of stances. ${ }^{62}$ So, too, does a transnational feminist perspective enable us to rethink the politics of mobility in a way that is 'attentive to material and historical locations of struggle'. ${ }^{63}$ This ultimately reveals feminist 'counter-topographies' that map alternative structures of power, disenfranchisement, shared experience, solidarity, and movement within global space, radically transcending national borders or indeed cultural boundaries. ${ }^{64}$ Transnational feminism also, though, requires careful nuance when applied to the landscape of women's forced migration. As Chandra Talpade Mohanty and M. Jacqui Alexander have argued, transnational feminism has also served at times as a 'normativizing gesture' emanating from the academies of the global North - one which perpetuates an ostensibly utopian but ultimately unequal global vision founded in the ideologies of 'neoliberal[ism]' and 'globalization', and fails to account for the enduring injustice and violence of the twenty-first-century transnational landscape. ${ }^{65}$ Writing some seven years later, Mohanty observes that this situation remains unchanged, but that forced migration has itself become a significant feature of the global landscape, which demands a different understanding of the 'transnational' as the basis of a feminist praxis:

The transnational necessitates acknowledging explicitly carceral regimes; geopolitical climate destruction; militarized national borders; massive displacement of peoples [...]; [the] proliferation of corporatist, racist, misogynist cultures; lean-in and glass-ceiling (liberal) feminisms; the decimation of labor movements, and the rise of right-wing, proto-fascist governments around the world. ${ }^{66}$

In order to be useful in this landscape, transnational feminism must, she argues, also be decolonised: capable of perceiving, critiquing, and shedding the multiple manifestations of colonial and imperialist power that are perpetuated through contemporary forms of capitalism, militarism, neoliberalism, and globalisation, amongst other forces. So, too, must a decolonised feminism seek liberating and emancipatory practices within this landscape, rather than resting easy with benign recognition of its injustices. And as Margaret McLaren notes, an integral aspect of a feminism that seeks to decolonise is that it should engage in self-scrutiny and critique of its own functioning, ${ }^{67}$ actively seeking, as Mohanty urged in her earlier essay, 'Under Western Eyes', 'to discover and articulate a critique of "Western feminist" scholarship on Third World women via the discursive colonization of Third World women's lives and struggles'. ${ }^{68}$ In the task of responding to women's forced migration, then, a decolonised transnational feminism proves essential - for women's movements, sociospatial, 
political, and discursive alike, are produced within the landscapes of imperialism, colonialism, capitalism, globalisation, militarism, climate change, and racism, and, as such, are inextricably tied to them. It is for this reason that 'feminism' remains a site of contestation, discussion, and interrogation throughout this volume, always emerging as a located discourse that must be read in relation to the complex geopolitical and sociocultural forces operating around it. Thus, over the course of the chapters, I deliberately turn to a range of 'feminist' tools from various cultural locations, each of which offers a different array of feminist possibilities and limitations. Collectively, these 'feminist' lenses - which include the 'maternal', 'humanitarian', 'third world', 'imperialist', 'postcolonial', 'decolonial', 'Iranian', 'cosmopolitan', 'diasporic', 'cinematic', 'literary', 'vocal', 'sonic', 'performative', 'queer', and 'trans' - operate as coordinates from which it is possible to map out and indeed traverse a 'counter-topography' of feminist response to women's forced migration. Thus, the feminist territory mapped out in this book must not be read as a utopian gesture that seeks to overcome or dismiss the boundaries of experiential difference between women, all of whom occupy distinctive positions in the landscape of forced migration. Rather, it calls for an alternative way of traversing this space that, as Mohanty would have it,

acknowledges the fault lines, conflicts, differences, fears, and containment that borders represent ... [and that] acknowledges that there is no one sense of a border, that the lines between and through nations, races, classes, sexualities, religions, and disabilities, are real - and that a feminism without borders must envision change and social justice work across these lines of demarcation and division. ${ }^{69}$

The 'feminist work' necessitated by the landscape of women's forced migration, then, is multi-directional, demanding careful (self-)reflection upon the intersecting dynamics of transnationalism, decolonialism, and feminism within this mobile landscape.

Yet it is not to a transnational but to a transcultural feminism that I turn in this volume. While inherently connected to the transnational landscape, the transcultural offers important nuance. As a term, it bears a distinctive heritage in postcolonial and mobility studies. Originating in the work of Fernando Ortiz, it grew in popularity throughout the 1990s as a means to characterise the process of hybridisation that occurs through cultural contact, and thus describes the ways in which 'individuals and societies chang[e] themselves by integrating diverse cultural life-ways into dynamic new ones. ${ }^{70}$ Within the context of this book, though, I use the term 'transcultural' in a slightly different manner - to describe not simply interaction between cultures but the specific role played by cultural expression as it emerges from the creative imagination, assuming many forms and places within the transnational landscape. In part, this move is the result 
of my own particular 'politics of location' as a feminist scholar, writer, and cultural practitioner trained primarily in the fields of postcolonial literary and cultural studies. Thus, cultural expression, as it emerges across global and disciplinary locations, has been my entry point into the wider political debates at stake within this study - and it remains foregrounded within this work as the path through which I approach the wider discursive territory surrounding women's forced migration. In transcultural feminist terms, though, this turn to the cultural also proves an essential move. As Nadera Shalhoub-Kevorkian has pointed out, 'space is...not only a material landscape but also a linguistic and symbolic one, replete with concepts of memory and historical legacies, ${ }^{71}$ and women's experiences of forced migration consequently emerge through linguistic, symbolic, and otherwise representational acts of remembering, thus necessitating cultural engagement. Part of the feminist work entailed in addressing the landscape of forced migration therefore involves constructing what Yến Lê Espiritu and Lan Duong describe as 'feminist refugee epistemologies' - alternative ways of knowing and thus perceiving the world when approached 'from the knowledge point of the forcibly displaced, which takes seriously the hidden and overt injuries but also the joy and survival practices that play out in the domain of the everyday, ${ }^{72}$ One of the ways in which Espiritu and Duong argue that such epistemologies become perceptible is by turning to the realms of cultural expression, which enable those who identify as displaced to project the complex interiorities of their physical and mental worlds, challenging the imbalanced 'looking relations' that prevail in cultural discourses of refugeeism and enabling us to 're-vie[w]...refugees as producers of knowledge and potent figures of critique'. ${ }^{73}$ Indeed, within the particular cultural works that they explore, Espiritu and Duong place great emphasis on the range of cultural objects and methods through which 'art' can be created, which include the objects of everyday existence, as well as acts usually considered 'private', such as letter writing: forms that, they argue, must be recognised as creatively valid if a feminist refugee epistemology is to operate. ${ }^{74}$ This position informs my assertion of the transcultural as a necessary analytic mode employed within the book. I understand this mode to rest at the interstices of the cross-cultural, the interdisciplinary, and the transnational, encompassing multiple forms of creative expression through which cultural practitioners engage with the subject matter of women's forced migration as it emerges across practice, genre, and disciplinary-based boundaries. Thus, the cultural acts I consider within this book take forms as varied as poetry, memoir, documentary, theatre, feature film, sound art, painting, and video art - as well as forms of protest, resistance, speech, listening, solidarity, or even 'everyday' tasks such as walking, all of which can be read as modes of cultural expression in their own right. Crucially, I note the emergence of these cultural forms across a range of transnational locations - including work from diasporic Afghan, Iranian, and Jamaican communities, as they meet at and 
travel across the borders between their countries, and those further afield including those in Canada, France, and the U.S. It also surfaces at the interstices of Middle Eastern, African, North African, and European existence, as creative practitioners and subjects (sometimes one and the same) travel across locations including Lebanon, Egypt, Iraq, Greece, Morocco, Sudan, and Somalia. Acts of cultural expression can even be found within immigration centres controlled by the U.K. and Australia, located as these may be in remote areas of the English countryside or the Pacific Ocean. Working in this transcultural manner that crosses forms and geographical locations, it becomes possible to recognise the range and breadth of cultural expression that speaks to women's forced migration globally - narratives that stretch far beyond the most prominently visible avenues of mainstream culture and media emanating from the global North. By reading these forms of expression transculturally, then - that is, across discursive, geographical, and cultural boundaries - it becomes possible to discern fresh sites of transcultural feminist debate, dialogue, and creative imagination that otherwise remain obscured.

This transcultural feminist stance also renders apparent the necessity of the term 'forced migration'. While a critical approach rooted in the less flexible and more highly governmentalised (also implicitly biopolitical and heteropatriarchal) geopolitics of the nation state would insist on a clearer classification of identity according to categories such as 'refugee'; 'asylum-seeker'; 'trafficked person'; 'internally displaced person'; 'stateless person'; or 'irregular', 'illegal', or 'economic' 'migrant' (each of which carries their own legal and cultural baggage), a transcultural feminist approach instead recognises the cultural contingency of mobile experiences and identities, allowing for sites of self-identification and ambiguity that do not negate the individual's claim to spatial sanctuary. Thus, in line with Mohanty's feminist vision of a 'world where women and men are free to live creative lives, in security and with bodily health and integrity', ${ }^{75}$ the usage of the term 'forced migration/migrant' throughout this volume is also intended to encompass all of those who face forms of necessary and disenfranchising mobility in order to realise the (feminist) rights to security, health, integrity, and, ultimately, sanctuary - whether those people are recognised or self-identify as 'refugees', or otherwise. ${ }^{76}$

There is one further sense in which transculturalism has informed my commitment to this work - and this stems from my creative cultural collaborations with the PAMOJA Women Together Group at Nottingham and Nottinghamshire Refugee Forum - a group that seeks to support and to empower women from a wide range of forced migrant backgrounds. ${ }^{77}$ As a scholar who follows Kobayashi's assertion that 'feminist scholars' should 'engage the political...to bring about social transformation' ${ }^{78}$ through their work, I seek to position my academic practice alongside my own writing, curatorial work, and political activities in order to produce conversations that, I hope, ripple transculturally across disciplinary and societal boundaries. 
Collaborations involving cultural expression have proved particularly productive and educational avenues for building forms of solidarity, alliance, and understanding with diverse groups of women. The PAMOJA group has been no exception here: though its members and those who collaborate with them all occupy the same city, we nevertheless inhabit many different cultural positions. Within the group, this ranges from Syrian to Sudanese to Iranian to Italian to Kurdish to variously defined Eritrean and Ethiopian cultural identities, while the women also occupy different religious, political, economic, and educational positionalities. All, however, are united in their possession of cultural skill sets that are of value to those within the group and to their collaborators. Here, the act of working transculturally that is, not only across languages but also across creative mediums (including photography, poetry, conversation, sewing, singing, painting, cooking, and indeed simply walking together) - has proved vital to the feminist functioning of the group, enabling all participants in the group to find shared communicative and expressive mediums that transcend linguistic or ideological boundaries. As a form of praxis as well as an academic stance, the transcultural therefore presents a form of what Maggie O'Neill describes as 'purposeful knowledge"79 that enables us to better understand our own implication within the political landscape around us. It thus calls us to what Schiff terms a position of 'mindful citizenship' through which we recognise 'the political responsibility of hospitality', implicated as we are as inhabitants and even as beneficiaries of the oppressive structures that perpetuate the suffering of those around us. ${ }^{80}$ Some might characterise this work as feminist 'research' that nevertheless produces the academic as 'participant $[\mathrm{t}]$ through the acts of witnessing and listening... [meaning that] we are compelled to speak out and provide space in our work for multiple voices despite the unequal relations that shape our engagement with those with whom we collaborate', ${ }^{81}$ and certainly, the volume's enduring emphasis on the importance of foregrounding forced migrant women as producers of knowledge and self-representation stems from this recognition. Yet my own experience of this work has been of an altogether more egalitarian nature. For it has been the PAMOJA women themselves who have extended hospitality by welcoming me into their group; displayed generosity in their sharing of time, insights, and expertise; and who have also themselves sought out opportunities to connect with those beyond the self-identified 'forced migrant' community, in order to build working and social relationships with those around them. These relationships have been forged out of our mutual and distinctive experiences as women occupying sometimes intersecting, sometimes diverging positionalities - and feminocentricity has thus also informed the projects that we have designed and created together. ${ }^{82}$ The insights from this work resonate throughout the chapters of this volume, sometimes emerging as material ripe for critical analysis though more often, surfacing as recognitions that have subtly informed the theoretical positions at which I arrive. The transcultural therefore also 
emerges as a mode of working that transcends the straightforwardly academic within this volume, then - constituting a vital mode of interpersonal, interdisciplinary feminist practice that creates communal knowledge and insight across sites of cultural difference.

Why, given the urgency of the landscape I have mapped out so far, is there no previously existing account of the 'transcultural feminist imagination', as it operates in relation to the discourse on twenty-first-century forced migration? Here, we must turn for a moment to the dominant narratives of twenty-first-century cultural and academic discourses within the global North. Both of these discourses have arguably suppressed forced migrant women's representational agency within their structures.

A fascination with forced migration has become a significant feature of cultural expression within the global North, particularly in the wake of the European 'crisis'. ${ }^{83}$ The physical and ideological encounters produced across Europe's borders account for the huge upsurge in cultural curiosity surrounding refugee lives and experiences. This has manifested in an outpouring of expressive activity spanning literature, film, art, music, and theatre. Here, 'refugee lives' have found themselves refracted, generally by authors residing in the 'West', into languages and genres comprehensible to a 'Western' audience. This has, at times, led to reductive representations of forced migrants. They may be presented as subjects of pity, vulnerability, and compassion (evident, for instance, in the trend towards documentaries portraying refugees in conditions of extreme precarity and desperate need, such as in Ai Weiwei's Human Flow ${ }^{84}$ ); as subjects of resilience, even superhuman heroism (evident, for instance, in the trend towards sensationalist, sometimes magic realist novels portraying 'extraordinary' journeys, such as Mohsin Hamid's Exit West ${ }^{85}$ ); or as subjects of curiosity, who leave the public desirous to hear refugees' 'real stories and views' (evident in the publication trend towards life narrative, often co-written with an experienced Western journalist, such as Gulwali Passarlay and Nadene Ghouri's The Lightless $S k y$, or in texts by forced migrants that 'explain' their experiences to a non-migrant audience. ${ }^{86}$ )

Despite the marginalisation of their gendered needs and experiences in the political arena, women have figured prominently in this cultural terrain, where their status as 'other' has often served to epitomise the perceived alterity of 'the refugee' more broadly. This has been reflected in the degree to which women's stories have often been read as the quintessential embodiment of 'refugee experience' through which the legitimate suffering of those forced to migrate can be represented. This is keenly apparent in the journalistic emphasis on 'photo essays' that feature the images of women - usually posed either in states of extreme vulnerability or in postures conveying strength and resilience - accompanied by short narratives conveying 'their story', which are often presented for NGO publicity. ${ }^{87}$ Despite the apparent sincerity of such images, they nevertheless tend to present women in reductively polarised positions that refuse recognition of 
the more complete spectrum of human experience and identity - thus 'refugee women' are employed as figures of advocacy, rather than as complex, even contradictory individuals who may not meet expected standards of 'need', 'pity', 'heroism', or indeed 'womanhood' as expected. In this sense, even when displaced beyond the boundaries of their national community, forced migrant women still find themselves charged with the role of cultural 'border-guard', their symbolic value lying in the degree to which their behaviours affirm the standards and values expected of their community. ${ }^{88}$ In turning to works that surface beyond these mainstream imaginaries, then, one of the tasks of the transcultural feminist imagination is to explore how women can be represented and indeed represent themselves in ways that do not simply affirm the discursive patterns and expectations of dominant cultural narratives within the global North. Casting a wider geographical net, the transcultural feminist imagination leads us to richer and more complex portraits of 'forced migrant female identity' (which ultimately, often, contest this as a category of experience).

How, though, have forced migrant women's voices surfaced in the cultural sphere to date, and what possibilities of agency have emerged with them? Writing of literary and filmic twenty-first-century narratives of forced migration, Agnes Woolley observes that 'oscillating between invisibility and overexposure in the public sphere, forced migrants have an ambivalent relationship to the aesthetic forms that seek to represent them, one which touches on questions of communicability, visibility and ethics'. ${ }^{89}$ This ambivalence is also keenly evident for forced migrant women, whose narrative silencing has been matched by a fascination with seeking to find out or indeed imaginatively construct 'what refugee women have to say'. This trend is, in many ways, in line with broader recognitions that access to voice is a vital aspect of cultural and political agency ${ }^{90}$ - yet it also hints at the salvational 'rescue narrative' that may, at times, undergird such efforts. This is evident in the trend towards 'collaborative life-narratives', which see 'refugee women' considered to bear an exceptional story of courage or survival paired with a more experienced (usually Western) author, who enables her to produce a narrative that adheres to the shape and interests of a Western audience. This is the case in texts such as Clemantine Wamariya's The Girl Who Smiled Beads: A Story of War and What Comes After, written with Elizabeth Weil, and Melissa Fleming's A Hope More Powerful Than the Sea: The Journey of Doaa Al Zamel, ${ }^{91}$ for instance. Both of these texts convey their protagonists as resilient heroines who undertake journeys not simply from the global South to North but also from oppression - as forced migrants and as women - to newly liberating and indeed empowering homes in the 'West'. This is a narrative that has, in some ways, been enforced through the appointment of what we might term 'feminist figureheads' in the Western cultural arena - empowered forced migrant women who have, themselves, undertaken journeys entailing extreme suffering and hardship premised on their gendered experiences, only to meet with newfound 


\section{Moving women, moving stories}

conditions of agency and liberation within the global North. In turn, these 'feminist figureheads' have sometimes come to act as spokeswomen or as facilitators of voice for other forced migrants. Malala Yousafzai, for instance, the Nobel Peace Prize recipient and recent Oxford University graduate who was internally displaced in Pakistan, shot by the Taliban for her pro-female educational activism and subsequently brought to England for medical treatment, has become a much-lauded figurehead for girls' and women's rights to education, and her 2019 anthology, We Are Displaced: My Journey and Stories from Refugee Girls Around the World, seeks to return vocal agency to those denied it. ${ }^{92}$ Certainly, Yousafzai presents an impressive model of female resilience and achievement. Yet the extent to which her story maps onto wider, implicitly Orientalist cultural imaginaries that present 'the West' as the loci of (feminist) emancipation and vocal agency must surely be viewed with some critical circumspection. Indeed, the laudatory response to Yousafzai - a model of female propriety, self-possession, and considered political expression - contrasts starkly with the altogether more ambivalent response levelled towards a very different 'female figurehead' of forced migrant experience: the musician M.I.A, also known by her Tamil name Matangi Arulpragasa, who has been an outspoken and often controversial spokesperson for Tamil and, more recently, refugee rights. ${ }^{93}$ Having arrived in the U.K. as a child, grown up in London, and explored her creativity through the multicultural circuits of rap music, anticolonial literature, and Britpop, M.I.A has made an extraordinary journey from niche underground music scene to global stardom. ${ }^{94}$ Cultural responses have duly shifted over the years, from celebrating her as an 'authentically' rebellious voice of forced migrant experience to an 'inauthentic', culturally unpalatable figure whose political views have been publicly shot down during television interviews. ${ }^{95}$ In her 'failure' to embody a recognisable model of dignified, suffering, and deserving femininity, or of female emancipation straightforwardly allied to the political views of the 'West', then, M.I.A surfaces as too challenging for the mainstream cultural imaginaries of the global North. Yet she also therefore invites us to consider the alternative ways in which female identity and agency might be formulated, beyond these discourses. As we move beyond the boundaries of the global Northern cultural mainstream, it becomes interesting to consider what other narrative and indeed feminist dynamics can arise out of individual and collaborative practices involving women - ones that perhaps present different forms of self-assertion, solidarity, alliance, and 'empowerment', and that may also push against, even reveal the hypocrisies entailed in the view that forced migrant women's liberation is necessarily to be found once they have 'escaped' their non-Western, 'inherently oppressive' homes.

How, then, has this mass of cultural material been approached in the critical realm? The renewed attention to refugees within the cultural circuits of the global North has also been reflected in the realms of critical cultural thought - yet we also sense problematic gender dynamics at stake within 
these discourses. Major philosophical thinkers of the age - Zygmunt Bauman, Slavoj Žižek, Jacques Derrida, and Giorgio Agamben, among then - have all turned their attention to some of the 'larger' questions that refugees raise, such as the nature of hospitality, the question of responsibility, sovereignty, or what constitutes 'bare life'. ${ }^{96}$ A critical desire to understand 'who refugees are' and 'what they mean' has also encouraged a return to the work of twentieth-century precursors such as Hannah Arendt and Edward Said, whose earlier reflections on 'the rights of man' and 'exile' have come to resonate with particular force in the twenty-first century. ${ }^{97}$ These critical tools, along with the proliferating number of texts available to them for scrutiny, have drawn scholars across the Humanities - predominantly in the fields of Literary, Theatre, Media, and Cultural Studies - to consider the cultural discourses circulating around refugees as a distinctive subject area of enquiry in its own right, rather than as a subset of diaspora or migration studies, and this has led to a rapid expansion in cultural-critical work considering the representational politics of refugees in particular. Despite the rich insights that variously positioned decolonial and transnational feminisms have to offer the field, however, little of this work foregrounds gender nor advances a feminist approach in its analysis. ${ }^{98}$ This apparent dearth of attention indicates the extent to which gender issues continue to be constructed as peripheral 'add-ons' to the more substantial business of addressing global 'humanity' - a tendency also reflected in the gender-blindness of thinkers such as Agamben and Arendt. Yet the assumption that women's rights are adequately accounted for within the discourse of 'human rights' is dangerous in transnational feminist terms. For, as Kelly Oliver reminds us, discussions of 'human rights' easily assume a 'universal and abstract nature...that discount the significance of social and historical conditions and contexts', including the unique structures of oppression produced in relation to gender. ${ }^{99}$ In the realm of the Humanities, attention to forced migration and its cultural representation may have proliferated - but it has yet to connect the necessity of its insights to those of feminist discourses, particularly the transcultural, which ironically present vital opportunities to extend and advance its commitments to 'imagining, historicizing and protesting the experiences of forced migration and statelessness'. ${ }^{100}$

Representations of women's experiences of forced migration therefore find themselves positioned at a problematic cultural interstices: between modes of cultural signification that reproduce the dominant discourses of the global North, in which 'forced migrant women' remain a category conflated with various forms of 'otherness', and an academic realm that continues to relegate transnational and indeed transcultural feminist perspectives to its margins. How, though, might it be possible to find a different way through this fraught landscape? The answer proposed in the remainder of this book is to assume different forms of movement altogether - ones that operate intersectionally, enabling us to cross, to circle, to (dis)entangle, to assemble, and to forge ahead through the transcultural feminist imagination. 


\section{Ways ahead: transcultural movements}

The remaining four chapters and Afterword to this book traverse the transcultural feminist imagination via a range of variously situated intersections between the geographical, feminist, and cultural. The geographical or spatial context to each chapter is sometimes nationally defined (for instance, Afghanistan and Iran), sometimes determined by type of space (such as the immigration detention centre, as it surfaces transnationally), but in each instance, the context is selected for their representational significance to women's forced migration in the twenty-first century. Between them, they also capture something of the diversity of 'forced migration' as a spatial condition, which may entail experiences of precarious travel; of settlement; of internal displacement; of detention; and indeed of un- and re-homing, physical, and psychological. These settings do not and cannot represent the entirety of twenty-first-century forced migrant experience, and I remain highly conscious of the omission of many important twenty-first-century geopolitical contexts. ${ }^{101}$ Indeed, some locations have been selected precisely for the lack of attention that they have gained in the cultural mainstream, while my long-standing focus on women's cultural production from the 'Middle East' has also no doubt alerted me more readily to work that has circulated within and beyond that tenuously defined region. Between them, though, they present something of the scope of different global contexts that reveal important facets of gendered experience and that generate acts of cultural representation in the twenty-first century. As such, they must be taken as representative not so much of the flows of global forced migration that have marked the twenty-first century, as the sites at which feminist imaginations have come to the fore.

Each chapter also focusses on a specific discourse of gendered identity that proves particularly significant within this landscape of forced migrant experience. These include discourses of maternity, of female victimhood and agency during war, of women's detention, and of 'queer' female identifications. These discourses do not represent anything approaching the entirety of gendered experiences, but they do indicate some of the issues that the transcultural feminist imagination has sought to highlight - issues which are often neglected or represented reductively in more mainstream treatments of them. In response to these issues, each chapter also explores and develops a distinctive transcultural feminist position and, in so doing, emphasises the importance of a mobile approach to 'feminist' identification which adapts to circumstance and context. So, too, does each chapter place the question of feminism itself under scrutiny - revealing the sometimes problematic or limiting forms it has taken, as well as its potentialities when dealing with the contexts and issues at stake. Finally, each chapter focusses on a particular creative approach that has been adopted towards these contexts and issues, as sites of transcultural feminist imagination. These creative approaches are loosely defined as the literary, filmic, sonic, and 
artistic - yet each 'category' in fact encompasses multiple creative modes within it, and in reality, these practices bleed between one another, spanning mediums that include literary journalism, the novel, documentary and feature film, music-making, life writing, performance poetry, painting, and video art. Each chapter also seeks to connect formally registered 'creative' practices with acts of what I consider to be everyday creativity - including protest, activism, conversation, listening, caring, and even walking. Thus, each chapter presents a distinctive 'transcultural' traversal of contexts, issues, ideologies, and approaches in its own right, and should be considered less as a critical position than as a series of critical movements.

These intersections are evident in each of the remaining chapters. Chapter 2, 'An Expectant Figure: Encountering the "Refugee Crisis" through Literary Maternal Feminism', turns to a pivotal moment in global twentyfirst-century consciousness of forced migration: that of the 'refugee crisis' of 2011 onwards, as it emanated most visibly across Europe - though less visibly, also across neighbouring countries within the Middle East. Following the shift from initial hostility to wider sympathy and hospitality towards these refugees, the figures of women bearing children - either in utero or in their arms - became prominent features of this representational landscape in ways that enforced the humanitarian stance of the global media. How, though, did those who mobilised a more distinctively feminist imagination engage with this discourse of maternity, as a crucial facet of many forced migrant women's experiences? What role did cultural positionality play in the generation of this discourse, and what narrative forms were mobilised in order to trouble the reductive figuration of the 'woman-and-child' as representative of Europe's own newly birthed 'crisis'? This chapter focusses its analysis on two differently positioned works that attentded to this topic: the literary journalistic work Cast Away by British journalist Charlotte McDonald-Gibson and the novel An Unsafe Haven by Lebanese writer and journalist Nada Awar Jarrar. ${ }^{102}$ Employing radically different approaches to questions of maternal agency, need, responsibility, and identification, these texts invite us to reconsider the significance of maternity as a facet of forced migrant women's experiences more broadly. In so doing, it posits the need for a discourse of maternal self-definition as integral to the transcultural feminist imagination.

Chapter 3, 'Feminisms in Conflict: Decolonising Afghan Women's Displacement through the Iranian Cinematic Gaze', steps deliberately away from a focal context of the Western cultural imagination to one that lies at its peripheries: that of Afghan women's displacement, both within Afghanistan and across its borders into neighbouring Iran, and further afield. Transporting us to the opening years of the twenty-first century, Afghan women's displacement constitutes one of the longest-running displacement crises in the world, but it also resurfaced with a particularly vehement significance following the U.S. bombardment of the country post-2001 an attack performed, at least in part, in the name of women's liberation. 
This chapter traces the complex place of feminist discourses relating to 'Afghan women's emancipation' within landscapes of displacement generated by conflict. In particular, it identifies a radically non-Western mode of cultural production - that of Iranian cinema directed by women - as offering sophisticated representations and negotiations of female agency that reveal the very different pressures and possibilities faced by displaced Afghan women from those imagined by the imperialist frameworks of the U.S. military and connected 'humanitarian' efforts. The complexity of displaced Afghan women's quest for agency surfaces in this chapter's exploration of two works by female Iranian directors: Samira Makmalbaf's feature film At Five in the Afternoon (2002) and Rokhsareh Ghaem Maghami's documentary Sonita (2015). ${ }^{103}$ While both films explore the multiple pressures generated for women within landscapes of displacement, they also present radically different approaches to the realisation of displaced women's agency. Through analysis of these films, then, the problematic alliance between Western feminist assumption and imperialist ideology falls into view - as does the absolute necessity of a creatively decolonial feminist approach to women's forced migration.

Chapter 4, 'Sounding Out Dissent: Learning to Listen to Women in Detention through Sonic Creativities', presses its ear to walls that all too often remain hidden within global landscapes of forced migration - those of the immigration 'removal' or 'detention' centre. ${ }^{104}$ As arcane facets of the nation state's governmental mechanics, immigration detention centres function, this chapter suggests, on a shared biopolitical approach to the containment of bodily agency, which is focussed not only on physical but also on vocal and communicative constraint. Ostensibly gender-blind in their functioning, detention systems in fact present particular forms of risk, threat, and violence for women - yet they have also surfaced as hubs of female-led protest and dissent, within and outside of their walls. In response to the gendered oppressions and feminist potentialities that emerge around the detention centre, then, this chapter turns to the specific politics of sound as the basis for feminist dissent and creativity. It explores the feminist politics of sound at stake in two very different acts of sonic creativity: firstly, in the creative work of Somali-born, Australian-detained Hani Abdile, as her voice resonates across the oral history project, They Cannot Take the $S k y$, and in her own vocal performances of her poetry ${ }^{105}$; and secondly, in a collaborative project entitled Hear Her Singing, developed by artist Charwei Tsai with film-maker Tsering Tashi Gyalthang. This project was conducted with women detailed at Yarl's Wood Immigration Removal Centre in the U.K., in collaboration with the organisations Women for Refugee Women and Bedford Music in Detention. ${ }^{106}$ Both of these projects entail creative collaborations between those within and beyond the immigration detention system and reveal the success with which the sonic can lead to radical bridgings of cultural positionalities, languages, and representational expectations across feminist standpoints. Yet this 'sonic politics' 
also presents important lessons about the feminist politics of listening as well as speaking - lessons that invite us to question the straightforward demand that forced migrant women can, and should, 'speak up and out' for themselves. Ultimately, this chapter proposes subtler and more ethically sensitive possibilities of connecting across sites of difference, containment, and disenfranchisement, founded in 'deep listening' practices as the basis of transcultural feminist activist praxis.

Chapter 5, 'No Straightforward Journey: Traversing Queer Feminist Territories through a Poetics of Crossing', turns to the moment of bordercrossing itself and considers the ways in which 'queer' sexual orientations and gender identifications impact upon this moment of profound significance for forced migrant women*. ${ }^{107}$ The chapter opens with an exploration of the highly intersectional positionalities expressed within the work of the Chinese-Jamaican-American poet Staceyann Chin, whose 2019 poetry collection Crossfire articulates both the homophobia that led her to leave Jamaica as a queer-identified woman and the endemic forms of homophobic, sexist, and racist discrimination that she is forced to negotiate within her current home in the U.S. ${ }^{108}$ As such, Chin's work invites us to resist straightforward readings of queer women's asylum-seeking as a journey from the global South to the global North, or from danger to safety, and instead apprehends the more complex territories of queer experience and sanctuary that can be forged through poetry as creative community-making. These creative queerings of border-crossing experience are extended through subsequent discussion of Wu Tsang's 2019 hybrid artistic work, One Emerging from a Point of View. ${ }^{109}$ Set on the island of Lesbos in 2016 and charting the paths of two women from different places, times, and indeed levels of 'reality' whose lives both intersect on the island despite never actually meeting, this work circles in in a delicately destabilising manner around the notion of the 'trans' as the basis for a revised queer feminist politics and of a radical connectivity between humans, species, and environment. Between them, these works invite us to consider the complex place of the 'queer' in relation both to the politics of border-crossing and to the politics of feminism itself. At one level, this chapter presents an important opportunity to acknowledge 'queer' sexual orientation and gender identification as a driver of forced migration for many women* across the world. At another level, though, this chapter offers an opportunity to extend legalistic and indeed feminist understandings of female identity beyond those of biological embodiment, and thus to extend transcultural feminist alliances beyond the realms of cisgendered and potentially cissexist assumptions. Ultimately, this chapter advocates the potential of a queer transcultural feminism that is at once politically grounded and imaginatively transgressive.

It is with this reassessment of the transcultural feminist landscape in mind that I turn, in the volume's brief Conclusion, 'Creative Mobilisations', to the work of the Iraqi-American artist Hayv Kahraman, specifically her 2016 work Search, as a potent exemplar of the creative territory in which we 
arrive when we travel via the transcultural feminist imagination. Through Kahraman's work, I suggest that forced migration does not simply demand a radical mobilisation of transnational feminist response, but that transcultural feminist mobilisation also provides us with vital new ways in which we can reapproach the study, understanding, narration, and response to forced migration. I also return to the PAMOJA group's journey along the river, and via their steps - transformed, through transcultural feminist creativity, into a poem - I trace the many imaginative tributaries yet to be followed through further acts of transcultural feminist enquiry.

And so it is only appropriate that as we set out, we should be led by the words of the moving women of PAMOJA who have guided me through this book - words that have travelled, via the modest path of the River Trent, across languages, memories, and mouths, to offer careful guidance to those who might follow them. Such are Senait's words, which in many ways serve as the source for the pages that follow in their wake:

The river -

It zig-zags but moves gently and does not stop, just travels with the wind. And in life

I have so many problems but like the zig-zag line of the river

I do not give up -

Just keep on going. ${ }^{110}$

In these words, we hear adversity and tenacity, danger, and the promise of sanctuary all surfacing at once, providing not so much a path as an ethos to guide our own movements. Come on, she is saying. Let's get moving.

\section{Notes}

1 This term is employed by Slavoj Žižek to describe the symbolic gesture that is meant to be rejected. This might be applied to much critical work surrounding forced migration, in which an ethos of hospitality articulated in theoretical terms is not meant to be extended to real-world contexts, precisely because of its theoretical nature. I explore the critical and theoretical terrains through which forced migration has been approached in the twenty-first century later in this chapter. See Slavoj Žižek, The Plague of Fantasies (London: Verso, 2008), p.37.

2 Wangechi Mutu, The End of carrying All (2015). Three-screen animated video installation; 9 minutes 27 seconds loop. This film first appeared at the Venice Biennale 2015. For further on this film and on Mutu's work more broadly, see Robert Enright and Meeka Walsh, 'Reverberating Images: The Various Arts of Wangechi Mutu', Border Crossings 151 (2019), https://bordercrossingsmag. com/article/reverberating-images (last accessed 19th June 2020) and Kevin Buist, 'Meet the Jurors: Wangechi Mutu', Artprize, 30th July 2015, https:// www.artprize.org/blog/wangechi (last accessed 19th June 2020).

3 For further on the 'affecting' role played by women in humanitarian discourses of forced migration, see Gil Loescher, The UNHCR and World Politics: A Perilous Path (Oxford: Oxford University Press, 2001), p.303 and 
Rita Manchanda, 'Gender Conflict and Displacement: Contesting "Infantalisation” of Forced Migrant Women', Economic and Political Weekly 39:37 (2004), pp.4179-4186.

4 For a useful overview of the multiple causes of forced migration in the contemporary landscape, see Alice Bloch and Giorgia Dona, eds., Forced Migration: Current Issues and Debates (Abingdon: Routledge, 2018).

5 UNHCR, 'Global Trends in Forced Displacement in 2019', UNHCR, June 2020, https://www.unhcr.org/5ee200e37.pdf (last accessed 27th July 2020), p.2.

6 A potent example here is the U.K.'s Referendum on European Union membership, which resulted in its exit from the European Union. This featured prominent discussion on 'asylum seekers' as divisive figures in the broader debate on immigration. See Pertti Ahonen, 'Of Walls and Fences: Brexit and the History of Cross-Border Migration', Contemporary European History 28:1 (2018), pp. $42-45$.

7 See, for instance, Melody Rowell, reporting on a photography project by Myrto Papadopoloulos with Syrian mothers in Greece, 'Inside the Harrowing Journeys of Refugee Mothers', National Geographic, 10th January 2017, https://www.nationalgeographic.com/photography/proof/2017/01/syriagreece-refugees-mothers-pregnancy/ (last accessed 12th December 2018). Like many critics operating within the field, I maintain a certain scepticism towards the usage of the term 'crisis' as a description of the European experience of receiving a high number of forced migrants at its borders, given the sense in which this characterisation legitimates 'exceptional' responses outside of the usual legal functioning of nation states. Indeed, the term 'crisis' fails to situate the contemporary European experience of forced migration as part of a much broader transnational and historical narrative of forced migration that is in no way exceptional to Europe. For further critique of the term 'crisis', see Nicholas De Genova and Martina Tazzioli, 'Crisis: New Keywords of "The Crisis" in and of "Europe", in Europe at a Crossroads: Managed Inhospitality (Zone Books Online, 2020), http://nearfuturesonline.org/europecrisisnew-keywords-of-crisis-in-andof-europe/ (last accessed 27th July 2020).

8 I explore the necessity of a decolonized transnational feminist positionality more fully later on in this chapter, but it is also useful to acknowledge the intersections between decolonial and postcolonial theoretical approaches here. The 'postcolonial' describes a primarily literary and cultural discourse that emerged from the work of academics based mainly in the global North, who explore the legacies of nineteenth-century colonialisms. The 'decolonial', meanwhile, describes a more sociological approach stemming primarily from Latin America that explores the longer-standing manifestations of colonialism to which countries have also been subjected. See Gurminder K. Bhambra, 'Postcolonial and Decolonial Reconstructions', in Gurminder K. Bhambra, Connected Sociologies (London: Bloomsbury Academic, 2004), pp.117-140. My approach draws on useful aspects of each in order to arrive at a 'decolonised' feminist position.

9 For further detail on the perceived 'threat' of male migrants, see Lesley Pruitt, Helen Berents and Gayle Munro, 'Gender and Age in the Construction of Male Youth in the European Migration “Crisis”, Signs 43:3 (2018), pp.687709. Further information on women's prominent representational function in humanitarian advocacy discourse, meanwhile, is available in R. Charli Carpenter, “Women, Children and Other Vulnerable Groups”: Gender, Strategic Frames and the Protection of Civilians as a Transnational Issue', International Studies Quarterly 49 (2005), pp.486-500 and Erin Baines, Vulnerable Bodies: Gender, the UN and the Global Refugee Crisis (Aldershot: Ashgate, 2004). 
10 Liisa H. Malkki, Purity and Exile: Violence, Memory and National Cosmology among Hutu Refugees in Tanzania (Chicago, IL: University of Chicago Press, 1995), p.11.

11 'Mainstreaming' describes the adoption of an institutional commitment to gender-consciousness within all of its policy areas - thus, in theory, ensuring that gender does not remain a 'niche' or peripheral concern. In reality, however, much resistance to 'gender mainstreaming' persists within NGOs, where variously 'universalised' desires to view forced migrants as undifferentiated categories may endure, or where it may prove difficult to practice genderconsciousness in all strands of activity. For further on the 'mainstreaming' of gender concerns in forced migration-related NGOs, see Jane Freedman, Gendering the International Asylum and Refugee Debate, Second Edition (Basingstoke: Palgrave Macmillan, 2015), pp.114-121. See also Victoria Bernal and Inderpal Grewal, eds., Theorizing NGOs: States, Feminisms, and Neoliberalisms (Durham, NC: Duke University Press, 2014).

12 For more on intersectional feminist approaches to the Black Lives Matter Movement, see Charlene Carruthers, Unapologetic: A Black, Queer, and Feminist Mandate for Radical Movements (Boston, MA: Beacon Press, 2018); on feminist participation within wider global justice struggles, see Catherine Eschle and Bice Maigushca, Making Feminist Sense of the Global Justice Movement (Lanham, MD: Rowman and Littlefield, 2010); for further on the transnational constellation of feminist approaches from the global North, see Lee Ann Banaszak, The U.S. Women's Movement in Global Perspective: Issues and Strategies for the New Century (Lanham, MD: Rowman and Littlefield, 2005); for an overview of the rise of feminisms in the global South, see Amrita Basu, ed., Women's Movements in the Global Era: The Power of Local Feminisms (Abingdon: Routledge, 2016).

13 Susan Martin, 'Global Migration Trends and Asylum', UNHCR New Issues in Refugee Research Working Paper Series 41 (2001), pp.1-27; p.3.

14 Funding and Donor Relations Services, UNHCR, 'UNHCR Global Appeal 1999 - Refugee Women', UNHCR Online, 1st December 1998, https://www. unhcr.org/uk/publications/fundraising/3eaff442e/unhcr-global-appeal-1999refugee-women.html (last accessed 10th July 2020).

15 UNHCR, 'Global Trends 2013', UNHCR, https://www.unhcr.org/uk/ statistics/country/5399a14f9/unhcr-global-trends-2013.html (last accessed 10th July 2020).

16 Freedman, Gendering the International Asylum and Refugee Debate, pp.21-22.

17 The UNHCR statistics office shows that in European countries that do disaggregate gender in demographic data, women constitute roughly $30 \%$ of asylum applicants. See Heaven Crawley and Trine Lester, 'Comparative Analysis of Gender-Related Persecution in National Asylum Legislation and Practice in Europe', UNHCR, May 2004, https://www.unhcr.org/40c071354.pdf (last accessed 20th July 2020).

18 UNHCR gender disaggregated data, where available, shows that women and girls comprise roughly $48 \%-50 \%$ of the world's 'people of interest' to them, which includes refugees, internally displaced people, stateless people, and returnees. UNHCR, 'Global Trends 2018', UNHCR, 2019, https://www.unhcr. org/uk/statistics/unhcrstats/5d08d7ee7/unhcr-global-trends-2018.html (last accessed 20th July 2020).

19 For a useful overview of this scholarship, see Katharine Donato, Donna Gabaccia, Jennifer Holdaway, Martin Manalansan, and Patricia Pessar, 'A Glass Half-Full? Gender in Migration Studies', International Migration Review 40:1 (2006), pp.3-26. 
20 Doreen Indra, 'Not a "Room of One's Own”: Engendering Forced Migration Knowledge and Practice', in Doreen Indra, ed., Engendering Forced Migration: Theory and Practice (New York: Berghan Books, 1999), pp.1-22; p.1; p.6.

21 V. Spike Peterson and Anne Sisson Runyan, Global Gender Issues (Westview: Colorado, 1993), p.1.

22 J. Ann Tickner, 'What Is Your Research Program? Some Feminist Answers to International Relations Methodological Questions', International Studies Quarterly 49:1 (2005), pp.1-21; p.3.

23 Doreen Massey, 'Power-Geometry and a Progressive Sense of Place', in J. Bird, B. Curtis, G. Robertson, and L. Tickner, eds., Mapping the Futures: Local Culture, Global Change (London: Routledge, 1993), pp.59-69.

24 Jennifer Hyndman, 'The (Geo)Politics of Mobility', in Lynn A. Straeheli, Eleonore Kofman, and Linda Peake, eds., Mapping Women, Making Politics: Feminist Perspectives on Political Geography (New York: Routledge, 2004), pp.169-184; p.175.

25 Freedman, Gendering the International Asylum and Refugee Debate, p.12.

26 Donato et al., p.6.

27 Ibid.

28 Jane Freedman, 'Who's Responsible for Violence against Migrant Women?' Open Democracy, 28th August 2015, https:/www.opendemocracy.net/ en/beyond-trafficking-and-slavery/whos-responsible-for-violence-againstmigrant-women/ (last accessed 13th July 2020).

29 Freedman, Gendering the International Asylum and Refugee Debate, pp.45-68.

30 See Refugee Council, The Vulnerable Women's Project: Refugee and Asylum Seeking Women Affected by Rape or Sexual Violence - Literature Review (London: Refugee Council, 2009); also, Cécile Pouilly, 'Refugee Women and Children Face Heightened Risk of Sexual Violence Amid Tensions and Overcrowding at Reception Facilities on Greek Island', UNHCR, 9th February 2018, https://www.unhcr.org/uk/news/briefing/2018/2/5a7d67c4b/refugeewomen-children-face-heightened-risk-sexual-violence-amid-tensions.html (last accessed 13th July 2020).

31 Leo Dobbs, 'UNHCR Backs 16 Days of Opposition to Violence against Women', UNHCR, 25th November 2008, https://www.unhcr.org/uk/news/ latest/2008/11/492c1eb74/unhcr-backs-16-days-opposition-violence-againstwomen.html (last accessed 13th July 2020).

32 UNHCR, 'Women on the Run: First-Hand Accounts of Women Fleeing El Salvador, Guatamala, Honduras, and Mexico', UNHCR, October 2015, https:// www.unhcr.org/uk/publications/operations/5630f24c6/women-run.html (last accessed 13th July 2020), p.58.

33 Kelly Oliver, 'The Special Plight of Women Refugees', in Margaret A. McLaren, ed., Decolonizing Feminism: Transnational Feminism and Globalization (London: Rowman and Littlefield, 2017), pp.177-200; p.181.

34 The Geneva Convention famously states that a refugee is defined as a person who, 'owing to a well-founded fear of being persecuted for reasons of race, religion, nationality, membership of a particular social group or political opinion, is outside the country of his nationality and is unable, or owing to such fear is unwilling to avail himself of the protection of that country; or who, not having a nationality or being outside the country of his former habitual residence as a result of such events, is unable, or owing to such fear is unwilling to return to it'. UNHCR, 'Convention and Protocol Relating to the Status of Refugees', UNHCR, December 2010, https://www.unhcr.org/uk/3b66c2aa10 (last accessed 13th July 2020). A number of scholars, campaigners, and lawyers have 
worked to critique and contest the gender-blind nature of the 1951 Convention and asylum legislation. See, for instance, Heaven Crawley, Refugees and Gender: Law and Process (Bristol: Jordan, 2001).

35 See Freedman, Gendering the International Asylum and Refugee Debate, pp.90-91 for an overview of these successive changes which have taken place from 1985 through to the early twenty-first century.

36 Cécile Rousseau, François Crépeau, Patricia Foxen, and France Houle, 'The Complexity of Determining Refugeehood: A Multidisciplinary Analysis of the Decision-Making Process of the Canadian Immigration and Refugee Board', Journal of Refugee Studies 15:1 (2002), pp.43-70.

37 Helen Baillot, Sharon Cowan and Vanessa Munro, 'Seen But Not Heard? Parallels and Dissonances in the Treatment of Rape Narratives across the Asylum and Criminal Justice Contexts', Journal of Law and Society 36:2 (2009), pp.195-219.

38 Nahla Valji, 'Women and the 1951 Refugee Convention: Fifty Years of Seeking Visibility', Refuge 19:5 (2001), pp.25-35; p.25.

39 See Freedman, Gendering the International Asylum and Refugee Debate, p.107 and Robert Barksy, Constructing a Productive Other: Discourse Theory and the Convention Refugee Hearing (Amsterdam: John Benjamins, 1994).

40 Jennifer Hyndman, 'Introduction: The Feminist Politics of Refugee Migration', Gender, Place and Culture 17:4 (2010), pp.453-459; pp.453-454.

41 Indra, ed., Engendering Forced Migration, p.xiv.

42 Freedman, Gendering the International Asylum and Refugee Debate, p.17.

43 Denise M. Horn and Serena Parekh, 'Introduction to "Displacement", Signs 43:3 (2018), pp.503-514; p.503.

44 I use the term 'women' in its broadest sense - as a category that encompasses those biologically defined as female; those who, though biologically classified as female, identify in gender-fluid ways, including as non-binary and genderqueer; and those who have transitioned to female identification as transgender subjects. I do not define an age boundary for 'womanhood'; at times, the category also speaks to adolescence. It should therefore be keenly apparent that 'women' cannot be reduced to a singular category of experience or identity, and acknowledgement of this heterogeneity is of paramount importance within this volume.

45 UNHCR, 'Women on the Run: First-Hand Accounts of Women Fleeing El Salvador, Guatamala, Honduras, and Mexico', p.58.

46 Ibid., p.44.

47 Katie E. Oliviero, 'Sensational Nation and the Minutemen: Gendered Citizenship and Moral Vulnerabilities', Signs: Journal of Women in Culture and Society 36:3 (2011), pp.679-706.

48 UNHCR, 'Women on the Run: First-Hand Accounts of Women Fleeing El Salvador, Guatamala, Honduras, and Mexico', p.47.

49 Arietta Messing, Rachel E. Fabi and Joanne Rosen, 'Reproductive Injustice at the U.S Border', American Journal of Public Health 110:3 (2020), pp.339-344.

50 Eleanor Acer, Rebecca Gendelman, and Kennji Kizuka, 'Orders from Above: Massive Human Rights Abuses under Trump Administration Return to Mexico Policy', Human Rights First, October 2019, https://www.humanrightsfirst. org/sites/default/files/hrfordersfromabove.pdf (last accessed 13th July 2020).

51 See, for instance, the protest at the Otay Mesa Detention Centre in San Diego in 2018. Eleanor Salsbury and Emma Encinas, 'We Will Be Judged for This: Feminist Lawmakers and Activists Protest Trump's Immigration Policies outside Otay Meda Detention Centre', Ms. Magazine, 26th June 2018, https:// 
msmagazine.com/2018/06/26/will-judged-feminist-lawmakers-activistsprotest-trumps-immigration-policies-outside-otay-mesa-detention-center/ (last accessed 27th July 2020).

52 For further on \#NoBanNoWallNoRaids, see https://nobannowallnoraids. wordpress.com/; for feminist analysis, see Karina Moreno, 'A Politics of Solidarity', Jacobin, 11th May 2017, https://www.jacobinmag.com/2017/05/ immigration-donald-trump-muslims-latinos-no-ban-no-wall-no-raids (last accessed 13th July 2020).

53 See, for instance, Anne Sisson Runyan, Amy Lind, Patricia McDermott, and Harriet H. Marchand, Feminist (Im)Mobilities in Fortress(ing) North America: Rights, Citizenships, and Identities in Transnational Perspective (New York: Routledge, 2013) and 'Feminist Resources for \#TheResistance', including a section on '\#NoBanNoWallNoRaids: Immigration, Borders and the Nation', in Signs: Journal of Women in Culture and Society, http://signsjournal. org/features/virtual-issues/feminist-resources-for-theresistance/\#noban (last accessed 13th July 2020).

54 Introductory text and code for Sara Ann Caroll, The Desert Survival Series available online at Academia.edu, file://Users/anna/Downloads/The_Desert_ Survival_Series_La_serie_de.pdf (last accessed 14th July 2020).

55 Laura Flanders, 'Why Immigration Is a Feminist Issue', The Nation, 6th December 2011, https:/www.thenation.com/article/archive/why-immigrationfeminist-issue/ (last accessed 13th July 2020).

56 Tom Phillips, “This Is Our Feminist Spring”: Millions of Mexican Women Prepare to Strike Over Femicides', The Guardian, 7th March 2020, https:// www.theguardian.com/world $/ 2020 / \mathrm{mar} / 07 /$ mexico-femicides-protestwomen-strike (last accessed 13th July 2020).

57 Hyndman, 'Introduction: The Feminist Politics of Refugee Migration', p.454.

58 For more on Fourth-Wave Feminism, see Nicola Rivers, Postfeminism(s) and the Arrival of the Fourth Wave: Turning Tides (Basingstoke: Palgrave Macmillan, 2017).

59 Matt Stromberg, 'For Artists, the U.S.-Mexico Border Is Fertile Territory', Artsy, 6th March 2017, https://www.artsy.net/article/artsy-editorial-mexicanartists-threat-trumps-wall-fuel-inspiration (last accessed 16th July 2020).

60 The term 'governmentality' is taken from the work of Michel Foucault and describes the range of strategies employed by governing bodies (including national governments, but extending to agencies beyond this) to control the population through the imposition of systems that determine how it is possible to behave and indeed live. Michel Foucault, 'Governmentality', in Graham Burchell, Colin Gordon and Peter Miller, eds., The Foucault Effect: Studies in Governmentality (Chicago, IL: University of Chicago Press, 1991), pp.87104. Migration is heavily regulated according to structures of governmentality and has been the subject of much critique within the field. See, for instance, Martina Tazzioli and William Walters, 'The Sight of Migration: Governmentality, Visibility and Europe's Contested Borders', Global Society 30:3 (2016), pp.445-464.

61 Caren Kaplan, 'The Politics of Location as Transnational Feminist Critical Practice', in Inderpal Grewal and Caren Kaplan, eds., Scattered Hegemonies: Postmodernity and Transnational Feminist Practices (Minneapolis: University of Minnesota Press, 1994), pp.137-152; p.139.

62 Oliver, 'The Special Plight of Women Refugees', p.177. I note here that the term 'feminism' does not operate in the same way across all geographical or cultural locations, and that what I might recognize as 'feminist' acts - such as those that defend women's rights, seek to advance their equality, or build 
structures of feminocentric solidarity - are sometimes consciously labelled in other ways, or the term resisted altogether due to the cultural connotations of the term as they exist within a particular setting. For instance, in some Middle Eastern contexts, the term 'feminist' bears specifically Western and hence colonial/imperialist associations - see Leila Ahmed, Women and Gender in Islam: Historical Roots of a Modern Debate (New Haven, CT: Yale University Press, 1992), p.167. Over the course of this volume, I deliberately avoid determining what can and cannot be considered to be 'feminist', recognizing that the term operates in a contingent and contextualized manner. Nevertheless, the underlying principle of all 'feminist' activities and attitudes, however defined and positioned, must surely be that they should operate to the benefit of women's well-being, equality, and advancement.

63 Jennifer Hyndman, 'Border Crossings', Antipode: A Journal of Radical Geography 29:2 (1997), pp.149-176; p.173.

64 Cindi Katz, 'On the Grounds of Engagement: A Topography for Feminist Political Engagement', Signs 26:4 (2001), pp.1213-1234.

65 Chandra Talpade Mohanty and M. Jacqui Alexander, 'Cartographies of Knowledge and Power: Transnational Feminism as Racial Praxis', in Amanda Lock Swarr and Richa Nagar, eds., Critical Transnational Feminist Praxis (Albany, NY: SUNY Press, 2010), pp.23-45.

66 Chandra Talpade Mohanty, 'Preface: Toward a Decolonial Feminism for the 99 Percent', in Margaret A. McLaren, ed., Decolonizing Feminism: Transnational Feminism and Globalization (London: Rowman and Littlefield, 2017), pp.vii-xi.

67 Margaret A. McLaren, 'Introduction: Decolonizing Feminism', in Margaret A. McLaren, ed., Decolonizing Feminism: Transnational Feminism and Globalization (London: Rowman and Littlefield, 2017), pp.1-18.

68 Chandra Talpade Mohanty, “Under Western Eyes” Revisited: Feminist Solidarity through Anticapitalist Structures', in Chandra Talpade Mohanty, Feminism without Borders: Decolonizing Theory, Practicing Solidarity (Durham, NC: Duke University Press, 2003), pp.221-252; p.222.

69 Chandra Talpade Mohanty, Feminism without Borders: Decolonizing Theory, Practicing Solidarity (Durham, NC: Duke University Press, 2003), p.2.

70 Dirk Hoerder, Yvonne M. Hébert, and Irina Schmitt, eds., Negotiating Transcultural Lives: Belongings and Social Capital among Youth in Comparative Perspective (Toronto: University of Toronto Press, 2006), p.13.

71 Nadera Shalhoub-Kevorkian, Militarization and Violence against Women in Conflict Zones in the Middle East: A Palestinian Case-Study (Cambridge: Cambridge University Press, 2009), p.154.

72 Yến Lê Espiritu and Lan Duong, 'Feminist Refugee Epistemology: Reading Displacement in Vietnamese and Syrian Refugee Art', Signs 43:3 (2018), pp.587-615; p.588.

73 Ibid., p.590.

74 Ibid., p.611.

75 Mohanty, Feminism without Borders, p.3.

76 There is no perfect term that describes all experiences of disenfranchised mobility. However, I use the term 'forced migration' as the most inclusive term available to describe the condition of those whose mobility - within or beyond national borders - has been generated to disenfranchising effect. This term encompasses the experiences of 'refugees', 'asylum seekers', and 'illegal immigrants' - terms that describe people assigned particular legal statuses (those granted refugee status, those seeking it, and those denied it, respectively). It also includes those who have been trafficked and those who are internally 
displaced within their own country; and it is also, in my usage, intended to collapse the perceived boundary between 'economic' and 'enforced' migration, which generally distinguishes between those who have chosen to migrate and those who have not. However, I consider this a controversial distinction to enforce, given the range of reasons that can drive migration - including poverty, an 'economic' condition that is far from chosen and that must be fled in order to facilitate survival. Within particular chapters, I will sometimes, however, select a particular term that captures the distinctive experiences or identifications of those who engage in specific forms of forced migration. For further discussion of the term 'forced migration' and its alternatives, see Alice Bloch and Giorgia Dona, 'Forced Migration: Setting the Scene', in Bloch and Dona, eds., Forced Migration, pp.1-18; pp.3-4.

77 Further information on PAMOJA Women Together can be found at the Nottingham and Nottinghamshire Refugee Forum website, http://www. nottsrefugeeforum.org.uk/projects/womens-group/ (last accessed 27th July 2020), and in the 'Foreword' to The World Is for Everyone: New Writing by PAMOJA Women Together, ed. Anna Ball and Camilla Reeve (London: Palewell Press, 2019), pp.1-2.

78 Audrey Kobayashi, 'Colouring the Field: Gender, "Race", and the Politics of Fieldwork', The Professional Geographer 46:1 (1994), pp.73-80; p.73.

79 Maggie O’Neill, Asylum, Migration and Community (Bristol: Policy Press, 2010), p.xiii.

80 Jade Larissa Schiff, 'Welcoming Refugees: Mindful Citizenship and the Political Responsibility of Hospitality', Signs 43:3 (2018), pp.737-762.

81 Catherine Nolan, Transnational Ruptures: Gender and Forced Migration (Abingdon: Routledge, 2016), p.37.

82 I have collaborated with PAMOJA Women Together since 2016, in my position as committee member/Chair of Nottingham Refugee Week and as an independent cultural practitioner. All projects have been designed to enable group members to explore creative expression as a means to articulate their thoughts and feelings, and to build solidarity. All projects have also been co-designed and collaborative. Our initial project in 2017, 'And Still I Rise', used the poetry of Maya Angelou as a starting point for considering issues of resilience and achievement, which we explored through the mediums of poetry discussion, free writing, poetry writing, photography, drama, and the eventual production of an exhibition for Nottingham Refugee Week, which subsequently toured venues throughout Nottingham, and was used as a self-representational tool by the group during a conference they ran on 'Empowering Women'. Between 2018 and 2019, we ran a subsequent collaborative project which invited the group to explore varied forms of creative self-representation in different cultural settings - including conversation as we walked alongside the River Trent, and subsequent 'river-writing' workshops with the poet Sarah Jackson, and sound artist Andrew Brown; baking at Sneinton Windmill in Nottingham, which generated conversations about bread and bread-making from different cultures; and a cookery project, which invited group members to share recipes and meals, and to find out the stories and memories connected to them. These projects resulted in the production of an anthology of writing, The World Is for Everyone, which also entailed a number of public speaking events, including at the Galleries of Justice in Nottingham and Five Leaves Bookshop. The workshops have led to a subsequent writing project with the Survivors' Alliance, a group for survivors of human trafficking and modern-day slavery, to which some PAMOJA members also belong. All projects have been subject to stringent ethical approval processes via both Nottingham Trent University, 
and Nottingham and Nottinghamshire Refugee Forum. My thanks to everyone who has supported and participated in these projects (many listed in this volume's Acknowledgements).

83 For further on the European response to the 'refugee crisis', see Matthew J. Gibney, The Ethics and the Politics of Asylum: Liberal Democracy and the Response to Refugees (Cambridge: Cambridge University Press 2004) and Mariangela Palladino and Agnes Woolley, 'Migration, Humanitarianism, and the Politics of Salvation', LIT: Literature Interpretation Theory 29:2 (2018), pp.129-144.

84 Ai Weiwei, dir., Human Flow (Germany/U.S/China/Palestine/France: 24 Media, 2017).

85 Mohsin Hamid, Exit West (London: Penguin, 2018).

86 Gulwali Passarlay with Nadene Ghouri, The Lightless Sky: My Journey to Safety as a Child Refugee (London: Atlantic, 2015). For instances of 'explanatory' texts about forced migrant experience, some of which also begin to push against and debunk the stereotypes projected onto forced migrants, see Dina Nayeri, The Ungrateful Refugee (Edinburgh: Canongate, 2019) and Nikesh Shukla, ed., The Good Immigrant (London: Unbound, 2017).

87 See, for instance, UN Women, 'Displacement and Resilience: Five Women, Five Stories', UN Women, 17th June 2019, https://www.unwomen.org/en/ digital-library/multimedia/2019/6/photo-essay-cameroon-displacement-andresilience-stories (last accessed 28th July 2020); Anna Karabet, 'Refugee Women Share Their Heartbreaking Stories', Action Aid, 5th January 2016, https://www.actionaid.org.uk/blog/voices/2016/01/05/refugee-women-sharetheir-heartbreaking-stories (last accessed 28th July 2020).

88 For further on the trope of the 'border-guard', see John Armstrong, Nations before Nationalism (Chapel Hill: University of North Carolina Press, 1982), p.6; p.242.

89 Agnes Woolley, Contemporary Asylum Narratives: Representing Refugees in the Twenty-First Century (Basingstoke: Palgrave Macmillan, 2014), p.3.

90 See, for instance, Birgit Locher and Elisabeth Prügl, 'Feminism and Constructivism: Worlds Apart or Sharing the Middle Ground', International Studies Quarterly 45:1 (2001), pp.111-129, who argue that voice is integral to improving agency for marginalized subjects, including women located transnationally.

91 Clementine Wamariya and Elizabeth Weil, The Girl Who Smiled Beads: A Story of War and What Comes After (London: Windmill Books, 2019); Melissa Fleming, A Hope More Powerful Than the Sea (New York: Flatiron Books, 2017).

92 Malala Yousafzai, We Are Displaced: My Journey and Stories from Refugee Girls around the World (London: Weidenfeld and Nicholson, 2019).

93 See, for instance, Harriet Gibsone, 'MIA's Borders: Artist Braves Boats and Barbed Wire in Video Crusade for Refugees', The Guardian, 27th November 2015, https://www.theguardian.com/music/2015/nov/27/mia-borders-videorefugee-crisis-europe (last accessed 28th July 2020).

94 For further on MIA, see the documentary film on her rise to stardom, which makes use of self-filmed footage as well as media coverage: Steve Loveridge, dir., Matangi/Maya/M.I.A (U.K/U.S./Sri Lanka: Dogwoof Films, 2018).

95 See for instance Lynn Hirschberg, 'MIA's Agitprop Pop', The New York Times, 25th May 2010, https://archive.nytimes.com/www.nytimes.com/2010/05/30/ magazine/30mia-t.html (last accessed 28th July 2020).

96 The term 'bare life' is used by Giorgio Agamben in Homo Sacer: Sovereign Power and Bare Life, trans. Daniel Heller-Roazen (Stanford: Stanford University Press, 1995). Indicative work by other key thinkers includes Zygmunt 
Bauman, Liquid Times: Living in an Age of Uncertainty (Cambridge: Polity Press, 2007); Slavoj Žižek, Against the Double Blackmail: Refugees, Terror and Other Troubles with the Neighbours (London: Penguin, 2016); and Jacques Derrida, 'Unconditionality or Sovereignty: The University at the Frontiers of Europe', Oxford Literary Review 31:2 (2009), pp.115-131.

97 See, for instance, Edward Said, Reflections on Exile: And Other Literary and Cultural Essays (London: Granta, 2012) and Hannah Arendt, The Origins of Totalitarianism (San Diego, CA: Harcourt, 1994); for a recent response to the work of Arendt in particular, see Lindsey Stonebridge, Placeless People: Writing, Rights, and Refugees (Oxford: Oxford University Press, 2018).

98 The breadth and significance of this emergent trend within the Humanities has most recently been reflected in the landmark publication of Refugee Imaginaries: Research across the Humanities, ed. Emma Cox, Sam Durrant, David Farrier, Lyndsey Stonebridge, and Agnes Woolley (Edinburgh: Edinburgh University Press, 2020). Extensive and wide ranging in its coverage, this volume nevertheless indicates a significant issue in existing Humanities-based attention to 'refugee imaginaries'. For out of its 32 chapters spanning multiple genres and issues, only 1 - notably, a sociologically and legally based enquiry into 'Sexual and Gender-Based Asylum and the Queering of Global Space', by Sudeep Dasgupta - foregrounds gender issues in its analysis. See Sudeep Dasgupta, 'Sexual and Gender-Based Asylum and the Queering of Global Space: Reading Desire, Writing Identity and the Unconventionality of Law', in Emma Cox, Sam Durrant, David Farrier, Lyndsey Stonebridge, and Agnes Woolley, eds., Refugee Imaginaries: Research Across the Humanities (Edinburgh: Edinburgh University Press, 2020), pp. 86-102.

99 Oliver, 'The Special Plight of Women Refugees', p.193. Gender-related issues have begun to be recognised by two key scholars, David Farrier and Agnes Woolley, each of whom draws upon and indeed extends the vital tools of postcolonial analysis in their work. In Postcolonial Asylum, for instance, Farrier notes the enduring 'androcentrism' of cultural, theoretical, and legal discourses relating to asylum, and indicates, at several points, the necessity of inflecting postcolonial analysis with gender-consciousness. The understanding of female identity that emerges through his analysis, though, is one that ultimately characterises the female refugee as akin to Spivak's 'subaltern' - a figure doubly silenced within the multiply oppressive structures of a heteropatriarchal asylum regime. See David Farrier, Postcolonial Asylum: Seeking Sanctuary before the Law (Liverpool: Liverpool University Press, 2011), p.25. While this characterisation gestures towards the necessity of a broader transnational feminist project that critiques and counters this gendered positionality, it locates gender-consciousness as a facet rather than a focus of the project in hand. Similarly, Agnes Woolley's Contemporary Asylum Narratives confines its outstanding exploration of cosmopolitan feminism, or 'cosmofeminism', as the basis for thinking through cross-cultural representational agency in the forced migrant narrative to its final chapter. See Woolley, Contemporary Asylum Narratives, pp.185-205.

100 Cox et al., Refugee Imaginaries, back cover.

101 The national (and transnational) contexts on which I focus in this volume are limited to a small range of case studies that cannot possibly encompass all locations affected by forced migration in the twenty-first century - which is indeed a phenomenon in which every part of the world is implicated. Particular contexts that are deserving of further attention in future studies, however, include the major flows of displaced people across countries in Africa - including South Sudan and Somalia, forced migrants from Myanmar, and forced 
migrants from Venezuela. There are also many enduring contexts of forced migration that span the twentieth and twenty-first centuries - for instance, the ongoing situation of Palestinian refugees, who number over 4 million people as of 2006 (Michael Dumper, Palestinian Refugee Repatriation: Global Perspectives (Abingdon: Routledge, 2006), p.2). Within the current study, however, I have elected to focus on major contexts of forced migration that are specific and contemporary to the twenty-first century and which constitute considerable foci within the cultural imagination.

102 Charlotte McDonald-Gibson, Cast Away: Stories of Survival from Europe's Refugee Crisis (London: Portobello, 2016) and Nada Awar Jarrar, An Unsafe Haven (London: The Borough Press, 2016).

103 Samira Makhmalbaf, dir., At Five in the Afternoon (Iran/France: Makhmalbaf Film House, 2002); Rokhsareh Ghaem Maghami, dir., Sonita (Germany/ Switzerland/Iran: New Wave Films, 2015).

104 While the official terminology is, within the U.K. context, IRC (Immigration Removal Centre), a term that stresses the temporary nature of the accommodation, the long periods for which people are often detained (on which there is currently no legal cap within the U.K. context), and the structural similarities to the prison system means that many critics instead elect to use the term 'detention centre' as a more appropriate descriptor. See, for instance, Daniel Wilsher, Immigration Detention: Law, History, Politics (Cambridge: Cambridge University Press, 2014).

105 Hani Abdile, 'When I Become Famous, I'll Give Tony Abbot a Job', in Michael Green and André Dao, eds., They Cannot Take the Sky: Stories from Detention (Sydney: Allen and Unwin, 2017), pp.29-47; poetry performances drawn from material within Hani Abdile, I Will Rise (Victoria: Writing Through Fences, 2016).

106 A video of the project by the artist is available on YouTube: see Charwei Tsai and Tsering Tashi Gyalthang, Hear Her Singing, 2017 video with sound and colour, 16 minutes 28 seconds, https://www.youtube.com/watch?v= SfaFCrQcWjo\&t=15s (last accessed 4th May 2020).

107 I use the term 'women"' in an expansive and inclusive sense within this chapter to include those who are cisgender and transgender, and who identify with the female and feminine in any sense - including within the realms of gender-fluid or non-binary identity.

108 Staceyann Chin, Crossfire: A Litany for Survival (Chicago, IL: Haymarket, 2019).

109 Wu Tsang, One Emerging from a Point of View, 43-minute, 2-channel overlapping projections, 2019.

110 Senait, 'My Peaceful River', in The World Is for Everyone, p.49. Name and work cited with the author's permission. 


\section{An expectant figure \\ Encountering the 'refugee crisis' through literary maternal feminism}

In May 2018, the online platform for Time Magazine ran with an unusual appeal to mark Mother's Day in the United States. ${ }^{1}$ Instead of encouraging daughters to conform to the standard purchasing pattern of the ' $\$ 23.1$ billion spent on flowers, cards and other gifts' in appreciation of their mothers, Kathy Calvin, President and CEO of the UN Foundation, urged them to 'celebrate mothers around the world' by pledging their support for the 'United Nations Population Fund (UNPF), the largest global provider of maternity care and reproductive health services' in humanitarian emergencies such as 'Syria, Yemen and Iraq'. ${ }^{2}$ Citing 'baby Yasmin and her mother' as exemplary of the 9,000-plus individuals to have benefitted from maternity care provided by the UNPF at the Za'atari refugee camp in Jordan, Calvin presents forced migrant women as a particular group who demonstrate the 'transformational impact' of supporting women's maternal well-being - not simply for the benefits to the individual but to the global community. Ensuring the health of women in politically precarious situations, she writes, 'sparks a ripple effect, generating not only healthy and empowered girls and women, but more stable communities and nations' of benefit to the transnational landscape as a whole. ${ }^{3}$ There is a sting in this 'feel-good feminist' tale, however. Calvin's plea has been prompted, she writes, by the U.S. government's 2017 decision to renege on its position as the leading supporter of the UNPF by withdrawing all U.S. funding, with disastrous consequences for the 34 million women of reproductive age facing humanitarian emergencies - an estimated 5 million of them pregnant, many of them in forced migrant situations. ${ }^{4}$ In this landscape of biopolitical hostility, Calvin's article suggests, it is women who must spring to the aid of forced migrant women - mothers who must support forced migrant mothers. And this alliance, she suggests, is more than personal. It is deeply - urgently - political.

Calvin's 'call to motherly arms' invokes a discourse of politicised maternal alliance that bears a complex historical and feminist heritage, mobilised as it has been from ideologically disparate positions at varied points of social crisis. ${ }^{5}$ But this appeal through what we might term 'the feminist maternal' - the recognition of maternity as both an important site of feminist intervention

DOI: $10.4324 / 9780429325403-2$ 
and a potential source of ethical, empathetic transcultural identification - is one that has surfaced with a particular potency in the cultural response to the 'refugee crisis' ${ }^{6}$ of 2011 onwards, and Calvin is far from alone in her vision of transnational feminist solidarity realised through the maternal. Numerous journalistic and documentary projects emerging at the peak of the Syrian humanitarian crisis around 2015 sought to unearth the 'hidden face of suffering' by turning their sights towards the voices and stories of refugee mothers - albeit often delivered in bite-sized, easily digestible online terms. ${ }^{7}$ More complex and sustained representational engagements with refugee mothers, though, have also emerged since 2015 from the pens of female authors bearing varied transnational identifications, including journalists Charlotte McDonald-Gibson (British), Samar Yazbek (Syrian), and Janine di Giovanni (North American); novelists including Jennifer Zeynab Joukhadar (Arab American), Malu Halasa (Jordanian-Philippina-American), and Nada Awar Jarrar (Lebanese-Australian); United Nations High Commissioner for Refugees (UNHCR) spokesperson and author Melissa Fleming (North American); and graphic artist Kate Evans (British). ${ }^{8}$

In this corpus of what we might term 'feminocentric crisis response literature', many of the authors seek compassionate alliance with newly arrived refugee populations through imaginative representation of and sometimes identification with the maternal. Kate Evans's graphic novel Threads, for instance, bears a distinctively feminocentric interest in the Calais Jungle's female health workers, who seek to locate and assist the oft-concealed figures of pregnant mothers and women with children. This focus on the generally marginalised maternal experience bears interesting feminist continuities with her previous graphic projects, including Red Rosa, a graphic novel depiction of the life of the Polish-German Marxist Rosa Luxemburg, and Bump, an 'alternative' feminist pregnancy guide. ${ }^{9}$ Her framing of the 'refugee crisis' through the maternal can therefore be read as an extension of her feminist commitment to the visualisation of women's marginalised life experiences of a simultaneously biological and sociopolitical nature and this is indicative of the broader feminist commitments at play in many other female-authored, female-focussed works. ${ }^{10}$

How might these transnational engagements with the refugee crisis through literary invocations of 'maternal feminism' enable us to better understand and respond to the challenges and needs experienced by forced migrant mothers? If we return to the discursive dynamics of Calvin's appeal for a moment, it becomes clear that the answer here is far from simple. Speaking to an informed, likely empathetic U.S. female readership and framed in the language of the '\#MeToo' era - a discourse of 'speaking up' and 'calling out' - Calvin's article mobilises a media-savvy feminist lexicon voiced in implicit defiance of the Trump presidency's hostile biopolitics (which has also exercised punitive measures designed to deter forced migrant women through the maternal). ${ }^{11}$ Yet her rhetorical focus on the figure of the forced migrant woman as one of 'precarious crisis' also falls squarely 


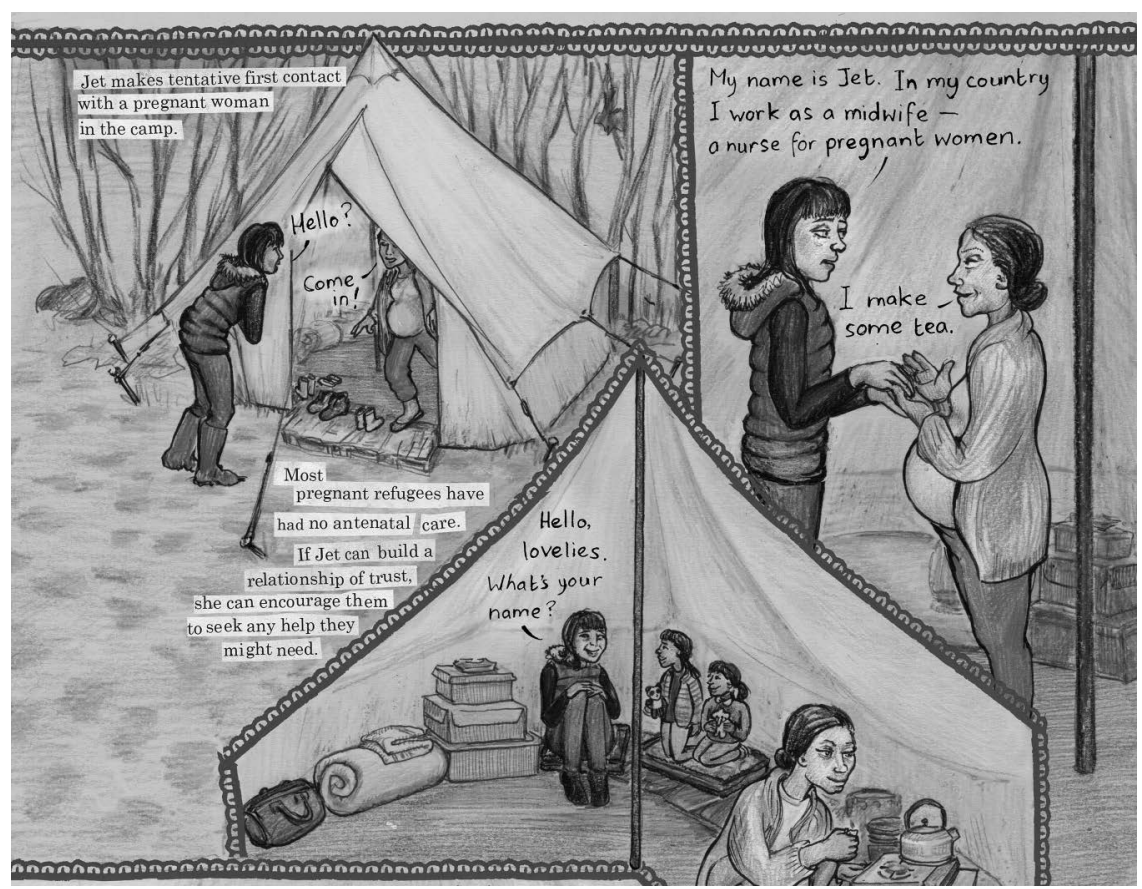

Figure 2.1 Humanitarian midwife 'Jet' makes 'tentative first contact' with a pregnant refugee and is invited into the private and concealed space of her tent. Image from Threads from the Refugee Crisis, Kate Evans, Verso 2017. Courtesy of the artist.

within the 'cultural toolkit' of humanitarian campaign strategies, which, as Heather Johnson argues, have tended to mobilise women as figures with apolitical ethical appeal, in need of (implicitly financial) rescue by those within the global North. ${ }^{12}$ Calvin's complex political positionality within the transnational landscape - as committed feminist battling a hostile U.S. patriarchal landscape, and as CEO of a gender-mainstreamed humanitarian operation with its own financial terms and international agendas at stake therefore begins to reveal some of the many discursive complexities that circulate in the task of forging a transnational feminist response to women's forced migration in relation to the maternal. ${ }^{13}$ So, too, does her representational approach reveal some of the weighty expectations that have become attached to refugee mothers as figures of 'crisis' and as facilitators of varied political imaginaries, including the feminist. Faced with these complexities, then, how are we to read representations of forced migrant mothers within the discourse of 'feminocentric crisis response' literature? What creative 
potentials and political problems are engendered by their engagement with the feminist maternal? And what insights do they yield into the task of forging effective and meaningful feminist responses attentive to maternity across cultures, contexts, and power differentials?

These dilemmas find astute responses in two differently positioned literary works, both published in 2016: Charlotte McDonald-Gibson's literary journalistic work Cast Away and Nada Awar Jarrar's novel An Unsafe Haven. Framed as an act of humanitarian advocacy, McDonald-Gibson's Cast Away employs journalistic 'testimonio' in order to present a powerful mobilisation of the pregnant refugee as a point of cross-cultural maternal recognition. McDonald-Gibson's text explores how the narrative centralisation of maternity might serve a powerful political purpose - yet it also raises questions about the politics of voice and hierarchies of care implicit in her identification with and as a mother. Nada Awar Jarrar's novel, meanwhile, presents a very different engagement with the maternal. Distinctive as a Lebanese-focussed Anglophone exploration of the impact of the Syrian refugee crisis on Arab host societies and written from a highly transnational positionality, Jarrar's novel displays a keen consciousness of the sociopolitical complexities that shape refugee mothers' experiences in the Lebanese landscape. Through her creative construction of maternal ambivalence and, ultimately, unknowability, Jarrar offers us alternative possibilities of feminist response and responsibility no longer founded in the need to occupy the position of $\mathrm{a}(\mathrm{n}) \mathrm{m} / \mathrm{other}$. By reading across these texts with the aid of variously situated feminist tools drawn from Gender and Development scholarship, Sara Ahmed's model of 'affect theory', and transcultural feminist cultural theory, this chapter develops insight into the varied transcultural modes of feminist response and responsibility that can be imagined through the maternal. Ultimately, it moves towards an understanding of 'the feminist maternal' in which refugee mothers feature not simply as icons and subjects - but also as self-determined representational agents, within and beyond the feminist cultural imagination.

\section{Safe delivery: maternal identification and the politics of care in Cast Away}

In 2015, a major ideological shift occurred in European media representations of the so-called migrant crisis confronting Europe. ${ }^{14}$ Images of European train stations 'swarming' with Arab and African men, mainly from Syria, Afghanistan, and Eritrea, and thus imagined by the center-right press as potential terrorists, ${ }^{15}$ were suddenly replaced with the figure of a small boy lying face down on a Turkish beach. The child was Aylan Kurdi, a three-year-old who had drowned alongside his mother and younger brother during his family's attempt to cross to Greece. ${ }^{16}$ Carried away limply in the arms of a Turkish policeman, his was an image not simply of death but of stillbirth - of the hope for a new life violently thwarted by the breaking 
waters of the Mediterranean. Within days, the political rhetoric shifted away from masculinised defence of 'Fortress Europe' towards a maternal response in which European leaders urged one another to 'open their arms' to the newly termed 'refugees'. And on the pages of the press, too, a new 'face' of the crisis began to emerge: that of the 'refugee mother'. ${ }^{17}$

It is in these terms that the 2016 work of literary journalism by British foreign correspondent Charlotte McDonald-Gibson, Cast Away: Stories of Survival from Europe's Refugee Crisis, seemingly opens:

Istanbul, Turkey

19 April 2015

A new life was on its way. Sina could feel it. Her hand moved over the curve of her belly, from the flatness to the swell and down again, a wave at the very center of her being, a life wriggling and kicking in his own sea inside of her. ${ }^{18}$

Transporting the Anglophone reader to an unfamiliar shore in an immersive and emotive fashion, McDonald-Gibson's presentation of 'Sina' projects the expectant woman as a trope of 'elementary humanity'19 by whom we cannot help but be moved, in spite of our transnational positionalities for as Jacqueline Rose reminds us, the expectant mother is a figure who 'blur[s] the boundaries between inside and out', rupturing the distinction between self and other, and inciting a powerfully 'touching' empathy (mirrored here in Sina's own gentle caress of her child in utero). ${ }^{20}$ This figure of expectancy is also politically situated, however - poised precariously 'on the edges of the European Union' (CA, p.3) along with 'hundreds of thousands of people gathering at Europe's gates' (CA, p.3) who were, in 2015, fleeing warfare particularly in Syria and Eritrea. Thus presented as an emblem of collective vulnerability, need, and precarious liminality (reflecting broader biopolitical imaginings of the pregnant woman as a 'threshold of the living subject ${ }^{21}$ ), the maternal imagery here is double-weighted: the 'new life' not simply that of the unborn baby but that of the safe-haven sought for mother and child in Europe; the 'swell' and 'wave' not only that of the amniotic fluid but that of the perilous Mediterranean Sea; and the 'life wriggling and kicking' not just the signal of a safe healthy baby but an omen of potential shipwreck and drowning. Here, as in humanitarian discourse more broadly, this 'refugee mother' emerges as 'figurehead' for what McDonald-Gibson goes on to describe as numerous other 'mothers, father, sons and daughters...faced with similar impossible choices' (CA, p.3) to Sina.

At first glance, this opening to McDonald-Gibson's text appears to reenact precisely the 'essentializing' representation of 'the refugee mother' that has defined her figuration within humanitarian discourse (exemplified earlier by Calvin). Despite the empathy she incites, she is, as Agnes Woolley describes it, 'appropriated for [her] signifying power' as a 'symbolic weapon 
in the war against injustice ${ }^{22}$ within this context, and, as Jacqueline Rose reminds us, also therefore evokes a longstanding heritage of symbolic association between 'suffering motherhood' and 'the burden of human misery' at a broader scale in terms that, crucially, deny her own representational agency and narrative complexity. ${ }^{23}$ Yet closer examination of the narrative, ideological, and technical strategies underpinning McDonald-Gibson's text unearths significant ways in which she distinguishes her engagement with maternity from this straightforwardly symbolic discourse. By exploring the literary journalistic stance mobilised by McDonald-Gibson, the critical position from which she engages with Sina's story, and the author's own transcultural identification through the maternal, distinctively feminist potentialities - as well as complexities - falls into view.

Cast Away is one of a number of works published in the period from 2015 to 2018 that saw journalists with distinguished credentials on 'reporting in the field' - usually as foreign correspondents - produce more sustained literary analyses of the refugee crisis in response to its short-form reporting in the media. ${ }^{24} \mathrm{As}$ a form of 'long-form' reporting, literary journalism 'replac[es] an ideology of "objectivity" with overt advocacy' and tends to be progressive, even adversarial in its promotion of 'social responsibility'. ${ }^{25}$ Stylistically, it is characterised by 'writers' long immersive periods with their subjects, adoptions of a subject's point of view, use of personal voice, narrative arc ... [and] scene reconstruction'. ${ }^{26}$ It also displays a particular interest in the use of 'testimonio' elicited from interviewees and renarrated at the journalistic pen, designed to enhance the authenticity and emotional impact of reportage imbued with the weight of (carefully re/constructed) 'real life' experience. ${ }^{27}$ McDonald-Gibson's Cast Away adheres to these literary journalistic tendencies, though arguably employs them to distinctively feminist effect.

Cast Away can be read as a continuation of the progressive counterdiscourse that $\mathrm{McD}$ onald-Gibson has built in prestigious journalistic roles including as Deputy Foreign Editor on The Independent. ${ }^{28}$ In the volume as a whole, she presents a compelling case for an altered form of European response to the refugee crisis that involves better protection of vulnerable lives and improved responsibility from European governments (see CA, pp.297-303). As such, her text is not limited to women as subject of enquiry, nor does it frame itself as explicitly feminist. Yet set against similar works from this period - many of which note the presence of mothers, but none of which afford them equal structural significance or narrative attention as McDonald-Gibson's work - Cast Away emerges as distinctive for its sustained engagement with one particular refugee mother's 'testimonio' - that of Sina. ${ }^{29}$ Indeed, McDonald-Gibson explains that Sina's narrative presence in the text stems from a desire to 'flesh out' her story, which was initially covered in more reductive terms within the international media following her rescue during a disastrous crossing to Greece. Saved by Antonis Deligiorgis, a Greek army sergeant working 
on night-time rescues who sprung to her aid while off-duty, Sina's story, as McDonald-Gibson writes, captured the imagination of British newspapers, with its 'image of strong and powerful Europe coming to the aid of those in need' (CA, p.245) - a narrative that, interestingly, also plays to familiar colonial 'corpo-geographies' of the sea as narrative site of 'masculine endeavor, ${ }^{30}$ and perhaps also presented a redemptive sequel to the tragic image of Aylan Kurdi. In McDonald-Gibson's renarration of her story, however, Sina is no longer foregrounded in her role as 'infantilized mother' scooped into the arms of a paternal/maternal Europe. Rather, Sina's own identity - as mother and as individual - forms the basis of a story stretching before and after her 'birth' into a new life in Europe, in which maternity is shown to shape her narrative in complex ways. In her decision to place maternity as central rather than peripheral to Sina's narrative, then, and to afford it a level of narrative complexity beyond the straightforwardly symbolic, McDonald-Gibson displays a desire for journalistic advocacy founded in an implicitly feminist desire to resist the reductive figuration of maternity in the mainstream European media.

The level of carefully researched attention that McDonald-Gibson pays to the details of maternity as driver and shaper of women's forced migration can be read as a literary journalistic extension of research performed by Gender and Development scholars such as Jane Freedman and Doreen Indra, which has stressed maternity not simply as a secondary feature of refugee women's experiences but as part of the complex 'relations of power, privilege and prestige' that drive and shape forced migration. ${ }^{31}$ While asylum-seeking is often characterised as a 'flight' mechanism hard-wired at human rather than gender-differentiated level, ${ }^{32}$ feminist scholars such as Marianne Githens have noted the subtle ways in which gendered positionalities nuance the decision to flee one's home for safety. Writing in her 2013 text Contested Voices, she observes that the impetus to a significant number of forced migrant women's movements may be associated with what might be crudely termed the 'maternal drive':

Seeking safety [from war, civil unrest, famine or persecution], women have immigrated ... to a more peaceful and stable society where they could raise their children. [But] the ability to do so has largely depended on being admitted as a refugee, since restrictions on immigration have afforded them virtually no other option. ${ }^{33}$

Based in a 'well-founded fear of persecution' not simply for themselves but also for their children (born or in utero), and limited in their options for alternative processes of economic migration often due, for instance, to their role as a child's primary carer, this desire for 'maternal sanctuary' - the assurance of resources to raise one's child safely - can also be extended to the desire to access healthcare services during pregnancy and delivery - an aspect of forced migrant women's engagement with host cultures that has 
often been met with political hostility. ${ }^{34}$ These charges of 'health tourism', however, sit uneasily against the reality of figures on maternal and infant mortality. Asylum-seeking women in the U.K., for instance, are three times more likely to die in childbirth and have an elevated risk of stillbirth and infant mortality. ${ }^{35}$ When reframed within the context of maternal responsibility, then, the act of asylum-seeking emerges not simply as a process of travel instigated out of fear for one's own life, but fear for those implicitly dependent on $\mathrm{a}(\mathrm{n}) \mathrm{m} / \mathrm{other}-\mathrm{a}$ fear generated not simply out of instinct but by the machinations of the political landscape.

In Cast Away, Sina's flight from her country of birth, Eritrea, is represented precisely as a manifestation of the 'maternal drive' - though a drive to which she responds in practical, rather than simply emotive terms. In Chapter 1, she is introduced to us more fully as Sina Habte, a 'smart and tough chemical engineer' from Eritrea, 'sent to the scrub of western Eritrea a decade ago for her military indoctrination' (CA, p.6) who has decided to desert from her enforced role within a military dictatorship and has in 'four months .... taken [her] unborn son over five countries and two continents' (CA, p.1). Here, then, Sina as mother is figured in active defiance of the 'harsh paternalism' (CA, p.6) of the Eritrean state, and maternity emerges as a condition of self-determined agency rather than victimhood, reflected in the name she assigns her unborn baby: 'Delina...She loved the meaning. Wanted. This is what we want' (CA, p.1). While the maternal drive leads her to actively contest the paternalist order imposed upon her, however, it also emerges as a source of risk - one that impacts on expectant mothers in particular ways. McDonald-Gibson reveals, for instance, that 'deserting [from military service] carried huge risks. The government had no qualms about locking away expectant mothers $[\ldots]$ often the beatings and the torture brought on miscarriages and premature labour' (CA, p.183). Her research here calls on a major UN Human Rights Council study into Human Rights in Eritrea, ${ }^{36}$ which reveals maternity as a political risk factor under military dictatorship, where it comes to be employed as a tool of leverage to coerce women and their families into State compliance. This is but one instance in which McDonald-Gibson's research-based enhancement of Sina's 'testimonio' enacts the deeper level of gender-conscious cultural, social, and discursive analyses urged by Gender and Development scholar Jane Freedman, who advocates a feminist approach to forced migration that does not simply call attention to the 'results' of forced migration for mothers but enables us "to "see" how the world is shaped by gendered concepts, practices and institutions' at a holistic level. ${ }^{37}$ Here, then, Sina's maternity is presented by McDonald-Gibson as a politically situated phenomenon in which her own 'maternal' response can also be read as a negotiation of biopolitical agency - presenting an important feminist retort to paternalist representations of the refugee mother as passive subject 'moved' by political and emotional forces beyond her control. ${ }^{38}$ 
Despite the political (self)determination that Sina displays within the text, however, McDonald-Gibson does not reduce Sina's narrative to the straightforwardly didactic, nor indeed biographical. Crucially, she utilises the advocatory potentials of the literary journalistic form in order to inject moments of highly emotive imagined psychological insight into Sina's story. At several points, McDonald-Gibson draws attention to the potential for comparatist empathy between reader and protagonist, founded in the 'understandable' nature of Sina's behaviour as a mother: 'Even expectant mothers in the safest places in the world feared for the mysterious life growing inside them and there were moments when the movement within would stop and she would grab Dani's arm' (CA, p.230), she writes as we learn of the symbiotic web of pressures that circulate around Sina's journey: 'Everything scared her - the birth, becoming a mother alone, the smuggler, the sea' (CA, p.236). Here, McDonald-Gibson mobilises maternal empathy for the recognisable anxieties of the pregnant woman as a source of implicitly transcultural advocacy. Interestingly, however, she also reveals this capacity to care for, and even as, a mother to be integral to her own journalistic approach. Tucked away in the very final paragraph to the book, McDonald-Gibson acknowledges the formative function of her own maternity in the genesis, creative process, and final form of the work:

This project emerged from a deeply misguided idea that I would have lots of free time on my hands after [my son] was born [...] Of course when Nathaniel arrived [in 2015] he was a lot more time consuming than I had imagined. But what an asset he turned out to be, accompanying me on research trips across Europe and delighting everyone he met with his charm and enthusiasm. This book would not be the book it is without him [italics mine].

Presented as an impressive act of defiance to the traditionally domestic confinement of new motherhood and projecting a vision of both maternal capability and privilege - for McDonald-Gibson's mobility as a new mother is driven out of choice and facilitated by economic independence, albeit a choice driven by political urgency and intelligent interest - Cast Away, then, is also imbued with an implicit awareness of connectivity between the author's expertise as a journalist and her newfound insights afforded as a mother: its responsibilities, its burdens and pleasures of care, its material constraints, its physical demands, and its psychological revelations. Thus, McDonald-Gibson's own unavoidable experience of producing the text 'through the eyes of a mother' arguably enables her to reposition maternity as central rather than peripheral to the 'stories of survival' that she sets out to tell in Cast Away. In her emotive appeal to an empathy founded in the maternal, however, her work perhaps also implies that there is a feminist potentiality to be found therein: a newfound openness to the responsibility 
of care projected onto others beyond the actual figure of the child, even a propensity for hospitality towards 'others' that may in fact be founded in the revelations of motherhood - for, as Jacqueline Rose suggests, 'to be a mother, to give birth, is to welcome a foreigner. ${ }^{39}$

As Sara Ahmed warns us, however, this idealisation of motherhood as source of loving hospitality also presents a mode of essentialist and exclusivist maternalism that proves deeply problematic in feminist terms: 'love', she writes, 'becomes a sign of respectable femininity, and of maternal qualities narrated as the capacity to touch and be touched by others'. ${ }^{40}$ It is to her credit that McDonald-Gibson in fact problematises the efficacy of 'loving maternity' as a political response through her portrayal of the double-edged implications of the 'maternal' response presented by European host societies: a gendered extension, we might say, of Derrida's model of 'hostipitality' - the propensity for hostility implicit in every act of hospitality extended by the 'host' towards those conceived as 'guest'. ${ }^{41}$ We sense this, for instance, in the feminocentric manifestations of charitable aid presented to Sina upon her arrival in Greece ${ }^{42}$ :

...if the [political] leaders struggled with the idea of accommodating a group of refugees, when it came to the welfare of just one woman and one baby - whose family shared the religion of their host country - it seemed that hearts could be kind and obstacles overcome.

(CA, p.265)

In her terse use of the affirmative here ('hearts could be kind...obstacles overcome'), McDonald-Gibson hints at an awareness of the emotive and arbitrary nature of the 'care' that is offered to Sina, which proves contingent on the legibility of her maternal identity as source of precarious need. ${ }^{43}$ Indeed, the exceptional nature of her status as 'mother in need' becomes evident when Sina becomes the particular beneficiary of 'Despina, the president of the Red Cross of Rhodes, a formidable woman in her late seventies' (CA, p.263) who advocates on Sina's behalf to make exceptional arrangements in her housing and stay on the island. Despina's care for her is implicitly maternal: 'Despina insisted...both mother and child needed looking after ... and each day [she] would come to the house to cook and clean' (CA, p.263). Here, then, Sina's exceptional status as vulnerable mother also incites an exceptional outpouring of maternal receptivity. In this, however, the societal response reflects Freedman's broader observations regarding 'salvational' structures of aid ${ }^{44}$ in which the discourse of maternity serves to 'idealize' women as " victims" without agency', to whom 'protection is offered ... purely in their function as "mothers" defending their innocent children from "harm"., 45 These structures, Freedman reminds us, define women according to prescriptive models of mothering that in fact adhere to the quintessential structures of patriarchal hierarchy, in which the mantra of 'women and children first!' has been used to define women's dependency 
(and value primarily as mothers) within dominant 'salvational' models of nationhood: an essentialism neatly summed up in Cythia Enloe's coining of the phrase 'womenandchildren'. ${ }^{46}$

McDonald-Gibson displays an awareness of this discourse in the reported hyperbole attached to descriptions of the host society's broader response to Sina, which constructs her as 'ideal mother':

....anyone who saw how tenderly [Sina] washed Adonis - so many more times a day than most parents - and how she strived to keep him warm would tell her that she was an inspiration, and that Andonis had the best mother in the world. [Italics mine]

Indeed, the eventual resolution to Sina's story - which sees her settling in Sweden, a location she selects because, crucially, she finds the State willing to support her own educational needs, as well as those of her son - also emphasises her accommodation into the European symbolic order of 'carer and cared-for':

She applied for asylum in Sweden, and just like everywhere else she went, Sina found friends and champions there who were happy to help out the extraordinary woman and her baby. [...] So on a snowy December morning, Sina [...] took Andonis to an Orthodox church. There, in front of new friends and old ones who had travelled from across Europe, Andonis was immersed in water, a young life starting anew.

(CA, p.306)

The aqueous imagery of baptism as a moment of rebirth brings us full circle to the text's opening image of 'new life on its way': passage by water through maternal Europe - has indeed resulted in the safe delivery of mother and child. ${ }^{47}$ There is something undeniably utopian about this moment: the child, liberated in his sanctuary from the burdens of dictatorship and precarity borne by his mother, echoes Arendt's claim that birth (here, spiritual rebirth, potentially of a child cleansed of the traumas experienced by the mother) marks 'the supreme anti-totalitarian moment': a 'freedom [that] is identical with the capacity to begin'. ${ }^{48}$ Yet in its Christian iconography, this passage also emphasises cultural sameness, and thus the capacity for cross-cultural identification: son baptised, Sina is now but one of those 'who had travelled from across Europe', a newly identified community founded on difference assimilated. In this, McDonald-Gibson alerts us to the extent to which ethical commitment for support of the (m)other is ultimately concerned with the communal politics of the group and its capacity for a love that it frames as unconditionally maternal - though which in fact proves highly contingent on cultural identification. As Ahmed writes, "when love is extended to others who are recognized as "being different" 
in their concrete specificity [...] the [multicultural] nation becomes an ideal through being posited as "being" plural, open and diverse; as being loving and welcoming to others'. ${ }^{49}$ Within Sina's narrative, the 'ideal' of the multicultural nation also conceals structures of power within it; for what Ahmed terms the "love for love" is bound up with the making of community' in which 'ideality is [restricted] to some bodies and not others' ${ }^{50}$ manifested here in the figure of the ideally maternal refugee woman towards whom others feel maternal. It is also, she reminds us, a mode of loving that is ultimately self-serving, in its structure that 'makes the loving subject feel better for having loved and given love to someone presumed to be unloved, but which sustains the relations of power that compel the charitable love to be shown in this way. ${ }^{51}$ As conditional and hierarchising, this manifestation of maternal multicultural love presents a problematic model in which to found a feminist response to forced migration - for to offer love and solidarity on particular terms does not in fact present a mode of alliance; rather, a perpetuation of hierarchical structural oppression.

In the knowing imagery of her account of Sina's story, McDonald-Gibson projects a crucial awareness of the endemically problematic terms in which the 'maternal state' offers its care to the infantilised figure of the refugee mother. Yet it is also this conscientious textuality that reveals a problem when it comes to her own authorial subject position. In her use of Sina's 'testimonio', McDonald-Gibson undeniably proves successful in 'fleshing out' the more complex narrative dynamics surrounding Sina's gendered experiences as forced migrant woman and mother. Yet the literary journalistic agenda underpinning her engagement with Sina's story also results in a degree of appropriation, whereby McDonald-Gibson retains her position as ethically self-appointed, albeit gender-conscious spokesperson who mobilises Sina's story in the service of her broader message regarding the duty of care towards refugees held by Europe. Thus, her own identification with Sina is also deeply bound up in her investment in the wider structures of the 'ethical nation' in which she, as caring journalist and as caring mother, wishes to live.

Cast Away's engagement with the figure of the refugee mother therefore exposes many of the power differentials and double-binds that surround the attempt to forge ethical, transnational alliance through the feminist maternal. While the centralisation of motherhood within the forced migrant woman's narrative proves an important feminist move, and the research-supplemented engagement with first-hand 'testimonio' delivers a vital engendering of forced migrant experience, the narrative positionalities at stake also risk imposing their own hierarchies of voice and of care. What alternative positionalities might therefore be imagined that relieve the refugee mother of some of these appropriative burdens within the feminist cultural imagination? For Nada Awar Jarrar, the answer seems to lie in the possibility of breaking the many frames that have defined maternal, forced migrant, and host positionalities - and in strategies of care that may extend 
beyond claims to unconditional love, into political alliances that respect the ultimate unknowability of a(n) m/other.

\section{The unknowable (m)other: repoliticising the maternal in $A n$ Unsafe Haven}

If McDonald-Gibson's text presents a maternally journalistic 'crisis response' situated on the shores of Europe, then the motherly and transnational positionalities at stake in Nada Awar Jarrar's 2016 novel An Unsafe Haven are altogether more complex. Distinctive as an Anglophone Arab exploration of the impact of the Syrian refugee crisis on Lebanon and written from a highly transnational positionality, Jarrar's novel also engages with the figure of the refugee mother as the focus to the narrative impetus. In contrast with McDonald-Gibson's implicitly feminist, pro-refugee advocacy agenda, however, Jarrar's engagement with the refugee mother through the realms of the literary imagination transports us into the more fluid ethical realm of what Shameem Black terms 'border crossing fiction': texts concerned less with persuasive accuracy than with 'the process of imagining social difference, ${ }^{52}$ In An Unsafe Haven, this processual encounter with social difference is constructed in specifically gendered, multifariously maternal terms through the encounter between two women: Hannah, a Beirut-based, dual nationality journalist whose work is focussed on the impact of the refugee crisis on Lebanon; and Fatima, a Syrian refugee who she encounters begging with her son in central Beirut. While the text revolves around Hannah's desire to unearth Fatima's story in order that she might find a way to help her, Fatima in fact remains elusive for much of the text - a shifting and transitory character who refuses to be contained by the spaces of seeming safety and care offered to her. Through her central presence - and absence - at the heart of this novel, then, Fatima prompts us to reflect on what and how we can and cannot know about the 'refugee mother' - and how we can and cannot care for her, through and not through the maternal.

A focus on both feminocentricity and the politics of hospitality informs much of Jarrar's work. Winner of the Commonwealth Best First Book Award in 2004 for Somewhere, Home, her oeuvre bears common threads of interest in Lebanese social and political history, particularly moments of social trauma such as the Civil War and Israel's bombing of Beirut in 2006 events which are mediated through the experiences and memories primarily of women. ${ }^{53}$ In An Unsafe Haven, Jarrar again scrutinises the contemporary Lebanese political landscape with a feminocentric eye, though this time, in order to explore the significant impact of the Syrian refugee crisis on Lebanon as one of the primary host nations in the region, home at the time of publication to over 1 million refugees, the highest per capita rate of any country in the world. ${ }^{54}$ In this, her text is in fact in keeping with a much longer heritage in Lebanese female-authored fiction to have emerged 
from her literary predecessors, the Beirut Decentrists, in whose work 'the most persistent traits associated with Beirut, as with its hinterland, Mount Lebanon, have been freedom and refuge. ${ }^{55}$

The transnational positionalities of Jarrar's texts are highly significant to the possibilities of cross-cultural conversation imagined within them. Written in English, readily available, and sold in Europe and the U.S. yet authored from within the Arab world, the hybrid textuality is an indication of the highly transnational positionality that has informed her life. Jarrar was born in Lebanon to a Lebanese mother and Australian father, and grew up between London, Paris, Sydney, and Washington, DC, though returned to Beirut in the 1990s, where she worked as a journalist for Lebanon's only English language newspaper. ${ }^{56}$ This transnational positionality is also reflected in the character cast of the novel, which constellates around three intersecting relationships: between Beirut-based, dual nationality journalist Hannah, wife to Peter, a British expatriate doctor; between Anas, an exiled Syrian artist, and his German wife Brigitte, friends with Hannah and Peter; and Iraqi refugee and aid worker Maysoun, also friends with Hannah and Peter. The implicit cosmopolitanism of the novel's geopolitics is important here: as postcolonial scholars such as Bhabha and Appiah have argued, the 'cosmopolitan ideal' is a utopian one founded in cross-cultural contact that 'flows from the free decisions of individuals or groups'. ${ }^{57}$ Despite the disjunctive hierarchies of mobility that drive the forced migration of Syrians into Lebanon, then, Jarrar implies the landscape of her text to be one of mutual mobility, in which none of her characters can stake an absolute claim to 'home' in Beirut - a location that, Hannah writes in her journal, 'offers a false impression of safety and permanence in the midst of all the upheaval' (UH, p.5; italics in the original). Indeed, as the artist Anas also reflects later, 'there are different ways of being a refugee, different expressions of displacement and dissonance, depending on the point at which we begin our experience of dislocation' (UH, p.77). In her recognition of mobility and precarity as shared yet also individually situated conditions, then, Jarrar's text already begins to destabilise some of the straightforward positionalities between 'carer' and 'cared-for', 'host' and 'guest', that have defined dominant representations of refugee encounter, particularly in the European media. In this, she begins to gesture towards an alternative understanding of feminist encounter that might not be founded so clearly in matriarchal structure - possibilities played out in powerfully deconstructive ways within the text, as we shall see.

Jarrar's decision to place the enigmatic refugee mother at the heart of this Beirut-centric text is a politically astute one. While there is no formal collation of data for the number of babies born to forced migrant women worldwide, nor for the number of forced migrant women worldwide who are mothers, ${ }^{58}$ data shows that $75 \%$ of Syrian refugees were women and children in $2014^{59}$; that around one in ten refugees travelling through Europe was pregnant in $2016^{60}$; and that around 40,000 births to Syrian mothers 
took place in Lebanon in 2017. ${ }^{61}$ This birthrate is considered high compared to that of the wider Lebanese society and has surfaced as the source of some antagonism among an already financially stretched Lebanese host population, where exaggerated media stories of Syrian women's birthrates have reflected a growing xenophobic sentiment. ${ }^{62}$ As such, the 'Syrian refugee mother' can be read as a contested figure, evoking simultaneous familiarity, homogenisation, and hostility within Lebanese social discourse.

Against this backdrop, Hannah's first perception of Fatima is significant. For while it resists the hostile xenophobia of media discourse, it also acknowledges her problematically dehumanising 'flattening' into a tragic but now-normalised feature of the urban milieu:

The refugees are like shadows, she thinks, colourless and in some ways invisible to everyone else. She has seen them there before, remembers especially a young woman with a very young boy sitting together on the median strip running down the center of the road. When night begins to fall, Hannah has watched the young woman wrap the boy tightly in her arms, both of them sitting very still, the little boy's head on his mother's shoulders.

(UH, p.61)

Mother gently cradling her son, Fatima is cast here in a Madonna-esque posture (strongly reminiscent of the famous evocation of the displaced Biafran woman in Chinua Achebe's poem 'refugee mother and child'63) - a figure of fragile pathos and, ultimately, deserving need. In Hannah and Fatima's first encounter after the accident, however - the moment at which Hannah seeks to present herself as saviour, even mother, observing that 'My god...she is a child herself' $(U H$, p.64), Jarrar also introduces an ambivalence around Hannah's perception of Fatima according to this trope, as Hannah senses Fatima's mood:

Beneath the clear anxiety in her eyes, Hannah also sees diffidence, and thinks that perhaps the young mother is reluctant to give in too easily to ber vulnerability.

(UH, p.65; italics mine)

This moment is significant in that it radically contests the role of mother as vulnerable victim 'without agency' ${ }^{\prime 64}$ : a 'frame' that has been assigned to women, Freedman argues, in order to enable structures of care exercised at an institutional level to 'ignore women's agency and voice', and ultimately to depoliticise and homogenise them, positioned as they are within a hierarchical relationship that posits mothers themselves as the needy recipient of the paternal - or arguably, maternal - state or aid organisation. ${ }^{65}$ Indeed, despite her implied youth (a politically astute narrative decision on Jarrar's part: adolescent Syrian girls have proven particularly vulnerable to forced 
marriage and resulting early pregnancy $\left.{ }^{66}\right)$, Fatima is never the willing recipient of aid, and nor does she allow herself to be readily cast in the role of deserving child - nor indeed, for that matter, mother. This narrative disruption emerges through Fatima's ambivalent attitudes towards a baby that she brings to Hannah and Peter's house two thirds of the way through the text - who may or may not be hers: an uncertainty that is ultimately left unresolved for Hannah and Peter within the novel.

Hannah - and likewise, the reader - finds what we might term Fatima's 'maternal ambivalence' deeply unsettling. While the baby is staying in her apartment, Hannah adopts a maternal role towards both mother and child, though she finds she cannot help but assume some level of judgement:

Rummaging earlier through Fatima's plastic bag, she had found only a less than clean bottle and two cloth nappies but nothing in the way of clothing for the baby [...] In truth, what she is concerned about is Fatima's apparent indifference to this child, something she finds much more alarming than anger or resentment... She is filled with dismay at the idea that the baby may not yet have been given a name.

$(U H$, p.233)

Indeed, in the novel's denouement, Fatima announces that she will be leaving to find her family in another camp without the baby and defers maternal responsibility onto those around her:

- I'm not abandoning her, am I? she says, her voice rising. You're all good people here. You can take care of her. And why do you keep saying she's mine? I never said she was, did I?

(UH, p.265)

Fatima's reticence to behave or even identify as mother is deeply challenging to our expectations of her as a 'refugee mother', driven, humanitarian discourse has trained us to believe, to place her child's interests above all else. Yet this challenge also serves an important feminist function. For feminist thinkers working in the European tradition such as Estella Welldon, the recognition of maternal ambivalence has been vital in the task of rehumanising mothers as complex psychological beings. ${ }^{67}$ For Fatima, too, maternal ambivalence serves to debunk the reductive cultural ideal of her as 'self-sacrificing victim mother' and to imbue her with a more complex psychological and narrative presence. Indeed, this ambivalence might be understood within the politicised terms of what Édouard Glissant has described as 'the right to opacity' - a resistance to the narrative drive towards transparency that has tended to define the colonial quest for knowledge of 'the other'. ${ }^{68}$ This resistance towards 'transparency' of narrativised, comprehensible identity, Glissant argues, bears a productive potential to break 
from the quest for interventionist understanding and to arrive at an altogether different relationship between mutually acknowledged subjects:

The thought of opacity distracts me from absolute truths whose guardian I might believe myself to be [...]

I am thus able to conceive of the opacity of the other for me, without reproach for my opacity to him [sic]. To feel in solidarity with him or to build with him or to like what he does, is not necessary for me to grasp him. It is not necessary to try to become the other (to become other) nor to 'make' him in my image. ${ }^{69}$

Might it be possible to extend this (casually universalised/masculinised) vision into the feminist domain? Jarrar's narrative reticence around Fatima - and Fatima's own selective narrativisation of herself - certainly suggests so. Indeed, the very opacity of Fatima's story incites a different kind of narrative engagement among the characters with the political possibilities rather than social realities she represents, which prove deeply illuminating in gendered terms. In this, then, Fatima's opacity moves the reader beyond the maternal need to 'like' or 'love' Fatima, towards a more respectful exploration of the unknown complexities that may (or may not) be attached to her subject position.

This opacity presents a productively feminist discourse of speculation among the characters in An Unsafe Haven, and indeed, speculation becomes a politicised mechanism through which Jarrar reveals some of the socially contingent gendered relations of power that may shape Fatima's relationship to motherhood. Fatima herself reveals some of these possibilities in conversation with Brigitte, the eventual adoptive mother to her baby daughter (a figure Fatima chooses, she says, because of their shared experiences of losing their husbands - thus an egalitarianism forged out of shared suffering, rather than the hierarchy of carer and cared-for):

You think I'm heartless, I know, Fatima says [...]

But I have to think of my son. I have to think about his future. [...]

What use do I have for a girl? She'll just be another burden for me and for Wassim as well, eventually. And once she gets older, what chance will she have without a father to protect her?

(UH, pp.262-263; 265)

Here, Fatima reveals the vehemently patriarchal structures of kinship that define gender roles and shape her attitude towards motherhood, but she also perhaps hints at the violations of honour that may underpin her maternal ambivalence. Indeed, aid worker Maysoun, herself an Iraqi refugee, explains some of the other potential causes of Fatima's maternal ambivalence to Hannah and Peter:

- Thousands of babies have been born among the Syrian refugee population in Lebanon alone, so many of them out of wedlock. If...her 
husband has been dead for a few years, of course she'll be afraid she'll be found out [...] She may have been raped or had an affair. Either way, she will be blamed for it. She thinks she's brought shame on the family [...]

- On the other hand, the child may not be hers [...] It's always useful to have a baby in your arms when you're on the street begging for money ... She may have borrowed it for the day.

Maysoun's comments reflect numerous reports into the endemic presence of sexual violence and predation faced by forced migrant women, during their journeys and within refugee camps. ${ }^{70}$ Indeed, 'forced pregnancy' through rape is a recognised warfare strategy within ethnic or national conflicts, in which 'pregnancy ... would result in [women from opposing ethnic groups] bearing the children of their enemies'. ${ }^{71}$ Such attacks operate through patriarchal nationalist discourses that imbue women with the role of 'guardian of the nation's honour': attacks on her sexual honour therefore imbue her with communal shame. The result is inevitably deeply felt at an embodied and psychological personal level, however. Victims of such crimes may no longer find support within their own communities and have to leave as a result of ostracisation; this process of alienation may, in turn, lead to a cycle of violent or sexual exploitation, even at the hands of 'protectors'. ${ }^{72}$ Reframed against this backdrop, Jarrar draws us beyond the catharsis of straightforward empathy towards a more complex mode of cross-cultural apprehension, in which Fatima's maternal ambivalence and stubborn possessiveness of her own story emerge as modes of social negotiation and agency, as well as trauma. She therefore moves us towards a more contingent, constructivist understanding of maternity analogous to that presented by Anastasia Christou, who reminds us that motherhood is a 'flexible concept [that] should be conceptualized within the particularities of the social and cultural geographies that surround it'. ${ }^{73}$ In this, Jarrar's opaque construction of Fatima incites careful self-scrutiny on the part of the feminist reader, who is invited to question their assumptions of Fatima's relative 'value' as a mother and to reconsider their position within the hierarchies of 'carer' and 'cared for'. Just as Glissant urges us towards an opacity that 'mak[es] me sensitive to the limits of every method...relativizes every possibility of every action within me, ${ }^{74}$ so does Fatima's opacity remind the feminist theorist of the cultural assumptions on which their own aspirations for solidarity and advocacy are built.

Jarrar's construction of Fatima therefore breaks many of the 'frames' that have limited 'the refugee mother' as literary trope and symbolic ideal, while also challenging the expectations of those who would seek to care for her according to the standardised structures of the humanitarian imagination. Interestingly, the political potentialities of this process are dramatised through the character of Hannah herself - a figure who, over the course of 
the text, seeks to assert a maternal role at multiple levels: as Fatima's saviour and carer; as potential adoptive mother to her child; and as journalist, who has a 'caring' responsibility towards those whose lives are birthed onto the international stage at her pen. Unable to care for Fatima and ultimately deselected as adoptive mother by her in favour of Brigitte, Hannah concludes her diary entries within the text with an interesting revelation:

I have discovered that there is no such thing as personal or public when it comes to displacement and suffering, no two sides to every story, no differing opinions and certainly no room for conjecture...

I have questioned how exactly we have come to accept that life and abundance are accidents of birth rather than a moral responsibility, how we reconcile this clear truth with the notion that the wretchedness of fellow human beings can reasonably be kept at arm's length.

(UH, p.247; italics in original)

Rejecting a discourse of what we might term maternal fatalism (life as biological chance) and instead assuming a responsibility founded in morality and human agency, Hannah's stance here seems to assume the well-worn feminist conclusion that the personal is inseparable from the political. What is more significant, though, is that her newly articulated commitment sees her setting aside her role as journalist to 'care for', and instead, assuming a dynamic of professionalised and politicised care no longer directed towards a single person, but instead towards her own representational responsibilities. Hannah, in other words, breaks from the hierarchised Eurocentric feminist tendency to identify as mother and recognises her separateness - a position of distance that does not exclude solidarity or advocacy, but does not assume the automatic desire of 'refugee mother' to be cared for as child, or indeed as mother.

This position, I would suggest, bears similarities to what Sara Ahmed, drawing on Jodi Dean, presents as 'reflective' or 'affectionate' solidarity - a feminist position that, while shaped by a love for a political vision, does not operate on the 'assumption that love can provide the foundation for political action. ${ }^{75}$ Ahmed posits instead that 'in the understanding that love comes with conditions however unconditional it might feel, we can find perhaps a different line or connection between the others we care for, and the world to which we want to give shape. ${ }^{76}$ This 'different line or connection' between refugee mother and more socially privileged feminist advocate emerges, in Jarrar's text, as a willingness to forsake the maternal hierarchy of carer and cared-for and, instead, to forge more responsive modes of action that take account of the desires and needs of the refugee mother herself.

In the complexity and partiality of her identity, history, and narrative, in her maternal ambivalence, and in her refusal of infantilisation, Jarrar's construction of Fatima therefore leaves us, as potential feminist advocates, with 
the recognition that responsibility must necessarily resist the idealisation of the refugee mother as imagined subject; that real caring cannot involve the implementation of maternal or infantilising hierarchies, but must operate within respectful and self-aware, if limited, boundaries; and that feminist solidarity is best founded not in the attempt to project unconditional love onto the ultimately unknowable refugee mother but in a love of and that is political. As we reapproach the figure of the refugee $(\mathrm{m})$ other through 'the feminist maternal', then, it seems we are confronted with a new question: not how we should write about but in conversation with those (m)others who we encounter - ethically, imaginatively, and beyond the page.

\section{Mutual expectations: re-encountering the conversation on maternity}

The 'Refugee Crisis' of 2011 onwards provides a microcosmic opportunity to witness the discursive and ideological intensities that have been attached to the 'refugee mother' in the cultural and political imagination - tendencies that reach far beyond the temporal or geographical remit of the Europeandefined 'crisis'. ${ }^{77}$ When mediated in non-feminist terms, this figure tends to function primarily as a 'symbol - rather than an agent - for reformed humanity ... removed from the politicized world of men ${ }^{, 78}$ - a position from which, as Jacqueline Rose writes, 'pathos neutralizes [her own] far more radical complaint'. ${ }^{79}$ Against this backdrop, works of 'feminist crisis response literature' present vital counter-discourses in which maternity, centralised as narrative driver rather than iconic position, enables the authors to advocate for individual mothers' politicised needs. In their feminocentric focus, and in their astute engagement with the complex narrative function of maternity, these texts demonstrate that the consideration of maternity as situational driver and shaper of forced migrant experience must form a necessary part of feminist scholarship. Within this context, recognition of women 'as mothers' should not be viewed as counter-intuitive to feminist agendas, which have long argued against the patriarchal 'institutionalization' of motherhood as women's 'natural' condition. ${ }^{80}$ Instead, maternity must be viewed as an aspect of the 'social arrangements' that shape (forced migrant) women's lives and are contingent on a complex mesh of positional factors. ${ }^{81}$

The forms of transcultural encounter imagined via the maternal within these texts, however, raise complex questions around feminist positionality: about the creative potentials - and risks - of constructing maternity as grounds for cross-cultural identification and advocacy and about the possibility of cross-cultural solidarity when presented through implicit hierarchies of care. These questions are in some senses anticipated by Sara Ahmed, who, in her 2000 work Strange Encounters, theorises the nature of encounter between embodied 'selves' and 'others' within the multifarious movements that take place within transnational landscapes. ${ }^{82}$ As Ahmed notes, these landscapes have produced a postcolonial, implicitly 
multicultural imagination in which the notion of 'stranger fetishism' is prevalent: a fascination with 'the alien' as source not only of intrigue but also of potential (self) knowledge, and indeed of imagined ethical recuperation (whereby the stranger is welcomed because they are a stranger). ${ }^{83}$ We might also understand the fascination with the refugee mother within the transnational feminist imagination in these terms: as a figure who appeals to those seeking feminist understanding through her as-yet unknown 'otherness', her potential for cross-cultural insight, and as site of feminist ethical recuperation (welcomed because she is a refugee m/other). McDonald-Gibson's and Jarrar's texts each demonstrate facets of multicultural 'stranger fetishism': for McDonald-Gibson, after all, Sina emerges as vessel of knowledge for the European reader through the value of her 'testimonio', while for Jarrar, it is precisely the unknowability of the 'refugee mother' that presents her as site of ethical representational recuperation in which the author is, to an extent, relieved of her burden of representational care through her acceptance of Fatima as 'other'. In both of these instances, then, the transcultural feminist imagination risks positioning refugee mothers, however heterogeneous, as objects rather than subjects of knowledge production: a longstanding limitation associated with models of Western feminist privilege, transposed here into the transnational realm through the constructs of knowledge production within the Anglophone book market. ${ }^{84} \mathrm{How}$, then, might maternity form the basis of a different kind of transcultural feminist encounter? Here, it becomes useful to turn for a moment to politicised models of transversal feminism - and to reconsider maternity as grounds not for representation but for conversation.

Writing of the possibility of working in solidarity with, and in the service of mothers within conflict zones, Cynthia Cockburn offers a simple reminder of immense importance to the transcultural feminist imagination:

An assumption of equality and similarity should prevail except when those liable to suffer from differentiation...say that difference should be taken into account. When should women be treated as 'mothers', as 'dependents', as 'vulnerable'? When, on the contrary, should they be disinterred from 'the family'... and seen as themselves, women - people, even? Ask the women in question. They will know. ${ }^{85}$

Here, Cockburn breaks from the assumption that refugee mothers form the basis of 'transversal feminist' coalition building, ${ }^{86}$ and instead points out that conversation must form the starting point for feminist co-working: the opportunity for women to self-define their positionalities as 'refugee', or 'mother', as potentially politicised identities - and, indeed, as intimately personal forms of identification. Within the context of the literary imagination, this does not mean that feminist cultural practitioners must await (or even engender) approach by a 'refugee mother' willing to share her story or begin a (literal) conversation. Rather, it might entail seeking out alternative 
sources of imaginative prompt from those limiting representations available in the mainstream, patriarchal cultural sphere - perhaps even those that emerge through (self)imaginings and (self)definitions of maternal identity by women from asylum-seeking and refugee backgrounds. And in response, perhaps authors might begin to seek alternative literary forms that respond, in conversational rather than necessarily authoritative terms, to the questions invited by these self-imaginings.

What kinds of alternative imaginative conversation might emerge by shifting the positionalities surrounding creative genesis and agency in this way? Let's move somewhere different for a moment - to a place where the international media hasn't looked.

It is a small workshop room in Nottingham, U.K., filled with 25 women from asylum-seeking and refugee backgrounds based at the Nottingham and Nottinghamshire Refugee Forum. They are called the PAMOJA Women Together Group. Women in the group come from Syria and Eritrea, yes; also Iraq, Sudan, Nigeria, Kurdistan, Pakistan, and Cameroon. They may or may not be in 'crisis'. But they're not talking about this. Instead, they're talking about what it means to 'rise' from adversity: a conversation generated through discussion of the work of African American poet Maya Angelou. ${ }^{87}$ They talk about 'moons and suns' and 'the certainty of tides'; they compare how they would translate the word 'rise' in their various languages. After an hour, they're invited to write something of their own about this word -working with translators, or through conversation with a workshop facilitator, or with other group members, some of whom are experienced performance poets. And then, when they are invited to share any drafts of their work, something interesting happens in this room: suddenly, it is teeming with mothers.

Unprompted, over half of the women in the group evoke their role as mothers as a source of pride, motivation, and strength within their work: 'The smile on my daughter's face...makes me sleep...wakes me up...gives me hope', writes Ditsupo. ${ }^{88}$ 'For what do I rise each morning? To see my children - and to talk to them about their dreams', writes Fadwa ${ }^{89}$ Evoking motherhood as 'a jewel...cloth...hope, ${ }^{90}$ many of the poems are addressed to the children themselves: love letters that also, implicitly, represent a self-selection of the maternal role, with politicised consequences. ${ }^{91}$ But in Kalkidan's poem 'My Tears', maternity breaks from this narrative to emerge as a site of irrecuperable loss from which she cannot rise:

In a country where I am lonely, Eyes filled with tears and pain,

No parent to hug and kiss,

My children at least wipe my tears.

When society and friends hurt my heart,

When they sent my children away,

It hurt, it hurt and I cried all day long -

My children at least wipe my tears. ${ }^{92}$ 
How might the transcultural feminist imagination respond to this work? Maternity emerges, here, as the locus of biopolitical aggression, of trauma, of solace, and of appeal - a positionality specific to Kalkidan's political and personal experiences and her imaginings. What is a responsible, respectful, and creative imaginative response? What writing practices - fictional or otherwise - can we use to build transcultural feminist coalitions that value and honour her creative voice? Is the best strategy simply to remain quiet, respectful of our difference and distance ${ }^{93}$ Does the creative conversation end here?

When Kalkidan first reads her poem to the PAMOJA group, she asks to stand up, and we listen to her carefully. She is suddenly unfamiliar before us. What does motherhood mean to her? We do not know her story, but she has written this, and asked to read it, and so we are listening. What should be our first gesture? No one dares move.

But then she looks up, expectantly. Somehow, we find words.

\section{Notes}

1 Or, perhaps not so unusual: 'Mother's Day' in the U.S. was initially proposed as part of the pacifist campaign by Julia Ward Howe, who suggested that 'A Mother's Day of Peace' should be celebrated each year, in response to the carnage of the American Civil War and Franco-Prussian War. Her appeal, however, was unsuccessful. See Julia Ward Howe, 'Appeal to Womanhood throughout the World, Boston', September 1870, Library of Congress, https://www.loc.gov/ resource/rbpe.07400300 (last accessed 11th December 2018).

2 Kathy Calvin, 'Mothers around the World Are in Crisis. Here's How You Can Help', Time Magazine, 12th May 2018, http://time.com/5274229/mothersday-gift-donation-women-conflict-refugees/ (last accessed 3rd December 2018).

3 Ibid., n.p.

4 Ibid., n.p. See also the UNFPA website: https://www.unfpa.org/emergencies (last accessed 13th December 2018).

5 Politicised identification forged through motherhood has proved a model with transnational appeal and spans the political spectrum. As Steph Lawler notes, motherhood has been used by women peace campaigners 'as both the impetus for their campaigns, and as the justification for those campaigns', as in the 'maternal thinking' demonstrated by Greenham Common protestors, for example. Steph Lawler, 'Motherhood and identity', in Tess Cosslett, Alison Easton, and Penny Summerfield, eds., Women, Power and Resistance: An Introduction to Women's Studies (Buckingham: Open University Press, 1996), pp.153-164; p.160. Motherhood, particularly when aggrieved/bereaved at the hands of the State, also emerges as a galvanising force for political accountability - evident, for instance, in the Mothers of the Plaza de Mayo, who fought for state and church transparency during the Argentine junta's 'Dirty War' against subversives. See Marguerite Guzman Bouvard, Revolutionizing Motherhood: The Mothers of the Plaza de Mayo (Wilmington, DE: Scholarly Resources, 1994). At the opposite end of the political spectrum, however, Sara Ahmed notes a 'feminization of fascism' in right-wing nationalist campaigns which present procreation as a 'defense of the nation'. See Sara Ahmed, The Cultural Politics of Emotion, Second Edition (Edinburgh: Edinburgh University Press, 2014), pp.123-124. 
6 A number of scholars have contested the concept of a 'crisis', noting that this term projects the 'exceptionality' of European encounter with non-European populations in need, elides the ever-present nature of forced migration on the global stage, and thus enables European states to respond in 'exceptional' terms that may include violations of human rights. See, for instance, Iain Chambers, 'Art and the refugee “crisis": Mediterranean blues', Open Democracy, 10th July 2017, https://www.opendemocracy.net/5050/iain-chambers/art-and-refugeecrisis-mediterranean-blues (last accessed 12th December 2018). The dates of the 'crisis' are also contested: the UNHCR cites the onset of the crisis as 2011 as unrest in Syria began, reaching a numerical peak in 2015/2016, but crossings to Europe from Libya date back to at least 2004. See UNHCR, 'Seven Years On: Timeline of the Syrian Crisis', UNHCR Philippines, 7th March 2018, https:// www.unhcr.org/ph/13427-seven-years-timeline-syria-crisis.html (last accessed 12th December 2018).

7 See, for instance, Rowell, 'Inside the Harrowing Journeys of Refugee Mothers', and the free digital comic, 'Madaya Mom', produced by ABC News as a method of representing the stories that were emerging from the Syrian city while under siege: Xana O'Neill and Rym Momtaz, 'Madaya Mom', ABC News, 3rd October 2016, https://abcnews.go.com/International/deepdive/madaya-mommother-struggle-survival-syria-civil-war-42362213 (last accessed 12th December 2017).

8 Not all of these texts focus specifically on the figure of the mother, though all focus on women, and many include characters who are maternal in some form. See McDonald-Gibson, Cast Away; Samar Yazbek, The Crossing: My Journey to the Shattered Heart of Syria, trans. Nashwa Gowanlock and Ruth Ahmedzai Kemp (London: Rider, 2015); Janine di Giovanni, The Morning They Came for Us: Dispatches from Syria (London: Bloomsbury, 2016); Jennifer Zeynab Joukhadar, The Map of Salt and Stars (London: Weidenfeld and Nicolson, 2018); Malu Halasa, Mother of All Pigs (Los Angeles, CA: Unnamed Press, 2017); Jarrar, An Unsafe Haven; Fleming, A Hope More Powerful Than the Sea; and Kate Evans, Threads: From the Refugee Crisis (London: Verso, 2017).

9 Kate Evans, Red Rosa (London: Verso, 2015) and Kate Evans, Bump: How to Make, Grow and Birth a Baby (Brighton: Myriad, 2014).

10 I provide further explanation of my engagement with the terms 'feminism' and 'the feminist cultural imagination' in Chapter 1, but within the present context, I understand 'feminist' to represent a broad spectrum of transnational ideological positionalities that share a commitment to advocate for and realise improvements in the lives of women, based on the multiple forms of disenfranchisement they face according to varied structures of gendered ideology, power structure, and practice. I do not assume that this 'feminist' potential is always stated overtly by the author.

11 For a snapshot of the extensive analysis that has taken place of the '\#MeToo' campaign, see Sarah Jaffe, 'The Collective Power of \#MeToo', Dissent 65:2 (2018), pp.80-87; and for broader U.S./transnational feminist contextualisation, see Alison Dahl Crossley, Finding Feminism: Millennial Activists and the Unfinished Gender Revolution (New York: New York University Press, 2017). At the time of writing, the misogynistic biopolitics of the Trump administration is ongoing: recent manifestations in the form of immigration policies include the 'zero tolerance' prosecution policy that enforced separation of children from parents at the U.S.-Mexico border, and the reversal of a policy that automatically seeks release for pregnant asylum seekers in detention. For some of the many feminist discussions, see Rebecca Maria Torres, 'A Crisis of Rights 
and Responsibility: Feminist Geopolitical Perspectives on Latin American Refugees and Migrants', Gender, Place and Culture 25:1 (2018), pp.13-36; for wider transcultural feminist responses, see the wonderful issue of Frontiers: A Journal of Women's Studies 39:3 (2018).

12 Heather L. Johnson, 'Click to Donate: Visual Images, Constructing Victims and Imagining the Female Refugee', Third World Quarterly 32:6 (2011), pp.1015-1037.

13 For further discussion of the complex feminist dynamics circulating around the practices of Non-Governmental Organisations, see Bernal and Grewal, eds., Theorizing NGOs.

14 Caroline Pedwell notes the 'affecting' politics implicit in the shift from the hostile term 'migrant' (denoting economic choice) to 'refugee' (denoting legitimate need and lack of agency) employed in European media. Carolyn Pedwell, 'Mediated Habits: Images, Networked Affect and Social Change', Subjectivity 10:2 (2017), pp.1-23; p.2.

15 See Jill Walker Rettberg and Radhika Gajjala, 'Terrorists or Cowards: Negative Portrayals of Male Syrian Refugees in Social Media', Feminist Media Studies 16:1 (2016), pp.178-181.

16 I have discussed the figure of Aylan Kurdi within the context of bio- and necropolitics more extensively elsewhere: see Anna Ball, 'Biopolitical Landscapes of the "Small Human": Figuring the Child in the Contemporary Middle Eastern Refugee Crisis in Europe', in Anna Ball and Karim Mattar, eds., The Edinburgh Companion to the Postcolonial Middle East (Edinburgh: Edinburgh University Press, 2018), pp.446-468.

17 Terence Wright notes the broader prevalence of 'the refugee mother' in the 'humanitarian visualities' of 'refugee crises', within and prior to 2011. Terence Wright, 'Moving Images: The Media Representation of Refugees', Visual Studies 17:1 (2002), pp.53-66.

18 McDonald-Gibson, Cast Away, p.1. All subsequent page references to this text will be cited in parentheses in the body of the text.

19 Malkki, Purity and Exile, p.11.

20 Jacqueline Rose, Mothers: An Essay on Love and Cruelty (London: Faber \& Faber, 2018), p.23.

21 Lorna Weir, Pregnancy, Risk and Biopolitics: On the Threshold of the Living Subject (Abingdon: Routledge, 2006). Weir's work presents a fascinating insight into the biopolitical function of maternity and antenatal care. In this light, it is interesting to note the prevalence of the figure of the midwife in humanitarian representations of refugee encounters: not only in Kate Evans' Threads but also in Charles Masson's graphic novel about 'illegal immigration' to Mayotte, Droit du Sol (Brussels: Casterman, 2009).

22 Woolley, Contemporary Asylum Narratives, p.108.

23 Rose, Mothers, p.12.

24 Examples of literary journalistic works written in this vein include Patrick Kingsley, The New Odyssey: The Story of Europe's Refugee Crisis (London: Guardian Faber Publishing, 2017); Daniel Trilling, Lights in the Distance: Exile and Refuge at the Borders of Europe (London: Picador, 2018); and Peter Tinti and Tuesday Reitano, Migrant, Refugee, Smuggler, Saviour (London: C Hurst and Co., 2018).

25 C. Atton, 'What is “alternative” journalism?' Journalism 4:3 (2003), pp.267$272 ;$ p. 267.

26 Lindsay Morton, 'Evaluating the Effects of Epistemic Location in Literary Journalism', Journalism 17:2 (2016), pp.244-259; p.244. 
27 See Marta Caminero-Santangelo, 'Narrating the Non-Nation: Literary Journalism and "Illegal" Border-Crossings', Arizona Quarterly 68:3 (2012), pp.157176 , for further discussion of 'testimonio', and for an interesting parallel in the surge in U.S.-based literary journalistic coverage of 'illegal' border-crossing that surfaced in response to the 'crack-down' on U.S.-Mexico border-crossing in the first half of the twentieth century. The wider fictional response to the issue of 'illegal' migration on the U.S.-Mexico border also displays a focus on the politics of maternity. See, for instance, Michel Stone, The Iguana Tree: A Novel (Spartanburg: Hub City Press, 2012) and Shanthi Sekaran, Lucky Boy (New York: G.P. Putnam's Sons, 2016).

$28 \mathrm{McD}$ onald-Gibson's political stance is liberal left-leaning and displays a concern with humanitarian rather than explicitly feminist issues, though a number of her articles focus on women and on children (hence, implicitly, on maternal politics). See, for instance, Charlotte McDonald-Gibson, 'Moms of Young Muslims Enlist in the Fight Against ISIS', TIME Magazine, 15th September 2016, http://time.com/4489886/isis-mothers-schools-edit-schlaffer-islamicstate/ (last accessed 14th December 2018).

29 Sina is not the only mother whose story is presented within the text. Cast Away is comprised of five key protagonists' stories, including that of Hanan al-Hasan, a Syrian-born woman of Palestinian descent and mother of four, as well as the stories of Majid Hussain, a Nigerian teenager who sought sanctuary in Libya; and Syrians Nart Bajoi and Mohammed Kazkji, each fighting on different sides in the Syrian conflict. It is Sina's story, however, that frames the text, opening and closing the narrative, and thus emerges as the figurehead of the volume.

30 Suvendrini Perera, 'Oceanic Corpo-Geographies, Refugee Bodies and the Making and Unmaking of Waters', Feminist Review 103 (2013), pp.59-79.

31 Doreen Indra, 'Introduction', in Doreen Indra, ed., Engendering Forced Migration: Theory and Practice (New York: Berghan Books, 1999), pp.xii-xviii; p.xiv.

32 Indeed, this gender-blindness is reflected in the 1951 Convention Relating to the Status of Refugees (Geneva Convention), which does not recognise gender as specific grounds for persecution, and maintains a stoically 'humanized' (read homogenised) attitude towards 'the refugee' as category undifferentiated by subject position. For further discussion, see Freedman, Gendering the International Asylum and Refugee Debate, pp.69-80.

33 Marianne Githens, Contested Voices: Women Immigrants in Today's World (New York: Palgrave Macmillan, 2013), p.63.

34 See Ronit Lentin, 'Pregnant Silence: (En)gendering Ireland's Asylum Space', Patterns of Prejudice 37:3 (2003), pp.301-322.

35 Sonia Asif, Amy Baugh, and Nia Wyn Jones, 'The Obstetric Care of Asylum Seekers and Refugee Women in the UK', The Obstetrician and Gynecologist, 17 (2015), pp.223-231; p.223.

36 This report details, for instance, a case in which access to maternity care was offered as a reward to a woman on the condition that she relinquished her Christian faith. See Human Rights Council, 'United Nations Office of the High Commissioner for Human rights - Report of the Detailed Findings of the Commission of Inquiry on Human Rights in Eritrea', OHCHR, 8th June 2016, https://www.ohchr.org/Documents/HRBodies/HRCouncil/CoIEritrea/A_ HRC_32_CRP.1_read-only.pdf (last accessed 15th December 2018).

37 Peterson and Runyan, Global Gender Issues, p.1.

38 This, as many sources have noted, tends to be the dominant framework of UNHCR and broader NGO response.

39 Rose, Mothers, p.139. 
40 Sara Ahmed, The Cultural Politics of Emotion, Second Edition (Edinburgh: University of Edinburgh Press, 2014), p.124.

41 Jacques Derrida, 'Hostipitality', trans. Barry Stocker, Angelaki 5:3 (2000), pp.3-18. As Derrida notes, there are power differentials entailed even in 'ethical' acts of 'benevolence' - and as David Farrier notes, the construct of 'hostipitality' is also one reproduced within the implicitly racialised structures of the (post)colonial transnational landscape - as is the case for Sina, entering Greece from a 'Third World' country. See Farrier, Postcolonial Asylum, pp.153-180.

42 I have also engaged in fuller discussion of the specifically 'maternal' dynamics of the European state - in Ball, 'Biopolitical Landscapes of the "Small Human"', pp.452-456.

43 Here, we might posit maternity as categorised according to what Ticktin has described as 'categories of innocence' underpinning the 'political imagination': Miriam Ticktin, 'A World without Innocence', American Ethnologist 44:4 (2017), pp.577-590.

44 Freedman, Gendering, p.132. Here, Freedman glosses Malkki - see Liisa H. Malkki, 'Speechless Emissaries: Refugees, Humanitarianism and Dehistoricization', Cultural Anthropology 11:3 (1996), pp.377-404.

45 Freedman, Gendering, p.132.

46 Cynthia Enloe, Bananas, Beaches, and Bases: Making Feminist Sense of International Politics, Second Edition (Berkeley: University of California Press, 2014), p. 25.

47 Terence Wright notes the broader tendency towards Christian iconography within European media representations of refugees that seek to project humanitarian appeal. Wright, 'Moving Images', pp.57-60.

48 Rose, glossing Hannah Arendt, The Origins of Totalitarianism, in Mothers, p.79.

49 Ahmed, Cultural Politics of Emotion, p.133.

50 Ibid., p.139.

51 Ibid., p.141.

52 Shameem Black, Fiction across Borders: Imagining the Lives of Others in Late Twentieth-Century Novels (New York: Columbia University Press, 2010), p.4.

53 See, for instance, Nada Awar Jarrar, Somewhere, Home (London: Harper Collins, 2011) and Nada Awar Jarrar, A Good Land (London: Harper Collins, 2009). For more on the author, see Dawn Mirapuri, 'Meditations on Memory and Belonging: Nada Awar Jarrar's Somewhere, Home', in Layla Al Maleh, ed., Arab Voices in Diaspora: Critical Perspectives on Arab Anglophone Literature (Amsterdam: Rodopi, 2009), pp.463-485.

54 Issam Fares Institute for Public Policy and International Affairs, 'Syrian Refugee Crisis in Lebanon: Fatigue in Numbers', American University of Beirut, April 2018, https://website.aub.edu.lb/ifi/publications/Documents/infographics/20180514_ fatigue_in_numbers.pdf (last accessed 14th December 2018).

55 miriam cooke, War's Other Voices: Women Writers on the Lebanese Civil War (Cambridge: Cambridge University Press, 1988), p.18.

56 Arab Women Writers, http://www.arabwomenwriters.com/index.php/201405-03-16-02-36/2014-05-03-16-35-43/nada-awar-jarrar. Last accessed 24th October 2018.

57 Anthony Kwame Appiah, 'Cosmopolitan Patriots', in Pheng Cheah and Bruce Robbins, eds., Cosmopolitics: Thinking and Feeling beyond the Nation (Minneapolis: University of Minnesota Press, 1998), pp.91-133; p.92.

58 See Aryn Baker and Lynsey Addario, 'For Refugee Moms, Giving Birth Can Be Fraught with Danger', Time, 13th December 2017, http://time.com/5058722/ refugee-mothers-europe-greece-pregnant-prenatal/ (last accessed 14th December 2018). 
59 Daniel Baker, 'Regional Situation Report for Syria Crisis', UNFPA 27 (2014), https://syria.unfpa.org/sites/default/files/pub-pdf/UNFPA\%20Regional\%20 SitRep\%201\%20-\%2030\%20November\%202014\%20\%20\%23\%2027_0.pdf (last accessed 7th December 2018).

60 Liza Ramrayka, 'The Quiet Crisis of Europe's Pregnant Refugees', The Huffington Post, 13th June 2016, https://www.huffingtonpost.com/entry/ europe-pregnant-refugees_us_575eba7ce4b0ced23ca88e5e (last accessed 14th December 2018).

61 Tania Karas, 'For Refugees in Lebanon, Giving Birth Comes at a High Price', NewsDeeply, 7th July 2017. https:/www.newsdeeply.com/refugees/ articles/2017/07/07/for-refugees-in-lebanon-giving-birth-comes-at-a-highprice (last accessed 24th October 2018).

62 See Anonymous, 'Debunked 300,000 Syrian Refugees Are Not Pregnant in Lebanon', The New Arab, 5th May 2017. https://www.alaraby.co.uk/english/ news/2017/5/5/debunked-300-000-syrian-refugees-are-not-pregnant-inlebanon (last accessed 7th December 2018).

63 Chinua Achebe, 'Refugee Mother and Child', Christmas in Biafra and Other Poems (New York: Doubleday, 1973), p.24. This poem perhaps speaks in response to Don McCullin's infamous photograph of a starving Biafran mother breastfeeding her infant, 'Starving Twenty Four Year Old Mother With Child, Biafra', published in 1968 (see https://www.tate.org.uk/art/artworks/mccullinstarving-twenty-four-year-old-mother-with-child-biafra-ar01204, last accessed 14th December 2018).

64 Freedman, Gendering, p.132.

65 Ibid.

66 See, for instance, Goleen Samari, 'The Response to Syrian Refugee Women's Health Needs in Lebanon, Turkey and Jordan and Recommendations for Improved Practice', Humanity in Action, n.d., https://www.humanityinaction. org/knowledgebase/583-the-response-to-syrian-refugee-women-s-healthneeds-in-lebanon-turkey-and-jordan-and-recommendations-for-improvedpractice (last accessed 7th December 2018). Samari writes:

Early marriage is used as a coping strategy for young girls in abusive home environments and poor living conditions. Sexual exploitation and violence also contributes to early marriage. Families marry off their daughters with the idea that they are providing protection for young girls, continuing family traditions, alleviating poverty or helping daughters escape the environment.

67 See Estella Welldon, Mother, Madonna, Whore: The Idealization and Denigration of Motherhood (London: Karvac, 1988) and Adrienne Rich, Of Woman Born: Motherhood as Experience and Institution (New York: Norton, 1976), p.279, for instance.

68 Édouard Glissant, Poetics of Relation, trans. Betsy Wing (Ann Arbor: University of Michigan Press, 1990), p.190.

69 Glissant, Poetics of Relation, pp.192-193.

70 See, for instance, Maria Von Welser, No Refuge for Women: The Tragic Fate of Syrian Refugees (Vancouver: Greystone Books, 2017).

71 Freedman, Gendering, p.54.

72 Freedman cites a report in The Independent that claimed women with young babies as a result of their rape by militiamen were ostracised from their own communities in the Democratic Republic of Congo, and their only means of survival was to exchange sex with UN troops for food. Freedman, Gendering, p.65.

73 Anastasia Christou, Adalgisa Giorgio, and Gill Rye, 'Mothering and Migration: Interdisciplinary Dialogues, European Perspectives and International Contexts', Women's Studies International Forum 52 (2015), pp.49-52. 
74 Glissant, Poetics of Relation, p.192.

75 Ahmed, The Cultural Politics of Emotion, p.141.

76 Ibid.

77 See Wright, 'Moving Images'.

78 Woolley, Contemporary Asylum Narratives, p.109.

79 Rose, Mothers, p.47.

80 See, for instance, Lawler, p.155, for further analysis of this position.

81 See Christou et al., 'Mothering and migration' for further discussion.

82 Ahmed's text is highly pertinent, particularly on its focus on embodiment. It is interesting to note, though, that while Ahmed theorises encounter according to tropes of bodily expulsion as implicit interaction - sneezing, breathing, 'shitting or vomiting' for instance - she does not consider the act of giving birth as an act of 'expulsion' both predicated on 'close encounter' with an/other, and which also engenders fresh encounter: between mother and child, and between mother-as-other-self. There is more work to be done on embodied encounters through the maternal in transnational feminist terms. See Sara Ahmed, Strange Encounters: Embodied Others in Post-Coloniality (New York: Routledge, 2000), p.134.

83 Ahmed, Strange Encounters, pp.3-5.

84 Chandra Talpade Mohanty has written of the production of the 'third world woman' as category. The dynamic here, however, is more complex, given the authors' varied transnational positionalities. The fault lines of privilege are instead reproduced through the authors' access to textual representation and Anglophone literary markets located in sites of Western power. See Chandra Talpade Mohanty, 'Under Western Eyes: Feminism and Colonial Discourse', in Chandra Talpade Mohanty, Ann Russo, and Lisa Torres, eds., Third World Women and the Politics of Feminism (Bloomington: Indiana University Press, 1991), pp.51-80; p.56.

85 Cynthia Cockburn, 'The Continuum of Violence: A Gender Perspective on War and Peace', in Wenona Giles and Jennifer Hyndman, eds., Sites of Violence: Gender and Conflict Zones (Berkeley: University of California Press, 2004), pp.24-44; p.29. In the light of this comment, it is interesting to reflect on grassroots cultural mobilisations that have surfaced among women in forced migrant settings from 2011 onwards. Within this context, mobilisations of the maternal role are in fact sparse: of the many cooperatives set up by women within camp settings (often with NGO support), women's self-presentation tends to be that of the entrepreneur: a modern mediation and mobilisation of her 'traditional' capabilities such as cooking and sewing, which become marketable commodities. See, for instance, the Soufra catering company run by Syrian refugee women in Lebanon, the subjects of the documentary Soufra, dir. Thomas Morgan (USA/Lebanon: Rebelhouse Studios, 2017). Syrian women have, however, asserted maternity as grounds for authority and respect when demanding accountability from the Assad regime concerning the detention and disappearance of those within and beyond their family through the 'Families for Freedom' movement. See Families for Freedom, https://syrianfamilies.org/ en/ (last accessed 12th December 2018).

86 See, for instance, Patricia Hill Collins, 'On Violence, Intersectionality and Transversal Politics', Ethnic and Racial Studies 40:9 (2017), pp.1460-1473.

87 These poems were produced within a series of community writing workshops run as a collaboration between PAMOJA and local creative practitioners, including myself, as part of the city's Refugee Week festival in May/June 2018. Refugee Week is an international cultural festival run by Counterpoint Arts, https://counterpointsarts.org.uk/ (last accessed 19th December 2018). Its model is to provide a cultural platform to celebrate the presence of refugees in 
society, and it emphasises the role of refugees in shaping and populating material for the festival. I volunteer as a member of the Committee Team for Refugee Week in Nottingham (which includes members within and beyond the refugee community) and initiated discussion with PAMOJA regarding their desires for a creative project that would lead to an exhibition space. Within the sessions, I facilitated practicalities - such as room provision, professional creche care, audiovisual equipment, and translated copies of poems - through the resources available to me as an academic. However, the sessions themselves were guided by the group, who decided their own modes of interaction with the 'tutors' in writing, photography, and performance made available to them via Refugee Week networks of local volunteers. The project was conducted according to the Nottingham and Nottinghamshire Refugee Forum's safeguarding principles. The exhibition was on display at Nottingham Central Library throughout June 2018 and toured to THINK gallery in July 2018, and is included in Ball and Reeve, eds., The World Is for Everyone.

88 Ditsupo, in Ball and Reeve, eds., The World Is for Everyone, p.101. I use the women's first names only, as they appear in the volume, with their full permission.

89 Fadwa, in Ball and Reeve, eds., The World Is for Everyone, p.101.

90 Ola, 'My Child', in Ball and Reeve, eds., The World Is for Everyone, pp.91-92.

91 Given the poems' context as the first public platform for the group within a local cultural setting, members of the group may have experienced an incentive to assert their maternal roles in order to validate their perceived social worth to the host community. Problematic as this may be, it also presents a reclamation of the maternal self-image as grounds for humanitarian appeal initially invoked by Calvin in her institutional plea for UNFPA funding.

92 Kalkidan, 'My Tears', in Ball and Reeve, eds., The World Is for Everyone, p.89.

93 I am compelled by Sara Ahmed's discussion of silence and its self-defeatist function in transcultural feminist discourse in Strange Encounters, pp.166-167, in which she suggests that to be paralysed by a position of privilege is to remain fixated with self-identity, at the expense of openness to encounter that might lead to transparency and scrutiny of the power differentials entailed in transnational feminist communication. 


\section{Feminisms in conflict \\ Decolonising Afghan women's displacement through the Iranian cinematic gaze}

Fifty years on from the landmark signing of the 1951 UN Convention Relating to the Status of Refugees, a young woman fixes her eyes on the sky. ${ }^{1}$ A tower rises above her, pluming smoke into the blue, and her head is tilted back in silent union with the group of children around her. It is September 11th, 2001, but it is not New York, and there are no aeroplanes in the skies - at least, not yet. Rather, this is Afghanistan, and the tower is in fact the chimney of a kiln manufacturing bricks for a bomb shelter being hastily assembled in anticipation of the airstrikes that her country now fears are inevitable. ${ }^{2}$ Beneath this woman's steady gaze, we might speculate at a complex play of emotions. For she is the teacher in a madarase khodgardarn ('makeshift school') of the kind common among displaced communities within Afghanistan. ${ }^{3}$ And while she has called her class of young children to stand beneath the chimney as a point of empathetic visual reference while they observe a minute's silence for the victims of the 9/11 attacks (a gesture that echoes the many other expressions of feminist solidarity and condemnation that emerged across the world, including from Afghan women ${ }^{4}$ ), the alignment of their gaze to this shared sky also speaks to an altogether more conflicted set of cultural interactions. What does this young woman sense on the horizon as she looks up into the air? Is it the fresh educational and political possibilities for women in an Afghanistan liberated from Taliban rule? Or could it be, rather, the looming shadow of renewed displacement - a phenomenon so prolific and markedly gendered in its implications that it has been deemed, by some researchers, to be of greater detriment to Afghan women's well-being than the regime of the Taliban? ${ }^{5}$ Perhaps the most bewildering visual conundrum of this scene, though, is one that only becomes apparent some 19 years on. This is the knowledge that many of the greatest challenges this woman will face will be generated by the competing international agendas - feminist and otherwise - that will circulate around Afghan women's social and spatial mobilities in the wake of a military invasion presented to the world as an act of liberation. ${ }^{6}$ As this woman looks to the skies, then, she prompts us to reflect critically on the material impact of conflict on women's lived realities, particularly in terms of the simultaneously spatial and social displacements that accompany

DOI: $10.4324 / 9780429325403-3$ 
military intervention. So, too, does she alert us to the political complexities that accompany the task of visualising 'liberating' mobilities for Afghan women within a landscape of radical spatial disenfranchisement - and in so doing, presents us with one of the most conflicted transcultural feminist discourses surrounding forced migration in the early twenty-first century.

Afghan women's displacement constitutes a severe but lesser-publicised 'mobility crisis' than those population flows that have proven more readily visible to Europe in the twenty-first century (such as the Syrian 'crisis', explored in Chapter 2 of this volume). ${ }^{7}$ As a phenomenon that spans this century and the last, however, it represents one of the longest-running displacement crises in the world and attests to the longstanding status of the country as a site of transnational leverage between superpowers. ${ }^{8}$ Population movements have been continual and complex, but military conflict has been a constant driving force. In the late 1980s, some 5 million Afghans became refugees as a result of the Soviet Invasion, the legacy of which meant that 'when American bombardment began in October 2001, 3.6 million Afghans remained refugees, mostly in Pakistan and Iran, while at least 700,000 more were internally displaced'. ${ }^{9}$ The United Nations High Commissioner for Refugees notes that today Afghans remain the largest protracted refugee population in Asia, though the number of internally displaced people peaked in 2002, at 1.2 million. ${ }^{10}$ Significantly, the landscape of Afghan displacement is a feminised one: as Judy Benjamin has noted,

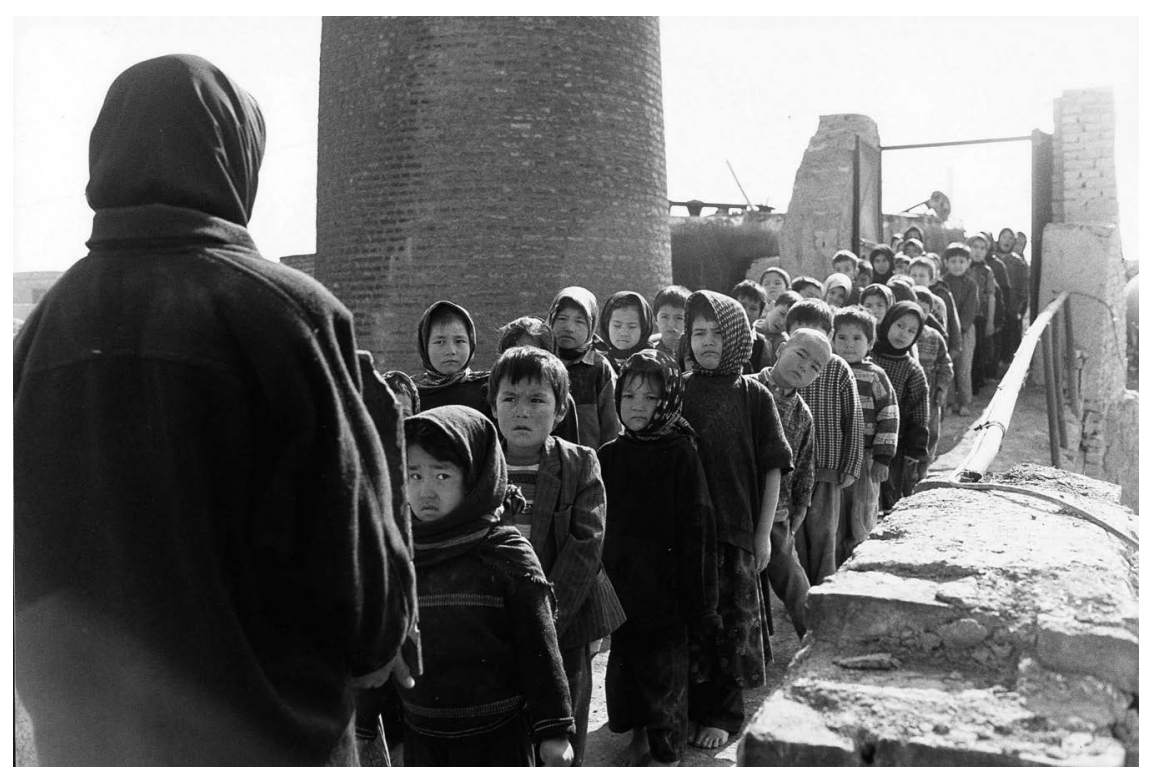

Figure 3.1 Still from 'God, Destruction and Construction' by Samira Makhmalbaf. Short film contribution to Alain Brigand, 11.09.01, September 11th, A Film (2002). Image courtesy of Alamy. 
'women are the predominant social category in Afghanistan, comprising 55 per cent or more of the population', 11 while Sima Wali notes that Afghanistan has long been considered to represent 'the feminization of poverty', since the majority of those reliant on international assistance for survival, and of displaced persons and refugees in Afghanistan, have been women. ${ }^{12}$ This is largely the result of the disproportionate death toll in men during the war against the Soviet Union. There has also been some targeted research assessing the especially deleterious effects of displacement specifically on Afghan women. Grant Farr, for instance, notes that widowed women particularly suffer when displaced due to the system of mahram, which places restraints on their ability to work, appear in public, or travel without a male relative. ${ }^{13}$ So, too, do circumstances common to many conflict zones such as increased threat of sexual violence, material restrictions on housing, healthcare and education, and reduced financial circumstances - all impact on Afghan women in ways that prove specific to their gendered positionalities. ${ }^{14}$ Indeed, the films scrutinised within this chapter identify a number of issues faced by their female Afghan characters - including lack of independent access to life-sustaining resources (shelter, food), denial of access to education, and the enduring practice of pishkesh (bride price) - as seemingly dissociated experiences that are in fact heavily shaped by the conditions of displacement and the characters' status as women. As such, Afghan women's displacement presents a vital site of feminist scrutiny. Yet as we delve further into the feminist dialogues that have circulated around Afghan women in the twenty-first century, it becomes all too clear that they have borne a complex set of transnational agendas - ones that have, in their own ways, generated simultaneously material and ideological conflicts, with particularly negative repercussions for those displaced.

Afghan women have long presented a source of 'concern' to transnational feminist coalitions - including those in the 'West', or global North who condemned the Taliban's brutally oppressive treatment of women with calls for international action that remained largely unobserved by Western governments for over a decade. ${ }^{15}$ As a number of feminist scholars including miriam cooke have observed, however, it was only with the impetus of 'retaliatory war' fought on the grounds of a 'crusade' for 'democratization' by then U.S. president George W. Bush that the U.S. government began to take the plight of Afghan women to heart. ${ }^{16}$ It was in fact the voice of Laura Bush, then First Lady of the U.S., who claimed 'the brutal oppression of women [as] a central goal of the terrorists ${ }^{\text {'17 }}$ who enacted the September 11th attacks - located, through a process of dubious reckoning, in Afghanistan. It is tempting to find echoes in these words of Spivak's formulation of the 'colonial rescue fantasy' in the salvational rhetoric of the self-styled 'War on Terror', characterised, as Gayatri Spivak would have it, by 'white men saving brown women from brown men'. ${ }^{18}$ Yet the connection constructed between masculinised foreign terrorism and incentive for military intervention is overt within this discourse and mirrors more 


\section{Feminisms in conflict}

clearly the Orientalism of an aggressive contemporary imperialism that, as a number of postcolonial feminist scholars have pointed out, marks much of the rhetoric of the 'War on Terror'. ${ }^{19}$ The feminised and indeed feminist channels through which these claims were mobilised alerts us to something more complex and insidious than the overt masculinism of imperialism at play here, though: a tension at the heart of feminist interventions negotiated across the global North and South. ${ }^{20}$ At stake, instead, is what Ann Russo has termed 'imperialist feminism': a mode of culturally unscrupulous Western feminism that seeks to engage the support of the State by shoring up its militarised rhetoric of liberation. ${ }^{21}$ The transnational short-sightedness of these feminist claims is brought astonishingly into focus when we turn our sights to Afghan women's displacement - a direct product of the military invasion that it helped to incentivise. While, though, Afghan women's displacement reveals the dangers of political appropriation that may indeed be embedded within the very same transnational feminist movements that seek to respond to the disenfranchising effects of women's forced migration, it also, this chapter will suggest, establishes a deeply productive site of transcultural feminist critique. For while imperialist Western feminists mobilised collectively around utopian visions of 'liberating' Afghan women through foreign intervention, the gazes of a very different group of gender-conscious creative practitioners were also turning their sights to conditions on the ground for Afghan women. It is by turning our sights to the work of these women - all of them twenty-first-century Iranian film directors - that we become able to visualise powerfully decolonial possibilities within the transcultural feminist imagination.

Working in much closer proximity to Afghanistan and with a different kind of cross-border interplay at stake, Iranian female film directors have displayed a particular interest in the lives of displaced Afghan women in the post-9/11 environment. ${ }^{22}$ Indeed, the moment of striking visual aporia described at the start of this chapter appears in the diasporic Iranian director Samira Makhmalbaf's contribution to Alain Brigand's short film compilation 11.09.01, September 11th, A Film (2002) which presents an accumulation of reflections on September 11th from 11 filmmakers around the globe. ${ }^{23}$ Forged from a position of Iranian-Afghan alliance, Makhmalbaf's short film - entitled 'God, Destruction and Construction' - leverages an important opportunity to invert the transatlantic perspective that dominated visual coverage of $9 / 11$. Yet the implicit emphasis of Makhmalbaf's gaze - which gestures towards the connectedness between military invasion and displacement ${ }^{24}$ - also speaks to a wider preoccupation with Afghan forced migration that has surfaced in Iranian cinema as a cultural genre often concerned with addressing social affairs through its distinctive aesthetic gaze. ${ }^{25}$ Indeed, it also presents what might be described as an implicitly postcolonial feminist potential 
in its desire to counteract the Orientalist tendencies of the Western media gaze through a radical contestation of the Afghan woman's subaltern status. ${ }^{26}$ In this genre, then, we find powerful potentials to critique the imperialist assumptions projected onto Afghan women and to visualise alternative representational modes. The work of two particular Iranian female film directors - Samira Makhmalbaf, and Rokhsareh Ghaem Maghami - yield especially potent insights into Afghan women's displacement through their films At Five in the Afternoon (Makhmalbaf, 2002) and Sonita (Ghaem Maghami, 2015), respectively. As these works both suggest, conflict - whether political, feminist, or representational in nature - forms the deeply destabilising core of displaced Afghan women's lives. And it is therefore through this very trope that subversive representational potentials may be realised.

While employing different directorial modes, Makhmalbaf and Ghaem Maghami both sit within a long and prestigious history of Iranian female directorship, within which attention to women's gender roles and lives forms an ongoing source of cultural scrutiny. ${ }^{27}$ They advance this heritage specifically in relation to displaced Afghan women's lives in the post-9/11 environment, displaying a renewed sense of global locatedness felt at and across Iranian borders, and within Iranian cultural consciousness in the post-9/11 environment. In Samira Makmalbaf's feature film At Five in the Afternoon, for instance, we encounter a female protagonist located directly within the intersecting arenas of mass displacement and of international humanitarian intervention in the wake of Afghanistan's invasion. The paths that this young woman must forge through the world articulate many of the conflicts of agency and mobility that characterise life for displaced Afghan women more broadly. In Rokhsareh Ghaem Maghami’s documentary Sonita, meanwhile, we trace the lasting legacies of Afghan displacement for women in Iran over a decade later. For this young woman, though, creative voice and self-directed performance present possibilities of international mobility - ones that grate uneasily against the pressures of poverty and associated threat of forced marriage. By reading across these films with the aid of tools drawn from postcolonial, transnational, and media-based feminist paradigms, it becomes possible not just to render Afghan women's mass displacement transnationally visible but to generate an alternative mode of feminist representation that enables us to perceive the political agendas directing Afghan women's paths through the world. This radically destabilising feminist visual potential emerges, this chapter will suggest, through the alternative modes of looking, seeing, and representing that are advanced through the female-directed Iranian cinematic gaze itself. In the gaze of these directors, then, we catch sight of fresh transcultural feminist potentialities divorced from the highly masculinist militaristic paradigms that have devastated so many facets of Afghan women's mobilities to date. 


\section{Steps forward and back: conflicted mobilities in At Five in the Afternoon}

The Iranian cinematic visions of the Makhmalbaf family circulate uneasily around the years of the War on Terror. Preoccupied with issues of gender, sociospatial mobility, and marginality, the films of this distinctively cinematic family (who also run their own Film House) have received significant international acclaim but have also played varied roles on the international stage - particularly when it comes to transnational feminist potential. ${ }^{28} \mathrm{We}$ find a powerful projection of this in the competing international responses to films made by Samira Makhmalbaf, eldest daughter within the family, and her father Mohsen in the years surrounding 9/11. ${ }^{29}$ Samira initially found herself propelled onto the world stage in her early 20s, when she received international acclaim for her feature film, The Apple - a work that gently critiqued the domestic seclusion of women through its poetic representation of two young Iranian girls kept prisoner in their house by their patriarchal father. Homeschooled in film-making by her own father, Samira's film presented a fortuitous alignment of liberal Iranian and transatlantic feminist agendas and was lauded as a distinctive feminist triumph on the international stage. ${ }^{30}$ This liberal strand of Iranian feminist critique would also characterise the film Mohsen would release just a year later, entitled Kandahar - a work that casts real-life refugee journalist Nelofer Pazira as a woman returning from Canada to Afghanistan in search of her sister, who has threatened by letter to kill herself due to the oppressive conditions for women in her country. ${ }^{31}$ After struggling to gain international distribution when first put to market in early 2001, however, this film was suddenly launched to prominence in the Autumn of that year after the White House administration ordered a screening of it in the wake of $9 / 11$ and run-up to the Afghan invasion. ${ }^{32}$ In just over a year, then, the political reception of the Iranian cinematic gaze would shift from one of transcultural feminist appreciation to militaristic appropriation. It was perhaps with a consciousness of this potential for ideological 'hijacking' that Samira would direct her next film - a neorealist work utilising untrained actors, some of them drawn from Afghanistan's displaced community, entitled At Five in the Afternoon. ${ }^{33}$ In this film, we find an ambivalent portrait of displaced Afghan women's quests for social mobility, framed against a backdrop of extreme spatial disenfranchisement. Yet so, too, do we sense some of the innovative ways in which women become able to negotiate paths through this fraught spatial, ideological, and psychological territory.

The first film to be shot in Kabul following the 'fall' of the Taliban, ${ }^{34}$ At Five in the Afternoon follows the story of an ambitious young woman named Nogreh who lives with her father, sister, and newborn nephew in the ruins of an abandoned building as members of Afghanistan's estimated population of 1.2 million displaced in $2001 .^{35}$ Refreshingly, though, she also attends the progressive 'Galeh School for Girls' and dreams of being 
the next president of Afghanistan. A backdrop of displacement therefore infuses this film, but in a manner that presents it as a deep underlying constant in the lives of Afghan citizens who have endured decades of conflict, and Nogreh's everyday circumstances within the film - the unstated but visible poverty of her family's existence and her patriarchal dependency therefore suggest the subtle but tangible ways in which displacement exacerbates women's sociocultural disenfranchisement. Indeed, a central irony of the film proves to be the arrival of several truckloads of refugees returning, post-Taliban, after long periods of life in Pakistan - people who Nogreh tries to house within her own basic accommodation, but who end up pushing her family out in search of new shelter and a bleak future. ${ }^{36}$ As such, displacement presents itself as a cyclical constant for the inhabitants of Afghanistan - a phenomenon that, as Saba Gul Khattak notes, destabilises the very meaning of watan - home - and presents it not as a space of refuge, but rather as a site of perennial absence. As one of Khattak's interviewees states, 'We are not only refugees here [in Pakistan] but also there [in Afghanistan]. We have no village [watan] anywhere'. ${ }^{37}$

The interrelationship between military conflict, displacement, and women's particular disenfranchisement is thrown into sharp focus in some of the final frames of the film. Here, Samira's camerawork assumes a plodding slowness that mirrors the painful passage of feet over the soil and is the very antithesis of Virilio's 'speed as the essence of war'. ${ }^{38}$ We watch as the father takes his daughters in search of refuge in what he terms 'a true religious city' (by implication, Kandahar) removed from the influence of North Atlantic Treaty Organisation (NATO) troops. Radically, his distrust of these foreign forces does not seem entirely unfounded: on their journey, the family sees planes and helicopters circle overhead and find refuge only in the burned-out shell of an abandoned aircraft - a remnant from Soviet fighting, perhaps, in which U.S. troops mobilised Afghanistan in their own fight against Communism. ${ }^{39}$ This image of vastly disjunctive mobility between foreign power and Afghan inhabitant - the first capable of transcending transnational airspace and the second limited even in their safe passage through home territory - seems to affirm Didier Bigo's view that 'freedom is not so much a value [but] a technology of power', 40 denied here to Nogreh and her sister in the most painful of senses. Pausing in this aircraft, though, we also encounter the deeply material impact of displacement on women's embodied well-being. We learn, for instance, that her sister Leylomah's milk has dried up and she can no longer feed her baby, who will indeed, in a manner reflective of the severely limited antenatal care and lack of resources available to Afghanistan's displaced new mothers and children, shortly die. ${ }^{41}$ With a missing husband and only an aged patriarch to protect her, she is presented as a figure as barren and static as the dull ochre landscape, incapable of an actantial role due to the restraints of mahram on her abilities to work, travel, and support herself. The removal of male family members' protectorship, then, proves a major 
factor in the destitution and vulnerability faced by the high percentage of Afghan women widowed by warfare. ${ }^{42}$ Indeed, the final frames of the film construct a powerful symbolic critique of the limited paths that remain open to Afghan woman within the context of displacement. For though the sisters eventually leave their ailing father behind, this 'liberation' from patriarchal guidance merely serves to set them adrift in a featureless landscape, devoid of shelter. It is no accident that in these final shots, we hear the poetic refrain of the title whispered by Nogreh beyond the frame: 'It was five in the shade of the afternoon'. As the poem continues, bleakly: 'the rest was death, and death alone'. ${ }^{43}$ These closing frames, then, seem to project a deep ambivalence around women's agency within the context of displacement - for, as Khattak writes, 'the patriarch who protects, the interchangeable father and the state, is absent and unable to protect', 'exposing them...to the danger of the unknown'. ${ }^{44}$ Here, we witness the barren logic at the heart of imperial feminist advocacy for the liberating effects of military invasion. For whatever the claims to emancipation from patriarchal influence, Samira's film shows here that without the stability of a home and its basic provision of sustenance and safety, women become bound by fundamentally embodied needs and remain exiled from even the most basic forms of social ability - even, Samira's film suggests, the ability to preserve one's own life.

Where, then, is the feminist potentiality to be found amidst such apparent despair - even pessimism? To locate this, we must turn to the subtler poetry presented through the Iranian cinematic gaze, which often operates primarily through visual poetic resonance, rather than action or script-based revelation. We begin to sense some of these alternative possibilities if we look again at Samira's reference to the poem that frames the entirety of the filmic narrative. Written by the Spanish poet Federico García Lorca, a figurehead for liberal creative dissent, this poem, entitled 'Lament for Ignacio Sanchez Mejias', honours a heroic national figure - an Andalucian bullfighter. ${ }^{45}$ In her daring equation of Afghan women with bullfighters, then, Samira hints at the subtle strength and courage they too possess. Indeed, while the women's eventual dissolution into the landscape of perpetual displacement constitutes a sober finale to the film, this conclusion resists despair due to the adaptability and resilience displayed by the heroine in her everyday life in Kabul - a context comprised of ideological disjunction that she must learn to traverse in strategic and indeed performative manners. By turning, now, away from displacement as a mode of travel and focussing instead on the micro-movements that mark Nogreh's everyday passage through the city, it becomes possible to perceive some of the subversive ways in which Samira as director reframes our perception of women's spatial and indeed social mobilities in an Afghanistan in limbo - and, in doing so, helps us to visualise productive forms of transcultural feminist movement.

The first form of movement towards which Samira directs our sights is a subtle one, though politically loaded: this is the movement of Nogreh's 
burqa, as it is lifted or lowered over her eyes - a movement also synchronised with Nogreh's passage through the varied social spheres available to her. The discourse of 'lifting the veil' is a loaded one in the post-9/11 transnational feminist context. As Stabile and Kumar note, in the weeks following September 11th, 'Burqa-clad women were featured on the cover of the New York Times magazine (in a feature story that, interestingly enough, had absolutely nothing to say about women), as well as Business Week, Newsweek, Time and other general interest magazines'. ${ }^{46}$ This repeated evocation of the burqa has served to reinforce Afghanistan as a location of unfamiliarity, alterity, and facelessness within an Orientalist and indeed masculinist spatial imaginary. ${ }^{47}$ Indeed, while the act of 'lifting the veil' was portrayed in post-9/11 Western media discourse as one that simultaneously liberated Afghan women and exposed their plight to the world, the motif also, with hindsight, exposes a correlation between the militaristic desire to conquer and to gain visual as well as epistemological mastery ('to see is to know/understand'), reminiscent of the Orientalist imaginary. ${ }^{48}$ When redirected through Samira's directorial gaze, however, this straightforward equation between women's unveiling, visibility, knowability, and agency is radically unsettled - and so, too, is the notion of ready access to social or spatial mobility.

Nogreh's engagement with the burqa reflects the complex political, social, and personal pressures that define the relationship between the female body and its spatial performances. The first few minutes of the film present us with the sight of a burqa-clad woman moving through and around her makeshift abode. We watch as she carries water, collects her books, and is transported by her father to the religious school in town. Anonymous and

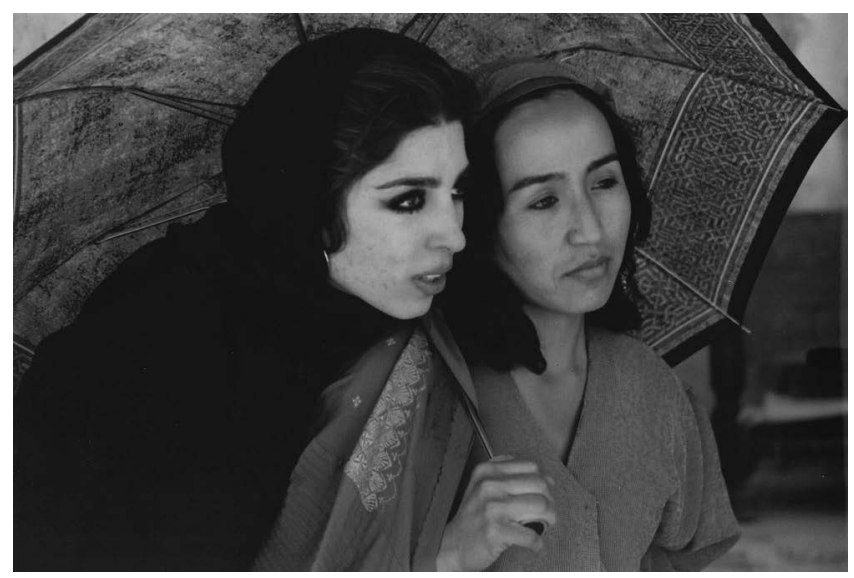

Figure 3.2 Director Samira Makhmalbaf (left) and protagonist Nogreh, played by Agheleh Rezaie (right), align their gazes on set in At Five in the Afternoon (2002). Still from At Five in the Afternoon, dir. Samira Makhmalbaf, courtesy of Alamy. 
subject to mahram, this female subject initially seems to convey the space of purdah (seclusion of women) ${ }^{49}$ as what some Afghan women refer to as qeit: 'confinement' or 'imprisonment'. ${ }^{50}$ As Brydon and Chant suggest, the burqa, when read in this context, 'symbolizes the invisibility of women in "male spaces" such as the street or public places', ${ }^{51}$ and Ardener has also described veiling as 'fictive invisibility'. ${ }^{2}$ Samira's directorial strategies, however, unsettle this clear-cut visual and gendered dichotomy. The woman, though anonymous, is kept centre-shot and dictates the slow pace of the opening sequence through her movement. The effect of this is to deny the usual voyeuristic or fetishistic pleasure with which the female subject is usually 'read' within moments of her appearance on screen. ${ }^{53}$ Instead, there is a more careful visual empathy at stake that prioritises respect for the protagonist over the imagined audience - a visuality that perhaps recalls Trinh T. Minh-ha's theorisation of a non-Western and non-monological filmic discourse as one that offers 'the possibility of a break with the specular structure of hegemonic discourse and its scopic economy which ... circularly bases its in-sights on the sight (a voyeur's theora) rather than the touch'. ${ }^{54}$ More subversive still, however, is the young woman's next movement. For passing through the shadows of a city walkway, we watch as she reaches the end of the passage, checks that her father has left, and tucks the burqa back from her face, before dropping a pair of white high-heeled shoes from beneath her burqa and popping up a parasol over her head, continuing on her way with a sense of calm self-assurance. Here, then, we see the young woman - who we now know to be Nogreh - reinscribing the space of purdah by appropriating its anonymity for her own purposes and locating sources of personal agency through its very restrictions. While this shot by no means claims the burqa itself to be 'liberating', Nogreh's concealment of shoes beneath it echoes the strategies employed by the Revolutionary Association of the Women of Afghanistan, who used the burqa as a means to conceal weapons, banned publications, and indeed film cameras with which they captured violations of human rights during Taliban rule. ${ }^{55}$ It also, however, indicates the instability of the burqa's straightforward legibility as a marker of women's social immobility - and in this, it suggests a more textured nature to Afghan social space - and of women's mobilities within it. As Chilla Bulbeck has pointed out, the iconic burqa does not, in fact, 'carry a single, unvarying message' but has an extensive and varied history; it is in itself a culturally situated practice. ${ }^{56}$ Several field researchers have noted that though some women initially cast off their burqas following the arrival of NATO forces, the majority of women in Herat and Kabul, as well as many other regions, still wore them due to the perceived fragility of Karzai's governance in the early years post-invasion and the enduring threat of Taliban militia. ${ }^{57}$ As Riphenburg describes it, the burqa now acts as a 'barometer of the level of insecurity women feel'. ${ }^{5}$ ' So, too, does it reveal the pressure of tradition that endures when it comes to women's engagement with the public sphere - a source of conflict widely 
documented by researchers, also evidenced through women's fraught passage into mainstream Afghan political representation. ${ }^{59}$ Thus, Nogreh's own performative engagement with the burqa gestures towards the wider situational ambivalence that characterises women's mobilities in 'liberated' Afghanistan.

Nogreh's white high-heeled shoes denote a similar symbolic instability. Produced at her moments of transition between spaces defined by her father's presence and her independent participation in the public sphere (as she makes her way, for instance, to the government-run girls' school rather than the religious classes her father thinks she attends), the shoes become a symbol of mobility and newfound political freedom. As white high heels, they break all the stipulations for flat, black, closed, and noiseless shoes stipulated under Taliban rule. ${ }^{60}$ Associated with 'Western' femininities, they might also be read as markers of what has been termed 'Westoxification' within Iran - or, in subtler terms, as an indication of the latent potential for Westernisation that may accompany any project of imposed 'emancipation' ${ }^{61}$ Later, however, these same shoes will emerge as a deeply ambivalent symbol of freedom. Displaced from her temporary shelter and on the road once again, Nogreh's family seeks shelter in the ruins of an abandoned palace. Out of sight and positioned centrally between the crumbling colonnades, Nogreh takes off her plimsolls and dons her white high heels. She steps slowly and deliberately forward, then comes to a halt and marches with strong, determined stamps of her feet - but on the spot. The sound of high-heeled footsteps echoes around the corridors of the palace. But though there is the sound of progress echoing in its space, there is no one to hear it, nor does Nogreh make any literal progress. In apparent recognition of this futility, Nogreh kicks off her shoes: donning the 'imports' of the West, she seems to realise, does not provide the easy route to freedom she might have thought. Barefoot, she jumps forward in a once-forbidden game of hopscotch. Her culturally progressive movement here morphs into a childish gesture, unacknowledged and unseen. For all of her aspirational fantasies, then, Nogreh remains culturally and politically static as a dislocated subject - a condition that keenly reflects the condition of her nation more broadly.

In an aesthetic sense, these episodes reveal the distinctive characteristics of Samira's Iranian cinematic practice. Writing of the 'poetic realist' qualities of Iranian cinema, Chaudhuri and Finn note the centrality that many directors, including Samira, afford to 'settings [that] retain their reality, but ... are no longer situations that disclose actions as they would in traditional realism. Instead, they open onto thought, dream, memory and feelings of déjà- $v u$, as the action "floats" in the situation'. ${ }^{62}$ Read in gender-conscious and culturally specific terms, however, it becomes clear that the 'poetic realist' qualities of these episodes - in which Nogreh's interactions with space (the abandoned palace, passageways, and doorways open to her) assume discursive primacy over any notion of 'plot' - also 
bear a powerful feminist message. In the visual conversations that she repeatedly instigates between her female protagonist and the space around her, she delivers a critical insight into how it is that we might better understand women's sociospatial mobilities in Afghanistan. This is, quite simply, by recognising that women's existences are situated - and that any feminist conversation must position itself within the precise and sometimes shifting coordinates of her existence 'on the ground'. In this, she speaks to Susan McWilliam's reading of 'the traveller's vision' as 'an evidently embodied vision [... which] deflate[s] the most hubristic human aspirations for transcending the corporeal'. ${ }^{63}$ Yet she also therefore follows in a long tradition of feminist thought that has emerged in varied transnational locations: from Simone de Beauvoir's second-wave feminist phenomenological recognition of the body not as an essence but a contextualised 'situation' ${ }^{64}$ to Chandra Talpade Mohanty's 'cartographies of struggle' that recognise each individual's intersectional situation within 'discontinuous locations' ${ }^{65}$ Located specifically within the discourse on forced migration, however, this insight constitutes a radical intervention. Not only does Samira's visuality reveal displacement as an overwhelming source of physical disenfranchisement for women, but she also articulates the deep interconnectedness between physical and social (im)mobilities. Refusing a clear-cut narrative of either progress or regression, however, she instead dramatises the social conflicts and political tensions that render these intersecting mobilities so complex to negotiate. In doing so, she affirms Craig Martin's observation that 'the texture of migration' is comprised 'not [of] a stable flow of individuals [...] [but rather] as troubled, unstable mobilities that are punctuated by periods of uncertainty, disjuncture, stasis, but also hope, promise and imagination ${ }^{66}$ as particularly apposite to Afghan women, subject as they are to multiple political forces that drive their sociospatial mobilities in complex and competing directions.

Conflict, then, is central to Samira's visual representation of Afghan women's mobilities. Not only does she reveal displacement to be the product of conflict, but she suggests Western intervention - implicitly feminist - to be a source of conflict in itself, presenting often inaccessible or contextually unsituated possibilities of advancement for Afghan women. Gently poetic as this discourse may be, it nevertheless constitutes a radically anti-imperialist feminist intervention when read against the backdrop of the post-9/11 landscape. For as Peterson and Runyan remind us, 'to resist Empire is to disrupt the gendered division of violence, not by claiming equality to do imperial violence but by challenging the power of gender to valorize it ${ }^{67}$ And as Arundhati Roy insists, cultural media bears a genuine ability to intervene within this context:

Our strategy should be not only to confront Empire, but to lay siege to it. To deprive it of oxygen. To shame it. To mock it. With our art, our music, our literature, our stubbornness, our joy, our brilliance, our sheer relentlessness - our ability to tell our own stories. ${ }^{68}$ 
With a witty pair of white high heels, a joyfully stubborn protagonist and a relentlessly considered gaze, Samira's film begins to dismantle the imperialist feminist myths that have facilitated the fantasy of ethical military intervention - and reveals a different way of moving, visually and imaginatively, with women who occupy the deeply conflicted and traumatically mobile landscapes of post-9/11 Afghanistan. It is a territory in which, like Nogreh, transcultural feminists must learn to move prudently, everconscious of the need for strategic, situated, and culturally considered negotiations with Afghanistan's shifting terrain.

\section{A conflict of values: redirecting agency in Sonita}

If At Five in the Afternoon dramatises the immediate effects of conflict on Afghan women's sociospatial mobilities, then Rokhsareh Ghaem Maghami's 2015 documentary Sonita reveals its legacies some 14 years on, as the effects of war and enduring threat of the Taliban continue to drive women from their homes, including across the border into Iran. ${ }^{69}$ This is the case for the central subject of Ghaem Maghami's film, Sonita - a 15 -year-old undocumented Afghan refugee who has fled from the Taliban by crossing illegally into Iran with her family and now finds herself eking out a meagre living as a cleaner, while accessing education via a NonGovernmental Organisation for working and street children in Tehran. While Samira's film presents us with a meticulously crafted vision of the conflicted role played by Western intervention in the lives of displaced Afghan women, Ghaem Maghami's documentary explores subtler and more deeply ingrained forms of ideological conflict as we follow Sonita's quest over the course of three years to find security by pursuing her dream of becoming a rap artist in the U.S. - and, in so doing, to evade her family's plans to 'sell' her as a child bride. Alongside this portrait of clashing cultural values and Sonita's associated struggle to find her voice, another source of conflict emerges within the documentary process itself. This is the director's ethical dilemma as to whether or not she should intervene in Sonita's story in order to help this promising young woman realise her ambitions. ${ }^{70}$ Through its highly self-reflexive gaze, then, Sonita invites us to consider not just the competing cultural frameworks and pressures that Afghan refugee women must negotiate but the ambivalent and indeed sometimes conflicted transnational locations of creative feminist potential - and of the complex representational interactions that may accompany them.

Ghaem Maghami occupies a distinctive position in relation to the field of Iranian cinema that is not without its own conflicts. Born in Tehran and a student of both film-making and animation at Tehran Arts University, her directorial style is characterised less by the auteur poetics of her female predecessors than by an interest in creative experimentalism - and in the potential for social change this may afford. Indeed, her previous works display a recurring preoccupation with marginalised female figures 


\section{Feminisms in conflict}

seeking agency through creative expression. Her 2011 work Going Up the Stairs, for instance, tells the story of Akram - an Iranian woman married at the age of nine who discovers a talent for painting in her later life, but who struggles to gain her husband's permission to travel overseas to exhibit her work. ${ }^{71}$ In Sonita, we again sense a resistant social agenda founded in gender-conscious critique at stake within Ghaem Maghami's work - a stance that has proved appealing to an international audience, evident in the film's triumph at Sundance in 2016 as winner of the World Documentary Audience Award and Grand Jury Prize. ${ }^{72}$ Yet as Ghaem Maghami is keen to point out in interview, her work resists the reductive identification of 'men as evil and women as victims', instead recognising that 'patriarchy is an economic, social and cultural system with its own dynamics and mechanisms ${ }^{73}$ Within Sonita, however, this patriarchal economic system proves pivotal to the intersectional pressures faced by the central protagonist as both an Afghan refugee in Iran and an Afghan woman. Through recognition of this system, Ghaem Maghami and Sonita ultimately become able to subvert and appropriate the economic values attached to Afghan women, realising different forms of creative 'worth' in Sonita.

Forced and child marriage present significant but generally underrecognised forms of gender-specific persecution faced by members of the displaced female Afghan population. While the legal age for marriage is set at 16 under Afghan civil law (enforced since the fall of the Taliban in 2002) and forced marriage is increasingly discouraged by NGOs, teachers, police, and some religious leaders in Afghanistan, ${ }^{74}$ a recent report by Amnesty concluded that 'forced marriages, and ever younger child marriages, and [women] being traded in settlement of disputes and debts' are still widespread. ${ }^{75}$ According to the United Nations Development Fund for Women (UNIFEM), ' $57 \%$ of Afghan girls continue to be married prior to the legal age of 16 years, and $60-80 \%$ of these girls are forced into marriage. ${ }^{76}$ Widespread as this practice may be within Afghanistan, it has been shown to present an even graver threat to girls and women within Afghan refugee communities. As the Strongheart Foundation summarises:

Humanitarian crises exacerbate poverty, insecurity, and lack of access to education, factors which drive child marriage. In crisis, parents often perceive child marriage as a safety mechanism for their daughters and overall survival strategy for their families.

[... Thus] displacement can increase girls' vulnerability to child marriage due to the breakdown of social networks and risk of sexual violence ... In situations of forced displacement, parents may marry off girls as a way to cope with poverty or safety concerns, and most married girls stop going to school. ${ }^{77}$

Thus, the socio-economic precarity faced by displaced Afghan families, combined with the pressure of patriarchal traditions surrounding female 
'honour', render daughters particularly vulnerable to forced marriage at an early age within the context of displacement. This certainly proves to be the case not just for Sonita but for many of the other Afghan girls who attend the school at the Tehran shelter with her.

Discussions of their own economic value punctuate the schoolgirls' discussions in a disarmingly mundane manner from early in the documentary. In one scene, we hear an unnamed girl presumed to be around 15 years of age discussing the fact that she has had her bride price set at $\$ 3,000$, though her father is campaigning for more money, as 'prices have gone up' - particularly given that this man, aged ' 30 -35', has a first wife in Afghanistan. Later, an air of competition infuses the discussions as one reveals that she has had a price of $\$ 12,000$ agreed for her dowry. The girls agree this seems a good deal since 'at least they asked you first'. 'They beat me first, then I agreed', the girl responds. Sonita, meanwhile, seems immune to these machinations - until her mother arrives somewhat unexpectedly from Afghanistan, announcing that her brother is getting married - and, thus, Sonita needs to be married herself, so that they can collect the money from her bride price (pishkesh) in order to pay for the brother's own bride. $^{78}$ The starkly transactional nature of this arrangement is not lost on Sonita, who comments of her family's attitudes that 'they think finding a good husband is like finding a job'. For Sonita, though, the implications of this arrangement stretch beyond their immediate bearing on her choice of partner. As an undocumented 'illegal migrant', her return to Afghanistan will likely preclude any possibility of re-entry into Iran - and, with it, her schooling and her creative ambitions. At this moment of crisis, though, it is her creativity that she draws upon as a resistant strategy, using it not to overturn the terms of this economic transaction, but rather to appropriate the discourse of pishkesh onto her own terms.

If Audre Lorde once argued that 'the master's tools will never dismantle the master's house...[only] allow us temporarily to beat him at his own game', 79 Sonita shows herself able to operate both within and beyond the patriarchal structures of pishkesh in ways that present strategic, albeit temporary evasion of patriarchal authority. It is Sonita who, for instance, first plants the idea of resisting through this discourse, in both her teacher's and her director's minds, asking Ghaem Maghami, 'If any Afghan man can buy me, would you too?'. Later, she tries to make a deal with Ms Poori, her teacher: 'If you can find someone to buy me, give me the money, and I'll pay them back as soon as I make money from singing'. While Sonita's teacher is unable to offer her money, Ghaem Maghami does indeed eventually agree to pay $\$ 2,000$ to Sonita's mother, in return for a temporary six-month reprieve on her forced marriage. Ghaem Maghami assumes a complex position here - for her payment exposes the economic and cultural privilege that enables her, as non-refugee creative practitioner, to appropriate the discourse of pishkesh onto her own feminised terms. This move arguably operates as an elucidation - though not transcendence - of the 'triumphal 


\section{Feminisms in conflict}

rise of capitalism in the global arena', of its embeddedness in masculinised structures of the patriarchal family, and of the increasingly complex class and economic relations that differentiate gendered experiences within the transnational landscape. ${ }^{80}$ As Chandra Talpade Mohanty has written, the global capitalist landscape presents complex challenges for 'constructing feminist solidarities across national, racial, sexual and class divides' ${ }^{81}$ Pishkesh, while embedded in Afghan tradition, is nevertheless implicated in the global capitalist arena as a perceived necessity arising from impoverishment as a result of unequal global flows of capital and the exercise of imperialist oppression. Mohanty nevertheless locates the possibility of solidarities in 'mutuality, accountability, and the recognition of common interests as the basis for relationships among diverse communities', who 'have chosen to work and fight together', even though they may not share 'enforced commonality of oppression'. ${ }^{82}$ We find evidence of this kind of cross-positional solidarity in Ghaem Maghami's payment - for her willingness to work subversively within this patriarchal economic discourse is not without cost to her own directorial position. Ignoring her crew's warnings that 'you as a filmmaker should not interfere', Ghaem Maghami chooses to compromise her 'objectivity' as documentary maker, instead assuming the role of personal advocate and supporter. As she explains in interview, this decision is based on a commitment to justice that, for her, transcends the importance of her own positionality within the representational sphere:

I can't film people who are suffering for something I can afford, when they are giving their life, their story, to me [... Objectivity is] always a lie. You are never a fly on the wall. You are always an elephant in the room. You change everything with your presence. I don't believe objectivity is important, or even happens. Human stories are always subjective and personal. The film-maker decides, creates. ${ }^{83}$

Here, Ghaem Maghami articulates a vision of ethical creativity that echoes documentary-maker and scholar Bill Nichols' vision of a 'documentary ethics' as ultimately malleable. While, he writes, there is a necessary responsibility to both documentary subject and viewer, 'what should be done is a question to answer in the particular moment', constituting a 'situated ethical standard...rooted in the concrete contingencies of time and place'. ${ }^{84}$ Ghaem Maghami's ethical positionality can be read as rooted in a mode of feminist solidarity that works strategically within the given circumstances in which she and Sonita find themselves at a given moment in time. While questions continue to circulate around her actions within the film (might Sonita's family not be exploiting her? Are her actions based solely on her desire to ensure her film doesn't fall through?), this imperfect act of solidarity nevertheless exposes the complexly intersectional economic and social structures that seek to limit Sonita's creative ambitions. Indeed, the latent feminist potential of Ghaem Maghami's actions is in many ways affirmed by 
the deep counter-hegemonism that emerges from Sonita once she achieves the capacity to project her creative voice - albeit through a medium that presents a number of transcultural feminist contradictions in itself: rap.

As a musical form springing from racial disenfranchisement in the U.S. yet mobilised through channels of global capitalism and undergirded by heteronormative, sometimes misogynistic gender stereotype, rap (and the associated genre of hip-hop) presents an inherently conflicted medium for transcultural feminist expression. ${ }^{85}$ As a number of scholars have noted, however, 'hip-hop feminism' has nevertheless emerged as a vibrant manifestation of 'black and woman-of-colour' self-expression articulated in an increasingly transnational frame, where it has been characterised by a 'refus[al] of easy and essentialist stances about ... who or what gets to be called feminist' and an instance on 'living with contradictions, because failure to do so relegates feminism to an academic project that is not politically sustainable beyond the ivory tower'. ${ }^{86}$ As a creative medium, rap's feminist potential emerges directly from its ability to embrace transcultural, cross-positional conflict. It is therefore small wonder that it presents the ideal medium for Sonita - a young woman who also finds herself positioned at the difficult intersections of global and local power structures as a displaced Afghan woman.

Sonita's creative value as a rap artist emerges from the outset of the film and assumes a distinctively feminist political potential. To her family, Sonita's love of music seems at best a joke and at worst an illegal, even heretic act. (Public vocal performance requires a permit in Iran, and it is illegal for women to sing publicly other than at all-female events, while it is culturally taboo in Afghanistan. ${ }^{87}$ Yet to Sonita's peers, it presents a source of inspiration. The opening frames of the film show Sonita performing to a group of younger schoolgirls, who cheer and smile as Sonita raps lyrics that seem to articulate their collective female voice spoken to a wider society: 'you don't have hope, so how can you encourage me? My future is bright, don't worry about me'. Here, Sonita harnesses what Daphne A. Brooks has described as the potential for feminist 'surrogation' within hip-hop as a medium: its potential to function as 'an embodied cultural act that articulates ... palpable sociopolitical loss and grief as well as spirited dissent and dissonance'. ${ }^{88}$ Indeed, Sonita's ability to speak for and with her female peers acquires a poignant potency when we later witness an intimate performance she gives to her schoolfriend, which articulates her friend's anxieties around her own forced marriage. Her friend responds, with deep feeling: 'that's exactly what I'd like to tell my father'. In turn, Ghaem Maghami's own act of 'surrogation' - here, performed through her 'surrogate mothering' of Sonita - facilitates further possibilities of oppositional female voice. Offering her camera equipment, expertise, and contacts to Sonita, she enables her to make a low-budget music video for her most stridently feminist rap song, 'Brides for Sale', in which Sonita presents a sharp critique of the practice of child marriage and brideprice. Ghaem Maghami circulates the 
film online, and, thanks to Ghaem Maghami's own global connectedness, it goes viral and eventually gains the attention of the U.S.-based Strongheart Group, which offers Sonita a scholarship to the music programme at Wasatch Academy, an elite U.S. preparatory school. Sonita's voice undeniably performs complex and conflicted traversals of the transnational domain here. Though initiated by her own localised and self-directed articulation of female resistance, her passage to sanctuary emerges through globalised, digitised, and implicitly capitalist pathways. These eventually lead her to a site of cultural empowerment within the U.S.: that same broad locus of imperialist power play within which her voice risks, we sense, being read as an articulation of 'victimhood' in need of 'rescue'. ${ }^{89}$ Conflicted as this position may appear, however, Sonita's self-termed 'rap-tivism'90 arguably retains a stridently localised and self-possessed feminist potential for her displaced Afghan peers - which she achieves by maintaining a conscious control over the performative potentials embedded in her identity as a rapper in itself. Turning now to the discourse of visual performativity, it becomes possible to see how Sonita presents a constructivist and strategic engagement with female, Afghan, and refugee identities that resists ready co-optation.

In her 2003 work Regarding the Pain of Others, Susan Sontag explores the function of visual representation in mediating our response to the traumas of warfare. She writes:

Being a spectator of calamities taking place in another country is a quintessential modern experience [...] Awareness of the suffering that accumulates in a select number of wars happening elsewhere is something constructed. Principally in the form that is registered by cameras, it flares up, is shared by many people, and fades from view. ${ }^{91}$

This, it might be said, is the function that journalistic camerawork has played in the reporting of the Afghan conflict within the international media. Yet, asks Sontag, 'what does it mean to protest suffering, as distinct from acknowledging it?'92 Drawing on the example of Goya's print series The Disasters of War, Sontag argues that the capacity to protest suffering emerges through a more interrogative visual mode designed 'to awaken, shock, wound the viewer. ${ }^{93}$ In the music video for 'Brides for Sale', Sonita and Ghaem Maghami advance precisely this kind of 'assault on the sensibility of the viewer' through their own visual confrontation of pishkesh, presenting a radical alternative to the passive iconography of victimhood more usually projected onto Afghan refugee women. ${ }^{94}$

The performative nature of Sonita's 'rap-tivist' identity is placed centre stage from the outset of the 'Brides for Sale' video, which opens with Sonita's theatrical transformation by a professional make-up artist, alongside Sonita voicing the stage direction that 'my vision of life is totally gloomy'. Indeed, Sonita's dramatic performance of female identity within this film is a consciously hyperbolic and indeed symbolic one - for the make-up artist 


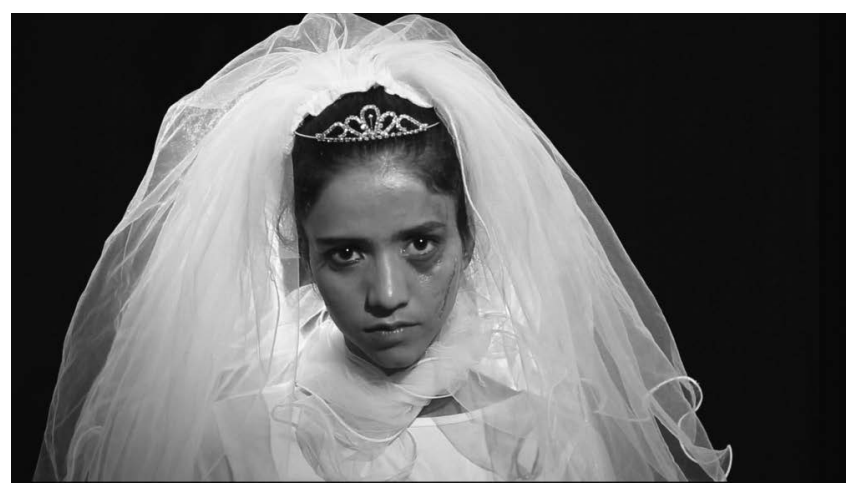

Figure 3.3 Still of Sonita in her video 'Brides for Sale', featured in Rokhsareh Ghaem Maghami, dir., Sonita (2016). Image courtesy of New Wave Films.

is applying not only eyeliner but a barcode to her forehead - a stark representation of her commodified status as 'bride for sale'.

Varied and dramatic in vocal tone, her lyrics also construct a theatrical relationship with the audience. Opening in a gently whispered voice, the listener/viewer is initially positioned in the role of subversive confidante: 'Softly I whisper my tale so no one hears/that I'm speaking about the selling of girls'. As her tone shifts to anger, however, it also increases in volume and assertiveness, and employs a lexis of rage against her entrapment within the confines of social expectation. Here, the audience assumes the role of witness:

I scream from a body exhausted in its cage

Broken by price tags that come with young age [...]

Like other girls, I'm caged and confined,

As a sheep grown on which others will dine.

Eventually progressing into a direct and increasingly desperate plea to the listener, constructed here in the role of oppressive parent, the lyrics retain a tone of subservient respectfulness ('no matter how you torture me, I will not embarrass you') that protests within, rather than against, the tradition of pishkesh. As such, Sonita projects herself as a deftly strategic and adaptable performer, capable of appealing to multiple positions of empathy and alliance through her lyrics.

Dramatic and consciously performative in style, the visual narrative accompanying Sonita's video forms a powerful intersecting narrative with the lyrics. Focussing initially on the barcode on her forehead, the camera soon pans back to reveal Sonita with bruises on her face. Through a series of jump cuts, her injuries gradually increase, until Sonita appears in bridal attire and, lifting the veil from her face, fresh cuts are revealed on her cheeks. In the denouement of the video, however, these visible wounds are 
replaced with thick and dramatic bridal make-up that she seeks to smear from her face: though she raps that 'no make-up can cover my bruised face', we sense that here the 'mask' of 'beautiful bride' is adopted as an indicator of abuse in itself. The video ends with her lowering her veil: an image no longer simply of subservience but also potentially of death. Hyperbolic in tone, Sonita's ghoulishly exaggerated performance of 'bride' in this video recalls something of Judith Butler's observations surrounding gender performativity - that it is in moments of 'de-formity, or a parodic repetition' of gender acts that 'the phantasmic effect of abiding identity as a politically tenuous construction' is exposed. ${ }^{95}$ This reading of performativity seems not, however, to account fully for the political positionality of Sonita's body as displaced. Here, Butler and Athena Athanasiou's more recent conceptualisation of 'political performativity' - a mode of performativity enacted through the body that does not simply reveal the constructed nature of gender identity but also presents a mode of counter-hegemonic and inherently politicised speech act in itself - seems to offer a more astute insight into the resistant qualities of Sonita's creativity. Speaking of work by the Greek performance artist Regina José Galindo but in observations that could equally apply to Sonita in 'Brides for Sale', Butler, in conversation with Athanasiou, writes:

None of these political concerns [the violent force of the state...violence against women] can remain abstractions in the course of her performance: her work shows how those forms of oppression are registered on and in the body, what they extract from the body [...] An attack on censorship, ... the work enacts the traces of memory in and through the body's movement ... [...] And though in these works the body suffers... and is constrained and overwhelmed by external force, the performing body also persists, survives, showing and enacting a social history. ${ }^{96}$

As both author and performer of her identity as 'bride for sale', Sonita powerfully registers pishkesh as a form of social and physical violence against women. Indeed, her performative act of 'calling out' the dehumanising commodification of women - evident in her prominent sporting of a barcode arguably enacts a double-edged act of retort to Western humanitarian discourses that may be tempted, in their own way, to commodify Sonita as 'poster girl' for Afghan women's oppression. Politically performative, then, Sonita transforms her suffering body from a site of victimisation into one that articulates a localised social history to a firmly transnational audience.

How, then, to characterise Sonita's and by extension Ghaem Maghami's transcultural feminist positionalities within this film, which operate subversively and strategically across sites of global capitalism and transnational disenfranchisement? Here, we might turn once more to Butler and Athanasiou's theory of political performativity and their connected conceptualisation of 'dispossession' as a resistant positionality. With a postcolonial 
consciousness of the multiple ways in which identity can be disavowed and individuals 'dispossessed' of their claims to place and belonging, Butler and Athanasiou recognise how refugees, 'sans papiers' and 'illegal' immigrants are in themselves 'dispossessed by capital', become 'increasingly disposable', and end up 'uncountable and unaccounted for'. ${ }^{97}$ And yet, as Athanasiou writes, such subjects are also 'individuated and subjectivated through subtler and reflexive biopolitical techniques of self-formation, selfcare, self-fashioning, and self-governance'98 - potentialities that emerge, for Butler and Athanasiou, through 'political performativity' itself. I would argue that Sonita's performative adoption of the commodified, vilified, and abused 'bride for sale' can be read in the light of this 'political performativity' of the 'dispossessed': the foundation of a creative alliance into which Ghaem Maghami enters, upon Sonita's own suggestion and direction. For far from operating as actress of a passive victimhood, Sonita's strident and self-authored performance of 'bride for sale' instead facilitates an opportunist and strategic negotiation of the transnational realm available to her precisely as a 'dispossessed' subject. Invisible to the Iranian state as an illegal migrant, she is without automatic identificatory agency, but also proves herself able to construct and rebuild her identity on terms that prove amenable to her. Sonita, in other words, takes possession of her own dispossession: a process that is perhaps incapsulated best in her revelation, early in the film, that her name, Sonita - which may or may not be that given to her by her parents - means 'migrant bird'. Her condition as refugee (woman-in-flight), and indeed her ability to take flight, therefore proves interdependent, resulting in what Butler and Athanasiou describe as the possibility of 'self-poietics' - a condition of liminality best described as an 'interval', in which 'self' 'does not refer to an autological and self-contained individuality, but rather to responsive dispositions [...] "owned" not only by ourselves...but by others as well', who produce us through our very interactions with one another. ${ }^{99}$ This is not to argue that Sonita's status as displaced Afghan woman presents a site of privilege or automatic agency, but rather that Sonita's own capacities for resilience and resistance enable her to locate those possibilities within, and in spite of, her position as multiply dispossessed by structures that are at once spatial, gendered, economic, cultural, and governmental.

Military conflict might initiate Sonita's passage across Afghanistan's borders, but Ghaem Maghami's documentary reveals the intersecting sociocultural conflicts that render the position of Afghan women so precarious within the landscape of displacement. These, she shows, create complex forms of cultural and ideological conflict around the task of imagining liberating feminist possibilities within the transnational landscape. Differentiated by structures of global and cultural capital, Sonita and Ghaem Maghami nevertheless formulate strategic solidarities that operate through rather than in defiance of these oppressive structures. Sonita's journey and the politics of cultural agency by which it is driven - therefore remains 
complex, conflicted, imperfect, sometimes deeply contradictory in transcultural feminist terms - most notably, in the granting of sanctuary to Sonita within the U.S. arena - a move that at once affirms it as locus of global privilege, yet also marks, perhaps, a redressing of an imbalance; a return of something owed to Sonita on her own terms. It remains notable, after all, that even following her move to the U.S., she continues to rap only in Farsi - an anti-assimilationist statement that can be read as a defence of her own creative autonomy and of the strategically negotiated hybridity she has constructed for herself. As evidence of a transcultural feminist positionality, then, Sonita projects a necessary embrace of contradiction and human imperfection as part of the messy work entailed in building creative solidarities within the deeply conflicted contemporary landscape of displacement. Yet as Chandra Talpade Mohanty also notes, 'global capitalism both destroys the possibilities [of alliances] and opens up new ones'; for 'economic and cultural globalization creates a context where material, economic and even psychic borders are porous'. ${ }^{100}$ Within this landscape, she concludes, 'our minds must be as ready to move as capital is, to trace its paths and to imagine alternative destinations'. ${ }^{101}$ Despite the powerful model of crossclass, South-South alliance presented by Ghaem Maghami's collaboration with Sonita, neither are able to escape implication within the transnational networks of global capitalism. Yet as women deeply capable of creative imagination, both show themselves capable of 'tracing its paths' in ways that ultimately lead Sonita to a position of powerful and transnationally resonant creative dissent - a journey that remains guided, above all, by the capacities of Sonita's imagination.

\section{Decolonising conflict through the transcultural feminist landscape}

Despite its enduring status as a site of intense gender disenfranchisement, Afghan women's displacement has not gained widespread visibility within cultural or indeed feminist circuits of the global North. Yet given the gravity of its scale, its continued impact on the lived realities of Afghan women's lives, and its ongoing production and maintenance though the power imbalances of the global capitalist and neo-colonial landscape, it proves a deeply significant context for transcultural feminist analysis - not least for the uncomfortable questions it raises about Western feminism's own implication in the imperialist militaristic project that generates displacement in itself, as well as the ongoing production of colonial paradigms through the creation of gender-focussed humanitarian programmes led and funded by the global North. ${ }^{102}$ Afghan women's displacement, then, renders visible the deep embeddedness of conflict in generating traumatic mobilities - while it also exposes the conflicts that may arise from cross-cultural feminist working practices in themselves. Given the deeply troubling implications that arise from these insights, how might it be possible to envisage alternative ways of working across sites of difference, division, and power imbalance? 
To locate these possibilities, we must allow our gaze to be led not by the politically enfranchised, State-sanctioned visions of feminists working in the global North - but by the alternative creative paths mapped out by the female Iranian film directors examined in this chapter.

As a mode of transcultural feminist intervention within the landscape of displacement, twenty-first-century, female-directed Iranian cinema presents us with a powerful counter-discourse to the limited gaze of the post-9/11 Western media upon Afghanistan's women. 'Unspectacular' but humane in their feminocentric, realist aesthetics, and willing to place their subjects' complex positionalities above their own directorial authority, Makhmalbaf and Ghaem Maghami's works are mobilised from a South-South perspective across localised, materially experienced borders. As such, they enact a number of the broader potentials that have been identified within South-South feminisms, as a radical alternative to the power imbalances of the North-South model. Not only do they elucidate the oft-ignored modes of border-crossing and cultural hospitality that emerge across borders of the global South, contesting the idea of a homogenised subalternity at stake within this region, but they also call attention to the unequal status of women maintained through North-South power relations, shored up by the enduring structures of colonialism and imbalance within the global capitalist landscape. ${ }^{103}$ Through their own cross-cultural gazes, they identify sites of shared experience as well as important positional differences. In doing so, they enable their protagonists to transcend their representational status as 'victim', instead presenting Nogreh and Sonita as situated social actants who are capable of traversing the landscape of conflict in strategic and performative manners. They thus advance what has been described as a 'decolonial feminist' stance that not only 'challenges the hegemony of "whitestream" feminism' but also urges 'attention to the particular material and social conditions of specific groups of women', ultimately arriving at a model of 'relational collectivity' rather than individualism. ${ }^{104}$ This position, though, is not an easy one - nor does it enable feminists to choose a position divorced entirely from the structures of the global North. For, as the very nature of Iranian cinema itself demonstrates, cultural expression inevitably circulates through the structures of global capitalism - as, indeed, do ideas, voices, and, in Sonita's case, individuals. How, then, to advance a decolonial feminist stance that recognises the transnational interconnectedness of women's mobilities, empowering and disenfranchised alike? It is possible to propose that this kind of politics must emerge out of a necessary engagement with the conflicted nature of transcultural feminism itself.

Writing of the possibility of a decolonial feminism, Rita Kaur Dhamoon notes three sources of inherent conflict that must be confronted and negotiated by those embroiled in this task:

...in responding to colonial manifestations of anti-racism, feminists must wrestle with [...] 1) the tension among feminists between the nation as a site of liberation or conversely as a site of oppression; 2) how 


\section{Feminisms in conflict}

to navigate differentials of power within various interconnected forms of heteropatriarchal and neoliberal racisms; and 3) the simultaneity of being a member of an oppressed group and being structurally implicated in Othering. ${ }^{105}$

Each of these three sites of conflict proves pertinent to the context of Afghan women's displacement, as reflected in Makhmablaf and Ghaem Maghami's films. In the complex malleability of their mobilities, both Nogreh and Sonita demonstrate the problematic nature of nationhood as an organising principle that underpins the 'transnational'. For Nogreh, her confinement within the boundaries of the nation offers no spatial security. Indeed, the fact that she cannot claim 'refugee' status as an internally displaced subject presents a source of nationally bound disenfranchisement rather than liberation. For Sonita, meanwhile, her 'illegal' passage into Iran does indeed offer her possibilities of emancipation - though ones that are also dictated by structures of patriarchy, governmental and familial alike. And while her passage to the U.S. is presented as a moment of 'liberation', it does not come without its own costs to her personal relationships and kinship structures. Within both of these films, meanwhile, we witness the enduring effects of 'neoliberal racisms' on Afghan women, exercised through the assumptions of subalternity and necessity of 'top-down' humanitarian intervention that pays little heed to the situational complexities they face, as shifting agents within the conflicted landscape. Both Noghreh and Sonita also experience intersecting heteropatriarchies, exercised through the inherent patriarchy of Western military imperialism, and of Afghan and Iranian governmental and familial structures. In the last of Dhamoon's points, though, we find both the directors and ourselves implicated. For Makhmalbaf and Ghaem Maghami, their status as Iranian women arguably situates them in a condition of what some might term 'oppression' - as women of the global South, living within structures of Islamic law. As women also in possession of international mobility and cultural agency, however, they possess forms of privilege that distinguish them from the displaced subjects of their films. And indeed, as transnational viewers of the films these directors have made, we too - as audience and as consumer - are structurally implicated within these intersectional cartographies of difference. Taken alongside one another, then, these films expose the enduring conflicts of positionality, and of politics, that must be confronted and negotiated in the necessary task of forging a transcultural feminist response to displacement.

As decolonial feminist practice, Iranian cinema offers the radical possibility of a re-turn of the political gaze that has been cast upon Afghan women. In seeking a way ahead from this point of intense military and feminist conflict at the outset of the twenty-first century, it strikes me that transcultural feminism must follow this gesture. And so - a way forward, by way of a return (of the gaze, of our steps) to the opening point of this chapter. 
It is the early years of the twenty-first century and a woman's eyes are fixed on the sky. There are no towers pluming smoke above her. But it is September 11th, 2001 - and she is looking up because she knows that this, too, is where the eyes of her colleagues, her friends, will also be directed, in silent if invisible union with her. And so she calls them. They exchange emails. And across their lines of difference, privilege, power, language, and capital, a shared vision emerges:

\section{Transnational Feminist Practices Against War}

October 2001. A Statement by Paola Bacchetta, Tina Campt, Inderpal Grewal, Caren Kaplan, Minoo Moallem, and Jennifer Terry.

We offer the following response to the events of September 11 and its aftermath [...]

As feminist theorists of transnational ... cultural formations, we believe that it is crucial to seek non-violent solutions to conflicts at every level of society, from the global, regional and national arenas to the ordinary locales of everyday life [...] Nationalist and international mobilization for war cannot go forward in our name or under the sign of 'concern for women'. In fact, terror ... is perpetrated under the sign of many different nations and agents [...] It is only through developing new strategies and approaches...that we can bring an end to the violence of the current moment. ${ }^{106}$

Feminisms, as transnationally situated phenomena, are implicated within 'the violence of the current moment' identified by this transnational feminist coalition. As effective transnational response mechanisms to women's forced migration, then, feminisms - whether political, creative, social, or operating at the intersection of these things - must not seek to render themselves innocent of or detached from this environment. Instead, they must recognise, operate within, and traverse its conflicted dimensions, through implicitly decolonial, demilitarised creativities and practices. In so doing, they articulate many sites of difference and division, but they also realise a site of shared aspiration that surely underpins every aspect of women's well-being, whether material or psychological, individual or collective: the ability to look to a sky devoid of terror, wherever they may be situated on the ground.

\section{Notes}

1 For further discussion of the 1951 Convention Relating to the Status of Refugees (the Geneva Convention), see Chapter 1 of this volume. Under its original terms, people displaced from and within Afghanistan would not in fact be eligible for refugee status as the Convention was initially limited to the protection of people fleeing before 1951 and within Europe. However, the 1967 Protocol lifts these temporal and geographical limitations. Nevertheless, it still does not extend to the protection of internally displaced people - who make up 
a significant proportion of Afghan forced migrants. It is therefore interesting to speculate as to how refugee law might be usefully extended in the future, in order to adapt to the shifting dimensions of international displacement and associated needs for protection. Indeed, it might even be suggested that the seismic impact of September 11th, 2001, on the international landscape represents a pertinent point at which to reassess the responsibilities of international protection agencies and States towards displaced persons - just as the events of the First World War initially prompted such a reassessment. For the full text of the Convention and Protocol, see 'Convention and Protocol Relating to the Status of Refugees', UNHCR, https://www.unhcr.org/uk/3b66c2aa10 (last accessed 4th June 2019).

2 As, indeed, they would prove to be. The ironically named 'Operation Enduring Freedom' was launched by the U.S. on 7th October 2001 with the backing of the U.K. This military operation, designed to drive the Taliban from power and dismantle al-Qaeda's base in Afghanistan, was carried out through airstrikes and on-the-ground combat. The end of the operation was officially announced in 2014 after numerous resurgences of violence, but instability remains - as does significant Taliban control across Afghanistan. See Alastair Finlan, Contemporary Military Strategy and the Global War on Terror: US and UK Armed Forces in Afghanistan and Iraq 2001-2012 (London: Bloomsbury Academic, 2014).

3 Elaheh Rostami-Povey, Afghan Women: Identity and Invasion (London: Zed Books, 2007), p.86. It is interesting to note that the Afghan women's organisation RAWA (Revolutionary Association of the Women of Afghanistan) has also set up schools in similar displaced communities in Pakistan. See Janelle Brown, “Fatima” Speaks: Resisting the Taliban', in Susan Hawthorne and Bronwyn Winter, eds., September 11, 2001: Feminist Perspectives (Melbourne: Spinifex Press, 2002), pp.70-75; p.73.

4 Many of these expressions of condemnation and solidarity with the U.S. are available in Hawthorne and Winter, September 11, 2001, which includes statements by the Revolutionary Association of the Women of Afghanistan, the Delhi Women's Petition, the Federation of Uganda Women, Women Living Under Muslim Laws, and the Afghan Women's Summit for Democracy. A truly transnational feminist alliance, then, united in its opposition to military intervention in Afghanistan.

5 See Grant Farr, 'Afghanistan: Displaced in a Devastated Country', in Marc Vincent and Birgitte Refslund Sorensen, eds., Caught between Borders: Response Strategies of the Internally Displaced (London and Sterling: Pluto Press, in association with the Norwegian Refugee Council, 2001), p.117. This view is expanded upon within the current chapter.

6 I engage with the political dimensions of these agendas within this chapter, but for an interesting insight into the discursive construction and convergence of agendas at stake in post-9/11 military campaigns, see Jack Holland, Selling the War on Terror (Abingdon: Routledge, 2013).

7 Note that I use the term 'displacement' throughout this chapter to describe both internal displacement and cross-border displacement due to their interconnectedness and out of a desire not to distinguish between the deeply felt need for sanctuary experienced by those who qualify as 'refugees' due to their movement across international borders, and those who remain within their own country but fail to qualify, though nevertheless lack sanctuary. I also avoid the term 'refugee' here as many of those who cross into Iran are considered 'illegal migrants'. The term 'displaced', however, refuses the governmentalized judgement that accompanies the notion of 'illegal migration'. 
8 See the Afghan Displacement Solutions Platform at https://adsp.ngo/ (last accessed 27th June 2019). For further on Afghanistan's conflicted transnational position, see Barnett R. Rubin, Afghanistan from the Cold War through the War on Terror (Oxford: Oxford University Press, 2015).

9 Hiram A. Ruiz, 'Afghanistan: Conflict and Displacement 1978 to 2001', Forced Migration Review 13 (2001), pp.8-13; p.8.

10 See Norwegian Refugee Council/Internal Displacement Monitoring Centre, Internal Displacement: Global Overview of Trends and Developments in 2009 - Afghanistan, 17th May 2010, https://www.refworld.org/cgi-bin/texis/ $\mathrm{vtx} / \mathrm{rwmain}$ ? page $=$ search $\&$ docid $=4 \mathrm{bf} 252560 \&$ skip $=0$ \&query=internal $\% 20$ displacement \%202001\&coi=AFG (last accessed 4th June 2019).

11 Judy A. Benjamin, Post-Taliban Afghanistan: Changed Prospects for Women? UN Coordinator's Office, Afghanistan (Rawalpindi: The Army Press, February 2002), p.8.

12 Sima Wali, 'Afghan Women: Recovering, Rebuilding', Ethics and International Affairs 16:2 (2002), pp.15-21; p.15.

13 Farr, 'Afghanistan: Displaced in a Devastated Country', p.117.

14 See Susanne Buckley-Zistel and Ulrike Krause, eds., Gender, Violence, Refugees (New York: Berghahn Books, 2017).

15 See Valentine Moghadam, 'Afghan Women and Transnational Feminism', The Middle East Women's Studies Review (Fall 2001), pp.1-7.

16 miriam cooke, 'Crusade! I Mean Democracy! You know: Women!', The Middle East Women's Studies Review (Fall-Winter 2002), pp.14-16; p.14.

17 Laura Bush, 'Radio Address by Mrs Bush,' The White House, 17th November 2001, http://www.whitehouse.gov/news/releases/2001/11/print/20011117. html (last accessed 4th January 2019).

18 Indeed, miriam cooke does so in her article, 'Saving Brown Women', Signs 28:1 (2002), pp.468-470; p.468.

19 See for instance Carol A. Stabile and Deepa Kumar, 'Unveiling Imperialism: Media, Gender and the War on Afghanistan', Media, Culture and Society 27:5 (2005), pp.765-783 and Zillah Eisenstein, Sexual Decoys: Gender, Race and War in Imperial Democracy (London: Zed Books, 2007).

20 These tensions - and ways of working beyond them - are explored in historical context by Moghadam in 'Afghan Women and Transnational Feminism'.

21 Ann Russo finds evidence of this in the U.S. Feminist Majority Foundation's campaign to stop 'gender apartheid' in Afghanistan, which simultaneously drew on and enforced the Bush administration's rhetoric and thus cemented 'U.S. imperialism and retaliatory violence as a method of maintaining U.S. power'. Ann Russo, 'The Feminist Foundation's Campaign to Stop Gender Apartheid: The Intersections of Feminism and Imperialism in the United States', International Feminist Journal of Politics 8:6 (2006), pp.557-580; p.558. For further on militarised (and indeed demilitarised) feminisms, see V. Spike Peterson and Anne Sisson Runyan, Global Gender Issues in the New Millennium, Third Edition (Philadelphia, PA: Westview Press, 2010), pp.176-180.

22 See, for instance, Samira Makhmbalbaf, dir., Blackboards (Iran/Italy: Makhmbalbaf Film House, 2000); Marzieh Meshkini, dir., Stray Dogs (Iran/ France: Makhmalbaf Productions, 2006).

23 Alain Brigand, dir., 11.09.01, September 11th, A Film (France: Studio Canal Plus and Galatee Films, 2002).

24 There have been many works charting this connection, but for an interesting text that explores the multiple social effects of war (including displacement and return - and thus presents an interesting inversion of the usual tendency 
in literature on forced migration to simply presume war as a key precondition, noted in passing), see Stephen C. Lubkemann, Culture in Chaos: An Anthropology of the Social Condition of War (Chicago, IL: University of Chicago Press, 2008).

25 Initially the product of the Islamic Revolution of 1979, Iranian cinema sought to make a radical break from the tropes, styles, and themes of European cinema, which was dismissed and even condemned as a technology epitomising debauched modernity. While it may have sprung from a conservative political environment, though, it has emerged as a medium that often seeks to critique rather than uphold the political position of the State. It often employs a distinctively 'poetic realist' style that focusses on the plight of humans within often hostile landscapes. See Khatereh Sheibani, Aesthetics, Modernity and Film after the Revolution (London: IB Tauris, 2011), p.5 and Shohini Chaudhuri and Howard Finn, 'The Open Image: Poetic Realism and the New Iranian Cinema', Screen 44:1 (spring: 2003), pp.38-57, for further on the distinctive characteristics of Iranian cinema. There are a number of Iranian cinematic works dealing with displacement, including Bahman Ghobadi, dir., A Time for Drunken Horses (Iran: Bahman Ghobadi Films, 2001) and Majid Majidi, dir., Baran (Iran: Mirimax Films, 2001). This preoccupation is unsurprising, given that Iran remains one of the largest host nations of Afghan refugees (alongside Pakistan) - a source of economic pressure on Iran, sometimes resulting in hostility towards Iranian refugees. See Elaneh Rostami-Povey, Afghan Women: Identity and Invasion (London: Zed Books, 2007), p.80.

26 Lindsey Moore also suggests postcolonial feminism as a useful critical lens through which to understand Iranian cinema. See Lindsey Moore, 'Women in a Widening Frame: (Cross-)Cultural Projection, Spectatorship, and Iranian Cinema', Camera Obscura 20:2(59) (2005), pp.1-33.

27 See several essays in Richard Tapper, ed., The New Iranian Cinema: Politics, Representation and Identity (London: IB Tauris, 2006), which all address attention to gender issues and the politics of female directorship.

28 The Makhmalbaf family present a distinctive phenomenon in Iranian cinema. Propelled by the film-making skills of father Mohsen Makhmalbaf, his wife Marziyeh Meshkiny, daughters Samira and Hana, and son Maysam all learned to make films through the 'Makhmalbaf Film House' established by their father. The family often works collaboratively. See Makbmalbaf Film House, https://www.makhmalbaf.com/?q=mfh (last accessed 25th June 2019).

29 Due to the family's shared surname, I henceforth refer to Samira Makhmalbaf as 'Samira' rather than 'Makhmalbaf' in my analysis of her film.

30 The film was invited to over 100 international film festivals and made the official selection in the 1998 Cannes Film Festival. See Zahra Kamalian, ed., The Apple (International Reviews and Screenplay), trans. Minou Moshiri (Tehran: Rowzaneh Kar, 2000).

31 See Lesley Farley and Alexis O'Hara, 'On the Road to Kandahar: Review', A Gathering of the Tribes, www.tribes.org (last accessed 11th April 2019).

32 A. Edemariam, 'The Film Bush Asked to See', The Guardian, 26th October 2001, p.10.

33 Samira's sister, Hana Makhmlabaf, documented the process of casting and making this film in her own documentary, The Joy of Madness (Iran/France: Makhmalbaf Film House, 2005).

34 Many, including Samira, contest the idea that the Taliban has 'fallen'. Samira speaks in interview of the many ways in which the Taliban continues to influence Afghan culture. See Geoffrey Macnab, 'A Women's Place', The Guardian, 19th May 2003, https://www.theguardian.com/film/2003/may/19/cannes 2003.cannesfilmfestival (last accessed 25th June 2019). 
35 Fernando Del Mundo, '2001 Global Refugee Statistics', UNHCR, 18th June 2002, https://www.unhcr.org/en-lk/news/latest/2002/6/3d0f6dcb5/2001global-refugee-statistics.html (last accessed 25th June 2019).

36 Del Mundo, '2001 Global Refugee Statistics'.

37 Saba Gul Khattak, 'Floating Upwards from History: Afghan Women's Experiences of Displacement', Development 45:1 (2002), pp.105-110; p.109.

38 See Paul Virilio, Speed and Politics, trans. Semiotext(e) and Mark Polizzotti (Los Angeles, CA: Semiotext(e), 2006), passim.

39 See Elisabeth Leake, 'Spooks, Tribes and Holy Men: The Central Intelligence Agency and the Soviet Invasion of Afghanistan', Journal of Contemporary History 51:3 (2018), pp.240-262.

40 Didier Bigo, 'Freedom and Speed in Enlarged Borderzones', in Vicki Squire, ed., The Contested Politics of Mobility: Borderzones and Irregularity (London: Routledge, 2011), pp.31-50; p.33.

41 Oliver, 'The Special Plight of Women Refugees', p.181. Famine has exacerbated this in some districts of Afghanistan in the early years of the twenty-first century. See F. Assefa, M.Z. Jabarkhil, P. Salama, and P Spiegel, 'Malnutrition and Mortality in Kohistan District, Afghanistan', JAMA 286:21 (2001), pp.2723-2728.

42 Wali, 'Afghan Women: Recovering, Rebuilding', p.15.

43 Federico García Lorca, trans. A.S. Kline, 'Lament for Ignacio Sanchez Mejias', http://www.artofeurope.com/lorca/ (last accessed 25th June 2019).

44 Khattak, 'Floating Upwards from History', p.106.

45 Lorca, a surrealist, leftist, homosexual, poet, and outspoken political critic, was murdered by Fascists shortly before the outbreak of the Spanish Civil War. Ian Gibson, Federico Garcia Lorca: A Life (London: Faber and Faber, 1989).

46 Carol A. Stabile and Deepa Kumar, 'Unveiling Imperialism: Media, Gender and the War on Afghanistan', Media, Culture and Society 27:5 (2005), pp.765-782; p.765. In the literary world, too, a plethora of life narratives which claim to 'pull Western eyes under the burqa' (Gillian Whitlock, 'The Skin of the Burqa: Recent Life Narratives from Afghanistan', Biography 28:1 (2005), pp.54-76; p.55) have emerged.

47 As Shohat notes, the veiled woman is a motif that figures in much Orientalist discourse, in which the sight/site of the female body beneath the veil signals a masculinist desire in which 'the process of exposing the female Other, of denuding her literally...came to allegorise the Western masculinist power of possession, that she, as a metaphor for her land, becomes available for Western penetration and knowledge'. Ella Shohat, 'Gender in Hollywood's Orient', Middle East Report (January-February 1990), pp.40-42; p.40.

48 See, for example, A. Mulvarine, 'Unveiled Threat: The Taliban Is Relentless in Its Oppression of Afghan Women', U.S. News and World Report 15th October (2001), pp.33-34 and M. Liu and A.T. Just, 'Now I See the Sunlight', Newsweek, 26th November (2001), p.46, which relates an account of women casting back their burqas following the arrival of the U.S. military.

49 A space determined by the presence of the woman's body, purdah is often cited as crucial to family pride and honour. It is designed to ensure modesty and limit contact with all men other than the husband or male kin. See Carol J. Riphenburg, 'Gender Relations and Development in a Weak State: The Rebuilding of Afghanistan', Central Asian Survey 22:2/3 (2003), pp.187-207; p.188; Lynne Brydon and Sylvia Chant, Women in the Third World: Gender Issues in Rural and Urban Areas (Aldershot: Edward Elgar Publishing Ltd., 1993), p.64.

50 Valentine Moghadam, 'Patriarchy, the Taliban, and Politics of Public Space in Afghanistan', Women's Studies International Forum 25:1 (2002), pp.19-31; p.22. 
51 Brydon and Chant, Women in the Third World, p.64.

52 Shirley Ardener, ed., Women and Space: Ground Rules and Social Maps (Oxford and Providence: Berg, 1993), p.13.

53 I am thinking of Laura Mulvey's visual theory of scophophilia here, transported into a transnational framework: Laura Mulvey, 'Visual Pleasure and Narrative Cinema', Screen 16:3 (1975), pp.6-18.

54 Trinh T. Minh-ha, When the Moon Waxes Red: Representation, Gender and Cultural Politics (London and New York: Routledge, 1991), p.4.

55 See Anne E. Brodsky, With All Our Strength: The Revolutionary Association of the Women of Afghanistan (London: Routledge, 2003), pp.17-18, 72-73, $82-83$.

56 Bulbeck discusses in some detail the varying uses and significances of the 'veil' in different cultural contexts. See Chilla Bulbeck, Re-Orienting Western Feminisms: Women's Diversity in a Postcolonial World (Cambridge: Cambridge University Press, 1998), p.187. See also Fatima Mernissi's seminal work, Beyond the Veil: Male-Female Dynamics in Modern Muslim Society (Bloomington: Indiana University Press, 1987).

57 See Wali, ‘Afghan Women: Recovering, Rebuilding', p.16 and Nahneed Gina Aaftaab, '(Re)Defining Public Spaces through Developmental Education for Afghan Women', in Ghazi-Walid Falah and Caroline Nagel, eds., Geographies of Muslim Women: Gender, Religion and Space (London: Guildford Press, 2005), pp.44-67; p.53.

58 Riphenburg, 'Gender Relations and Development', p.191.

59 Women were expelled from all forms of education and participation in public life under the Taliban. Yet following its 'fall', women's passage into the political sphere has remained fraught. See Riphenburg, 'Gender Relations and Development', p.190.

60 These stipulations are outlined further in Deborah Ellis's Women of the Afghan War (London: Praeger, 2000), p.63.

61 See Shirin S. Deylami, 'In the Face of the Machine: Westoxification, Cultural Globalization, and the Making of an Alternative Global Modernity', Polity 43:2 (2011), pp.242-263.

62 Chaudhuri and Finn, 'The Open Image', p.43.

63 Susan McWilliams, Travelling Back: Toward a Global Political Theory (Oxford: Oxford University Press, 2014), p.63.

64 For an interestingly positioned political reading of the body as 'situation', see Sonia Kruks, 'The Philosophy of Simone de Beauvoir: Ambiguity, Conversation, Resistance', Contemporary Political Theory 9:2 (2010), pp.256-258.

65 Chandra Talpade Mohanty, 'Introduction: Cartographies of Struggle: Third World Women and the Politics of Feminism', in Chandra Talpade Mohanty, Ann Russo, and Lourdes Torres, eds., Third World Women and the Politics of Feminism (Bloomington: Indiana University Press, 1991), pp.1-50.

66 Craig Martin, 'Turbulent Stillness: The Politics of Uncertainty and the Undocumented Migrant', in David Bissell and Gillian Fuller, eds., Stillness in a Mobile World (New York: Routledge, 2011), pp.192-208; p.194.

67 Peterson and Runyan, Global Gender Issues in the New Millennium, p.179.

68 Arundhati Roy, War Talk (Cambridge, MA: South End Press, 2003), p.112.

69 In 2014, Iran hosted 980,000 refugees, making it the fourth largest refugee hosting country in the world at that point. UNHCR, 'Operation: Islamic Republic of Iran, 2014 Year-End Report', UNHCR, 2014, http://reporting.unhcr. org/sites/default/files/pdfsummaries/GR2014-IslamicRepublicofIran-eng.pdf (last accessed 25th June 2019).

70 Ghaem Maghami discusses this dilemma further in interview: Zahra Dalilah, 'Filmmaker Rokhsareh Ghaem Maghami on Afghan Rapper Sonita: "I Just 
Wanted Her and Myself To Win”', Gal-Dem, 1st November 2016, http:/galdem.com/sonita-documentary-film/ (last accessed 25th June 2019).

71 Rokhsareh Ghaem Maghami, dir., Going up the Stairs (Iran/Netherlands: Women Make Movies, 2011).

72 New Wave Films, 'Sonita', New Wave Films, http://newwavefilms.co.uk/viewfilm-detail.html/?viewListing=MTU1\&cat=2 (last accessed 26th June 2019).

73 Eboni Boykin, 'Sundance 2016 Women Directors: Meet Rokhsareh Ghaemmaghami - "Sonita", Women and Hollywood, January 22nd 2016, http://womenandhollywood.com/sundance-2016-women-directors-meetrokhsareh-ghaemmaghami-sonita-cf42f1134948/ (last accessed 22nd May 2019).

74 Anita Raj, Charlemagne S. Gomez, and Jay G. Silverman, 'Multisectoral Afghan Perspectives on Girl Child Marriage: Foundations for Change Do Exist in Afghanistan', Violence against Women 20:2 (2014), pp.1489-1505; p.1490.

75 Amnesty International, Afghanistan: Women Human Rights Defenders Continue to Struggle for Women's Rights (2008), https://www.amnesty.org/ download/Documents/52000/asa110032008eng.pdf (last accessed 23rd May 2019).

76 UNIFEM (2008), cited in Raj et al., 'Multisectoral Afghan Perspectives on Girl Child Marriage', p.1490.

77 Strongheart Foundation, 'The Impact of Child Marriages: Refugees', Sonita.org, https://static1.squarespace.com/static/59b6f61cf14aa1d3e46429eb/t/5a0cf58 ae4966bbd235c6016/1510798730306/CM+Impact+Refugees+PDF_Nov_15. pdf (last accessed 23rd May 2019).

78 Research has exposed the widespread practice of brideprice as a generator of conflict within 'shatterbelts' (regions facing significant external culturalpolitical pressures) of the global South due to the pressures that it exerts on young men in particular. Inflations in brideprice have been linked to terrorist recruitment and political violence within contexts such as Nigeria. It is possible to sense a similar intensification of patrilineal pressure within the context of Afghan displacement. Valerie M. Hudson and Hilary Matfess, 'The Neglected Role of Brideprice in Catalyzing Instability and Violent Conflict', Military Review (January-February 2018), pp.34-47.

79 Audre Lorde, 'The Master's Tools Will Never Dismantle the Master's House', Sister Outsider: Essays and Speeches (Berkeley, CA: Crossing Press, 2007), pp.110-114; p.111.

80 Mohanty, Feminism without Borders, p.4.

81 Ibid., p.140.

82 Ibid., p.7.

83 Homa Khalili, 'Sonita's Director: Why I Paid \$2000 to Stop a Rapper Being Sold into a Forced Marriage', The Guardian, 24th October 2016, https:/www. theguardian.com/film/2016/oct/24/sonita-director-interview-rokhsarehghaem-maghami (last accessed 26th June 2019).

84 Bill Nichols, 'What to Do About Documentary Distortion? Toward a Code of Ethics', International Documentary Association, 30th April 2006, https:// www.documentary.org/feature/what-do-about-documentary-distortiontoward-code-ethics (last accessed 26th June 2019).

85 See Venise T. Berry, 'Feminine or Masculine: The Conflicting Nature of Female Images in Rap Music', in Susan Cook and Judy Tsou, eds., Cecilia Reclaimed: Feminist Perspectives on Gender and Music (Chicago, IL: The University of Illinois Press, 1994), pp.183-201.

86 Aisha Durham, Brittney C. Cooper, and Susana M. Morris, 'The Stage HipHop Feminisms Built: A New Directions Essay’, Signs 38:3 (2013), pp.721737; p.723. 
87 Wendy S. DeBano, 'Enveloping Music in Gender, Nation, and Islam: Women's Music Festivals in Post-Revolutionary Iran', Journal of Iranian Studies 38:3 (2005), pp.441-462. Interestingly, Sonita is not alone in her embrace of rap music as an Afghan woman: Sosan Firooz has been identified as Afghanistan's first female rapper, and indeed discusses displacement in some of her songs. See Torie Rose DeGhett, 'Afghanistan's First Female Rapper Tells the Stories That Might Otherwise be Lost', The Guardian, 2nd November 2012, https://www. theguardian.com/commentisfree/2012/nov/02/afghanistan-feamle-hip-hop (last accessed 26th June 2019).

88 Daphne A. Brooks, “All that you can't leave behind”: Black Female Soul Singing and the Politics of Surrogation in the Age of Catastrophe', Meridians: Feminism, Race, Transnationalism 8:1 (2008), pp.180-204; p.183.

89 There are hints of this positionality in Sonita's subsequent passage into U.S.based humanitarian advocacy, evidenced on her website, https://www.sonita. org/ (last accessed 26th June 2019). However, her more recent work suggests an enduring and direct critical engagement with Afghanistan, where her latest songs have been based and to whose political agendas her raps speak more directly.

90 See https://www.sonita.org/ (last accessed 26th June 2019).

91 Susan Sontag, Regarding the Pain of Others (London: Penguin, 2003), pp.16-17.

92 Ibid., p.36.

93 Ibid., p.40.

94 See Johnson, 'Click to Donate', p.1016.

95 Judith Butler, Gender Trouble: Feminism and the Subversion of Identity (London: Routledge, 1999), p.179.

96 Judith Butler and Athena Athanasiou, Dispossession: The Performative in the Political (Malden, MA: Polity Press, 2013), p.171-172.

97 Athanasiou, in conversation with Butler, in Butler and Athanasiou, Dispossession, p.29.

98 Ibid., p.29.

99 Ibid., pp.71-72.

100 Mohanty, Feminism without Borders, p.251; p.189.

101 Ibid., p.189.

102 For further on the colonial undertones of North-led and funded humanitarianisms, see Elena Fiddian-Qasmiyeh, 'Southern-led Responses to Displacement: Modes of South-South Cooperation?', in Elena Fiddian-Qasmiyeh and Patricia Daley, eds., Routledge Handbook of South-South Relations (London: Routledge, 2019), pp.239-256; p.242.

103 R. Baksh and W. Harcourt, 'Introduction: Rethinking Knowledge Power and Social Change', in R. Baksh and W. Harcourt, eds., The Oxford Handbook of Transnational Feminist Movements (Oxford: Oxford University Press, 2015), pp.1-47.

104 Oliver, 'The Special Plight of Women Refugees', p.178.

105 Rita Kaur Dhamoon, 'A Feminist Approach to Decolonizing Antiracism: Rethinking Transnationalism, Intersectionality, and Settler Colonialism', Feral Feminisms 4 (2015), pp.20-38; p.20.

106 Transnational Feminists, 'Transnational Feminist Practices Against War. October 2001. A Statement by Paola Bacchetta, Tina Campt, Inderpal Grewal, Caren Kaplan, Minoo Moallem, and Jennifer Terry', in Hawthorne and Winter, eds., September 11, 2001, pp.58-63; p.58. 


\section{Sounding out dissent Learning to listen to women in detention through sonic creativities}

It is Spring in the Bedfordshire countryside and something is moving. A line of people is beating a path through the fields in search of a discordant structure tucked deep amidst the crops of rapeseed. When they find it, they pause: the perimeter is too high to scale, but that is not what they are here to do. Instead, they turn their backs on the fences and beat the metal panels with the flats of their feet; rattle the struts in their hands. They pull drums, pots, pans, cowbells from their bags and beat and shake them until the air all about them is a vast dissonance of clanging, juddering, jangling, and crashing - a wall of noise rising high above the fences. And before long, hands begin to reply to their call. Windows open and arms wave homemade banners. Voices crackle through megaphones projecting phone calls from those inside the building: 'I never committed a crime, never did anything wrong. I need freedom, please'; 'I miss my son, I miss my husband. My son is nine years old... freedom'.

These voices do not bring the walls crumbling to the ground. But across the airwaves of these most verdant and secretively governmentalised of spaces, it is nevertheless possible to sense a distinctive movement at play one based, certainly, in a demand for social justice, but also in a complicated reciprocity produced through the process of voicing and listening: in the passage of sound as a dissident movement in itself.

This 2017 protest, led by the umbrella organiser Movement for Justice but displaying protest stances heavily weighted towards feminist and LGBTQ+ activisms, ${ }^{2}$ was one of many to be staged in the past decade outside Yarl's Wood: a predominantly female-populated U.K. 'Immigration Removal Centre' (IRC) for around 400 asylum seekers and immigrants facing deportation or awaiting confirmation of their immigration claims. ${ }^{3}$ In itself, this protest presents a powerful articulation of the grassroots opposition that has grown concurrently with the increased governmental popularity of immigration detention as a bio/necropolitical mechanism over the course of the twenty-first century. ${ }^{4}$ A significant strand of this opposition has proven feminocentric, sparked in outrage not simply at the traumatisation and radical dehumanisation of already-vulnerable people that this system engenders but also at the generally unrecognised structures of 


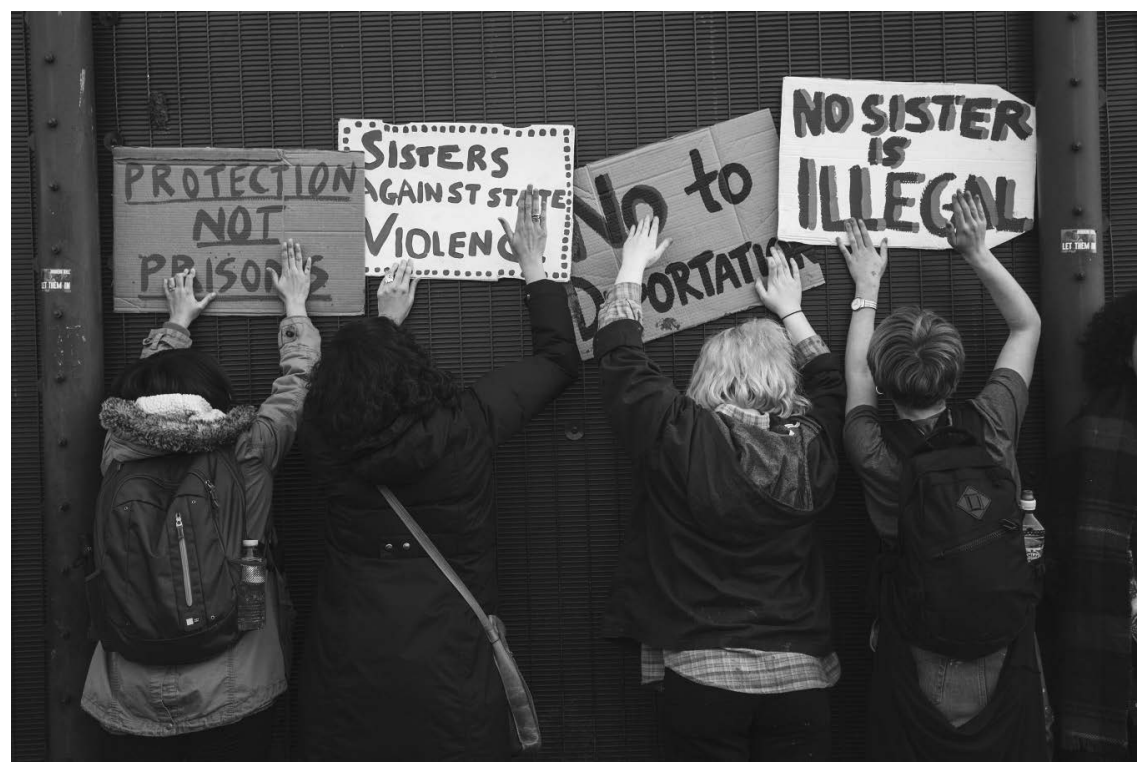

Figure 4.1 Protestors create a 'wall of sound' around Yarl's Wood, Bedfordshire. Photograph by and courtesy of Chris Bethell.

interlocking disenfranchisement that place women in especially precarious and painful positions within it. ${ }^{5}$ Gender-conscious reports produced in response to immigration detention systems in the U.S., Australia, and the U.K. have identified commonalities in gender-specific forms of trauma and oppression exercised against women - notably, lack of attentiveness to female health needs within a male-dominated system, a dearth of gender sensitivity in the supervision of women within mixed facilities, and the prevalence of sexual coercion, abuse, and violence towards women, including by guards - a phenomenon that women have little opportunity to report without fear of repercussion. ${ }^{6}$ These reports have all called for the necessity of dramatic changes within the system. More recently, U.S.-based lawmakers and activists have voiced public feminist outrage at the misogynistic tendencies evident in the strategic implementation of mother-and-child separation policies instated in the U.S., which have been widely interpreted as a deterrent targeted at the increasing numbers of women, many of them single mothers, seeking asylum from countries in South and Central America. ${ }^{7}$ Callous disregard for the physical and emotional trauma that detention may entail for women who are pregnant or who are victims of sexual violence has also proved a particular impetus for grassroots activism in the U.K. notably, the \#SetHerFree campaign led by the London-based organisation Women for Refugee Women. Launched in 2014 with a groundbreaking report into the gender violence and iniquities enacted against women in U.K. 
detention, ${ }^{8}$ the campaign galvanised collaboration among former female detainees, refugee women, and high-profile female politicians in order to effect policy changes that, in theory, ended the detention of survivors of sexual violence, placed a 72-hour cap on the detention of pregnant women, and banned the use of male staff to oversee women on suicide watch. As the organisation's most recent research shows, though, these policies remain inconsistently applied in practice. ${ }^{9}$ As a system that seems to perpetuate the abuse of women, then, immigration detention occupies a powerful presence within the transnational feminist imagination and surfaces as a site of urgent activist commitment.

Yet while the 2017 Yarl's Wood protest affirms feminist positionality as an essential and productive basis for anti-detention activisms, its distinctively sonic dynamics also alert us to the creative and contentious potentials of sound as the loci of feminist dissent. The particular structures of sound at play here call to mind Tom Western's assertion that, within the context of forced migrant landscapes and beyond, 'sounds have politics', constellating multiply as assertions of presence; as environmental, sensory feedback; as potential wellsprings of 'sonic agency'; and as sites of 'political ventriloquism' that enact their own silencing practices. ${ }^{10}$ When we relisten with this political consciousness, the 'wall of sound' instated around Yarl's Wood also comes to reverberate not simply with dissident potential but with the astonishing quietness of the detained women's own voices, mediated as they are through the disembodied technologies of the telephone, or presented silently through handwritten placards. Listening not simply to sound but to the structural politics of sound for detained women therefore invites us to turn our attention to the sonic architectures of inclusion and exclusion, voice and listening, and noise and silence that operate even through feminist acts of dissent and solidarity. These structural politics extend, inevitably, to acts of creative representation - particularly those that engage with sound. By turning to creative works in which the potentials of the sonic are mobilised with dissenting feminist intent, then, this chapter asks not simply what a feminist politics for detained women might look like but what it might sound like. In particular, it explores what happens when we seek to listen to detained women's own exterior and interior soundscapes - worlds that, as Salomé Voegelin argues, enable us to embrace 'sound's...formlessness' and to move beyond the 'surface[s] of a visual world'. ${ }^{11}$ It is here that we hear feminist potentials that do not simply beat against but reverberate beyond the biopolitical architectures of detention, ultimately enabling us to move connectively, sensitively, and invisibly via a sonic feminist politics.

Given the notoriously rigorous restraints placed on the movement of bodies, voices, and narratives within the detention system, ${ }^{12}$ from where might detained women's articulations of sonic sensibility, ripe for feminist reception, emerge? Not, it would seem, from the lips of the detained woman herself. ${ }^{13}$ As postcolonial scholars in particular have noted, the detained woman's relationship to discursive agency is peripheral at best, 


\section{Sounding out dissent}

and this has led her to be connected, in classically postcolonial feminist terms, with the Spivakian trope of the 'subaltern'. For David Farrier, for instance, the detained woman is 'doubly silenced' within the 'community of "aporia" in which multiple operations work against the production of asylum seeker voices ${ }^{14}$ - a situation that at once evokes Gayatri Chakravorty Spivak's formulation of 'the subaltern' as 'speechless' female subject of epistemic violence and Liisa Malkki's description of the refugee as 'a figure who is thought to "speak" to us...wordlessly', through their production as 'speechless emissaries' within dominant humanitarian narratives that leave no room for the refugee's self-representation beyond tropes useful for advocacy purposes. ${ }^{15}$ Detained women have sometimes articulated this lack of vocal agency in distressingly corporeal terms such as hunger strikes, lip-sewing, or 'naked protest', which render the body itself an actantial vessel of speech. ${ }^{16}$ As cultural agents, though, detained women have found limited avenues for self-expressive voice - as we shall see shortly.

This relative absence of detained women's voices from the realms of cultural representation has proven a matter of much complexity for creative practitioners who have also found themselves called, in different ways, to the detention system as a site of feminist concern. Interestingly, however, the difficulty of accessing detained women's voices has not led to a proliferation of fictionalised accounts. ${ }^{17}$ Instead, the extreme ethical sensitivity attached to the task of 'giving voice to the voiceless' has led to what might be described as a strikingly self-reflexive streak in work by non-detained women. In Ali Smith's 2018 novel Spring, for instance, the sparky and mythical Florence - daughter of a detained woman, who manages not just to enter but to effect change within an IRC through her exceptional rhetorical powers - responds to her new friend Brit's curiosity regarding her identity with the sharp retort that 'My mother told me, they'll want you to tell them your story... [D]on't. You are not anyone's story' [italics in original]. ${ }^{18}$ Florence's caginess perhaps reflects Smith's broader ethical consciousness around the dangers of rendering detainees or refugees emblematic of a sensationalised or dehumanised plight. In the delicately muted film Island of the Hungry Ghosts, meanwhile, the voices of female detainees in Australia's Christmas Island facility prove vocally accessible only via the recollections of their trauma and torture counsellor, and through staged therapy sessions with former detainees upon their release. ${ }^{19}$ The aporias within these narratives are instead articulated visually in the near-silent interludes of the film, which document the surreal site of thousands of red crabs that migrate to the island each year. The crabs' natural instincts are diligently guarded by the island's environmentalists, and thus present a phenomenon in cruel juxtaposition with the more hostile attitudes towards human migration indicated by the island's detention facility. Kay Adshead's 2008 play The Bogus Woman, meanwhile, engages creatively and self-consciously with the vocal compulsions and restrictions placed on detained women. The play enacts a critique not only of women's detention but of the narrative ability 
to 'speak on behalf of' such women. Drawing on documents relating to the trial of the 'Campsfield Nine', a group of protestors who were prosecuted for their role in the riots at Campsfield IRC in protest at the treatment of a Ghanaian detainee, the play melds multiple sources, stories, and voices into the central narrative of the protagonist, an unnamed African journalist forced to seek asylum in the U.K. on political grounds. While focussed on a single woman, however, the play demands that the central actress should perform multiple roles and must voice competing, sometimes contradictory characters. The result is a play that both 'bear[s] witness to the way the culture of disbelief surrounding asylum fetishizes the female body, ${ }^{20}$ and "constitutes a rejection of the "voicing" of refugee testimony common to much theatre of asylum', by instead 'focus[sing] on the performing body'. ${ }^{21}$ Thus operating at the cusp of a 'verbatim' theatre grounded in the desire to articulate 'truth' and a postmodern discourse acknowledging the limits of asylum as a discourse that 'privileg[es]...historical, rather than emotional, accuracy', 22 The Bogus Woman presents a powerfully dissenting critique of the creative strategies that claim to 'give voice' to an 'authentic' experience of the detained woman.

These creative engagements present delicately balanced and indeed vitally necessary portraits of the in/accessibility and in/stability of detained women's voices. It is the contention of this chapter, however, that the positional anxieties that circulate around 'authentic' sonic expressions by detained women have led to a lack of critical attention to the practice of listening as a site of limited, risky, unstable, and compromised but nevertheless feminist potentiality. This chapter therefore turns to two much more precariously positioned acts of sonic representation in which the voices of detained women are mobilised by non-detainee practitioners in order to ask how we may listen to such voices in creatively feminist ways. The first of these emerges via the 'sonic journeys' of Somali-born Australian refugee Hani Abdile, whose literary identity as writer and eventually performance poet was nurtured through the outreach project 'Writing Through Fences' during her interment on Christmas Island. While her vocal presence originates in what has now been widely critiqued as the problematic genre of the 'asylum anthology', I argue that applying a mode of reading founded in a politicised understanding of sound also constitutes a deeply dissenting and implicitly feminist challenge to the biopolitical structures of detention, including that of the governmentalised compulsion towards testimony. Reading in this way, then, we become able to 'hear' Hani's disquieting experience of detention in a way that connects us to it sonically, somatically, and politically, and imbues her with what LaBelle terms 'sonic agency'. 23 In the second section, I explore non-textual sonic expressions that emerge at the interstices of several creative practices: music in detention, participatory art, and sound and video installation. These forms are brought into dialogue through a collaborative project entitled Hear Her Singing, developed by artist Charwei Tsai with film-maker Tsering Tashi Gyalthang 
in collaboration with the organisations Women for Refugee Women and Bedford Music in Detention, based in the U.K. As a participatory process that placed women detained in Yarl's Wood in dialogue with the advocacy group Women for Refugee Women through the medium of music, this work invites us to consider the extent to which the process of music-making and its subsequent performance operates as a mode of sonic dissent targeted at the sociospatial, institutional, and indeed representational marginalisation of female asylum seekers' voices within the detention system. In spite of the spatial limitations that endured for detained women during this project, I argue that the processes of sonic expression and reciprocal listening enacted by the project indeed bring us closer to what Brandon LaBelle describes as a 'hearing that is the basis for an insurrectional activity, a coming community' [italics in original] ${ }^{24}$ : a community that, I suggest, resounds with transcultural feminist potentials.

Now, quiet your voice for a moment. Press your ear to the wall. Listen.

\section{Yes you: relearning to listen through Hani Abdile's sonic journeys}

When we place our ear to the walls of the Australian detention system, we encounter an unexpected sound: the sea. Implemented in 2001, the 'Pacific Solution' turned to the ecological architectures of Australian territory, notably its associated non-self-governing external isles and independently governing neighbours, in order to provide a 'solution' to the influx of refugees approaching Australia's shores by boat. ${ }^{25}$ During the second decade of the twenty-first century, Australia has enacted a 'deterritorialisation' of asylum through the establishment of detention centres in peripheral locations, including offshore on Christmas, Manus, and Nauru islands, which are located in the archipelagos of Papua New Guinea. The heavily governmentalised nature of this system is articulated starkly in the title of the 2013 Australian immigration policy, 'Operation Sovereign Borders'. The result of this system has been to contain Australia's refugees through its natural architectures of distance and separation - a move that also, as Mares notes, serves to limit communication between those offshore on remote islands and Australia's onshore concentration of advocates, legal advisors, media representatives, and interpreters, hence curbing representational agency for those in immigration detention. ${ }^{26}$ These limitations are compounded for women within the system. During a rare research-based interview with Yvette Zurek, detained women articulated a lack of access to female guards and dearth of cultural sensitivity towards women's biological and psychological needs as enduring issues. Women also reported exacerbation of trauma as a result of these conditions in which many were also detained with children. ${ }^{27}$ Distinctively isolationist in its formation, then, women face exceptional sonic challenges within the Australian system, their voices required to travel not simply across walls but also over waves in search of sanctuary and of agency. 
It is against this backdrop that the 'asylum anthology' has emerged as a literary genre of distinctive popularity in Australia. ${ }^{28}$ Writing of its potential as an advocacy method, Emma Cox notes that such anthologies are inevitably collaborative endeavours and thus can be understood as 'inextricably political collectivities', engaging simultaneously in 'political, cultural, social, educational and therapeutic work', and mobilising a polyphony of vocal positions within them. ${ }^{29}$ More recently, this cultural advocacy model has been extended via the Behind the Wire project: a multimedia oral history programme which has utilised podcast, installation, and performance methodologies in order to '[bring] a new perspective on mandatory detention [through] the reality of people who have lived it'. ${ }^{30}$ While the sonic features most prominently in the podcast and performance formats used within the project, it is to the more traditional model of the oral history anthology, They Cannot Take the Sky: Stories from Detention - which might also, within this context, be understood as a mode of collaborative life narrative ${ }^{31}$ - that I wish to turn in this instance. Unusually for such an anthology, a number of the voices contained within the anthology belong to detained women. ${ }^{32}$ Unlike many of the other Australian 'asylum anthologies', though, this collection refuses to homogenise structure, style, or topic across the narratives, and allows distinctive literary voices to circulate within the volume. It is the voice of one particular speaker/author within the anthology who presents a distinctively 'sonic sensibility' that, if listened to carefully, voices dissenting feminist potential. This is the voice of Somali-born, would-be journalist and eventual performance poet Hani Abdile, who found herself detained within the Christmas Island facilities upon arrival in Australia but whose literary voice has since risen to prominence through the writing outreach project, 'Writing Through Fences'.

Hani's contribution to They Cannot Take the Sky, entitled 'When I Become Famous I'll Give Tony Abbot a Job', is a collaboratively produced life narrative that follows the oral history model of production, whereby the author engages in verbal conversation with a scribe (in this case, Angelica Nevillea freelance writer, also trained in Forced Migration policy at the University of Oxford), then collaborates editorially on the resulting narrative. ${ }^{33}$ This production of the narrative through vocalised testimony may initially ring a number of alarm bells in postcolonial feminist terms. The oral history model has, after all, raised many questions for a literary critical audience suspicious of the 'unequal power relations'34 and 'entanglement of literary and legal technologies'35 entailed in its reliance upon the testimonial form. Indeed, in feminist terms, the use of oral testimony proves particularly problematic, given the sense in which the testimonial form mirrors the method through which a claim to asylum is made, 'heard', and judged within the asylum system: narrative terms that may prove particularly problematic for women. As Carol Bohmer and Amy Schuman have pointed out, capability of voice - the ability to narrate a claim to asylum that fits an accepted narrative - becomes the measure of an asylum seeker's claim to sanctuary 
within this system and those 'who cannot prove who they are, or who cannot convey the truth of their experience are rendered illegible in their own lives' ${ }^{36}$ This fallibility of voice may be something to which women are particularly susceptible: as Jane Freedman notes, it may be culturally unacceptable or indeed too psychologically traumatic for women to convey fully and in cross-culturally recognisable terms experiences such as rape or gender violence. These experiences may form the basis of an asylum claim founded in gender persecution - though at times, these experiences are also dismissed as forms of 'private', non-political suffering. ${ }^{37}$ Such difficulties in producing 'convincing' testimony may be further compounded through gender insensitivities such as leaving children in the room while women are testifying. ${ }^{38}$

In postcolonial terms, the compulsion towards the production of life narrative as a mode of validating and voicing subaltern experience has also been stridently problematised by scholars including Gillian Whitlock. Drawing on Sara Ahmed's understanding of 'economies of affect' and Liisa Malkki's critique of 'humanitarian testimony' as one of the modes through which refugees are produced as 'silent emissaries' serving a broader political agenda, Whitlock argues persuasively that testimony often circulates in self-circumscribed terms, whereby the claim to 'authentic access' borne by the testimony 'commands recognition and ethical response'. ${ }^{39}$ The effect of testimony is therefore the impression of vocal agency, performed within a structure that in fact limits the very terms in which it is possible to think of refugees as 'human' or 'grievable'. Indeed, from a postcolonial perspective, it is possible to draw parallels between the model of the refugee testimonial, generally facilitated and transcribed (as is the case in They Cannot Take the Sky) by authors other than the speaker themselves, and that of the eighteenth- and nineteenth-century slave narrative, in which the heavy hand of the amanuensis served to chisel the 'authentic voice' of the freed slave a figure of ethical compulsion for many at the time - into a tone and style both palatable and affective for its largely white abolitionist readership. ${ }^{40}$

These literary critical concerns certainly invite the reader to approach Hani's narrative with a level of astute circumspection. What happens, though, if we listen to Hani's narrative differently, pressing our ear to the wall instead with a sensibility inspired by the self-aware listening models that have been developed within transcultural feminist creative and academic practices? Here, 'deep listening' has emerged as 'an embodied and active standpoint for speaking and listening across difference ${ }^{41}$ that enables those positioned differently to 'defer their assumptions... and thus understand the positions of [others] with greater precision and compassion'. ${ }^{42}$ As Carol Gilligan, a pioneering 'listening practitioner', explains, the impetus for rethinking listening practices is founded in an act of feminist dissidence, as a means to challenge the dominant

psychological literature...[that] ha[s] a distinctive voice [that] [is] androcentric, reflecting a gender binary and hierarchy that privilege[s] 
autonomy over intimacy and relationships, reason over emotion, and actively discourage[s] research on women and girls as if human were synonymous with masculine. ${ }^{43}$

Thus, feminist listening practices seek to relisten in a way that 'join[s] reason with emotion and self with relationship ${ }^{44}$; that recognises the interdependency of intimate and wider social relations' through which voice and sound are produced ${ }^{45}$; and that ultimately embraces the "contrapuntality,46 inherent within a single narrative, thus facilitating an understanding of 'the tensions, the harmonies and dissonances between different voices... [and of] modulations and silences'. ${ }^{47}$ Listening deeply in this way renders audible Hani's own experience of the sonic. Through this sonic sensibility, we arrive at a deeply feeling and felt account of experiential memory that radically destabilises the biopolitical governmentalities through which her existence as detainee is contained. So, too, does it build structures of expression, solidarity, and empowerment distinctive to her own needs as a young, female, creative detainee - one whose world is shaped not simply by how it appears to others but by how it sounds to her. Ultimately, then, Hani's own sonic sensibilities enable her dissenting voice to be heard.

Hani's narrative foregrounds the sonic from the outset and charts her experience via vividly aural description of the shifting soundscapes that mark her passage through the immigration detention system. Initially housed in a 'big tent' where, as she puts it, 'Serco welcomed us really well', her arrival is marked by a technological facilitation of voice and invitation to connectivity: 'they gave us a phone so we could call our families. I called my sister'. 48 On the evening of her first night, she finds that all 45 of her fellow passengers from the boat that brought her to Christmas Island have been housed together in the same tent. Hani offers a powerful account of the aural terms in which their collective euphoria is voiced:

It was a very remarkable moment because all of us ... were together in that big tent. So we start singing, crazy stuff... and then we all started dancing. We ate food, it was so happy [...] Everyone was just shaking their heads and their bodies. Everyone was doing whatever they were capable of, because the night before we were on the boat, and we were just, you know, lying on the water.

(31, emphasis added)

Here, Hani offers a potent sonic portrait of what LaBelle terms the 'itinerancy' of sound: its constantly mobile capacities that mean we are 'always speaking after sound, running after it'; 'the bodies that rush by and that send vibrations across the floor, and that move like bundles of energy suddenly cut loose, surging and flowing around each other [reminding us that] sound is movement' (italics in original). ${ }^{49}$ Here, Hani as plural, communal, and moving subject articulates, sonically, a resilience and psychological 
agency beyond voice and narrative: a collectively experienced and mutually felt joy at living for which there are no words - but instead sounds and movements. Communal rather than feminocentric, we nevertheless sense transcultural feminist possibilities at stake in the nurturing, collective, and pseudo-familial structures of 'creative citizenship' described here: collectives that, as Tom Western explains, are forged sonically and socially in contravention of the governmental frameworks within which the sonorous subject finds themselves. ${ }^{50}$

It is not long, though, before architectures of division begin to emerge. The evening ends, Hani recalls, by Serco segregating men, women, and under-18s; two weeks later, she is sent for medical checks and transferred to 'Aqua', a more permanent residence compound. En route, she is processed through the immigration office, and it is here that Hani's experiences of listening become mediated through the biopolitics of detention. In her feminist analysis of the securitisation of borders, Kim Rygiel notes that mobility must be understood as implicitly embodied, constituted through a physical positionality that is 'interpelated into and produced through relations and hierarchies of power'. Consequently, she argues for a 'corporeality of mobility' that registers how bodily experience and feeling intersect with the technologies determining mobility. ${ }^{51}$ For Shoshana Felman, meanwhile, the 'speech act' must be recognised as a 'problematic production of the speaking body [that] destroys from its inception the dichotomy between the domain of the "mental" and the domain of the "physical". 52 When we listen for Hani's own experiences of listening (to others, and of being listened to) in these terms, we encounter a soundscape that operates at the cusp of these discourses, simultaneously invoking 'technologies of power' and prompting a 'corporeally' registered sonic experience in Hani. This is the soundscape that she experiences when she is processed through the immigration office, where she finds herself confronted by what can only be described as a wall of words:

So before they took us to the camp they took us to the immigration office ... So this lady came, she's got a miniskirt and a blue shirt, and she's got sunglasses. This lady looked really heartless. She looked as if she'd never smile even if you tickled her. [Laughs.]

Then she got a Somali interpreter, a Kurdish interpreter and a Tamil interpreter - she had all these interpreters beside her. The interpreters, it was like they were all in front of God and they were being judged. They were all looking down [...] And this lady just started reading all these laws [...]

She was just speaking for almost one hour. She was just speaking like a radio. It's like you turn it on, and you can never turn it off. You'd think that before she walked into the room she took out her heart and put it in a locker. Because she never smiled. She was like, 'Listen, you will never settle in Australia. Why did you come to this country? We 
don't need people...' And she was saying all these horrible things and everyone was crying. It was so bad - it was really, really heartbreaking.

Within this excerpt, the exclusionary architectures of the Australian asylum system are dramatised in spectacularly sonic terms. Mechanically inhuman ('she was speaking just like a radio'), unrelenting ('you can never turn it off'), and omnipotent ('the interpreters, it was like they were all in front of God and being judged'), this 'voice of the law' bars Hani's passage to safety with a single sonic command: 'listen, you will never settle in Australia' (emphasis added). Distinctively feminised ('this lady...she's got a miniskirt') yet devoid of humane connectivity ('you'd think ... she took her heart out'), Hani's account reveals, at one level, a violently Spivakian vision of silenced subalternity, enacted through both a command and refusal to listen on the part of the immigration officer: an aural enactment of the 'sovereign governmentalities' identified by Butler within structures of indefinite detention. ${ }^{53}$ Yet within Hani's narrative voice, we also sense the centrality she affords to sonic experience, as a means of giving shape to personally felt memory. Indeed, in delivering this scathing critique of the 'voice of the law' in such distinctively sonic terms, Hani's account also operates as an ironic inversion, even appropriation of testimony as a 'technology of control' - for here, she employs sonic detail in order to expose the corporeal, psychic, emotional, and narrative impact of this violently biopolitical voice through her capacities for sonic memory, thus exposing it for critique and assuming, in herself, the position of sonic witness, who now bears the capacity to renarrate the definitive version of her own 'hearing process. ${ }^{54}$

It is possible to hear in Hani's subversive sonic recounting of this episode an expression of what Tom Western terms 'refugee feedback': ways in which refugees proffer sonic responses to their systems and environments, constructing those spaces as 'a resonance chamber for protest, making audible the violence of borders and exclusionary citizenship regimes'. ${ }^{55}$ Thus, 'refugee feedback' also undermines and overturns the authoritative soundscapes or narratives attached to those spaces, and indeed, elsewhere within the narrative, Hani's own emphasis on listening also disrupts the assumptions of the humanitarian imagination. Here, we sense distinctively feminist underpinnings to her privileging of sonic connectivity and dialogue over governmental status within the detention system - for alliance, kindness, and assistance prove dependent on the degree to which people listen in Hani's narrative. As Hani explains:

At CC [Construction Camp, a low security detention facility] I met amazing [Serco] officers [...] Even though their job is to be grumpy, they have a heart. They are still in my life, and these are people I can call for advice. They listened. When you are sad and you find someone who listens, that means the world. 


\section{Sounding out dissent}

Transgressing the assumptions of the humanitarian imagination, Hani in fact finds support among the very staff responsible for enforcing the authoritarian system in which she is contained. The willingness of these officers simply to listen is deeply significant to Hani and transcends their governmentalised status in her imagination: an act of feminist hierarchisation, we might argue, in which the emotive, connective, and humane are privileged over structures of 'official' biopolitics.

In her critique of the testimonial model, Gillian Whitlock, following Shoshana Felman, suggests that 'testimony must become literary to engage the reader in the work of the belated witness [...] to make history available to imaginative acts'. ${ }^{56}$ Significantly, Hani's community of listeners also extends into the realms of the literary - through which she is ultimately encouraged to locate paths to voice that extend beyond the testimonial model, into the poetic and performative. These paths emerge via Janet Galbraith - an Australian-based poet who facilitates the 'Writing Through Fences' writers' group for people in Australian detention and who Hani describes as having 'changed my life into poetry' (36). Hani describes her interactions with Gilbraith only briefly within the narrative, revealing that Gilbraith contacted her after she posted a poem on Facebook and 'started sending me [writing] exercises' (36). If we listen attentively to the literary cues in Hani's narrative, though, we later learn that once released into community detention, she participates in 'performing poetry' (45), and an online search for epitextual clues reveals an extraordinary literary path has subsequently unfolded for her. Working via the 'Writing Through Fences' project, Hani has since established a reputation as a performance poet; published a first poetry anthology, I Will Rise; been appointed as an honorary fellow of PEN International; and become the lead facilitator for 'Writing Through Fences' in Sydney. ${ }^{57}$ Tracing her journey via these epitextual sources, Hani's literary voice emerges in richly sonic forms: as a new performer at the Bankstown Poetry Slam, where she intimates to the audience that 'the government didn't want to listen to me, but they listened to what I write'; as a well-rehearsed professional at the Queensland Poetry Festival, where she imagines, eyes closed, the voice of the ocean, asking if she is remembered by her. ${ }^{58}$ But it is within her own anthology that the dissenting potential of the sonic emerges most clearly. In the poem 'Listen', Hani constructs a confrontational conversational poem addressed in the second person to an imagined listener whose own voice is never heard. Interspersed with the refrain of 'Listen / Listen / Listen / Listen', the verses act as a strident retort to the suspicions of the asylum system, and indeed mirror the accusatory, one-directional speaking style that Hani recalls from her interview during processing in They Cannot Take the Sky: 'Who is calling me a terrorist?'; 'I give you truth but you give me lie talk'. ${ }^{59}$ Indeed, invoking a lexis of postcolonial and implicitly feminist justice-seeking, the poem demands a recognition of reciprocity in 
the non-refugee, perhaps even governmental listener as agent of a formerly colonial power regime:

Listen, it's not long ago, my name bore the mark of you

who divided us

ruled us

looted us

raped our girls and women. ${ }^{60}$

Here, then, Abdile turns the 'hearing process' of the asylum regime back upon itself and exposes the simultaneously racial and gendered injustices upon which its biopolitical structures are premised. Her voice, here, is not that of victim, nor of amanuensis; rather, in its performative transition to the realms of the literary, Hani finds her speech act capable of transcending the positional identity ascribed to her, within the asylum system and the textual circumstances of the 'asylum anthology'. Instead, her mobilisation of voice and call to listening recreates sound as a space of implicit reciprocity and responsibility between bodies and selves, thus creating what Brandon LaBelle has described as the creation of an 'emergent public' through the realms of the sonic:

From my perspective, sound operates in support of an emergent public by specifically bringing together bodies...that do not necessarily search for each other, forcing them into proximity, into a form of nearness. ${ }^{61}$

In Hani's dissident poetic command to 'Listen', then, she produces what can be understood, in LaBelle's terms, as an 'unruly public discourse' that "challenges the "master narrative" of the political demand in favour of lived struggles and shared desires', ${ }^{62}$ ultimately arriving at the assertion of 'sonic agency'.

When we listen in a manner attentive to the 'restless acoustics'63 of Hani's own sonic experience, then - to the music that moves her to joyous release; to the mechanical insensitivity of the official processing her asylum claim; to the feedback she offers on those who have helped by listening, and those who have not; to the modest gestures towards her own literary skills, signalled quietly within the text; to her voice of emerging confidence, growing on-stage beyond the pages of the anthology; and to her own poetry, we engage in acts of listening that take their call from Hani's own resistive voicing of what she hears and that emerge as dissident in their own right. Responsive to the shifting nature of sound - to the echoes and reverberations that never remain static - this mode of listening cannot be described as straightforwardly feminist in its positionality. It does not, after all, listen solely to the articulation of gendered experiences or relationships (though these are often implicit in the voicing of experience); nor does it 


\section{Sounding out dissent}

seek to reveal a straightforwardly gendered narrative founded in a stance of unequivocal feminist resistance. Instead, its dissident feminist potential is to be found in the nature of the listening practice itself: not simply in the foregrounding of a female voice, thus countering what Farrier describes as the psychosocial 'construction of the normative refugee as male', ${ }^{64}$ but also in the ethos undergirding the listening practice as one founded in a feminist commitment to 'deep listening'.

Restricted as Hani's narrative may be, then - by the physical architectures of detention, by the biopolitical technologies that produce her narrative as 'asylum-seeker', and indeed by the formalistic parameters of the 'asylum anthology' - it is nevertheless possible to catch dissident soundwaves reverberating through the air when we quiet our own critical voice for a moment and lean in closer, willing to provide Hani with what she needs: not another's mouth through which to shout but an ear open to listening deeply. Only then, she writes,

You will hear my voice.

That is my sound - flying like a bird. ${ }^{65}$

\section{Listening through walls: sonic feminist cosmopolitanism in Hear her Singing}

If Hani's voice can grow wings and soar across borders, it is telling that her flight path into the public realms of the internet and performance circuit emerges only following her release from the Australian detention system. How, though, might it be possible to hear the voices of those women currently interred within immigration detention? Within the rigorously policed confines of the U.K. immigration detention system of IRCs, which housed approximately 2000 women in $2019,{ }^{66}$ one creative strategy that has gained rare sanction is the use of music, as therapeutic and communicative gesture, delivered via the charity Music in Detention. ${ }^{67}$ Operating more usually as a charity that "works through music to give voice to immigration detainees and create channels of communication between them, immigration and detention staff, local communities and the wider public', ${ }^{68}$ Music in Detention assumed a distinctively feminist role during a project commissioned for National Refugee Week in 2017, when it acted as the creative intermediary through which artist Charwei Tsai was able to forge a collaborative project between members of Women for Refugee Women, one of the most prominent U.K. campaigning organisations for detained women and female detainees at Yarl's Wood, Britain's highest female-populated IRC. Working through the medium of song and with the assistance of sound recording technologies, Tsai's commissioned work entitled Hear Her Singing - not only enabled asylum-seeking and refugee women both within and outside of detention to hear, listen, and communicate with one another through song, but ultimately created spaces for their 
singing voices to be heard in the public domain through a video and sound installation at the Southbank Centre in London. While this project ostensibly sidestepped the vocal possibility of dissenting narrative through its turn to the medium of song (no doubt one of the reasons that music has proven a palatable medium to those who run the IRCs), it is my contention, however, that resistive feminist potentials nevertheless resonate from this work - not simply through its capacity to facilitate voice but through the more intrinsic connections borne by song to the physical body, to emotional existence, to transcultural communication, and indeed to sociopolitical structures of the city-space and of the wider cosmopolitan landscape - all of which enabled this project to subvert the biopolitical architectures of the detention system in the service of an alternative feminocentric musicality. By exploring these feminist potentialities of song, it also becomes possible to discern the necessarily transcultural or, as Salomé Voegelin has described it, 'sonic[ally] cosmopolitan ${ }^{69}$ underpinnings of feminist creativity articulated within the context of immigration detention. Indeed, it is in the sonic process of crossing between cultural practices and identities that affronts to the restrictive border architectures of detention emerge with the greatest force - formulating walls not as sites of containment but as sites of audible dissent in themselves.

How, then, might the singing voice present a feminist alternative to the biopolitical regime of the IRC? Within the context of the U.K. asylum system, the audibility of the body - its ability to 'speak' of its traumas - proves an increasingly significant aspect of the asylum claim. The collection of 'scientific' evidence such as the documentation of scars, DNA testing, and invasive examination for pregnancy or female genital mutilation means that, as Fassin and Halluin observe, 'the body has become the place of production of truth on the asylum seeker'. ${ }^{70}$ Faced with this invasive scrutiny of both body and voice, singing in fact emerges as an apt mode of counter-discourse - for, as Jean-Luc Nancy writes, the acts of producing and indeed hearing song constitute embodied experiences that operate through a 'sonorized body [that] undertakes a simultaneous listening to a "self" and to a "world" that are both in resonance'. ${ }^{71}$ Also operating as a mode of vocal expression that encourages emotional and expressive rather than narrative authenticity, singing can additionally be read as the antithesis of the biopolitical demands placed upon voice as a mode of testimony within the asylum process, while allowing the singer to nevertheless express how the world 'feels' to them, affirming their place within it. The therapeutic potentials of singing as embodied and expressive practice have been embraced with a particular force by feminist music therapists, who, as Sandra Curtis writes, often employ music therapy within contexts where women have experienced physical violence. Here, the underlying feminist principles - that 'the personal is political', that 'interpersonal relationships are to be egalitarian', and that 'women's perspectives are to be valued ${ }^{72}-$ present modes of embodied interaction in stark contrast to a normalised 


\section{Sounding out dissent}

societal environment in which 'women are violently reduced to bodies... for men as seen in the widespread objectification of women...[which] can then be violated'. ${ }^{73}$ These observations resonate deeply with women within the detention system - a majority of whom, according to the research conducted by Women for Refugee Women, have experienced rape or torture prior to entering the system, and many of whom continue to experience sexist or racist abuse, sexual harassment, or sexual exploitation while within U.K. immigration detention. ${ }^{74}$ Thus, as an embodied expressive mode that places women's well-being and value at the very core of its practice, singing presents a radically dissenting feminist counter-discourse to the biopolitical abuses of embodied voice within the detention system.

If feminist principles underpin singing as a woman-focussed therapeutic practice, however, then equally important is the radically transcultural ethos that drove Hear Her Singing as a project. Commissioned by Hayward Gallery curator Stephanie Rosenthal, the project sprang from Rosenthal's desire to engage people who are not usually able to visit the Southbank Centre. ${ }^{75}$ Asylum seekers in detention emerged as a group of particular pertinence within this context, due to the fact that the Southbank Centre operates as host for the cultural outreach programme for Women for Refugee Women, some of whose members are former detainees, and who continue to advocate for reforms to the detention system. As a project, then, Hear Her Singing sought not only to counter the exclusionary architectures of cultural privilege within the structures of the metropolis but to challenge the range of those voices rendered immobile through the detention system, enabling them to be heard in usually inaccessible loci.

Principles of transcultural communication also prove pivotal to the way in which the project was formulated by the commissioned artist, Charwei Tsai. Tsai, an artist of Taiwanese heritage who currently lives between Taipei and Paris, bears an ongoing interest in socially engaged art that draws on a diverse range of spiritual beliefs and knowledge forms, which she mobilises through varied multimedia practices - ranging from film-making to sculpture to performance. ${ }^{76}$ An interest in displacement and migration underpins a significant strand of her work. Married to the Tibetan filmmaker Tsering Tashi Gyalthang, who himself grew up among the exilic Tibetan community in Dharamsala, India, Tsai has also collated issues of her curatorial journal, Lovely Daze, on issues of 'displacement, inequality and environmental devastation, ${ }^{77}$ while an awareness of mobile identity has informed works throughout her career - including the 2009 photographic series, Étrangère, and her 2018 video work, Songs of Khaosiung Migrant Workers. ${ }^{78}$ In Hear Her Singing, Tsai draws upon the insights she gained into singing as a form of spiritual practice during her travels to Nepal, where she met a Tibetan yogi, who, she explains in interview, 'is known for teaching through spontaneously singing his songs of spiritual realization'. This led her to consider 'the spiritual connections people make through singing', which in turn formed the basis of her 2017 artistic work 
Songs of Chuchepati - a work that captured survivors of the 2017 earthquake in Nepal 'singing songs that expressed their current state of mind'. ${ }^{79}$ The act of singing, then, is employed within her work as an artistic strategy designed to be at once individually therapeutic, spiritually eviscerating, and culturally connective - for, as we shall see, the bridging of cultural differences and incitement to cross-border community was integral to the project's formation.

In The Political Possibility of Sound, Salomé Voegelin has written of what she terms 'sonic cosmopolitanism': sonic practices that embrace a 'political, institutional and ethical focus on global inter-connectedness', and which thus work towards finding 'common structures, universal values and practices.... and potential solutions to global problems such as migration, war, climate change.... ${ }^{80}$ Crucially, however, sonic cosmopolitanism 'does not practice a multiculturalism that is the adaption of plurality into one, hearing voice, but the meeting of plural voices in an invisible, fleeting and uneven volume'. ${ }^{81}$ It is instead, as Voegelin writes,

.... about the amplification of the unheard, the invisible and the incoherent, not through the referent that calls it but from the concrete sound of its own voice. A sonic cosmopolitanism is not a speaking for but a hearing of. It practices a listening out not for the signifiers and the references of the other, whose meaning will inevitably be read within the criteria of the self but focuses on our meeting in the viscous expanse of sound where we are indivisibly together and negotiate what makes us both contingently. ${ }^{82}$

Thus, sonic cosmopolitanism resists the principle of ventriloquism and seeks equitable, responsive, and respectful transcultural listening practices in which the voice of the usually unheard speaker/singer is foregrounded. Hear Her Singing displays many of these principles of a sonic cosmopolitanism through its emphasis on both vocal interaction and responsive listening, which were embedded in the first two stages of the project whereby women in Yarl's Wood and members of Women for Refugee Women communicated via song, in spite of the exclusionary biopolitical structures of the detention system.

At its initial stage, women detained within Yarl's Wood were offered vocal workshops via the charity Music in Detention, during which they were encouraged to explore the voicing of songs from their homeland, or that reflected how they felt. Here, workshops followed the established 'music in detention' format of employing participatory music-making as an outlet for mental distress and trauma. ${ }^{83}$ The songs the women selected emerged from many different contexts: some proved to be folk songs, recited, perhaps, with a nostalgia for home; others, hymns in which calls for salvation bear a poignant resonance, or stream-of-consciousness songs projecting thoughts, crooned as though to oneself. An inherent cosmopolitanism 


\section{Sounding out dissent}

characterises these songs, drawn as they are from what Tsai describes as the surprisingly diverse range of geographical contexts represented by the women: 'Russia, Poland, Kyrgystan, India, Sri Lanka, China, Vietnam, Indonesia, Philippines, Algeria, Namibia, Botswana, Uganda, Eritrea, Jamaica, Trinidad. ${ }^{84}$ Indeed, memories of place and vivid mental landscapes inform a number of the songs. In one, an unnamed woman sings, to a slow, minor tune loaded with melancholy and nostalgia, of 'When Alatoo mountains are wearing their white hats...When the tops of the mountains reach the sky where the white birds fly' - a song that seems to evoke memories of Kazakhstan. ${ }^{85}$ Functioning 'beyond song' as forms of 'ritual' that invite participants to connect with cultures and memories from which they 'may have been torn', these pieces of music bear symbolic potentials that exceed the straightforward realms of narrativised dissent, and instead express more innate aspects of selfhood such as 'current life, past, future, experiences, fears or fantasies' ${ }^{86}$ The transcultural feminist potential of these singing practices lies in the fact that the context to the songs remains unglossed within the project, the private genesis of each musical process remaining unexplained - something that, as Nancy suggests, positions music 'always ... on the edge of meaning', inciting ' $[\mathrm{a}]$ concern, a curiosity or an anxiety' in the listener. ${ }^{87}$ Thus, the singing body retains its own sonic agency within this musical practice. Unyielding to finite 'meaning' or explanation, it resists the coherence and capability of voice demanded of women within the asylum process. Indeed, in its deeply felt and ultimately intimate performance, singing enacts the 'amplification...of the unheard, invisible and incoherent' described by Voegelin. In a further anonymous recording from Yarl's Wood, for instance, we encounter what seems to be a stream-of-consciousness sharing of one detained woman's mental state. Singing reflectively and without strict tempo in her mother tongue (subtitled in English on screen), she shares with us her feelings that 'I can feel, I can feel... Is this a new life? My heart feels the morning dew... Yesterday, I didn't see the good in this world... But how come I see it today?' Within this piece, it is in the intimacy of the faltering notes, the markers of a wavering but determined body rising to a challenge that the call to empathic listening emerges, affirming a feminism founded in a supportiveness of 'amateurism' that replaces the emphasis on narrative quality and unsympathetic scrutiny embedded within the asylum system. The closeness incited by these rawly intimate - if anonymous - performances is not simply between the singer and the listener, however. As Nancy writes, 'the listening body ... listens to itself becoming distressed and rejoicing, it enjoys and is distressed at this very listening where the distant resounds in the closest'. ${ }^{88}$ Thus, this work ultimately affirms the detained woman's own embodied voice as a site capable of inciting a 'deep listening' of which she is in control and possession. 
Hear Her Singing further enacts its sonic cosmopolitanism through its emphasis on vocal communication established in spite of physical distance and architectural containment, thus facilitating the principle of a 'meeting of plural voices' that is indeed, as Voegelin writes, 'not a speaking for but a hearing of'. In the second stage of the project, audio recordings of the detained women's voices were played to members of Women for Refugee Women, who were invited, in turn, to record songs and audio messages that would then be played back to the women in Yarl's Wood. Women drew on a surprisingly wide variety of musical genres in these pieces: in one particularly striking piece, a participant speaks rather than sings the lyrics to the 2011 dance hit, 'Titanium'. Delivered in a strikingly matter-of-fact manner, the words 'you shoot me down / but I get up / I'm bulletproof / nothing to lose / I am titanium' acquire a tone of quotidian defiance: an incontrovertible statement of resilience to an asylum system likened here to a violent assailant. As a further dialogic development within the project, some of the songs recorded by women in Yarl's Wood were also used as the basis of choral ensemble pieces performed by Women for Refugee Women as a collectivity: a Namibian song performed by 'Louise' in Yarl's Wood, for example, forms the basis of the harmonised chorus subsequently developed by the group working at the Southbank Centre. While taking place across vast physical distance, this communicative and spontaneous process of musical exchange echoes communal 'call and response' modes of song that characterise group singing practices particularly within informal settings, and indeed within contexts of protest and resistance. ${ }^{89}$ Thus, we sense a sonic feminist resistance at stake within the project's cosmopolitan structures.

While inciting a cosmopolitan connectivity, though, what also resonates across these recordings is the disparity between the physically present body of the Women For Refugee Women performers and the vocal anonymity of

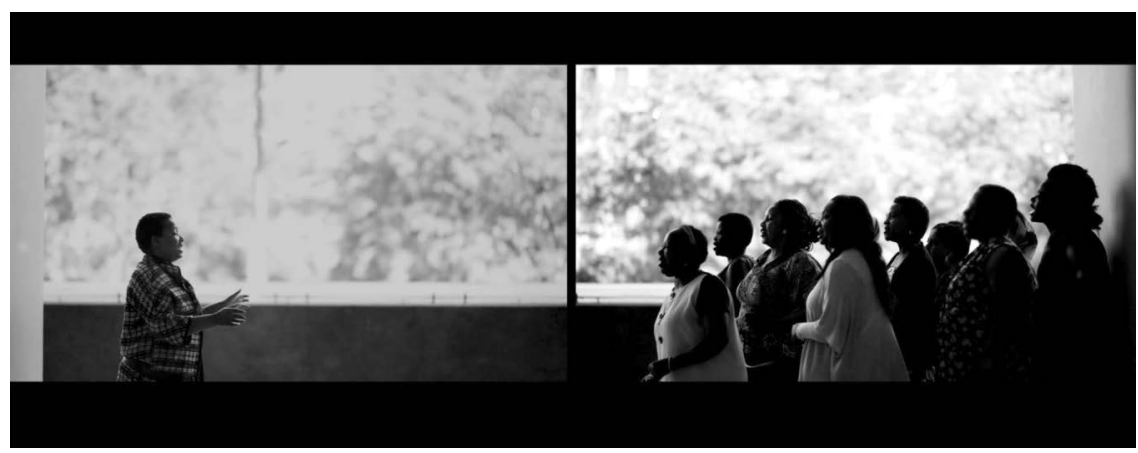

Figure 4.2 Still from Hear Her Singing, Charwei Tsai, 2017. Image courtesy of the artist. 
her absent singing partner-in-detention. The juxtaposition of these recordings therefore foregrounds not just connectivity but disparity, enabling us to hear, as Voegelin would have it,

the in-between ... the asymmetries of the world: what voices are heard, what accents dominate its landscape, what interests are represented in its soundscape and what in turn remains inaudible, unable to make itself count, silenced, muted even and ignored..$^{90}$

While any hint of narrative dissent is therefore carefully locked out of women's voices within this work, its potential nevertheless resonates in the distances between women within the architectural and cultural structures of immigration detention, which present an implicit critique of the restrictions enforced upon this divided chorus.

The final installation of Hear Her Singing within the city-space itself also resonates with an inherent 'sonic cosmopolitanism'. By projecting films onto interior and exterior spaces of the Southbank Centre in central London, the project externalised the voices of the women within Yarl's Wood, radically transporting their audibility from their secretive rural location to the very heart of the urban metropolis - a postcolonially sonic shift, if you like, from margins to centre. This transferal of voice from the site of political disenfranchisement to extreme cultural capital can be read as strategically confrontational: the audience for these women's voices may sometimes be unwitting, encountered by those who have not already selected a position of solidarity. For them, the invitation to stop and listen is optional, but it has the potential to produce what Liisa Malkki has described, more usually in the context of asylum-seeking, as an 'accidental community' forged from 'accidents of life and hazards of history', which nevertheless presents the possibility of coalition within 'momentary, out-of-the-ordinary periods of shared history' ${ }^{\prime 1}$ - a description that seems particularly apt within the context of the post-Brexit 'hostile environment' of 2017, when the piece was made. Here, the possibility of joining that 'accidental community' is created through the invitation to listen - and in so doing, to encounter an unfamiliar voice, without the authority of reply - an inversion of the aural power dynamics within the asylum 'hearing process'. Indeed, this inversion of the detention system can also be read within the spatial dynamics of its installation. Projected onto walls more usually employed to contain, silence, and conceal women within them, we encounter a reversal of power dynamics at stake here, the detained woman's own vocal agency rendered audible and visible, her voice in command of sonic capacities far beyond the sounds demanded of her by the asylum system. In this invitation to sonic interaction, indeed in its very call to Hear Her Singing, the installation thus arguably instates what Voegelin describes as 'sound's focus on the in-between [which] destroys the logic of partition... [and] articulates an imagination of indivisibility... question[ing] the logic of separation..$^{92}$ By 
rendering the singing voice of detained women audible, and by inciting an implicit conversation between detained voices and those usually unable or unwilling to hear them, then, Hear Her Singing ultimately gestures towards a world in which walls invite conversation, even transgression.

Gentle as the acoustic qualities of Hear Her Singing may be, they also speak - or rather, sing - of the dissenting transcultural feminist potentialities of the sonic. In this project's engagement with song as embodied and highly emotive mode of expression, it shifts beyond the narrative demands of the asylum system, thus resisting the inherently androcentric and patriarchal logic of biopolitics upon which the detention system rests. Turning instead to forms of bodily and emotional recognition founded in an egalitarian respect for human individuality, the project emphasises female body and female subjectivity over the detained woman's legal status. The transcultural also proves integral to the value of this project. Drawing on cross-cultural models of cultural understanding and nurturing an inherent cosmopolitanism in its sonic practices, Hear Her Singing resists the overarching logic of biopolitically enforced boundaries embodied in the structures of the nation state. Yet this work proves far from utopian. For what remains audible above all is the abiding absence of name or face for those who, though singing, can only be present through projection. Encapsulated within the sonic politics of Hear Her Singing, then, is a deep melancholia that invites us, as Voegelin puts it, to 'hear the fragile within the circumstances of the possible', and indeed to 'hear with a care for... the unheard'. 93 The sonic politics of Hear Her Singing therefore remind us that much as we might like to assert our solidarity by listening through walls, there remain divisions between speaker and listener that cannot be bridged easily or completely. In its sonic feminist cosmopolitanism, Tsai's work therefore renders audible the connective human capacity for creativity, certainly - but it also testifies to the enduring disparities between women within and beyond the brutally biopolitical structures of the U.K.'s immigration detention system.

\section{Playing it by ear: in praise of feminist dissonance}

In the twenty-first century, the immigration detention system resonates as perhaps the most explicitly biopolitical manifestation of the contemporary sovereign state's desire to control what it considers to be erroneous bodies - including those of women who cross boundaries without the explicit sanction of the law. ${ }^{94}$ Seemingly gender-blind in its architectures of containment and exclusion, it in fact upholds implicitly androcentric understandings of mobility that serve to marginalise and disadvantage women, perpetuating an endless cycle of violence, fear, and abuse analogous to that which has already characterised and indeed possibly even initiated their journeys. Despite the voices of protest that often rise around its exterior walls, forced migrant women's detention remains a highly secretive and 


\section{Sounding out dissent}

under-scrutinised phenomenon, subject as it is not only to the limitations of governmental authority but to the privileges afforded the private companies that run many IRCs. It is in the face of these structures that the sonic emerges as a medium of vitally dissident potential. It proves capable not simply of transcending (some, by no means all) physical barriers to communication but, in its feminist enactment, of inciting a mode of communication radically opposed to that of the biopolitical regime. This is a mode of communication that values individual experience, that refuses to privilege 'reliability' as the basis of valid voice, that actively draws women's voices to the fore, that respects the simultaneous value of physical and emotional experience, and that pushes towards a practice of 'deep listening' rather than superficial hearing. Like the voices of detained women more broadly, the sonic also represents a realm that is generally passed over in favour of emphasis on the physical or visual - yet as an experiential mode, it presents a deeply connective source of transcultural insight, capable as it proves of transcending the barriers of language and indeed cultural codification. As Brandon LaBelle concludes, the sonic therefore presents us with nothing short of

...an ethics for the transnational present by aligning us with ... epistemologies and ontologies, emotionalities and imaginaries drawn from sounded experience and audition. ${ }^{95}$

Sound, it would seem, enables us to transcend the boundaries not simply of physical architectures but also of knowledge systems, drawing us into a space in which it is possible to hear powerful articulations of dissent.

Yet a transcultural feminist approach to sonic politics must not simply posit the utopian potentials of sound. As we have seen from the works scrutinsed within this chapter, a feminist approach to the sonic must recognise the structural inequality and asymmetry that produces silences and imbalances in the capacity for voice and sound production across cultural subject positions - including the varied array of positionalities occupied by people who are nevertheless collectively committed to contesting the politics of detention. From a transcultural feminist perspective, listening practices therefore remind us of the ethics of responsibility and recognition of limitation that must inform transcultural feminist engagements with women's experiences of detention - and, indeed, of women's experiences of forced migration more broadly. For the act of voicing dissent may also, as the protest outside Yarl's Wood cited at the start of this chapter seems to demonstrate, serve to silence, obscure, or ventriloquise the voices of detained women themselves. As the extreme narrative caution of nondetainee authors and film-makers also implies, there is risk attached, however, to the reduction of detained women's lives to 'stories'. This narrative compulsion, sometimes replicated in the desire of verbatim theatre or oral history testimonial, also risks limiting the terms on which detained women can be heard. Yet as Hani Abdile's writing reminds us, listening attentively to sonic politics also reveals dissenting potentials beyond the parameters in 
which these kinds of life narratives are often produced. In listening deeply to the nature of the sonic in itself, we unearth emotional, physical, and psychological experiences that disrupt the assumptions of both the biopolitical asylum system and the humanitarian narrative.

How, then, faced with these complex and conflicting dynamics, might it be possible to sound out a transcultural feminist approach to sonic politics that recognises the many problems relating to how, and what, we hear of detained women? Crucial requirements for this approach are the need for sonic expression and the recognition of silence; the compulsion towards voice and the necessity of listening. These, however, are not necessarily reconcilable as a single approach. Rather than seeking to harmonise these inherently distinct melodies, it seems that a transcultural feminist sonic ethos must instead embrace a level of dissonance that is open to the variance of waves and frequencies through which sound can emerge from detention, and the complex range of positionalities occupied by women in relation to detention, each of which requires us to use our voice or to listen in distinctive ways.

When we learn to listen to women in detention, then, we discover that transcultural feminist politics is far from harmonious. How, though, to atune to one another in the service of collective dissent and solidarity across these boundaries of differentiated subject position? We find an answer if we turn for a moment to lived experience - notably, that of one of the PAMOJA group members at Nottingham and Nottinghamshire Refugee Forum, some of whom have passed through the immigration detention system. ${ }^{96}$ While we were walking and talking one day, this PAMOJA member (who shall here remain anonymous) happened to relate a memorable conversation that had passed between her and her 12-year-old daughter: a bright student and emerging musician, who had asked her mother how she should hone her talent without a piano on which to practice. 'Do what your mother has done all her life,' she had responded to her daughter; 'Improvise'.

Women who seek asylum in the U.K. have to learn to improvise - with their voices, their bodies, their resources, and their minds. But what is feminism if not also a process of improvisation - a constantly creative response to shifting structures, positionalities, and power plays on the ground and in the air; an act of straining beyond walls every time that they are put up before us; an act of listening to, being inspired by, riffing off of one another's calls and songs? These feminisms may be far from harmonious - but as the singing voices of the women in Yarl's Wood remind us, there is still music to be found, even in all this dissonance.

\section{Notes}

1 Details of these signs and calls are noted in first-hand reporting of the event: Simon Childs, 'Yarl's Wood Detention Centre is at the Front Line of British State Racism', Vice, 15th May 2017, https://www.vice.com/en_uk/article/bmw5a8/ yarls-wood-detention-centre-is-at-the-front-line-of-british-state-racism (last accessed 11th June 2019). 


\section{Sounding out dissent}

2 Ibid., n.p. Participating organisations included Women for Refugee Women, WomCam, Black Women Rape Action, WAST Manchester, and Queers for Justice. Note, however, that even 'sonic activisms' such as this produce dissonance: there are reports of some division among organisations. Sisters Uncut, for instance, refused to participate in this demonstration on the grounds of alleged intimidation of some protestors, and instead organised their own protests at Yarl's Wood. See 'Yarl's Wood Demonstration: A Statement of Solidarity', Sisters Uncut, http://www.sistersuncut.org/2018/03/19/yarls-wood-demonstration-astatement-of-solidarity/ (last accessed 13th November 2019).

3 Mary Bosworth and Blerina Kellezi, 'Citizenship and Belonging in a Women's Immigration Centre', in Coretta Phillips and Colin Webster, eds., New Directions in Race, Ethnicity and Crime (Abingdon: Routledge, 2014), pp. 80-96; p.83. As I write, there are interesting and troubling developments taking place in the structures of women's detention in the U.K. Following the outbreak of the COVID-19 pandemic in 2020, many women were removed from Yarl's Wood in favour of monitored community housing. However, despite promises that more vulnerable woman would be spared detention, there are recent reports of a new detention facility for women opening at the former Medomsley detention centre in County Durham in Autumn 2021. Mark Townsend, 'Revealed: Priti Patel U-Turn on End to Detention for Refugee Women', The Guardian, 27th February 2021, https://www.theguardian.com/world/2021/feb/27/revealedpriti-patel-u-turn-on-end-to-detention-for-refugee-women (last accessed 5th March 2021).

4 Immigration detention has been described by UN High Commissioner for Human Rights, Navi Pillay, as 'one of today's most critical human rights challenges' and has been widely criticised at transnational level for its criminalization, traumatization, and radical dehumanization of already-vulnerable people seeking protection. Navanethem Pillay, 'Opening Remarks at the Panel Discussion on Human Rights of Migrants in Detention Centres', UN Human Rights Council, 17th September 2009, http://www2.ohchr.org/english/issues/ migration/taskforce/docs/HCStatementPanelMigrants.pdf (last accessed 22nd July 2019). For further discussion of the gathering protest and solidarity movements around immigration detention, see Ilker Atac, Kim Rygiel, and Maurice Stierl, eds., The Contentious Politics of Refugee and Migrant Protest and Solidarity Movements: Remaking Citizenship from the Margins (Abingdon: Routledge, 2017), pp.1-3. For a discussion of detention as a mechanism that has grown in global popularity over the course of the twenty-first century, see Michael Flynn, 'The Hidden Costs of Human Rights: The Case of Immigration Detention: Global Detention Project Working Paper No. 7', Global Detention Project, September 2013, https://www.globaldetentionproject.org/the-hiddencosts-of-human-rights-the-case-of-immigration-detention (last accessed 22nd July 2019). 'Immigration Removal Centre' is the official term for these facilities in the U.K. as they are presented as a temporary 'last stop' before deportation. In reality, however, 'removal centres' detain those with undecided immigration status for up to several years at a time, without trial. Indeed, the U.K. is the only country in Europe to have no cap on the period for which someone can be detained. I thus refer to them as 'detention' rather than 'removal' centres throughout this chapter. For further information on detention centres in the U.K., see Melanie Gower, 'Immigration Detention in the U.K.: An Overview', House of Commons Briefing Paper 7294 (September 2015), pp.1-26. For a global overview and proposed response, see the UNHCR, '2014-2019. Beyond Detention: A Global Strategy to Support Governments to End the Detention of Asylum-Seekers and Refugees', UNHCR, 2014, https://www.unhcr. 
org/53aa929f6 (last accessed 15th November 2019). Immigration detention is officially described as a temporary measure employed by states while immigration status is being determined, or while those denied leave to remain within a country are being prepared for deportation. It functions as a governmentally enforced (though often privately outsourced) administrative system designed to contain the movement of those with 'undecided' immigration status (thus including refugees, asylum seekers, failed asylum seekers, trafficked people, stateless people, and irregular migrants). According to The Migration Observatory at the University of Oxford, however, 'the single most common category of immigration detainees is people who have sought asylum in the U.K. at some point', Stephanie J. Silverman, 'Immigration Detention in the U.K.', Migration Observatory Briefing, COMPAS, September 2016, http://www.aviddetention. org.uk/sites/default/files/images/Briefing-Immigration_Detention-1.pdf (last accessed 15th November 2019), p.2.

5 Freedman, Gendering the International Asylum and Refugee Debate, p.158.

6 In the U.K., the large majority of those entering detention are male (in 2016, some 27,812 men and 4,634 women entered detention), Silverman, p.3. However, as I argue within the chapter, this minoritarian status is a major contributor to the specific difficulties faced by women in a predominantly male system. For cross-cultural reports, see, for instance, the series on women in detention in Forced Migration Review: Michelle Brané and Lee Wang, 'Women: The Invisible Detainees', Forced Migration Research 44 (September 2013), pp.37-39, on the U.S. context; Yvette Zurek, 'The Experiences of Women in Australian Immigration Detention Centres', Forced Migration Research 20 (May 2004), pp.37-38; and on the U.K. context, Ali Mcginley, 'Detention of Women: Principles of Equality and Non-Discrimination', Forced Migration Review 44 (September 2013), p.31. For a further groundbreaking insight into the U.K. system, see also the Women for Refugee Women report, Gemma Lousley and Sarah Cope, 'We Are Still Here: The Continued Detention of Women Seeking Asylum in Yarl's Wood', Women for Refugee Women (October 2017), https:// www.refugeewomen.co.uk/wp-content/uploads/2019/01/women-for-refugeewomen-reports-we-are-still-here.pdf (last accessed 15th November 2019).

7 Salsbury and Encinas, 'We Will Be Judged for This'.

8 Marchu Girma, Sophie Radice, Natasha Tsangarides, and Natasha Walter, 'Detained', Women for Refugee Women, January 2014, https://www.refugeewomen. co.uk/wp-content/uploads/2019/01/women-for-refugee-women-reportsdetained.pdf (last accessed 13th November 2019).

9 See the Campaign Timeline on the Women for Refugee Women website: 'Set Her Free: Five Years of Campaigning against Immigration Detention', Women for Refugee Women, 28th January 2019, https://www.refugeewomen.co.uk/ set-her-free-5-years-of-campaigning-against-immigration-detention/ (last accessed 13th November 2013), and most recent report, Lousley and Cope, 'We Are Still Here'.

10 Tom Western, “"Refugee Voices” in the Sonopolis: Ethics and Aesthetics of Collaborative Field Recording in Athens', British Forum for Ethnomusicology Conference (April 2019), file:///Users/anna/Downloads/Refugee_Voices_in_ the_Sonopolis_Ethics_a.pdf (last accessed 15th November 2019)

11 Salomé Voegelin, Sonic Possible Worlds: Hearing the Continuum of Sound (New York: Bloomsbury Academic, 2014), p.3.

12 Detention very deliberately limits the passage of both bodies and voices. Smartphones are usually removed and replaced with a more basic phone that cannot receive pictures. Visitors may be permitted, but only during set hours and in visiting rooms; letter writing may be allowed, but only at certain times: all 


\section{Sounding out dissent}

activities that limit detainees' fundamental human right to free speech. Journalistic reporting from inside facilities is also frequently banned, though there have been some undercover reports produced - for instance, Channel 4 News, 'Undercover in Yarl's Wood: Britain's Most Secretive and Notorious Immigration Removal Centre', Channel 4 Interactive, https://www.channel4.com/ news/yarls-wood-immigration-detention-removal-centre-undercover (last accessed 6th January 2020).

13 A broader strategy for facilitating voice has been for creative practitioners to create conditions in which the voices of detained women can escape the confines of the detention system, to be heard by those beyond it - enacted through the development of 'word-for-word' mediums such as 'verbatim theatre' (e.g. the Asylum Monologues), which use 'transcripts, textual sources and oral testimonies' as their point of imaginative genesis and seek to project 'truthful', hence morally instructive, portrayals of asylum to their audience' (Woolley, Contemporary Asylum Narratives, pp.118-119), or in the development of 'asylum anthologies' of detainees' narratives, usually delivered as an oral history to a non-detainee scribe, often with literary training. As the second section of this chapter will explore, however, there are limitations and ethical issues attached to both of these genres.

14 Farrier, Postcolonial Asylum, p.25.

15 Gayatri Chakravorty Spivak, 'Can the Subaltern Speak?', in C. Nelson and L. Grossberg, eds., Marxism and the Interpretation of Culture (Urbana: University of Illinois Press, 1988), pp.271-316; Malkki, 'Speechless Emissaries', p.390.

16 On 'naked protest', see Imogen Tyler, 'Naked Protest: The Maternal Politics of Citizenship and Revolt', Citizenship Studies 17:2 (2013), pp.211-226; on lip-sewing, see Nithya Rajan, 'What Do Refugees Want? Reading Refugee Lip-Sewing Protests through a Critical Lens', International Feminist Journal of Politics 21:4 (2019), pp.527-543; on hunger-striking, see May Bulman, " "It's like hell": Yarl's Wood Women Launch Hunger Strike against Their Indefinite Detention and Imminent Charter Flight', The Independent, 26th November 2018, https://www.independent.co.uk/news/uk/home-news/yarlswood-women-hunger-strike-detention-centre-home-office-flight-a8653111. html (last accessed 16th November 2019).

17 Notable exceptions here are Sekaran's novel Lucky Boy, which explores the context of U.S. immigration detention through the story of a Mexican mother separated from her son, and his subsequent placement in adoption; and poetry that draws inspiration from first-hand encounter, such as Warsan Shire's 'Conversations About Home (at the Deportation Centre)', in Teaching My Mother How to Give Birth (London: Mouthmark Poetry, 2011), pp.24-27 and Caroline Smith, The Immigration Handbook (Bridgend: Seren Press, 2016).

18 Ali Smith, Spring (London: Penguin, 2019), p.229. See also Ali Smith's contributions to the Refugee Tales project (for instance, Ali Smith, 'The Detainee's Tale', in David Herd and Anna Pincus, eds., Refugee Tales (Manchester: Comma Press, 2016), pp.49-62. Refugee Tales currently campaigns to end indefinite detention through the consciousness-raising activities of many of its associated authors and those who share their stories.

19 Gabrielle Brady, dir., Island of the Hungry Ghosts (Australia: Third Films, 2018).

20 Farrier, Postcolonial Asylum, p.102.

21 Woolley, Contemporary Asylum Narratives, p.124. Both Woolley and Farrier have engaged in extensive and compelling analyses of this play - particularly its innovative engagement with voice. 
22 Ibid., p.125.

23 Brandon LaBelle, Sonic Agency: Sound and Emergent Forms of Resistance (London: Goldsmiths Press, 2018), p.4.

24 Ibid., p.5.

25 Paul Hodge, '\#LetThemStay \#BringThemHere: Embodied politics, asylum seeking, and performativities of protest opposing Australia's Operation Sovereign Borders', EPC: Politics and Space 37:3 (2019), pp.386-406; p.387. See also T. Magner, "A Less Than "Pacific" Solution for Asylum-Seekers in Australia', International Journal of Refugee Law 16:1 (2004), pp.53-90.

26 See P. Mares, Borderline (Sydney: UNSW Press, 2002). An interesting contestation of this, however, emerged in the form of Behrouz Boochani's memoir, No Friend but the Mountains: Writing from Manus Prison (London: Piccador, 2019), composed via WhatsApp messages to his translator. The book went on to win the Victoria Prize for Literature in 2019.

27 Zurek, 'The Experiences of Women in Australian Immigration Detention Centres', p.38.

28 Examples of such anthologies include Thomas Keneally and Rosie Scott, eds., Another Country: Writers in Detention (Broadway, NSW: Sydney PEN and Halstead Press, 2007) and Sonja Dechian, Heather Millar and Eva Sallis, eds., Dark Dreams: Australian Refugee Stories by Young Writers Aged 11-20 Years (Kent Town, SA: Wakefield, 2004).

29 Emma Cox, 'Dialogue and Decentralisation in Australian Asylum Anthologies', Life Writing 7:3 (2010), pp.285-302; p.286.

30 For further information on Behind the Wire, which employs multimedia formats including a podcast, public art installations, audio stories, and educational resources, visit www.behindthewire.org.uk (last accessed 17th August 2019).

31 While the term 'oral history' is used by the editors of this project, I also perceive points of overlap with the genre of 'collaborative life narrative', which sees authors produce their stories in collaboration with an experienced author, sometimes also originating in oral interview. Indeed, the anthology's self-description as 'stories' from detention would seem to enforce this. The collaborative life narrative model implies greater room for authorial manoeuver and recognises the editorial role more extensively - particularly in its interventionist role as shaper of a text. See Sidonie Smith and Julia Watson, Reading Autobiography: A Guide for Interpreting Life Narratives (Minneapolis: University of Minnesota Press, 2001), p.191, for further on the collaborative life narrative.

32 It is the case across all 'asylum anthologies' that I have seen - with the exception of the specifically female-focussed anthology of writing by the PAMOJA Women Together Group that I co-edited with Camilla Reeve, conscious of this demographic trend (though this anthology does not engage with the narratives of women currently in detention - see Ball and Reeve, eds., The World Is for Everyone) - that the majority of narratives therein belong to men. We might speculate on a number of reasons for this: the higher number of men in detention, where such anthologies are specific to that context; or indeed the greater sense of precarity and vulnerability that women may experience, thus rendering them reluctant to 'expose' themselves through narrative.

33 'Afterword', in Michael Green and André Dao, eds., They Cannot Take the Sky: Stories from Detention (Sydney: Allen and Unwin, 2017), pp.305-306.

34 Cox, 'Dialogue and Decentralisation in Australian Asylum Anthologies', p.286.

35 Agnes Woolley, 'Narrating the "Asylum Story": Between Literary and Legal Storytelling', Interventions 19:3 (2017), pp.376-394; p.378. 


\section{Sounding out dissent}

36 Carol Bohmer and Amy Shuman, Political Asylum Deceptions: The Culture of Suspicion (Basingstoke: Palgrave Macmillan, 2018), p.36.

37 Freedman, Gendering the International Asylum and Refugee Debate, pp.79-80.

38 Farrier, Postcolonial Asylum, p.101.

39 Gillian Whitlock, Postcolonial Life Narratives: Testimonial Transactions (Oxford: Oxford University Press, 2015), p.170.

40 Whitlock, Postcolonial Life Narratives, p.20.

41 Shauna Butterwick and Jan Selman, 'Deep Listening in a Feminist Popular Theatre Project: Upsetting the Position of Audience in Participatory Education', Adult Education Quarterly 54:1 (2003), pp.7-22.

42 Lauren Rosenberg and Emma Howes, 'Listening to Research as a Feminist Ethos of Representation', in Kristine L. Blair and Lee Nickoson, eds., Composing Feminist Interventions: Activism, Engagement, Praxis (Boulder: University of Boulder, Colorado Press, 2019), pp.75-91.

43 Carol Gilligan, 'The Listening Guide Method of Psychological Enquiry', Qualitative Psychology 2:1 (2015), pp.69-77; p.70.

44 Ibid., p.70.

45 Kate Smith, 'Stories Told by, for, and about Women Refugees: Engendering Resistance', ACME: An International E-Journal for Critical Geography 14:2 (2015), pp.461-469; p.462.

46 Contrapuntality is a term derived from music that describes the independent yet intersecting lines in a musical composition, which at once harmonise and play off one another. Edward Said, 'Reflections on Exile', Granta 13 (1984), pp.157-172; pp.171-172. For further application of the concept of contrapuntality to representations of and by forced migrant women, see forthcoming work by Margaret Ravenscroft.

47 Gilligan, 'The Listening Guide', p.72.

48 Hani, 'When I Become Famous, I'll Give Tony Abbot a Job', p.29. All further references to this text will be included in parentheses within the analysis.

49 LaBelle, Sonic Agency, pp.96-97.

50 Tom Western, 'Aural Borders, Audible Migrations: Sound and Citizenship in Athens', British Forum for Ethnomusicology Conference, Newcastle, April 2018, https://www.academia.edu/36416837/Aural_Borders_Audible_Migrations_ Sound_and_Citizenship_in_Athens (last accessed 12th January 2020).

51 Kim Rygiel, 'Governing Borderzones of Mobility through E-Borders', in Vicki Squire, ed., The Contested Politics of Mobility: Borderzones and Irregularity (London: Routledge, 2011), pp.143-168; p.144.

52 Shoshana Felman, The Scandal of the Speaking Body: Don Juan with J.L Austin, or A Scandal in Two Languages (Stanford, CA: Stanford University Press, 2002), p. 65.

53 Judith Butler, 'Indefinite Detention', Precarious Life: The Powers of Mourning and Violence (London: Verso, 2004), pp.50-100; p.65.

54 Within the U.K. asylum system, immigration decisions that are appealed are subject to a public 'hearing process' in court. See https://www.gov.uk/immigrationasylum-tribunal/if-theres-a-hearing (last accessed 28th July 2020).

55 Western, “Refugee Voices” in the Sonopolis', n.p.

56 Whitlock, Postcolonial Life Narratives, p.169.

57 See 'Hani Abdile', Word Travels, http://www.wordtravels.info/hani-abdile-sf (last accessed 10th April 2020); 'Hani Abdile', Writing Through Fences, http:// writingthroughfences.org/writers/hani-abdile/ (last accessed 10th April 2020); and Hani's own Wordpress site, https://abdilehani.wordpress.com/poetry/ (last accessed 10th April 2020). 
58 See 'Hani, “Here I Am”, Bankstown Poetry Slam', 2nd March 2015, https:// www.youtube.com/watch? $v=$ sLkWpuj9Vqo (last accessed 10th April 2020) and 'Hani Abdile Live at QP2017', 17th December 2017, https://www.youtube. $\mathrm{com} /$ watch? $\mathrm{v}=-\mathrm{iFNvb}-\mathrm{emPE} \& \mathrm{t}=58 \mathrm{~s}$ (last accessed 10th April 2020).

59 Abdile, 'Listen', in I Will Rise, pp.65-67; p.66.

60 Ibid., p. 67.

61 Brandon LaBelle, 'Restless Acoustics, Emergent Publics', in Marcel Corbussen, Vincent Meelberg, and Barry Truax, eds., The Routledge Companion to Sounding Art (New York: Routledge, 2016), pp.275-286; p.276.

62 LaBelle, Sonic Agency, p.15.

63 LaBelle, 'Restless Acoustics, Emergent Publics', p.26.

64 Farrier, Postcolonial Asylum, p.100.

65 Abdile, 'Here I Am', in I Will Rise, pp.53-54; p.53.

66 Women comprise a minority of those in U.K. detention, which 24,052 people entered into in 2019 according to Home Office statistics. Home Office, 'National Statistics: How Many People Are Detained or Returned?', 22nd August 2019, https://www.gov.uk/government/publications/immigration-statistics-yearending-june-2019/how-many-people-are-detained-or-returned (last accessed 16th April 2020). Figures for the number of women are cited in the report by Women for Refugee Women, 'Set Her Free: Women Asylum Seekers and Immigration Detention', 2019, https://www.gov.uk/government/publications/ immigration-statistics-year-ending-june-2019/how-many-people-are-detainedor-returned (last accessed 16th April 2020).

67 Music in Detention is the only charity sanctioned by the Home Office and outsourced management of IRCs to undertake musical outreach work in several U.K. IRCs. See http://www. musicindetention.org.uk for further information (last accessed 15th April 2020).

68 John Speyer, 'For Music. Education Zone', Music in Detention, 2008, http:// www.musicindetention.org.uk/aboutmid.htm (last accessed 15th April 2020).

69 Voegelin, The Political Possibility of Sound, p.54.

70 Didier Fassin and E. d'Halluin, 'The Truth from the Body: Medical Certificates as Ultimate Evidence for Asylum Seekers', American Anthropologist 107:4 (2005), pp.597-608; p.599.

71 Jean-Luc Nancy, Listening, trans. Charlotte Mandell (New York: Fordham University Press, 2007), p.42.

72 Sandra L. Curtis, 'Feminist Music Therapy: Transforming Theory, Transforming Lives', in S. Hadley, ed., Feminist Perspectives in Music Therapy (New Haven: Barcelona Publishers, 2006), pp.227-244; p.229.

73 Ibid., p.233.

74 In their 2014 report 'Detained', 93\% of women interviewed by Women for Refugee Women stated that they had been either raped or tortured prior to arriving in detention, while detainees at Yarl's Wood described feelings of harassment by male guards who either 'barged in' or monitored them in intimate situations and who left them feeling vulnerable. The report also highlights accusations of sexual harassment and abuse at Yarl's Wood. See Women for Refugee Women, 'Set Her Free: Women Asylum Seekers and Immigration Detention', p.3.

75 C. A. Xuan Mai Ardia, 'Hear Her Singing: Taiwanese Artist Charwei Tsai and the Song of Women Refugees - in Conversation', Art Radar, 28th June 2017, http://artradarjournal.com/2017/06/28/hear-her-singing-taiwanese-artistcharwei-tsai-and-the-song-of-women-refugees-in-conversation/ (last accessed 28th July 2020).

76 'Charwei Tsai', Ocula, https://ocula.com/artists/charwei-tsai/ (last accessed 17th April 2020). 
77 Kenesha Julius, “A "Universe of Possibilities": Taiwanese Artist Charwei Tsai - Interview', Art Radar, 6th November 2016, https://artradarjournal. com/2016/11/06/a-universe-of-possibilities-taiwanese-artist-charwei-tsaiinterview/ (last accessed 17th April 2020).

78 Étrangère (2009) consists of three photographs of a baby octopus, each inscribed differently with the word 'étrangère' (stranger), her passport number, and 'Chinese words relating to the meaning of being Taiwanese', Jill Wong, 'Chawei Tsai: The Art of Change', MutualArt, July/August 2009, https://www.mutualart. com/Article/Charwei-Tsai--The-Art-of-Change/951052D8A9F26195 (last accessed 17th April 2020), while Songs of Khaosiung Migrant Workers (2018) is a video work of songs sung by migrant workers from Southeast Asia and Africa. It was exhibited alongside Hear Her Singing in her exhibition, Root of Desire. 'Root of Desire', TKG+, https://www.tkgplus.com/en/exhibitions/16root-of-desire-charwei-tsai-solo-exhibition/press_release_text/ (last accessed 17th April 2020)

79 Charwei Tsai, 'Conversation between Stephanie Rosenthal and Charwei Tsai', hearhersinging.info, http://hearhersinging.info/ (last accessed 12th June 2019).

80 Voegelin, The Political Possibility of Sound, p.54.

81 Ibid., p.66.

82 Ibid., p.63.

83 Caroline Lenette, Donna Weston, Patricia Wise, Naomi Sunderland, and Helen Bristed, 'Where Words Fail, Music Speaks: The Impact of Participatory Music on the Mental Health and Wellbeing of Asylum Seekers', Art and Health 8:2 (2015), pp.1-15.

84 C. A. Xuan Mai Ardia, Hear Her Singing.

85 See Charwei Tsai and Tsering Tashi Gyalthang, Hear Her Singing, 2017 video with sound and colour, 16 minutes 28 seconds, https://www.youtube.com/ watch? $v=$ SfaFCrQcWjo\&t=15s (last accessed 4th May 2020).

86 Heidi Ahonen and Antoinetta Mongillo Desideri, 'Heroines' Journey Emerging Story by Refugee Women during Group Analytic Music Therapy', Voices: A World Forum for Music Therapy 14:1 (2014), pp.1-22; p.2.

87 Nancy, Listening, p.8; p.5.

88 Ibid., p.42.

89 'Call-and-response' modes of song are evident within a wide range of cultural settings - including in the development of African American women's work songs, and gospel music, as well as Western classical music. The structure of call-and-response fosters a sense of dialogue and communality within the music. See Gale P. Jackson, Put Your Hands on Your Hips and Act like a Woman: Song, Dance, Black History and Poetics in Performance (New York: AC Books, 2018).

90 Voegelin, The Political Possibility of Sound, p.58.

91 Liisa Malkki, 'News and Culture: Transitory Phenomena and the Fieldwork Tradition', in James Ferguson and Akhil Gupta, eds., Anthropological Locations: Boundaries and Grounds of a Field Science (Los Angeles: University of California Press, 1997), pp.86-101; p.92.

92 Voegelin, The Political Possibility of Sound, p.66.

93 Ibid., p.36.

94 See Vicki Squire, The Exclusionary Politics of Asylum (Basingstoke: Palgrave Macmillan, 2009), p.5 for further on the sovereign biopolitics of asylum.

95 LaBelle, Sonic Agency, p.156.

96 I discuss PAMOJA and my work with them further in the Preface and in Chapter 1 of this volume. 


\section{No straightforward journey \\ Traversing queer feminist territories through a poetics of crossing}

For an instant, it must feel to Sarah Hegazi that she is flying. The Cairene air is pulsing with music, and the crowd is singing along to every word mouthed by Hamed Sinno, the openly queer frontperson of the Lebanese indie band Mashrou' Leila. It is 2017, and for Hegazi, herself an openly queer LGBTQ+ advocate, ${ }^{1}$ a self-described feminist who has renounced the hijab, an anti-governmental activist and a communist, these people, this evening, must seem a safe space - one in which the conservative religious forces in Egyptian society that condemn and punish queerness are out of sight and out of reach. ${ }^{2}$ And so she climbs atop her friend's shoulders and unfurls it to the sky: a rainbow flag that spans her arched back and makes of her form a brightly Winged Victory. The crowd cheers: they are with her, and at this moment, Hegazi's face alight with it all, her friend cannot help but reach for their phone to capture this extraordinary image of transcendence.

But over the forthcoming week, Hegazi's photograph will circulate on social media as evidence of what will come to be described as 'a gay satanic orgy in the heart of Cairo', against which a fatwa will be issued by AlAzhar University. ${ }^{3}$ And the arrests will begin: of 75 LGBTQ+ (lesbian, gay, bisexual, trans, queer, plus)-identified individuals, Sarah Hegazi the only queer woman amongst them. In an article she will later write for the independent Egyptian magazine Mada Masr, Hegazi will disclose the torture to which she will be subjected during her detention: electrocution, death threats against her family, sexual harassment, and isolation. ${ }^{4}$ Fearing further reprisals from her government upon her release on bail some three months later, she will seek and be granted asylum in Canada in 2018 on the basis of her well-founded fear of persecution based on her sexual orientation. But her experiences will follow her in the form of post-traumatic stress disorder, and on 13th June 2020, Hegazi will be found dead in her Toronto apartment, having taken her own life. The wave of grief amongst the transnational LGBTQ+ community will find expression in many forms - vigils, murals, Pride tributes, and expressions of activist solidarity. But it is Hamed Sinno who will articulate the fully destructive weight of the embodied boundaries imposed upon Hegazi most poignantly, in a song

DOI: $10.4324 / 9780429325403-5$ 


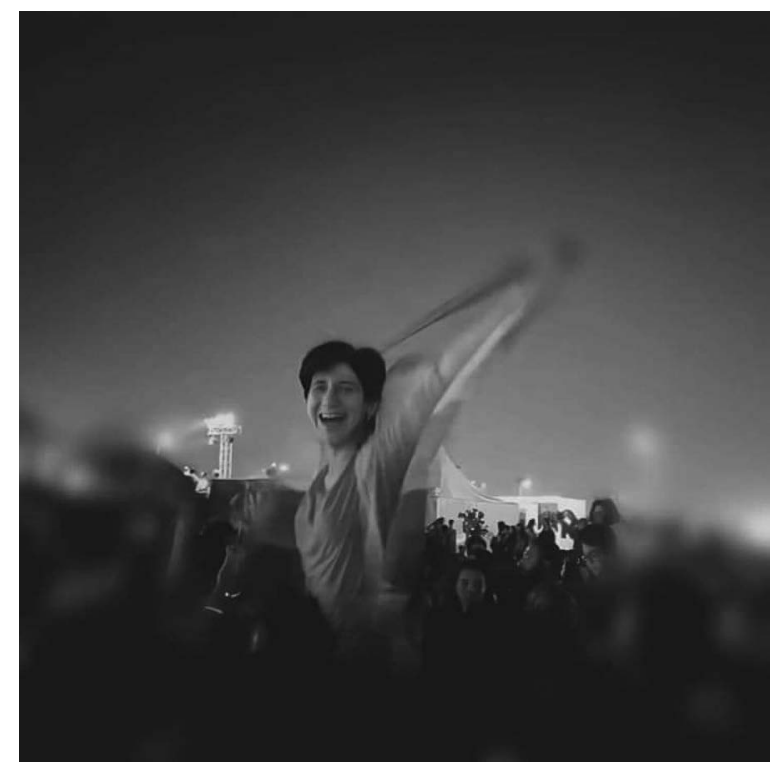

Figure 5.1 Photograph of Sarah Hegazi taken at the Mashrou' Leila concert in Cairo, 2017. Courtesy of Amr Magdi/Twitter.

composed from some of the last words Hegazi posted online just before her death: 'The sky is more beautiful than the earth. And I want the sky, not the earth'. ${ }^{5}$ Unable to find true sanctuary within the confines of any physical territory, it would seem that Hegazi felt the only path open to her remained to take flight from the boundaries of her own body altogether - towards the sky that she had, so briefly and proudly, unfurled her rainbow flag.

Sarah Hegazi's queer journey presents a brutal reminder of the extent to which the discrimination experienced by queer women* (a term used in an expansive and inclusive sense within this chapter to include those who are cisgender, transgender, or who identify as women in any sense - including within the realms of gender-fluid or nonbinary identity) can drive forced migration. ${ }^{6}$ As Hegazi's story makes clear, persecution against people on the basis of their sexual and/or gendered identity - including queer sexual orientations and gender identifications, such as transgender, gender-fluid, or non-binary selfhoods - may be perpetuated at the level of the state, through social discourses or through cultural ideologies that leave queer women vulnerable to abuse, violence, and even death. As Aengus Carroll notes, queer sexual and gender identifications increasingly drive women's forced migration in the twenty-first century. ${ }^{7}$ Current interpretations of the 1951 Geneva Convention enable people of LGB (lesbian, gay or bisexual) orientations to be considered 'a particular social group' and can thus seek asylum on the basis of their sexual orientation as the source of potential 
persecution within their own society, ${ }^{8}$ while claims to asylum can also be made on the specific grounds of gendered persecution by those who identify as transgender. ${ }^{9}$ Collectively, these claims are referred to according to the acronym SOGICA (sexual orientation and gender identity claims of asylum) and are recognised within the international asylum law under International Protection Number 9 within the context of Article 1A(2) of the 1951 Convention. ${ }^{10}$ Yet the outcome of Hegazi's story and indeed the extent to which it echoes the tragic narratives of Camila Díaz Córdova and Roxsana Hernández, queer women* who, like Hegazi, failed to find psychological or physical sanctuary through the asylum process, ${ }^{11}$ alert us to the extent to which, as Fobear puts it, 'no journey is ever straight'. ${ }^{12}$ Forced into what Laurent Berlant describes as the time of 'slow death' experienced by refugees - that 'of ongoingness, getting by, and living on, where the structural inequalities are dispersed, the pacing of their experience intermittent', ${ }^{13}$ or what Sima Shakhsari describes as the 'in-between zone' of asylum characterised by ambivalent transition between "oppression and freedom", "homophobia and gay rights", "backwardness and progress, and "rightlessness and rightfulness", ${ }^{14}$ Hegazi also leads us to consider the altogether more ambiguous realms of queer forced migrant experience. This is a realm in which gendered embodiment cannot be reduced to binarised categories of identification, nor the forced migrant journey to a linear passage from oppression to freedom. For when we circle back through Hegazi's journey, refusing to 'straighten' it, we find altogether more creative potentialities oscillating within it: not simply of her transition from activism to persecution to freedom, but of an enduring and uncompromising LGBTQ+ advocacy that travelled with her across borders; of communal solidarities inspired by her legacy, spanning transnational contexts; and, in her euphorically embodied response to the music of Mashrou' Leila, as well as in the fierce utopianism of her writing, a vibrant political imagination that could not help but look beyond the confines of the political spaces presented to her. When we take this alternative route into Sarah Hegazi's journey as a queer forced migrant woman, then, we find ourselves no longer in straightforwardly feminist territory, but instead in queer realms where the very boundaries of the gendered and sexualised body and the trajectory of the forced migrant journey find themselves destabilised. Here, we encounter an alternative politics - and poetics - of crossing that is simultaneously embodied, political, social, creative, and imaginative, and it draws us towards a necessarily reconfigured understanding of transcultural feminisms.

What does it mean to enter into the realm of 'the queer' within the context of a transcultural feminist approach to forced migration? Drawing upon and extending the formative insights of queer theorists such as Judith Butler, Jack Halberstam, and Jay Prosser, 'queer of colour' theorists and those attentive to the dynamics of the 'postcolonial queer' such as Gayatri Gopinath have connected queerness not just to 'nonnormative sexual practices, desires, affiliations, and gender embodiments, but also...[to] alternative ways of seeing (and sensing) space, scale and temporality ${ }^{15}$ that stem, ultimately, from a 


\section{No straightforward journey}

resistance to the 'colonial endeavor to gaze at, categorize, own and catalogue things and people' - manifested in many ways, including in the medicalised classification of the desiring gendered body. ${ }^{16}$ Thus, a transcultural queerness can be read as a resistance not simply to normative gender boundaries but to the territorial mappings of colonial and imperialist perception that are projected onto the world and the bodies within it. As Gayatri Gopinath has also argued, a transcultural understanding of queerness must additionally be situated in relation to the spaces inhabited by queer subjects, taking account of the movements performed across communal, social, and national boundaries. Here, she locates the potential for an alternative 'cartography of a queer diaspora' that 'radically resituates questions of home [and] dwelling. ${ }^{17}$ Indeed, for Eve Kosofsky Sedgwick, queerness is inherently related to movement, specifically the process of moving across, and hence, of crossing:

Queer is a continuing moment, movement, motive - recurrent, eddying, troublant. The word 'queer' itself means across - it comes from the Indo-European root twerkw, which also yields the German quer (transverse), Latin torquere (to twist), English athwart. ${ }^{18}$

The realm of the queer therefore invites us to cross into a fluid range of intersections between the sexed, gendered, and sexual body as it is situated in (transitional) space. Within this realm, we are invited to dispense with conservatively cisgender understandings of 'female' identity and experience as the basis of feminist scrutiny and, indeed, to push against the boundaries that determine gendered and sexual identifications altogether. When we follow these queer paths into forced migrant experience, then, we become able to explore alternative understandings of home, belonging, and community to those established through biopolitical, heteropatriarchal state boundaries. As an inherently destabilising, transitional, some might even say queer mode of experience, forced migration therefore proves particularly fertile ground for the cultivation of transcultural 'queer feminist' intersections and alliances - albeit connections that require careful negotiation and respect for multiple positionalities across them. Indeed, we find a vital creative precedent in the work of the queer Chicana poet, writer, and feminist thinker Gloria Anzaldúa who, in her own quest to locate a space of psychological sanctuary for herself as a queer, mixed-race woman living across cultures and power differentials, evokes what she describes as 'the borderland': the space produced in the friction between the U.S. and Mexico border, where 'the Third World grates against the first and bleeds... the lifebloods of two worlds merging to form a third country - a border culture'. ${ }^{19}$ It is in this 'border culture' that Anzaldúa in fact finds a space of imaginative refuge and the possibility of reconciling her multiple identities:

As a mestiza [mixed-race woman/person of the in-between] I have no country, my homeland cast me out; yet all countries are mine because I 
am every woman's sister or potential lover... I am cultureless because, as a feminist, I challenge the collective cultural/religious male-derived religious beliefs of Indo-Hispanics and Anglos; yet I am cultured because I am participating in the creation of yet another culture... a new value system with images and symbols that connect us. ${ }^{20}$

For Anzaldúa, then, the borderland itself - the space produced in the act of crossing - becomes a safe-haven for a body that does not otherwise 'fit' into nationally, culturally, or heteropatriarchally defined boundaries. It is, for her, a space of inherently queer community inhabited by 'los atravesados', 'the squint-eyed, the perverse, the queer, the troublesome, the mongrel, the mulato, the half-breed, the half-dead; in short, those who cross over, pass over, or go through the confines of the normal'. ${ }^{21}$ Yet it is also where she is able to tie together the 'loose ends' of her identity, producing a 'state of psychic unrest... [that] makes poets write and artists create'. ${ }^{22}$ Thus, Anzaldúa demonstrates the possibility of reconciling the political attentiveness to situated embodiment and to cross-cultural, gender-based solidarity entailed in a transcultural feminist approach with the more fluid and open communal identifications entailed in the queer, and indeed reveals their simultaneous necessity based on her intersectional cultural identifications. Following the queer feminist path mapped out by Anzaldúa, this chapter therefore seeks to explore how forms or processes of crossing - between borders, embodied boundaries, gendered communities, and imaginatively constructed territories - surface in representations of queer women's forced migrations, in ways that also lead us towards a position of creative selfdefinition and self-possession. In doing so, it asks: what roles do gendered and sexual embodiment play in the act of border-crossing within the context of queer women's experiences and lives? How do creative practitioners articulate these processes of crossing within their work, and to what degree do such articulations move against, reconfigure, or even transcend borders and embodied boundaries? And what boundaries are crossed, destabilised, and remade through these critical interactions between feminist, queer, and forced migrant frameworks of reference? As we shall see, the queer journeys of forced migrant women charted within this chapter tread a delicate path through these territories, poised as they are not just on the cusp of national boundaries but in between social and personal self-definitions, trauma and transcendence, oppression and empowerment. Ultimately, though, the deeply creative expressions of crossing that emerge from these very different queer subjectivities draw us towards an imaginative territory self-fashioned in excess of these divides: a queerly feminist realm forged across and between gender boundaries, cultural divisions and disciplinary territories that are characterised by a poetics not just of crossing but of connection.

Queerness has registered in a variety of ways within discourses of forced migration. Non-Governmental Organisations and charities dedicated to the support of queer forced migrants have made clear the forms of social 


\section{6}

and political threat that drive individuals from their homes - including discriminatory, homophobic laws currently present in 80 countries around the world, which may result in imprisonment or even the death sentence for those found guilty, as well as grave societal pressures placed upon LGBTQ+ individuals such as familial disownment, forced marriage, sexual violence, honour killing, confinement to psychiatric wards, and mob violence. ${ }^{23}$ Queer women may be more prone to experiencing certain forms of such discrimination. As the U.K. Lesbian and Gay Immigration Group points out, while gay men may more often be the targets of legal sanction and mob violence, lesbian women tend to face punishment through gender-based violence and sexual harassment, as well as forced marriage during which they may face rape by their husband. ${ }^{24}$ Forced Migration Studies, meanwhile, has presented a thorough critique of conventional refugee law in its approach to validating SOGICA claims. This approach, it argues, fails to accommodate the fully complex, sometimes-shifting and culturally contingent nature of sexual and gendered identifications. As Sudeep Dasgupta writes, for instance, LGBTQ+ asylum seekers' claims to belonging within a particular 'social group' on the basis of sexual and/or gendered identification may prove difficult

when their identities are continually, often forcibly, transformed by the power dynamics involved in the process of displacement [and] conventional stereotypes of gender, age and sexuality come into conflict with the transformations in identity produced through culturally specific locations and their traversal through displacement. ${ }^{25}$

In particular, the asylum system's demand that the claimant should articulate a coherent, unswerving narrative of specifically categorisable sexual or gender identification proves problematic within a transcultural arena where people's life stories and experiences may not adhere to 'Western' configurations of LGBTQ+ identities. ${ }^{26}$ The demand for 'evidence' of sexual orientation or gender identification in the form of corroborating letters from partners, photographic proof, or testimonials from advocacy groups indicating one's 'social visibility' as an openly LGBTQ+ individual has also been the rightful subject of much condemnation. ${ }^{27}$ Thus, a critical disjunction emerges between the classificatory and regulatory demands of the asylum system and the inherently transgressive queerness of desiring, transitional subjects. Operating through a multidisciplinary lens of discourse analysis, Thibaut Raboin, meanwhile, has called attention to the ways in which forced migrant LGBTQ+ voices come to be homogenised and instrumentalised across a wide range of platforms - including within NGO advocacy, the Western media, and indeed 'queer liberal' discourses where sexual and gendered claims to asylum may become appropriated as part of a broader 'geopolitics of sexual rights where hospitality for refugees has a performative value in relation to the representation of a racialized 
queer-positive liberal state'. ${ }^{28}$ Raboin's work thus issues an important reminder that queerness, while potentially understood as fluid and allencompassing, must also be read in carefully situated terms that resist the reproduction of exclusionary boundaries of privilege in which the 'liberal queer' subject enters into collusion with the structures of 'imperialism and white privilege'. ${ }^{29}$ B. Camminga, meanwhile, has warned against the homogenising assumptions of work on LGBT identifications from a different perspective by drawing attention to the specific experiences and needs of those who identify as 'trans'. As subjects who experience particular forms of persecution and vulnerability, trans individuals have nevertheless tended to be marginalised within wider discussions of LGBTQ+ experience, as well as finding themselves excluded from many gender mainstreaming policies enacted by NGOs, and their status as 'gender refugees' has only begun to be elucidated. ${ }^{30}$ Collectively, these insights point us towards the necessity of formulating an understanding of queerness that at once resists the categorising impulse of the asylum regime, embraces the transgressive potentials of queer capacities for imagining, and recognises the embodied consequences of cultural situatedness for queer subjects. Poised at these precarious interstices, it becomes appropriate to incite the potentials of a transcultural queer feminist imagination, and to ask: how do the figures of queer women - in all of their self-identified, contingent, transitional, and creative manifestations - feature in representations of forced migration?

Variously articulated queer forced migrant identities have emerged as the subject of very recent interest in the transcultural creative landscape. In particular, there has been a marked focus on narrative and visual documentation of LGBTQ+ experience in a number of recent artistic projects that have engaged with the potentials of to-camera portraiture or to-page testimonial over the past few years. Potentially mirroring the journalistic desire to 'reveal' the 'hidden' stories of forced migrants, a number of these projects, though, have consciously subverted the dehumanising, evidencebased approach of the asylum interview in favour of alternative strategies of self-representation. Columbian artist Carlos Motta's Netherlands-based 2017 exhibition The Crossing, for instance, employs to-camera (sometimes anonymised) interviews with 11 LGBTQ+-identified individuals in a style that is consciously 'unspectacular' and that allows room for the interviewees to self-narrate in a stream-of-consciousness style undictated by the demand that they should produce a clear 'story' or account of themselves. ${ }^{31}$ As in broader LGBTQ+-focussed scholarship, though, the nuances of gendered identification remain largely unscrutinised, and indeed dynamics of the fluidly female and feminine remain resigned to a minority of portraits - a phenomenon that, as Gopinath notes, echoes a wider tendency towards the marginalisation of lesbian and otherwise female/feminine-oriented sexual and gendered identities within cultural representations of queerness. ${ }^{32}$ 
Perhaps in conscious defiance of this trend, film-maker Tamara Shogaolu and journalist Nada El-Kouny focus their 2019 animated documentary and virtual reality experience 'Another Dream' (part of a transmedia trilogy entitled Queer in a Time of Forced Migration) specifically on the true-life story of an Egyptian lesbian couple forced to flee Cairo in the post-revolutionary backlash against the LGBTQ+ population. Enacting humanising connectivity through its interactive visual mode, this piece also mobilises queer female presence through autobiographical testimony and thus the broader suggestion that viewers (or participants) should be called to empathy through an appeal to the weight of reality. ${ }^{33}$ This 'call to reality' and to self-narration is consciously queered in Israeli artist Oreet Ashery's 2009 project, Staying, however. Conducted with a group of 12 queer women through the U.K. Lesbian and Gay Immigration Group, Ashery's approach to the self-narration of sexual identity counteracts the demand for realistic recollection by instead encouraging 'gaps, slippages, repetitions and new structures of embodying and imagining the self 34 through playful narrative exploration of sexuality via the creation of alter-egos for the participants. Sometimes poignant, sometimes absurd, queerness registers within these works as a shift away from sexual categorisation towards a circulation of self-expressed creative desires and identities. Notably, the alter-egos slip between male, female, and non-human forms, and assume voices that are sometimes individual, sometimes collective. Ashery's project is indicative of a much wider trend towards participatory art with queer asylum-seeking communities that has become visible in a variety of transnational locations - including in South Africa, the U.S., and the U.K. Typically, these projects are designed to nurture self-esteem and to enhance social visibility. ${ }^{35}$ Here, then, creativity presents a vital alternative to the linear autobiographical accounts demanded by the asylum system.

When we turn to the realms of fiction, it is the journey through and to queerness rather than the arrival at sanctuary that registers most clearly in literature and film. In Nigerian-American author Chinelo Okparanta's 2015 novel Under the Udala Trees, for instance, the central character, Ijeoma, must grapple not only with a homophobic society and family but with the physical and psychological traumas of the Biafran war, her subsequent displacement, and the religious and tribal tensions that drive the conflict. Far from asserting Ijeoma's same-sex desire explicitly from the outset of the novel, Under the Udala Trees instead presents a gradual process of ideological questioning on Ijeoma's part, as she begins to unravel the Christian and heteronormative values through which she has long read the world. Thus, rather than driving her border-crossing experience, her displacement instead mirrors the process of self-realisation that she must undertake. ${ }^{36}$ In filmic terms, meanwhile, variously understood 'female' and 'feminine' articulations of queerness are relegated to but a handful of independent U.S.- and U.K.-produced films, which focus on the specific complexities of lesbian asylum seekers' journeys through Western host systems. ${ }^{37}$ Of particular note 
here is Angelina Maccarone's 2005 film Unveiled, which charts the journey of an Iranian woman named Fariba who claims asylum in Germany on the basis of having conducted a same-sex relationship in Iran (an experience that she never defines as 'lesbian', in line with differing cultural definitions of sexuality, and which she initially conceals from border officials, fearful of her immediate deportation). ${ }^{38}$ When her claim is denied, however, she assumes the identity of a male asylum seeker who has committed suicide and, through 'passing' as a heterosexual man, is able (for a time, at least) to pursue a romantic relationship with a woman and to live in safety. While deeply queer in its portrayal of Fariba's performative, gender-shifting identity, the film's message, however, remains one critical of the German asylum system's ability to embrace queerness: only by adhering to the clear-cut categories of 'lesbian cisgender woman' or 'heterosexual trans man' is she able to gain sanctuary - a quest in which she fails. More fluid and diverse portraits of (female-allied or female-oriented) queerness have surfaced in the realms of experimental film-making, such as that showcased by the annual International Queer and Migrant Film Festival. Most of such works, however, are dominated by the documentary medium and, in their own ways, seek to give presence to queerness through a process of rendering queer lives visible and audible through the narration of queer stories. ${ }^{39}$

As this brief journey through transcultural representations of femaleassociated queerness suggests, the field has been somewhat dominated by the desire to ascribe presence and recognition for queer forced migrants through narration of their stories and travels. These are structures that imply a linearity to the construction of queer identity, though - a process of transition that ultimately results in what Aren Aizura describes in the context of transgender experience, but which can perhaps be ascribed to all self-affirmations of gendered or sexual identity, as a "coming home" to one's new body' with the granting of asylum. ${ }^{40} \mathrm{How}$, then, might it be possible to imagine queer (women's) forced migrant journeys differently - in ways that do not assume clear-cut processes of departure from or arrival at authentic or inauthentic selves, genders, or sexualities, and that instead recognise the queer circulation of multiple positionalities mobilised through the act of crossing itself - a movement in which queer, gendered, sexual, feminist, and forced migrant identifications are in constant interplay? This chapter turns away from 'straight forward' narrative articulations of queer forced migrant journeys to explore instead what might be described as a 'poetics of crossing': the creative articulation of queerness-in-motion in which multiple pathways through gendered, sexual, queer, and feminist interpretation, alliance, belonging, and identification circulate. It does so by exploring two very different 'poetics of crossing', as they surface in radically different transcultural locations, mediums, and queer forms.

In the first section of the chapter, a 'poetics of crossing' emerges via the Caribbean-American writer, political activist, and performer Staceyann Chin's 2019 poetry collection, Crossfire: A Litany for Survival. ${ }^{41}$ Charting 
two decades of work forged since her arrival in the U.S. from Jamaica, a journey driven by the impossibility of living safely as a queer woman against a backdrop of legally enshrined homophobia, Crossfire articulates Chin's multiple locations at the precarious interstices between variously defined queer, lesbian, feminist, embodied, anti-racist, and migrant positionalities: boundaries that she remains determined to traverse, even if this process of perpetual crossing places her in the firing line of criticism and threat. This position of transitional discomfort and of empowerment echoes the queer feminist territories of Anzaldúa's 'borderlands' in Borderlands/La Frontera. By tracing the queer traversals of sexual, political, racial, and spatial positionality at stake in Chin's work in creative dialogue with Anzaldúa, it becomes possible to perceive the queerly feminist alliances that she forges both in the process of crossing and ultimately in the crossfire of multiply directed hostilities, arriving eventually at an understanding of queer feminist positionality that offers her modes of self-constructed haven.

A very different 'poetics of crossing' emerges in the second section of the chapter, which turns to the 2019 hybrid artistic work One Emerging from a Point of View by the self-described 'multi-multi' artist Wu Tsang. ${ }^{42} \mathrm{~A}$ video work first exhibited at the Sharjah Biennial 14 in the United Arab Emirates, One Emerging invites us to connect the multiple narratives of crossing present in this film to a space that might be conceived of as inherently 'trans(-formational,-itional)' in nature. The piece comprises a two-screen video installation with overlapping visual and verbal narratives featuring, on the one hand, poetic documentary footage of the inhabitants of the Greek island of Skala Sikemenias on Lesbos, including the photojournalist Eirini Vourloumis, who have all become implicated in assisting forced migrant arrivals; and, on the other, a performance by a queer-identified forced migrant woman from Morocco who performs a fantastical story, co-authored with Tsang, about a radical, and indeed radically liberating, transformation of female embodiment. In both its aesthetic and its subtext, One Emerging evokes a realm of inherent queerness that serves to destabilise the bodily and environmental boundaries of those who feature within it. Reading this queer potentiality according to Donna Haraway's conceptualisation of 'oddkin' as a transgressively queer vision of radical interspecies, planetary connection, the analysis suggests that One Emerging ultimately leads us towards a vision of extreme connectivity in which trans-ness characterises and indeed unites all of those who surface within this work. As these readings suggest, the traversal of boundaries between the queer and the feminist, embodied and imagined, spatial and abstract demands the most careful of critical negotiations. Yet as we shall see, a process of crossing that is attentive to the demands, threats, and possibilities of queerness for forced migrants perhaps enables us to make some final tentative steps towards reconciling those radical divisions between the material and the imaginative - or what Sarah Hegazi once so poignantly described as the territories of the earth, and of the sky. 
'Not comfortable, but home': constructing a queer transcultural feminist haven in Staceyann Chin's Crossfire

In Borderlands/La Frontera, a hybrid work of criticism, fiction, poetry, and memoir generated from her position in the U.S.-Mexico borderlands, queer Chicana feminist writer and academic Gloria Anzaldúa recalls a moment from her teaching career that resonates in manners both humorous and poignant for those who find themselves forced to seek sanctuary on the basis of their sexual orientation:

In a New England College where I taught, the presence of a few lesbians threw the more conservative heterosexual students into a panic. The two lesbian students and we...lesbian instructors met with them to discuss their fears. One of the students said, 'I thought homophobia meant fear of going home after a residency.'

And I thought, how apt. Fear of going home. And of not being taken in. ${ }^{43}$

Homophobia can indeed take the form of rejecting queerness from a 'home' culture identified as heteronormative - an alienation that induces spatial and psychic exile for the queer subject. This is arguably the case for the rising number of female-identified asylum applicants who flee their homes due to discrimination and persecution levelled against them on the basis of their sexual identification - often from countries with deeply rooted cultures of homophobia. This is the case for the Chinese-Jamaican-American poet Staceyann Chin, whose own flight from Jamaica to the U.S. was motivated by her desire to be able to live safely and openly as a lesbian woman - an impossible task in her home country due to the intolerance and hostility she encountered on the grounds of her sexuality. ${ }^{44}$ Yet as Chin recognises in her poetry, the act of crossing beyond the borders of 'Jamaica/the island that rejected me ${ }^{35}$ does not result in a straightforward passage to safety, acceptance, and equality. Instead, the queer complexity of Chin's intersectional identities - which include gendered, feminist, racial, national, queer, activist, and Caribbean positionalities - locates her in a state of constant movement as she negotiates, crosses between, the multiple facets of her belonging and homemaking within her poetry. Just as Anzaldúa ultimately finds herself reconciled to existence on 'this thin edge of barbwire', a position that is 'not comfortable but home', ${ }^{46}$ though, so does Chin actively engage in the construction of her own 'queer haven' out of the movements she performs between and across these positionalities. This is a stance that sees her both condemn the discriminatory cultures endemic to her homeland and nurture a 'double-edged' love for it ('My Jamaica', 23), while also battling against the deeply engrained forms of homophobia, sexism, and racism that she encounters within the U.S. itself - including within 'feminist' structures. In doing so, she suggests the complexity of 'home' and 'belonging' for queer 
women who cross borders in their search for sanctuary, finding themselves not in a state of utopia but rather placed 'in the cross/fire' ('Crossfire', 9) of multiple senses of estrangement, hostility, alliance, and belonging. Embracing her position in the 'crossfire', then, Chin invites us, via her poetic and indeed border-crossing alliance with Anzaldúa, to consider how a 'queer transcultural feminist' poetics of asylum might be produced not at the moment of arrival but rather in the process of perpetual movement across borders and between boundaries subtler than the national. In doing so, she draws us towards a queer transcultural feminism that does not simply embrace the margins, but that ultimately mobilises itself as a political movement through the very gesture of crossing, in defiance of the borders and boundaries that police identity.

Chin's poetic work has not usually been connected to forced migrant positionalities. Read more often within the contexts of U.S.-based women of colour, transnational, Caribbean, and queer cultural expression in academic and public circles, ${ }^{47}$ she has built a vibrant profile as a performer, poet, and activist now renowned for her participation in the Russell Simons Def Poetry Slam on Broadway, her appearance on The Oprah Winfrey Show's 'Gay Around the World' programme in 2007, and her performance at the Gay Games' opening ceremony in Chicago in 2006, as well as several off-Broadway, one-woman shows that combine dramatic monologue with poetry. ${ }^{48}$ It is tempting, in this light, to read her as a strident spokesperson for global LGBTQ+ and women's rights (the two of which intersect in her work) whose stance chimes readily with what Massad has termed the remit of the 'gay international', whereby the global North emerges as a site of liberation and of access to voice for those who have relocated there from 'elsewhere'. ${ }^{49}$ Yet as Sean Metzger attests, it is also possible, indeed important, to recognise how Chin's poetic positionality can be read as that of the 'queer refugee' (a term that refers to those who seek asylum on the basis of their sexual or gender orientation and that also suggests a destabilisation of the category of refugee itself). For Metzger, the 'queer kinships' and 'transient [modes of] performance' presented by the 'queer refugee' collectively challenge 'the very construction of the category of citizen'. ${ }^{50}$ Ultimately, then, the 'queer refugee' refuses to fall into line when it comes to the biopolitics of the asylum system and reveals alternative configurations of home and sanctuary beyond the boundaries of the nation state.

In line with the 'queer refugee' positionality that Metzger ascribes to her, Chin circles around the particular categorisation of her cross-border movement in her work. In the Acknowledgements to her 2019 poetry collection Crossfire: A Litany for Survival (which collects together work that she had been informally publishing and performing since the 1990s), Chin thanks her 'magical, fairy godfather' Peter - her eventual husband, with whom she had intended to start a family and who also identified as gay - for providing her with a sense of 'home' when she 'landed in America...undocumented and alone'. ${ }^{51}$ In the final chapters of her 2009 memoir, The Other Side of 
Paradise, meanwhile, Chin specifically describes her recognition that she 'might have to leave Jamaica' on the basis that she 'could get jumped or raped or killed if somebody suspect (sic) [she] could be serious about a woman'. ${ }^{52}$ Indeed, upon becoming more 'open' about her sexuality, she experiences a violent assault from a group of boys seeking to punish her for the 'nastiness' she 'promote[s]', ${ }^{53}$ and in the closing pages, as she flies from Jamaica, states that 'I intend to be away until it is safe for Jamaicans to be openly gay'. ${ }^{54}$ Yet in the very final lines of the text, she asserts a strong sense of agency in what she has earlier described as her 'migration': 'the choice to go is $m y$ decision. For the first time in my life my leaving is something I want to be happening to me'. ${ }^{55}$ This assertion of choice is not necessarily incompatible with Metzger's claim that 'Chin sought refugee status specifically because she wished to flee the homophobia of her native island, ${ }^{56}$ for, indeed, the decision to flee based on a well-founded fear of persecution - certainly present in Chin's case - need not only be understood as a matter of 'force' but can also be recognised as an expression of agency. The assertion that she applied for asylum in the U.S. on the basis of her sexual orientation, however, is not corroborated directly within either Crossfire or The Other Side of Paradise. ${ }^{57}$ It is instead a more ambivalent lexis of forced migration that surfaces in Crossfire - one poised between threat, fear, desire, and longing, in which she describes Jamaica as 'never... safe ground' offering 'harsh words of rigid correction' while also proving the site of a 'double-edged' 'love affair' ('My Jamaica', 23) - a 'paradise' she has 'abandon[ed]' in order 'to write/poems about leaving paradise' ('Traveling', 52). Frustrating as Chin's stance may be to those who wish to be able to 'place' her more clearly within the frameworks of 'refugee status', this ambivalence in fact serves an importantly queer function through its resistance not just to the classificatory drive of the asylum system but also to the rigid structures of the 'gay internationalist' framework that might seek to frame Chin's journey in a more 'straight forward' manner, as one of transnational transition from oppression to liberation. ${ }^{58}$ For instead, as Chin reveals, even her location within the 'sanctuary' of the U.S., and of her queer poetic expression, places her in the 'crossfire'.

A number of Human Rights-focussed reports have outlined the legally enshrined and culturally endemic nature of homophobia within the context of Jamaica. While male homosexual acts are specifically legislated against through the anti-buggery laws contained within the Offences Against the Person Act, ${ }^{59}$ it has often been suggested that female homosexual acts are not deemed illegal - though the law does prohibit "acts of gross indecency" between persons of the same sex, in private or in public'. ${ }^{60}$ While these laws are said to be poorly enforced, international reports, including those by the Associated Press, typically describe Jamaica as 'by far the most hostile island towards homosexuals in the already conservative Caribbean ${ }^{61}$ and evidence this with reports of mob violence, attacks, harassment, and threat against LGBTQ+ people, ${ }^{62}$ alongside much-discussed instances 


\section{No straightforward journey}

of homophobia evident within dancehall and reggae music, the lyrics of which have been interpreted as a platform for 'the "straight" man's working out of homophobic anxieties'. ${ }^{63}$ Lesbianism, meanwhile, has generally been deemed less 'visible e $^{34}$ and somewhat more tolerated - 'the object of ridicule rather than of the contempt and hostility reserved for males'. ${ }^{65}$ Nevertheless, reports of rape, forced marriage, and persecution of lesbian women in Jamaica abound. ${ }^{66}$ While many such reports have been critiqued as manifestations of a culturally unnuanced First World bureaucracy, these conditions nevertheless form the basis of many asylum claims from Jamaica made on the basis of sexual orientation and gender identity - including in the context of the U.S., where Chin comes to settle. ${ }^{67}$ Significantly, however, Chin's own poetic articulation of her queerness, and of the place of the queer within Jamaica, cuts against this potentially reductive categorisation of the Caribbean as a site of undifferentiated homophobia, and of binarised opposition to the global North - for within Crossfire, her awareness of homophobic discrimination in Jamaica cannot be disentangled either from her simultaneously feminist critique of gender violence against women or indeed from the parallels she finds between homophobia, misogyny, racism, and anti-immigrant sentiment in the U.S., her place of 'sanctuary'. Thus, by working in transcultural terms, Chin engages in acts of poetic crossing that undo the straightforward trajectory from danger to safety so often ascribed to the queer asylum claimant, instead asserting more complex forms of cross-border movement.

In Borderlands/La Frontera, Anzaldúa observes the competing forces that must be continually negotiated by the mestiza (woman of mixed race/of the borderland): those of patriarchal and misogynistic 'cultural tyrannies' stemming from one's 'home' culture, alongside the homophobia of the 'heterosexual tribe's fear'. ${ }^{68}$ For her, these intersecting oppressions result in the dual compulsions that both 'the struggle of the mestiza [should] above all be a feminist one' and the border dweller should develop a queer 'tolerance for contradictions, a tolerance for ambiguity ${ }^{69}$ : what we might describe as a distinctly queer feminism. This is also the case for Chin, who projects a similarly queer feminist critique of homophobic and gendered violence in Jamaica within her poetry, while also envisaging queerly transgressive feminist potentialities in her own subject position. In 'Know When to Fold', for instance, Chin describes her brother as 'my Jamaican boy/raised on a stout diet of violent homophobia', 'like we like our boys/unforgiving' while 'the pretty girls' who desire women are forced into 'the smallest closets on campus' (39-40). In 'Common Truths, or: Why I Love My Pussy', meanwhile, Chin recalls how 'being girl in Jamaica/in 1980 meant I had to run faster/ than my cousin's fingers [...]/my tiny breasts had to be brave' (12). In both of these poems, specific references to the locatedness of the gendered body within Jamaica reveals it as vulnerable to violent homophobia and to misogynistic sexual violence, necessitating an assertively queer feminist stance 
of resistance that surfaces repeatedly throughout her poems, including in 'Song of Survival', where she writes of 'the everyday spill of our daughter's blood' as 'our bloody history together' through which she must 'learn to pitch/this voice far beyond ... to reach for the greater intention/to save more than my own life' (44). Crucially, however, Chin also characterises this simultaneously sexualised and gendered violence as 'the death of more than one nation' (44), and in 'Passing', she finds this violence replicated within her U.S. home as she describes how 'butch bodies...too strong/too strange/ too dark' find themselves unable to 'pass' through a heteronormative U.S. Brooklyn neighbourhood without encountering homophobic violence: 'it takes two minutes for them to break two ribs/one for her lover who passes all the time/the other she keeps for herself' (54). In this poem, Chin herself finds herself able to 'pass' as 'a femme/a real lipstick lesbian'; yet she chooses to build a critical parallel between her sexual passing and her own Chinese grandmother's ability to 'pass' 'as white women sat in judgement/ on plantation stools overlooking fields.../ of Black blood and sweat' (54). The act of crossing performed by Chin here is not linear but circular, connecting white U.S. heteronormativity to a culture of privilege that has also spawned racism, and indeed slavery - a direct link between the U.S. and Jamaica that subverts the binary division instated by asylum-granting governmentalities between violent Caribbean 'backwardness' and salvational U.S. First World 'superiority'. Here, then, she gestures towards complex intersections between the structures of oppression and oppressor, privilege and disenfranchisement. Indeed, it is pertinent to note that a number of the laws according to which homosexuality has been prosecuted within the context of the Caribbean in fact stem from the implementation of European-derived colonial laws that have endured in its postcolonial condition ${ }^{70}-$ a recognition that destabilises the presentation of First World asylum-granting nations as those offering sanctuary and equality, given their status as former colonisers. This is an illusion that Chin shatters most forcefully in her poem 'Raise the Roof', in which she presents an enraged call-to-arms against contemporary manifestations of racism within the U.S., noting how 'this country continues to default/on the promise of citizenship for Black people' (164). This invocation of violated citizenship is significant when read against the backdrop of Chin's own positionality as 'queer refugee' - for as Aihwa Ong has written, the connected categories of 'refugee' and 'citizen' are 'political effects of institutional processes' established through the enforcement of 'common...values concerning family...social welfare [and] gender relations' ${ }^{71}$ Thus, by viewing citizenship as denied to Black U.S. citizens, she presents them as stateless people or asylum seekers within their own nation. Indeed, following M. Jacqui Alexander's observations that 'women's sexual agency [and] sexual and erotic autonomy have always been troublesome for the state', ${ }^{72}$ and that hence 'not just any body can be a citizen', ${ }^{73}$ Chin further 'queers' the conceptualisation of national 
citizenship through the highly intersectional 'roll call for protection' she performs within this poem, in which she declares that

all Black bodies must be accounted for

straight/queer/transgender

lesbian/feminist/Muslim/man

woman/immigrant/dark-skin

non-binary/tall/fat/skinny/light-skinned.

Here, then, it is the gendered, sexual, and racialised body itself that emerges as an alternative and legitimate 'body politic' to that of the asylum-granting state - one that is inherently inclusive and that registers multiplicity of identity. Thus, Chin's own crossing between her positionalities as queer, refugee, feminist, 'woman of colour', Jamaican, and U.S. inhabitant echoes something of Anzaldúa's own claim that as

the supreme crossers of cultures, homosexuals have strong bonds with the queer white, Black, Asian, Native American, Latino, and with the queer in Italy, Australia and the rest of the planet... Our role is to link people with each other. ${ }^{74}$

Rather than this queer feminist positionality appearing utopian, however, it surfaces as Chin's ability to cross between national, historical, gendered, and sexual contexts in her work, thus rendering visible the 'deep histories' of violence and inequality that underpin these transcultural locations. In Chin's poetry, then, she resists any straightforward perception of her journey from the Caribbean to the U.S. as one from danger to safety, enacting what we might describe as a queerly transcultural feminist movement performed through the very process of crossing.

If a home providing sanctuary proves evasive within the physical locations of either Jamaica or the U.S. then Chin's poetry also reveals her ability to construct a space of 'haven' through the connections she forges via creativity, political alliance, and, ultimately, loving relationships, both communal and individual. Crucially, however, this 'haven' does not emerge straightforwardly through either the 'queer' or 'feminist' communities that Chin encounters in the U.S. Indeed, these communities seem to demand limiting identifications on Chin's part, replicating, in some senses, the demand for 'categorisable' expressions of sexual orientation and gender identity by the asylum system. In 'Crossfire', for instance, Chin satirises the questions that she receives regarding 'where she stands' in relation to her sexual and gendered identity:

Am I a feminist

Or a womanist 
The student needs to know

If I do men occasionally

And primarily am I a lesbian...

Chin's response - that 'this business of dykes and dykery.../ is often messy [... and] primarily.../ I am concerned about young women/who are raped.../ after poetry readings like this one' (9) - points towards a queer feminist stance that is at once resistant to self-categorisation and committed to the practical work of tackling violence and injustice. As she explains within the poem, this stance is inherently resistant to the biopolitical regimen of the nation - whether that might take the form of 'the State [that] needs us to be left or right' (10), or indeed to what Jasbir Puar has described as a 'homonationalism' which presents 'queerness' as acceptable and capable of celebration only on terms compatible with and regulated by the neoliberal, primarily white, nation state. ${ }^{75}$ Instead, for Chin, as for Anzaldúa, the challenge is for her as intersectional, border-crossing subject 'to shift out of habitual formations; from convergent thinking...to divergent thinking, characterized by a movement away from set patterns and goals and toward a more whole perspective, one that includes rather than excludes'. ${ }^{76}$ This divergent, inclusive thinking surfaces in a number of Chin's poems, in which she incites a call to community coalition that is founded in acceptance of mutual alterity, and the empowerment that can arise from the creation of what José Esteban Muñoz has characterised as the politically affective bonds of queer collectivity. ${ }^{77}$ In her 'Speech Delivered in Chicago at 2006 Gay Games', for instance, she commands: 'gather round ye fags, dykes, trannies/ - and all those committed to radical social change', for 'all oppression is connected' $(96$; 94). Yet the intersectional alliances Chin forges are not uncritical, and while her desire to work 'across all the borders of feminism' ('Tweet This, Motherfucker', 27) forms an enduring critical backdrop to all of her writing, she nevertheless demonstrates a willingness to cross beyond the 'haven' that secure alliance with this term might bring. Instead, in 'Tsunami Rising (\#MeToo)', she points out the complex exclusions that have failed to build a racially and sexually inclusive feminism, or indeed a sexually or gender-inclusive racial politics in the U.S. that might serve

...every

Black woman who has disproportionately borne

the weight of racial and sexual violence

while everyone in the suffragette movement

and the Black civil rights movement

and the LGBT movement

turned a blind eye

to her swollen lips mouthing/me too. 
Yet just as Anzaldúa envisages the position of 'living on borders and in margins' as one that can result in 'an act of uniting and joining that not only....produce[s] a creature of darkness and a creature of light, but also a creature that questions the definitions of light and dark and gives them new meanings', ${ }^{78}$ so does Chin view her intersectional position as one that can ultimately produce a critical consciousness that is generative rather than simply disconnective, resulting in a space of queerly feminist, and racially liberated, haven. Ultimately, this haven assumes the lexis of love within her work - a trope that is not conceived of in straightforwardly romantic terms, but which is in itself associated with the act of journeying: 'love/is about endurance/it is a journey of distance', as she puts it in 'Fuck What You Heard About Falling' (193), or, as she describes it in the 'queer' love poem to her mother, 'I Have Never Known What We Are', 'I required nothing/to love you ... what I felt had no geography/no name/no borders' (186-187). In this declaration, we hear echoes of Anzaldúa's observation that 'the new mestiza copes by developing a tolerance for contradictions, a tolerance for ambiguity. ${ }^{79}$ In Chin's case, however, this tolerance is not synonymous with passivity, but is instead the very basis of her queerly transcultural feminist haven - one that is forged through the very process of crossing.

In Chin's Crossfire, then, haven does not emerge as the outcome of her journey from Jamaica to the U.S. - for as her poetry reveals, this journey is far from straightforward and refuses the trajectory that might be imposed by 'gay internationalist' stances on asylum which assume that travel from a 'homophobic' Caribbean to 'liberal' U.S. automatically grants safety and security. Indeed, this homonationalist, neoliberal drive towards 'queer citizenship' is founded in what Thibaut Raboin describes as a 'cruel optimism that cannot but fail in its promise of happiness', given the sense in which it 'simultaneously imagines futures for asylum seekers and closes them off to make them unachievable. ${ }^{80}$ In Chin's work, this does indeed register as the enduring discomfort of racist, misogynist, and homophobic violence stemming from the deep histories of slavery and imperialist First World dominance resonating between the U.S. and Jamaica. In place of this 'false promise' of asylum, though, Chin instead constructs a haven that is founded in her subversive status as both queer refugee and queer transcultural feminist - positionalities that both actively contest the reliance upon a claim to nationally legitimated citizenship and that instead present sanctuary through self-constructed, critically aware, cross-border, intersectional alliances. It is out of her very border-crossing, transcultural precarity that Chin's political power emerges, as a poet committed to working both within and across the borders of the queer, transcultural, and feminist - for as Anzaldúa puts it, those who actively cross boundaries of the gendered, sexual, and national are 'the people who leap in the dark... the people on the knees of gods. In our very flesh, (r)evolution works out the clash of cultures' ${ }^{81}$ 


\section{We are all already connected: trans-it and trans-formation in Wu Tsang's One Emerging from a Point of View}

If crossing surfaces as an act that is at once fraught and politically empowering in the work of Staceyann Chin, then it emerges as a space of altogether more otherworldly (or perhaps cross-worldly) transformation in the work of the film-maker and performance artist Wu Tsang. While self-identifying according to the possessive pronoun 'she/her', Tsang is consciously resistant to the 'confines of identification and language' in her own self-description, gendered, and otherwise, and has used the term 'multi-multi' in interview to describe what others have defined as her Chinese-Swedish-American heritage and trans identity. ${ }^{82}$ Throughout her career, however, Tsang has displayed an interest in documenting, performing, and imagining 'queer' lives, spaces, and states in ways that actively interrogate the boundaries of gendered and sexual identity, and that display an openness to transcultural, transitional spatial existences, and connectivities - as well as to the porous boundaries between reality and fantasy. In her 2012 feature film Wildness, for instance, she invokes a magic realist approach in her portrayal of the Silver Platter, a bar in Los Angeles that serves as a haven to the Latin immigrant and queer community, ${ }^{83}$ while her 2015 film Duilian sees Tsang return to her own Chinese heritage in an oblique manner in its portrayal of the Chinese feminist revolutionary Qiu Jin and her queer relationship with calligrapher Wu Zhuying. ${ }^{84}$ In her 43 -minute overlapping projection video work from 2019, One Emerging from a Point of View, however, her exploration of the porous nature of embodied, spatial, imaginative, and interpersonal boundaries is transported to Lesbos, Greece, where she seeks to conjure the extreme transformations that take place not just for those crossing the Mediterranean in search of safety but also for those who find themselves drawn into other kinds of personal encounters with forced migrant populations, whether as local inhabitants of Lesbos or as those documenting the crisis. ${ }^{85}$ Significantly, this work's complex exploration of transition and transformation is mediated through the overlapping narratives of two women who 'cross paths ... [but] never meet'. ${ }^{86}$ One of them, Yassmine Flowers, is a forced migrant from Morocco who performs the fantastical story of a young woman who undergoes a magical transformation after being persecuted by her family and those around her for her radical female alterity as a witch. The other, meanwhile, is the photojournalist Eirini Vourloumis who is assigned to document 'the migrant crisis' but ends up becoming involved with the rescue efforts of those who live within the fishing village of Skala Sikamineas and who also performs a reading of a story that invokes both the mythical beauty and the deep history of migration that has transformed the island over the past century. ${ }^{87}$ One Emerging therefore approaches the subjects of forced migration and of queerly gendered identity from aslant, resisting any straightforward narrative of queer female journeying and instead foregrounding the transformations of 
subjectivity, embodied form, and narrative drive that emerge from the film's (ironically) multiple points of view. Yet in its portrait of radical connectivity borne from transition and thus in its resistance to the heteropatriarchal limits of any nationalised, bounded conceptualisation of belonging, this work nevertheless invites us to imagine transgressive possibilities of selfhood, community, and kinship. Indeed, in the deeply queer connectivities imagined between bodies and location in this work, One Emerging seems to lead us towards the queer ecological feminist intersections of Donna Haraway's invocation of 'oddkin' as a way of imagining how it is that we should 'make kin in lines of inventive connection as a practice of learning to live and die well with each other in a thick present'. ${ }^{88}$ By exploring the relationship between transit, transition, and transformation (and, by implication, the broader state of the 'trans') within One Emerging, then, it becomes possible to perceive the construction of a creative community of 'oddkin' at stake within this work - one that enables us to think about the connections between transcultural movement, gendered embodiment, and feminist commitment in newly queer and transformational ways.

In what sense might it be possible to characterise the territory explored in One Emerging as 'queerly feminist' in nature, and how might this lead us to the notion of 'oddkin'? Tsang herself has described the diverse traversals of gendered, spatial, and historical boundaries that permeate her work as a preoccupation with 'in-betweenness': 'a state in which people and ideas cannot be described in binary terms', ${ }^{89}$ and this in itself seems to invoke much of the destabilising potentiality of the 'queer'. Her preoccupation with the relationship between transition and transformation, however, also invites us to connect this work with another queer realm: that of the multiple resonances of the term 'trans'. A prefix that means, in a literal sense, 'across, through, over, to or on the other side of,${ }^{90}$ the term 'trans' has travelled a complex path through gendered and sexual discourse to emerge, in contemporary usage, as an 'umbrella term' which encapsulates

...a wide variety of bodily effects that disrupt or denaturalize heteronormatively constructed linkages between an individual's anatomy at birth, a non-consensually assigned gender category, psychical identifications with sexed body images and/or gendered subject positions, and the performance of specifically gendered social, sexual, or kinship functions. ${ }^{91}$

Thus, the term 'trans' can be used to describe any assertion of gendered identity that disrupts the heteropatriarchally and heteronormatively ascribed system through which bodies are sexed as statically cis-male or cis-female at birth and corresponding qualities of 'masculinity' or 'femininity' imposed upon each, respectively. As a spectrum of gendered identities instead produced through a process of crossing 'the boundaries between gender, sex, and sexuality and the boundary that structures each as a binary 
category, ${ }^{92}$ trans not only incorporates male-to-female or female-to-male transsexual, transgender, drag, cross-dressing, bigender, gender-fluid, genderqueer, non-binary, and Two Spirit identifications but also entails the recognition that, as Jay Prosser puts it, trans identity may be 'open-ended', a state or experience that one 'refus[es] to pass through'. ${ }^{93}$ In the broader context of Tsang's work, it is interesting to note her early alliance with the self-described 'transfeminist' movement through her participation in the transfeminist activist video collective, PILOT TV: Experimental Media for Feminist Trespass!!! ${ }^{94}$ Defined by Emi Koyama as 'a movement by and for trans women who view their liberation to be intrinsically linked to the liberation of all women and beyond, ${ }^{95}$ transfeminism opens up the possibility of connecting trans identity to broader feminist struggles and alliances, and offers a possible lens through which to read the imaginative connection traced between the female protagonists of One Emerging, Yassmine and Eirini. Indeed, within One Emerging, this connection to the realm of the trans is affirmed through the presence of Yassmine Flowers, whose own performative queerness is registered in the epitexts surrounding this piece where she is described as 'a transgender woman' who has travelled from Morocco through Turkey and on to Lesbos in search of safety. ${ }^{96}$ Though Tsang herself is resistant to this categorisation of identity, we might nevertheless argue that the narrative of 'otherness' performed by Flowers - in which she describes the fictional Yassmine's alienation and persecution by her family for being 'a witch', a female figure associated with threatening and powerful alterity - can be read as allegorical in this piece. Echoing, in some senses, Anzaldúa's observation regarding the figure of the mita' $y$ mita' (half-and-half person) that 'maimed, mad, and sexually different people [have been] believed to possess supernatural powers by primal cultures' magico-religious thinking, ${ }^{97}$ Yassmine's story can also be read as a reflection of the social discrimination and harassment that may drive trans people to seek asylum, as well as to the violence - sometimes deadly - that they may experience within their 'home culture' and at the hands of the authorities during their journeys in search of asylum. ${ }^{98}$

When evoked by Tsang, though, the fluidity of Yassmine's identity also invites us to observe how, as B. Camminga notes, concepts such as transgender 'transfor[m] as [they] trave[1], taking on meaning in relation to bodies, national homes, institutional frameworks and imaginaries' specific to the context around them. ${ }^{99}$ Indeed, for Tsang, the realm of the 'trans' surfaces just as much through the transitional journeys that Yassmine makes within the story - into the realm of death and, subsequently, into resurrection as a 'sea witch', where she comes to 'live for eternity...in the depths... because she preferred to be far from people'. ${ }^{100}$ Yassmine's transitions - as 'real-life' forced migrant and as narrative construction - therefore seem to affirm Jay Prosser's observation that 'trans' experience has often been conjured through narrative motifs of journeying 'through space, from one location to another' in which the embodied subject '[crosses] several boundaries 


\section{No straightforward journey}

at once: both the boundaries between gender, sex, and sexuality and the boundary that structures each as a binary category'. ${ }^{101}$ Yet when placed within the multi-layered, interwoven narrative strands of One Emerging, the straightforward equation of transgender with transitional identity reads as reductive. Instead, it is a more holistic vision of crossing that emerges through this film's hybrid poetics - one that draws us beyond established conceptualisations of the 'trans' and closer, instead, to Haraway's queerly connective vision of 'oddkin' as the model of 'interspecies alliance' that must prevail within what she terms our 'troubling and turbid times'. ${ }^{102}$

Haraway's work stems from a radically connective interdisciplinary position at the interstices of the 'anticolonial, antiracist, proqueer feminist movement' 103 from which she posits a vision of 'multispecies ecojustice, which can also embrace diverse human people'. ${ }^{104}$ This work, she argues, is essential to our 'vulnerable and wounded earth'105 - a world which 'is full of refugees, human and not, without refuge'. ${ }^{106}$ While, like Tsang, she refuses confinement to any positionality founded in straightforward notions of sex, gender, or sexuality, her approach can nevertheless be read as deeply queer - for it is by 'staying with the trouble', 'stir[ring] up potent response to devastating events', ${ }^{107}$ that we might find new ways of inhabiting our planet resistant to the violent inequalities of the present-day 'Anthropocene' and 'Capitalocene'. ${ }^{108}$ Indeed, pivotal to this queerly troubling strategy is the 'feminist communitarian anarchis[t $t$ ' ${ }^{109}$ recognition that in place of a focus on reproduction as our future-leaning strategy, we must instead find ways to 'make kin as oddkin rather than, or at least in addition to, godkin and genelogical and biogenetic family'. ${ }^{110}$ 'Oddkin' does not simply refer to forging bonds between humans, however. Instead, the formation of oddkin requires 'inter/intra-action with other processes and species' - for 'all species share a common "flesh", laterally, semiotically, and genelogically. ${ }^{111}$ Haraway's vision, then, comprises a radical crossing of boundaries, both territorial and embodied - for amongst communities of 'oddkin', restraints such as gender, sexuality, or indeed nationhood fail to signify and are replaced instead with a wildly connective understanding of planetary existence in which humans are part of the 'humus' of 'hot compost piles' forged from 'unexpected collaborations and combinations'. ${ }^{112}$

'Unexpected collaborations and combinations' abound within One Emerging and indeed throughout the film, they materialise as 'multispecies alliances' between 'oddkin' of various compositions. In the opening scene to the film, this queer connectivity is conjured through a striking portrayal of the act of crossing - a motif that resonates throughout multiple narrative strands over the course of the work and which forges bonds between species human, animal, and otherworldly alike. This crossing, though, is not initiated by human actants. Instead, it is performed by a herd of goats that first appear in the frame, amassing at the edge of an inlet between sea and land that in itself gestures towards a fluid opening of boundaries - one that duly seems to entice the goats across it, as though drawn by a force 
larger than themselves - an instinct for survival, perhaps, or for progress. The drawn-out static long shot through which this movement is presented invites a meditative response on the part of the viewer, who is inevitably led towards interspecies substitution here, the goats' crossing invoking the passage of forced migrants across the Mediterranean to Greece in search of safety. Indeed, this connection is later affirmed in the film's subsequent transition to the figure of the goat farmer, who delivers his own narrative account of the mass arrival of forced migrants onto the island. As we see him expertly coaxing and controlling the frenetic flow of goats into his barn, he tells of the profound effect that his rescue efforts for those arriving had on him:

I have pulled out a lot of people - babies, women, what I can [sic] - it can't be described in words. All day I was in the sea soaked... The easiest thing is to die. The hardest thing is to continue living.

The interwoven visual and narrative threads conjured by Tsang, then, forge lines of connectivity between goats, farmer, and forced migrants whose paths have crossed through a shared compulsion towards the preservation and nurturing of life, in all of its 'troubled' circumstances - a connection that, Tsang seems to imply, emerges within the very space of crossing over, or indeed what might in its broadest sense be described as the state of the 'trans'.

Integral to Tsang's construction of connectivity through trans(ition) is her use of hybrid, interwoven narrative strategies - what she describes as 'visual entanglements' which 'intertwine' the otherwise 'disparate narratives.'.113 This strategy bears interesting parallels with Haraway's model of 'multispecies storytelling', which seeks a similarly connective and ambiguous space of interplay across sites of difference. For Haraway, 'multispecies storytelling'

is about recuperation in complex histories that are as full of dying as of living [...] real stories that are also speculative fabulations and speculative realisms. These are stories in which multispecies players, who are enmeshed in partial and flawed translations across difference, redo possible ways of living and dying attuned to still possible finite flourishing, still possible recuperation. ${ }^{114}$

We see the particularly important role played by 'speculative fabulation' in One Emerging through the fantastical story of Yassmine which, we learn from interview, was co-authored by Tsang and the real-life Yassmine Flowers during their time on the island together. ${ }^{115}$ Mythical in tone, this story operates in stylistic parallel with the narrative excerpts read by the photojournalist, Eirini, from the text The Mermaid Madonna, by Stratis Myrivilis - a book that tells the story of early twentieth-century Turkish 


\section{No straightforward journey}

refugees who fled to the island and whose descendants now include those living in present-day Skala Sikamina. In these excerpts, however, the island is described as a mermaid - a fantastical and hybrid creature, 'half-land, half-sea', part-woman, part-creature, her symbolic presence registering the psychic tensions present in the island's inhabitants themselves who must contend with their hybrid status as both 'immigrant' and 'native', beholden to the demands of the land and its surrounding waters. ${ }^{116}$ This 'complex history' is in some ways recuperated through the narrative evoked by Tsang and Yassmine, which conjures another tale of interspecies alliance - though this time, between Yassmine and the goats that her family are responsible for herding. Treated cruelly by the humans around her, the fictional Yassmine turns to the goats for friendship and love, and indeed rescues one of them from slaughter. It is this same goat that later returns to Yassmine once she has been murdered for rejecting the affections of a king and whose soul combines with hers in order to raise her from the dead, though in new form so that 'Yassmine came to have two legs like a goat, and horns like a goat'. The speculative fantasy conjured here thus connects Yassmine not just with the complex histories of forced migration to Skala Sikamina - both those who fled from Turkey and who are now the inhabitants of the island, herding its goats, and those in present-day Lesbos, of whom real-life Yassmine is one - but also to the more oblique embodied transitions that circulate around these histories: those of connection between the island's inhabitants and the animals they tend; of the island's own transitional identity, as documented by Eirini and as represented in the figure of the mermaid; and indeed, of the epitextually evoked backdrop of trans asylum-seeking experience that underpins the 'real-life' Yassmine's own journey. Indeed, in the final frames of the film, Yassmine undergoes a final transformation that seems to imbue her with a certain connective mastery over these disparate threads. We learn that she decides to seek refuge 'in the depths of the sea because she preferred to be far from people'. While the spoken narrative evokes alienation, the visual narrative, however, conjures a profound interspecies, inter-world connectivity between fantasy and reality. For around Yassmine's delicately undulating body appear the spectacular illuminations of deep-sea creatures: jellyfish and other 'tentacular' beings who, for Haraway, present the very embodiment of those who 'make attachments and detachments...weave paths and consequences but not determinisms', for 'tentacle comes from the Latin tentaculum, meaning "feeler", and tentare, meaning "to feel" and "to try". ${ }^{117}$ As though 'feeling' her way through these new waters, Yassmine's dancing limbs also seem tentacular in these final frames as they reach out, seemingly inviting the boats upon the water into her arms - a gesture of openness and hospitality that reclaims the sea from its associations with violent hostility.

Indeed, this exquisitely fantastical image seems to circle back as a referent to an earlier scene in which we witness the film's other narrative subjects - the farmer, Eirini, and other local inhabitants - united in their embodied efforts to pull upon a rope that, we assume, is hauling a 


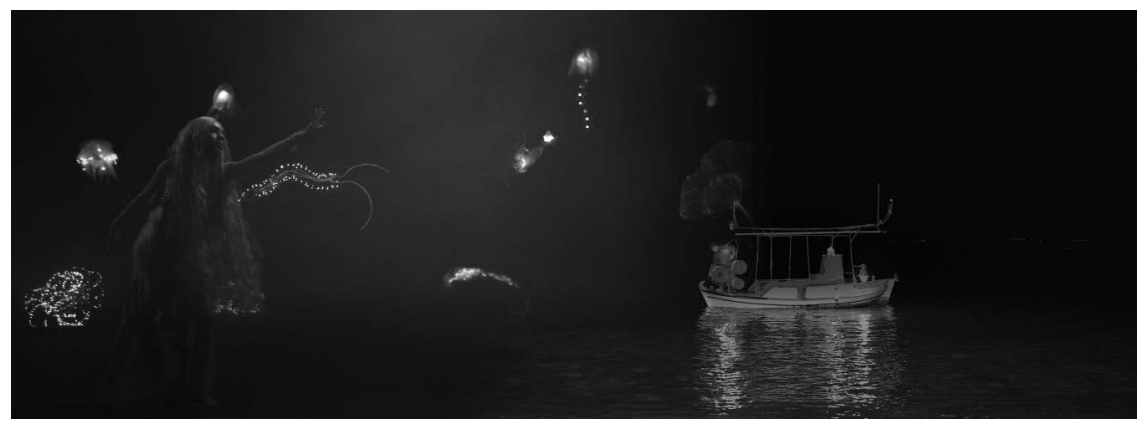

Figure 5.2 Still from One Emerging from a Point of View by Wu Tsang (2019). Image courtesy of the artist; Galerie Isabella Bortolozzi, Berlin; Cabinet, London; Antenna Space, Shanghai.

rescue vessel in to safety. Drawn into symbiotic existence through these visual 'feelers', Tsang thus conjures the island's 'oddkin' as those connected through their tentacular abilities to 'feel' for others. These are abilities that arise from the shared experience of reaching out to those engaged in the act of crossing over, but which also bring about forms of transformation - psychological and social - in all those who make such tentacular connections.

Just as Tsang resists the reductive tendencies of linguistic categorisation in her own engagement with issues of gendered identity and sexual orientation, so too does One Emerging refuse to be drawn into a straightforward narrative of 'trans' asylum-seeking. Like the currents of the waters surrounding Skala Sikamina, though, the presence of the trans is nevertheless an unspoken undertow within this work, making itself felt in the subtle reference to Yassmine's female alterity and 'otherworldly' qualities; in her social alienation and persecution; and in her association with hybrid, transitional bodily form. Tsang's decision to collapse the presence of the 'trans' into the realm of the mythic and fantastical allows its resonances to infuse the film in a manner that is connective and generative, rather than socially prescriptive, however - for within this work, it also evokes the transition of forced migrant bodies, the island's own transitional identity, and the transformative transitions through which those who encounter the island's new arrivals must pass, which see them moved to action, compassion, and trauma. In some senses, Tsang's work demands that we take seriously the concerns of critics such as Camminga and Jack Halberstam who urge that transgender experience must not be reduced to a metaphor of 'coming home' to a 'new body' but should instead be carefully contextualised in relation to 'wider issues around mobility and access, outside of metaphor, within specific locales'. ${ }^{118}$ Indeed, for Nael Bhanji, the oversimplification of the 'trans' journey stems from the fact that it is often reduced to a 'transitional journey [that] is merely a link between locations - a sort of gendered 
non-zone between origin and destination - and not a place to call home'.119 One Emerging arguably resists the realm of metaphor as a socially evasive zone, however, by grounding its poetics in the situated political realities surrounding the act of crossing within this work. For while 'trans-ness' signifies multiply as transit, transition, and transformation within One Emerging, its radical openness also connects it to the ecological, political, spatial, and embodied realities of those many others for whom the island is 'home' - a state that, as this film demonstrates, is itself defined by transition and transformation.

In its queer counternarrative of crossing, One Emerging therefore projects a radical openness that can be read as queerly and transculturally feminist in many senses. Not only does it enact a powerful critique of bounded models of the nation state, but it also resists the compulsion towards straightforward narrativisation embedded within the asylum system - a compulsion that limits and even terrorises those whose journeys are compelled or nuanced by queer gender identification. Instead, it situates the queer female subject at the heart of the generative connections forged between the 'oddkin' who inhabit and pass through the troubled world of the island - a space in which claims to national belonging are dissolved and replaced with a powerful vision of interspecies, planetary connectivity. Within this world, gender circulates as a fluid undercurrent rather than definitive politics. Yet in its vision of wildly connective community-making, alliance-building, and storytelling, it is hard to deny the queerly feminist potential at stake within this work - for as Haraway reminds us,

If there is to be multispecies ecojustice, which can also embrace diverse human people, it is high time that feminists exercise leadership in imagination, theory, and action to unravel the ties of both genealogy and kin, and kin and species. ${ }^{120}$

Unravelling and reweaving newly creative kinships via the multiple forms of crossing at stake within this film, Tsang's work arguably mobilises this queerly inclusive feminism to powerful effect - for as we emerge from her point of view, we are both many and one, and though we may not yet know it, we are all already connected.

\section{Communities of movement: towards a queer feminist art of crossing}

Crossing emerges as a loaded act in representations of queer women's forced migration. When manifesting as the physical act of crossing borders, it reveals the forms of discrimination and persecution based on sexual orientation and gendered identification that may drive people's journeys as forced migrants. So too does it expose the manifestations of bias, limitation, and structural violence embedded within the border mechanism itself - notably in the classificatory demands of the asylum system and the 
phobic nature of the structures through which it functions. These are vital recognitions for the transcultural feminist imagination, for they affirm its necessary commitment to recognising the situated nature of embodied identity and the necessary politics of strategic resistance that must be mobilised in response to the biopolitical and heteropatriarchal regimes that police the nation state. 'Queer' works such as Chin's and Tsang's therefore prove integral to the development of a culturally attentive twenty-first-century feminism - for in their representations of border-crossing, they also invite us to consider how gendered boundaries are transgressed, untied, and rewoven into new forms that, as Stryker et al. put it, enable us to 'understand genders as potentially porous and permeable spatial territories...each capable of supporting rich and rapidly proliferating ecologies of embodied difference. ${ }^{121}$ Indeed, in the work of both Chin and Tsang, the act of crossing does not simply emerge as one that involves the traversal of national borders but as a negotiation of spaces defined more subtly and invisibly, along communal, societal, and environmental lines. Within these more nuanced cartographies of planetary existence, both poet and artist show us that the art of seeking a home involves constant traversal of boundaries established in relation to gendered, sexual, racial, ethnic, political, environmental, and indeed interspecies positionalities. Viewed from this perspective, crossing cannot be understood as a linear or 'straight' narrative of a journey from danger to safety, but instead as a constant and ongoing process of negotiation in which subject positions and senses of self are being remade.

Where, then, do these queer crossings leave feminists as they seek to navigate the transcultural landscapes of forced migration? Ultimately, they seem to guide us towards an understanding of feminism that resists static positionality and that embraces the transformational possibilities of rethinking feminism as a movement. While feminism has often been understood as a political movement, Sara Ahmed also invites us to envisage feminism as a state of perpetual mobility engaged in its own constant quest for sanctuary:

Feminism is a movement in many senses. We are moved to become feminists. Perhaps we are moved by something: a sense of injustice... A feminist movement is a collective political movement. Many feminisms means many movements. A collective is what does not stand still but creates and is created by movement [...] Feminism: the dynamism of making connections. ${ }^{122}$

Motivated by feeling as much as by politics and plural rather than singular in its construction, Ahmed's vision of feminist movement(s) mirrors the shift towards collectivity, community, and connectivity that also ultimately arises from Chin and Tsang's work - whether it might take the form of intersectional queer feminist community, as in Crossfire, or of planetary 'oddkin', as in One Emerging. As we have seen from the queer crossings performed within this chapter, no forced migrant journey is ever straightforward, and nor is any single narrative of 'female' experience or identity. 
In response to these movements, it is vital indeed that feminism should remain nimbly mobile - able and willing to traverse diverse disciplinary territories, guided by paths of experience and communities of feeling rather than by the cartographies of state borders.

Rather than alerting us to experiences that might more usually be considered marginal or peripheral, then, the queer feminisms of the works explored within this chapter in fact reveal queerness itself as pivotal to the functioning of any twenty-first-century transcultural feminist movement. For it is in the very interplay between situated, political knowledge and creative, imaginative world-making - the territories traversed by queer forced migrant women - that a transcultural feminist movement might emerge from the landscapes of twenty-first-century forced migration. Queer and feminist movements are not simply connected but collective, then. Between them, they reveal new paths by which we can traverse the territories encountered by women, however self-defined, and travel in mutual support through a territory at once hostile and full of creative promise.

\section{Notes}

1 The terminology surrounding gender identity and sexual orientation is the subject of ongoing debate and must be read contextually. Within this chapter I employ the term 'queer' either where it is the self-selected term employed by a particular individual (as was the case for Hegazi) or, in a broader sense, to denote a transgressive resistance to heteronormativity as it manifests in relation to both gendered and/or sexual identity, or indeed in relation to other hegemonic biopolitical structures (such as the asylum system). I also, however, employ the terms LGB, LGBT, LGBTQ+, or lesbian/gay/trans where these terms are more appropriate to describe particular self-identifications or otherwiseascribed identifications determined by law, policy, or advocacy platforms. At times, I also employ the term 'queer women' or 'queer female' to describe particular manifestations or mobilisations of queerness performed by those who identify as female.

2 For further on cultural and political responses to female queerness within the context of the Middle East, see Samar Habib, Female Homosexuality in the Middle East: Histories and Representations (London: Routledge, 2007). For further on the hostile response to queerness that has emerged specifically within the context of post-revolutionary Egypt from 2017, see Patrick Solomon, 'Two Years after Egypt's "Rainbow Flag Arrests”, LGBTIQ People Face an Ongoing Security Crackdown', Open Democracy, 22nd September 2019, https://www.opendemocracy.net/en/5050/two-years-after-egypts-rainbowflag-arrests-lgbtiq-people-face-an-ongoing-security-crackdown/ (last accessed 21st September 2020).

3 Hamed Sinno, 'Hamed Sinno on Pride and Mourning in the Middle East', Frieze, 26th June 2020, https://www.frieze.com/article/hamed-sinno-prideand-mourning-middle-east (last accessed 20th August 2020).

4 Sarah Hegazi, 'A Year after "the Rainbow": A Regime Arrests, and the Islamists Applaud', Mada Masr, 24th September 2018, https:/www.madamasr. com/a r / $2018 / 09 / 24 /$ opinion / u / \% d $8 \%$ b $9 \%$ d $8 \%$ a $7 \%$ d $9 \% 85$ \%d8\%b9\%d9\%84\%d9\%89-\%d9\%85\%d9\% $88 \%$ d9 $\% 82 \%$ d $8 \%$ b9\%d8\%a $9-\%$ d $8 \%$ a $7 \%$ d $9 \% 84 \%$ d $8 \%$ b1\% d $9 \% 8$ a $\%$ d $9 \% 86 \%$ d $8 \%$ a $8 \%$ d $9 \% 88$ - $\%$ d $9 \% 86 \%$ d $8 \%$ b $8 \%$ d $8 \%$ a $7 \%$ d $9 \% 85$ - \% d $9 \% 8$ a \% d $8 \%$ b $9 \%$ d $8 \%$ a a 
$\%$ d $9 \% 82 \%$ d $9 \% 84 \%$ d $8 \% 8 c-\%$ d $9 \% 88 \%$ d $8 \%$ a $5 /$ ? fbclid=IwAR 2 BxGcS3JhkU1ZRMrTidEazsiDQ1JjkPXcHIremRgDrU-tjyklqunEp20 (last accessed 20th August 2020).

5 The World, 'Remembering Sarah Hegazi, the Egyptian LGBTQ Activist Arrested for Unfurling the Rainbow Flag', The World, 16th June 2020, https://www.pri. org/stories/2020-06-16/remembering-sarah-hegazi-egyptian-LGBTQ-activistarrested-unfurling-rainbow-flag (last accessed 20th August 2020).

6 I employ the asterisked term 'women"' here to denote the multiplicity of female identity at stake within this chapter, in line with contemporary queer usage. Further uses of the term 'woman' in this chapter assume this multiplicity, though silently, in non-asterisked form (which I subsequently remove in order to eliminate the division between women and women* that might otherwise emerge across chapters of this book).

7 See Aengus Carroll, State-Sponsored Homophobia 2016: A World Survey of Sexual Orientation Laws: Criminalisation, Protection and Recognition (Geneva: International Lesbian, Gay, Bisexual, Trans and Intersex Association, 2016).

8 Thibaut Raboin, Discourses on LGBT Asylum in the UK: Constructing a Queer Haven (Manchester: Manchester University Press, 2017), p.3.

9 B. Camminga, Transgender Refugees and the Imagined South Africa: Bodies over Borders and Borders over Bodies (Cham: Springer International, 2019), p.9.

10 See UNHCR, 'Guidelines on International Protection Number 9: Claims to refugee Status based on Sexual Orientation and/or Gender Identity within the context of Article 1A(2) of the 1951 Convention and/or its 1967 Protocol relating to the Status of Refugees', UNHCR, 12th October 2012, https://www.unhcr. org/publications/legal/509136ca9/unhcr-guidelines-international-protection-9claims-refugee-status-based.html (last accessed 16th September 2020).

11 Both Camila Díaz Córdova and Roxsana Hernández were trans women who died following failed or uncompleted asylum claims to the U.S. Following her failed asylum claim in 2017, Córdova was deported back to El Salvador, a country in which trans women have a life expectancy of only 35 years due to the extreme violence and discrimination they face. See Anna-Catherine Brigida, 'El Salvador's Justice System Takes on a Historic Case', Foreign Policy, 9th March 2020, https://foreignpolicy.com/2020/03/09/el-salvador-justice-system-historiccase-transgender-asylum-seeker/ (last accessed 21st September 2020). Hernández, meanwhile, died while in immigration detention within the U.S. following her claim for asylum from Honduras where trans women are also persecuted. According to Antonio Tomas De La Garza, Hernández was refused proper medical attention required for HIV-related illness due to endemic transphobia within the U.S. asylum system, which resulted in her death. See Antonio Tomas De La Garza, 'A Eulogy for Roxsana Hernández: Tracing the Relationship between Border Rhetoric and Queer Disability', QED: A Journal in GBLBTQ Worldmaking 6:3 (2019), pp.94-99.

12 Katherine Fobear, 'Nesting Bodies: Exploration of the Body and Embodiment in LGBT Refugee Oral History and Participatory Photography', Social Alternatives 35:3 (2016), pp.33-43; p.41.

13 Laurent Berlant, 'Slow Death (Sovereignty, Obesity, Lateral Agency)', Critical Enquiry 33:4 (2007), pp.754-780; p.759.

14 Sima Shakhsari, 'The Queer Time of Death: Temporality, Geopolitics, and Refugee Rights', Sexualities 17:8 (2014), pp.998-1015; p.1000.

15 Gayatri Gopinath, Unruly Visions: The Aesthetic Practices of Queer Diaspora (Durham, NC: Duke University Press, 2018), p.20.

16 Donna McCormack, Queer Postcolonial Narratives and the Ethics of Witnessing (New York: Bloomsbury Academic, 2014), pp.5-6.

17 Gayatri Gopinath, Impossible Desires: Queer Diasporas and South Asian Public Cultures (Durham, NC: Duke University Press, 2005), p.11; p.14. 
18 Eve Kosofsky Sedgwick, Tendencies (Durham, NC: Duke University Press, 1993), p.xiii.

19 Gloria Anzaldúa, Borderlands/La Frontera: The New Mestiza (San Francisco: Aunt Lute, 1999), p.3.

20 Ibid., p.103.

21 Ibid., p.3.

22 Ibid., p.95.

23 See Lyra Bieksa, Laurynas Jakuleviciene, and Egle Samuchovaite, 'Procedural Problems in LGBTQ Asylum Cases', Jurispudencija 19:1 (2012), pp.195-207 and Louis Middlekoop, 'Normativity and Credibility of Sexual Orientation in Asylum Decision Making', in Thomas Spijkerboer, ed., Fleeing Homophobia: Sexual Orientation, Gender Identity and Asylum (New York: Routledge, 2013), pp.154-175.

24 Jill Power, 'Lesbian, Gay, Bisexual and Trans People and Persecution: Experiences of LGBT People and the U.K. Asylum System', in Oreet Ashery, Staying: Dream, Bin, Soft Stud and Other Stories, available as PDF via Artangel, https://www.artangel.org.uk/project/staying/ (last accessed 24th August 2020), pp.8-13; pp.8-9.

25 Sudeep Dasgupta, 'Sexual and Gender-Based Asylum and the Queering of Global Space', p.90.

26 Lauri Berg and Jenni Millbank, 'Constructing the Personal Narratives of Lesbian, Gay and Bisexual Asylum Claimants', Journal of Refugee Studies 22:1 (2007), pp.195-223.

27 Fatma E. Marouf, "The Emerging Importance of "Social Visibility" in Defining "a Particular Social Group" and Its Potential Impact on Asylum Claims Related to Sexual Orientation and Gender', Yale Law and Policy Review 27:1 (2008), pp.47-106.

28 Raboin, Discourses on LGBT Asylum in the UK, p.13.

29 Ibid., p.12.

30 Camminga, Transgender Refugees and the Imagined South Africa, pp.1011 and Erkan Affan, 'The Marginalisation of Transgender Refugee Women from UNHCR's Policies of Gender Mainstreaming', Jadaliyya, 27th May 2019, https://www.jadaliyya.com/Details/38692 (last accessed 21st August 2020).

31 See Carlos Motta, The Crossing, Stedelijk Museum, Amsterdam, 16th September 2017-21st January 2018, https://www.stedelijk.nl/en/exhibitions/carlosmotta-the-crossing (last accessed 24th August 2020).

32 Gopinath, Impossible Desires, p.6.

33 Ado Ata Pictures, 'Another Dream', Queer in a Time of Forced Migration, 2019, animated documentary/virtual reality, 20 minutes. See Ado Ata Pictures, https://www.adoatopictures.com/another-dream (last accessed 24th August 2020).

34 Oreet Ashery, 'Staying: Now and Later', in Oreet Ashery, Staying, p.7.

35 See for instance the UndocuQueer project in the U.S. led by Julio Salgado, http://yonah.org/channel/undocuqueer-movement (last accessed 24th August 2020), and the poetry project explored in Dill J. LeConté, Jo Vearey, Elsa Oliveira, and Gabriela Martínez Castillo, "Son of the Soil...Daughters of the Land": Poetry Writing as a Strategy of Citizen-Making for Lesbian, Gay, and Bisexual Migrants and Asylum Seekers in Johannesburg', Agenda 30:1 (2016), pp.85-95.

36 Chinelo Okparanta, Under the Udala Trees (London: Granta, 2017).

37 See for instance John Scagliotti, dir., Dangerous Living: Coming Out in the Developing World (U.S., 2003), Jill Burnett, dir., This Way Out (U.S., 2004) and Fatih Akin, dir., The Edge of Heaven (Germany, 2007).

38 Angelina Maccarone, dir., Unveiled (Germany/Austria, 2005). 
39 See International Queer and Migrant Film Festival, https://iqmf.nl/ (last accessed 25th August 2020).

40 Aren Aizura, 'Transgender Travel Narratives', in Trystan T. Cotten, ed., Transgender Migrations: The Bodies, Borders and Politics of Transition (New York: Routledge, 2012), pp.139-156; p.142.

41 Staceyann Chin, Crossfire: A Litany for Survival (Chicago, IL: Haymarket, 2019).

42 Wu Tsang, One Emerging from a Point of View, 2-channel overlapping projections, 43 minutes, 2019. See Sharjah Art Foundation, http://sharjahart.org/ sharjah-art-foundation/projects/one-emerging-from-a-point-of-view-2019 (last accessed 25th August 2020) for further information.

43 Anzaldúa, Borderlands/La Frontera, pp.41-42.

44 See Staceyann Chin, The Other Side of Paradise: A Memoir (New York: Scribner, 2009), pp.246-273 and Kelly Baker Josephs, 'Dissonant Desires: Staceyann Chin and the Queer Politics of a Jamaican Accent', Mosaic: An Interdisciplinary Critical Journal 42:2 (2009), pp.153-170.

45 Staceyann Chin, 'My Jamaica', in Crossfire, p.29. All subsequent references to this poetry collection will be included as in-text page numbers.

46 Anzaldúa, Borderlands/La Frontera, p.25; p.vii.

47 See for instance Jeannine Murray-Román, 'Multimedia Staceyann Chin: Performing and Blogging "Cyberjournal"', Extensions: The Online Journal of Embodiment and Technology 3 (2006), http://www.performancestudies. ucla.edu/extensionsjournal/ roman.htm (last accessed 21st September 2020); Valerie Palmer-Mehta, 'Subversive Maternities: Staceyann Chin's Contemplative Voice', QED: A Journal in GLBTQ Worldmaking 3:1 (2016), pp.34-60; and Birgit M. Bauridl, 'Contemporary "Black"? Performance Poetry', Amerikastudien/American Studies 55:4 (2010), pp.715-724.

48 Staceyann Chin has collated five chapbooks in addition to her autobiography and collected poems in Crossfire. Her performance pieces include Hands Afire (New York: Bleeker Theatre, 2000), Border/Clash: A Litany of Desires (New York: Bleeker Theatre, 2005) and Motherstruck (Chicago, DC and NYC, 2015-2016). For further on her media contributions, see Baker Josephs, 'Dissonant Desires', p.154.

49 Joseph Massad, 'Re-Orienting Desire: The Gay International and the Arab World', Public Culture 14:2 (2002), pp.361-385.

50 Sean Metzger, 'Concerning the Queer Refugee: Staceyann Chin's Transient Performance', Cultural Dynamics 0:0 (2020), pp.1-16; pp.5-6.

51 Chin, Crossfire, p.205.

52 Chin, The Other Side of Paradise, p.244.

53 Ibid., p.261.

54 Ibid., p.273.

55 Ibid., p. 273.

56 Metzger, 'Concerning the Queer Refugee', p.7.

57 I have been unable to corroborate Metzger's claim that Chin applied for asylum in the U.S. based on any of her publications. However, it cannot be discounted that there may be further evidence for this in Chin's performances, which have not all been recorded. As I argue within the chapter, however, Chin's 'queer refugee' status need not be taken as narrowly confined to her having made a formal asylum claim, and it is important to resist a compulsion towards evidence-based classification of identity that might mirror that of the asylum system. Indeed, the term 'forced migration' encompasses the potential for forms of migration not formally processed through the asylum system to, nevertheless, be understood as coerced at some level.

58 In The Oxford Handbook of Refugee and Forced Migration Studies, for instance, the editors state that 'being a refugee is qualitatively different from 
being a migrant'. Elena Fiddian-Qasmiyeh, Gil Loeschr, Katy Long, and Nando Sigona, eds., The Oxford Handbook of Refugee and Forced Migration Studies (Oxford: Oxford University Press, 2014), p.5. Chin's forced migrant experiences, however, cross between coercion and choice, states of belonging and unbelonging, and thus challenge this claim.

59 See, for instance, Lucas Paoli Itaborahy, 'Jamaica', State-Sponsored Homophobia: A World Survey of Laws Criminalising Same-Sex Sexual Acts between Consenting Adults (Geneva: International Lesbian, Gay, Bisexual, Trans and Intersex Association, 2012), p.59.

60 Bureau of Democracy, Human Rights and Labour, 'Jamaica: Country Reports on Human Rights Practices for 2011', U.S. Department of State, https://2009-2017.state.gov/j/drl/rls/hrrpt/humanrightsreport/index. htm?dlid=186525 (last accessed 21st September 2020).

61 See Research Directorate, Immigration and Refugee Board of Canada, 'Jamaica: Treatment of Sexual Minorities, Including Legislation, State Protection and Support Services', IRB: Immigration and Refugee Board of Canada, January 2013, http://www.irb-cisr.gc.ca:8080/RIR_RDI/RIR_RDI. aspx? id $=454341 \& \mathrm{l}=\mathrm{e}$ (last accessed 21st September 2020).

62 Ibid.

63 Carolyn Cooper, Noises in the Blood: Orality, Gender and the 'Vulgar' Body of Jamaican Popular Culture (London: Macmillan, 1993), p.162.

64 Makeda Silvera, 'Man Royals and Sodomites: Some Thoughts on the Invisibility of Afro-Caribbean Lesbians', Feminist Studies 18:3 (1992), pp.521-532. See also Rosamond S. King, 'More Notes on the Invisibility of Caribbean Lesbians', in Thomas Glave, ed., Our Caribbean: A Gathering of Lesbian and Gay Writing from the Antilles (Durham, NC: Duke University Press, 2008), pp.191-196.

65 Barry Chevannes, 'Gender and Adult Sexuality', in Patricia Mohammed, ed., Gendered Realities: Essays in Caribbean Feminist Thought (Kingston: University of the West Indies Press, 2002), pp.486-494; p.488.

66 Rhon Reynolds, Rebecca Schiefler, and Neela Ghoshal, 'Not Safe at Home: Violence and Discrimination Against LGBT People in Jamaica', Human Rights Watch, 21st October 2014, https://www.hrw.org/report/2014/10/21/ not-safe-home/violence-and-discrimination-against-lgbt-people-jamaica (last accessed 21st September 2020).

67 David A. B. Murray, 'The Homonational Archive: Sexual Orientation and Gendered Identity Refugee Documentation in Canada and the US', Ethnos 82:3 (2017), pp.520-544.

68 Anzaldúa, Borderlands/La Frontera, p.38; p.40.

69 Ibid., p.106; p.101.

70 Joseph Gaskins Jr., "Buggery" and the Commonwealth Caribbean: A Comparative Examination of the Bahamas, Jamaica, and Trinidad and Tobago', in Corinne Lennox and Matthew Waites, eds., Human Rights, Sexual Orientation and Gender Identity in the Commonwealth (London: Human Rights Consortium, 2013), pp.429-454.

71 Aihwa Ong, Buddha Is Hiding: Refugees, Citizenship, the New America (Berkeley: University of California Press, 2003), p.79; p.xvii.

72 M. Jacqui Alexander, 'Erotic Autonomy as a Politics of Decolonization: An Anatomy of Feminist and State Practice in the Bahamas Tourist Economy', in M. Jacqui Alexander and Chandra Talpade Mohanty, eds., Feminist Genealogies, Colonial Legacies, Democratic Futures (New York: Routledge, 1997), pp.63-100; p.64.

73 M. Jacqui Alexander, 'Not Just (Any) Body Can Be a Citizen: The Politics of Law, Sexuality, and Postcoloniality in Trinidad and Tobago and the Bahamas', 
in Catherine Hall, ed., Cultures of Empire: A Reader (New York: Routledge, 2000), pp.359-376.

74 Anzaldúa, Borderlands/La Frontera, p.107.

75 Jasbir Puar, Terrorist Assemblages: Homonationalism in Queer Times (Durham, NC: Duke University Press, 2017), p.2.

76 Anzaldúa, Borderlands/La Frontera, p.101.

77 José Esteban Muñoz, Cruising Utopia: The Then and There of Queer Futurity, 10th Edition (New York: New York University Press, 2019).

78 Anzaldúa, Borderlands/La Frontera, p.vii; p.103.

79 Ibid., p.101.

80 Raboin, Discourses on LGBT Asylum in the UK, p.126.

81 Anzaldúa, Borderlands/La Frontera, p.103.

82 See Niloo Sharifi, 'How Wu Tsang is Rejecting the Confines of Gender and Language', Sleek, 14th November 2017, https://www.sleek-mag.com/article/ wu-tsang-interview-identity-fact/ (last accessed 30th September 2020) and Alex Greenberger, 'Take Me Apart: Wu Tsang's Art Questions Everything We Think We Know about Identity', ARTNews, 26th March 2019, https://www. artnews.com/art-news/artists/wu-tsang-12224/ (last accessed 30th September 2020).

83 Wu Tsang, dir., Wildness (U.S., 2012).

84 Wu Tsang, dir., Duilian (Hong Kong: Spring Workshop, 2016). See also Ariela Gittlen, 'In Her New Film, Wu Tsang Unveils the Queer History of One of China's Most Famous Poets', Artsy, 21st March 2016, https://www.artsy.net/ article/artsy-editorial-wu-tsang-unveils-the-queer-history-of-one-of-china-smost-famous-poets (last accessed 30th September 2020).

$85 \mathrm{Wu}$ Tsang, One Emerging from a Point of View, 43-minute, 2-channel overlapping projections, 2019 (hereafter referred to as One Emerging). This work was commissioned by the Fast Forward Festival 6 and first displayed at the Sharjah Biennial 14. See Wu Tsang, One Emerging from a Point of View, Sharjah Art Foundation, http://sharjahart.org/sharjah-art-foundation/projects/oneemerging-from-a-point-of-view-2019 (last accessed 5th October 2020).

86 See Wu Tsang, One Emerging From a Point of View, n.p.

87 See Eirini Vourloumis, 'The Mermaid Madonna', Eirini Vourloumis Photography, http://www.eiriniphoto.com/the-mermaid-madonna/ (last accessed 5th October 2020).

88 Donna Haraway, Staying with the Trouble: Making Kin in the Chthulucene (Durham, NC: Duke University Press, 2016), p.1.

89 Alex Greenberger, 'Take Me Apart'.

90 Oxford English Dictionary, 'trans-, prefix', Oxford English Dictionary Online, June 2020, https://www.oed.com/view/Entry/204575? result=4\&rskey= JS0R8f\& (last accessed August 14, 2020).

91 Susan Stryker, 'The Transgender Issue: An Introduction', GLQ: A Journal of Gay and Lesbian Studies 4:2 (1998), pp.145-158; p.149.

92 Jay Prosser, Second Skins: The Body Narratives of Transsexuality (New York: Columbia University Press, 1998), p.22. I note that Prosser writes specifically of what he terms 'transsexual' identity - a category now integrated into the broader realm of the 'trans', which had not yet developed at the time when Prosser's work was first published.

93 Ibid., p.11.

94 Alex Greenberger, 'Take Me Apart'.

95 Emi Koyama, 'The Transfeminist Manifesto', in Rory Dicker and Alison Piepmeier, eds., Catching a Wave: Reclaiming Feminism for the Twenty-First Century (Lebanon, NH: Northeastern University Press, 2003), pp.244-262. 


\section{No straightforward journey}

96 Ilyn Wong, 'Between Opacity and Transparency: Wu Tsang at Gropius Bau', Berlin Art Link, 29th November 2019, https:/www.berlinartlink.com/2019/11/29/ between-opacity-and-transparency-wu-tsang-at-gropius-bau/ (last accessed 2nd October 2020).

97 Anzaldúa, Borderlands/La Frontera, p.41.

98 Don Operario and Tooru Nemoto, 'On Being Transnational and Transgender: Human Rights and Public Health Considerations', American Journal of Public Health 107:10 (2017), pp.1537-1538.

99 Camminga, Transgender Refugees and the Imagined South Africa, p.2.

100 Yassmine's narrative performed by Yassmine Flowers in One Emerging from a Point of View.

101 Prosser, Second Skins, p.5; p.22.

102 Haraway, Staying with the Trouble, p.1.

103 Ibid., p.139.

104 Ibid., p.102.

105 Ibid., p.10.

106 Ibid., p.100.

107 Ibid., p.2.

108 Haraway defines the 'Anthropocene' as 'a new geological term for a new epoch' defined by 'the transformative effects of human activities on the earth' (ibid., p.44). Haraway, however, advocates for an alternative understanding of the 'Capitalocene' as one in which planetary change has been driven primarily by the interconnection between 'economies and ecologies' (ibid., pp.49-50).

109 Haraway, Staying with the Trouble, p.12.

110 Ibid., p.2.

111 Ibid., p.103.

112 Ibid., p.4.

113 Wu Tsang, One Emerging from a Point of View n.p.

114 Haraway, Staying with the Trouble, p.10.

115 Kathryn O'Regan, 'How Collaboration Is the Driving Force Behind Wu Tsang's Mesmerising New Film on the Migrant Crisis', Sleek Magazine, 10th October 2019, https://www.sleek-mag.com/article/wu-tsang-migrant-crisis/ (last accessed 5th October 2020).

116 Stratis Myrivilis, The Mermaid Madonna (London: Hutchinson, 1959).

117 Haraway, Staying with the Trouble, p.31.

118 Camminga, Transgender Refugees and the Imagined South Africa, p.8.

119 Nael Bhanji, 'TRANS/SCRIPTIONS: Homing Desires, (Trans)sexual Citizenship and Racialised Bodies', in Trystan T. Cotten, ed., Transgender Migrations: The Bodies, Borders and Politics of Transition (New York: Routledge, 2012), pp.157-175; p.162.

120 Haraway, Staying with the Trouble, p.102.

121 Susan Stryker, Paisley Currah, and Lisa Jean Moore, 'Introduction: Trans-, Trans, or Transgender?', WSQ: Women's Studies Quarterly 36:3 (2008), pp.11-22; p.12.

122 Sara Ahmed, Living a Feminist Life (Durham, NC: Duke University Press, 2017), p.3. 


\section{Conclusion}

\section{Creative mobilisations}

To gaze upon Hayv Kahraman's 2016 work Search is to enter into a state of creative dislocation. ${ }^{1}$ Suspended within the indeterminate landscape of a blank canvas, a multitude of variously fragmented female forms float in unfamiliar poses - caught, perhaps, in a moment of transcendence or of torment; in a self-aware posturing for the viewer's gaze or a moment of intimacy with her female companions. The pale radiance of the women's skins conjures the painterly quality of a Renaissance nude - yet the elegant stylisation of the women's hair and their careful arrangement evokes the visual language of the Persian miniature, while the women's facial features seem to reverberate with Kahraman's own Arab identity. ${ }^{2}$ And marking the canvas itself are a series of precise, delicate ' $\mathrm{x}$-s' - penetrations that also embellish; lend dimensionality even as they destroy. Try to seek out an explanation for us, these women seem to say to us. We will always exceed what you can know.

Search represents an important moment in the development of Kahraman's oeuvre for it is part of a series - Audible Inaudible - in which the artist not only experiments with rupturing the canvas itself for the first time but also seeks to evoke multisensory experience through an engagement with her memories of sound. ${ }^{3}$ It is possible to impose an autobiographical interpretation upon this work in order to understand the significance of these shifts in Kahraman's practice. As a woman of Iraqi origin, Kahraman's early years are defined by the American-led 'Operation Desert Storm', which punctuated her Baghdadi childhood with the sound of sirens - a form of 'sonic violence' that she counters through the puncturing of the canvas and the insertion of sound-absorbing acoustic foam, thus 'enabling the painting to breathe...reacting, resisting, defending and accepting these sonic wounds'. ${ }^{4}$ The women's postures, meanwhile, recall those of Iraqi insurgents depicted on U.S. military cards, though they are layered palimpsestically with the female form that appears repeatedly across Kahraman's works: that of 'She', a figure created from body scans of the artist herself, yet rendered culturally ambiguous through the stylistic utilisation of sfumato painting techniques drawn from the Italian Renaissance that render 'Her' 'someone under the spell of coloniality' - 'someone

DOI: $10.4324 / 9780429325403-6$ 


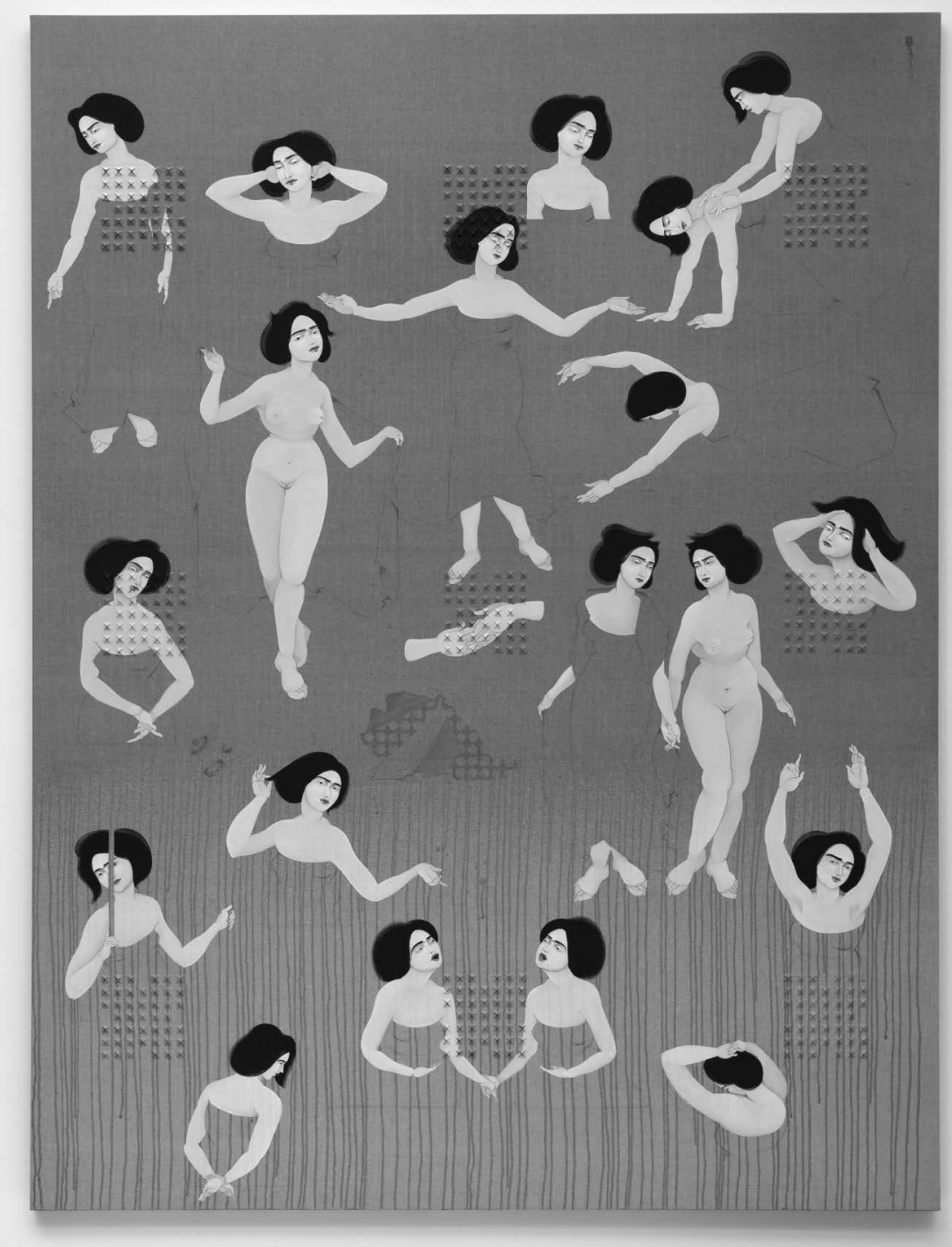

Figure 6.1 Hayv Kahraman, Search, 2016, oil on linen, $96 \times 73$ inches. (C) Hayv Kahraman. Courtesy of the artist and Jack Shainman Gallery, New York.

who dwells in the margins, surviving and navigating a life of spatial and temporal displacement'. ${ }^{5}$ Thus, at one level, Search presents a portrait of forced migration generated by the violent biopolitics of a deeply uneven global landscape, registered through the physical and psychic experiences of the gendered body. In this, it enacts a powerfully transcultural feminist 
agenda, reminding us, as much transnational and decolonial feminist analysis already has, 'of the intimate connections between war, political economy, nationalism, and human displacement and their various impacts', ${ }^{6}$ while foregrounding the centrality of gendered identity, embodiment, and positionality to the experience of forced migration.

Yet in its deliberate fragmentation, its spectral spaces of incomplete tracing, and its rupture of two-dimensionality, this work also exceeds the straightforwardly autobiographical or political, presenting a deeply defiant return of the viewer's gaze. For the women in Search are neither simply cut-out figures of U.S. occupation nor silent victims of displacement but hybrid, shifting, mobile subjects whose reappropriation of the sensory language of warfare engages the viewer in a potently feminocentric dance. While the female subjects of Kahraman's work certainly register violence and dislocation, they also present a heterogeneous and shifting community of those who, like Kahraman herself, appear 'wounded and healed and transcended,. These are women who not only cross over and beyond the two-dimensional realm but actively challenge the legibility of national, racial, and ethnic boundaries, forming between them what Kahraman has described as an 'army of fierce women'8 that resists narrative and interpretive fixity via the fluid expressionism of their own forms. Theirs is a multiple mobilisation, then. United by their uprootedness, they also present a call to community that stands in radical contrast to the androcentric, exclusionary, and violent biopolitics of the nation state. In this, they position themselves firmly within the territory into which this book has sought to guide the reader: in the transcultural feminist imagination.

How might Search enable us to visualise the nature of this transcultural feminist territory? Like Kahraman's 'army of fierce women', the figures that circulate across the multidisciplinary, multisensory, transnational terrains of variously defined feminist imaginaries both are and are not legible as forced migrant women. Just as the figure of 'She' in Search proves an amalgamation of projected stereotypes and of a colonising gaze, forced migrant women have also often featured as palimpsests of external presupposition, surfacing as figureheads and symbols, heroines and villains of imaginations variously hostile and humanitarian; as targets of military violence and of benevolence in equal measure. Yet each chapter of this book has also revealed how women who experience forced migration variously perform, embody, exceed, or resist the tropes that are often imposed upon them tropes that range from 'the mother', 'the victim', and 'the subaltern' to 'the heroine', 'the detainee', and 'the queer subject'. Indeed, we have seen how those operating from a transcultural feminist positionality in their creative practice often work to destabilise these tropes and to realise alternative representational possibilities. Just as the women in Kahraman's work push back against reductive attempts to determine their identity or location, so have many of the creative representations presented within this volume actively sought to break the frames that typically limit the narratives through 
which forced migrant women have too often been defined and read. As Maroussia Hajdukowski-Ahmed observes, it is perhaps therefore most productive to understand the formation of identity for women who experience forced migration as 'dialogic', 'a continuous and relational process' rather than a fixed construct in which 'every new location or situation challenges [the] sense of self' yet also 'generate[s] resisting discourses... [and new] initiatives in their everyday lives'. 'The category of 'the forced migrant woman' proves a redundant one in the transcultural feminist imagination, then, leading us instead towards a realm of mobile imaginative possibility in which gendered experiences, identities, and positionalities are in constant states of transition and transformation.

Just as the women in Search assume shifting positions in their visual dance with the viewer, the creative works explored over the course of this volume also reveal the varied positions that women with lived experience of forced migration assume within the transcultural feminist imagination. At times, those with lived experience may assume the role of author, director, or artist; of activist or of leader; of collaborator or conversant; and of performer or subject. While it proves empowering for those with lived experience of forced migration to assume self-representational powers in many instances, there are also circumstances in which the demand 'to speak' may become a performative burden in its own right. At these times, solidarity and alliance with others also present vital opportunities. Thus, the representational networks that circulate across transcultural contexts prove essential, revealing feminism as a necessarily collective and expansive project that must respond strategically to the unique contexts in which each representational act occurs.

As we have also seen over the course of this book, though, 'feminism' proves as diverse in its construction as the notion of 'forced migrant womanhood' in itself. In the early chapters of this book in particular, selective strands of 'feminist' discourse - particularly those driven by Eurocentric humanitarianism or 'colonial rescue fantasy' - emerge as complicit in the political regimes that have ultimately silenced the agency of forced migrant women, seeking to 'speak for', 'rescue', or 'mother' forced migrant women as subjects of their own political imaginaries. At times, these discourses have even proved complicit with military violence that ultimately generates women's displacement. Yet as the works examined in this book affirm (in a move that echoes Mohanty), feminisms also prove capable of mobilising against such discourses through the shared tools of anticapitalist, anticolonial struggles for gender equality. ${ }^{10}$ This proves to be the case when transcultural feminisms work to reveal and counter the global conditions that produce forced migration - such as the regimes of 'bordering', detention, and state violence that typically demarcate the global landscape. These transcultural feminist discourses, though, surface in forms as varied and as fluid as the those presented by the women in Search, appearing sometimes via decolonial, postcolonial, queer, trans, or other specifically identifiable 
feminist stances, while at others, emerging via more ambiguous modes of solidarity, alliance, and activism in the form of literary, visual, sonic, or multidisciplinary creativities. What ultimately unites the transcultural feminist imaginations examined in this book, however, is the shared commitment to non-reductive representation that expands rather than limits the range of gendered identities, experiences, and positionalities circulating around women who have engaged with forms of forced migration during their lifetimes. In this, the transcultural feminist imagination proves a shifting and contingent realm that, like the landscape of Search, yields a proliferation of interpretive and discursive possibilities. Indeed, it arguably enacts what Ella Shohat has described as a 'relational feminist approach [that] demands moving beyond nation-bound and discipline-bound teaching, $\mathrm{cu}-$ rating and organizing' in order to respond to the 'cultural consequences of the worldwide movements and dislocations of people' that currently define the transnational landscape. ${ }^{11}$ Cross-disciplinary, transnational, intersectional, and cross-genre, the transcultural feminist imagination therefore emerges as the very condition of twenty-first-century mobility, reclaimed as a source of creative potential rather than of disempowerment.

Like the 'army of fierce women' in Search, then, those who participate in the formation and traversal of the transcultural feminist imagination are above all those who mobilise when faced with the hostile landscape around them. It is this act of mobilisation - between women with lived experience of forced migration and those without; between creative practitioners working across locations and genres; and between scholars, activists, and teachers working in the classroom, the library, and on the ground - that ultimately produces the transcultural feminist imagination as a shared realm. Mobile and mobilised as this transcultural feminism proves, though, the question remains: where might it lead us beyond these pages? The answer to this is surely to be found if we return to the source from which so many of these words have flowed - to the river walk with which this volume opened, conducted along the banks of the River Trent with members of the PAMOJA Women Together Group at Nottingham and Nottinghamshire Refugee Forum. In line with the many other creative transformations witnessed within this volume, PAMOJA's river walk also came to assume the form of a collective poem - and in its lines, we encounter tributaries that guide us towards far-reaching paths that the transcultural feminist imagination might enable us to follow.

In 'Speaking With the River', we hear PAMOJA members share the memories and thoughts prompted by the act of shared walking along the River Trent. Drawn together as a protectively anonymous flow of conversational voices, the poem's lines meander between recollections of the place where the White and Blue Nile meet in Sudan, and how women would meet for coffee by the river in Eritrea; between a lake and palms in Libya and of an economically precarious life of unemployment on the Amalfi Coast. ${ }^{12}$ In its evocation of such varied and unexpected locations, this poem therefore 
invites us towards an expansive transcultural vision in which we must surely turn our sights to geographical locations beyond those more usually represented as sites of migratory 'crisis'. Indeed, in its shift away from crisisbased migration streams, the PAMOJA women's memories also remind us to recognise the varied forms that forced migration can take - inclusive of the traumatic paths followed by those who find themselves trafficked or subjected to forms of modern-day slavery. ${ }^{13}$ Just as altering our gazes in order to peer low along the banks of the river revealed hidden sights to those of us on the walk together, so must scholars of forced migration look beyond the obvious headlines of mainstream media coverage in order to recognise alternative modes of expression, creative forms, and articulations of agency invoked by women who have experienced forced migration. In 'Speaking With the River', for instance, one participant shares a story about going to meet her new mother-in-law for the first time; another shares the qualifications she is currently taking in order to be able to move into teaching, while others speak of the PAMOJA group itself, and of how they 'gather, like a family thing' in order to resist the boredom of 'looking at the four corners of the house on a daily basis. ${ }^{14}$ Stories, memories, education, and community-building: all of these must be recognised as forms of creative mobilisation and as valuable forms of cultural knowledge worthy of academic recognition.

In this poem's distinctive and unexpected location, 'Speaking With the River' also invites us to turn our sights to the creative and political significance of environment for women experiencing forced migration - a concern that demands further scholarly investigation. Indeed, in this poem, the river itself surfaces as a source of powerful mobilisation and alliance. In contrast with 'the hostile environment' that renders you 'limited in so many things', the river is described as 'a kind place' that 'makes me feel more emotional...free and liberated', with the 'light bending' over the water; 'the sound of the white bird flying [that] reminded me of home'; the 'reeds that wave like salam alaikum to everybody. ${ }^{15}$ In one sense, the PAMOJA group's river walk therefore draws us towards an understanding of forced migrant women's experiences and creativities as highly situated, and it invites us to turn our attentions away from geographically determined boundaries towards the more intimate landscapes of sensory, emotional, and remembered experience. Equally, the poem's vivid evocations of the river's ecology and sociology - present in discussion of its reeds and waterfowl; its cleanliness and safety; its usage for cooking, bathing, and farming; and its potential scarcity - remind us of the powerful connection between environmental change and forced migration - a relationship that is in its own way nuanced by gender, given many women's dependency on income from agrarian labour, and by pressure on the provision of sustenance for the family. ${ }^{16}$ The complex interrelationship between environment, forced migration, and gender is one that must surely surface as the 
subject of increasing interdisciplinary and transnational concern as climate change continues to have progressively devastating impacts on the global landscape.

The transcultural feminist imagination therefore proves not just mobile but also malleable, assuming forms that range from critique of neocolonial, imperialist and biopolitical governmentalities to acts of creative defiance, expressed on the page, on the screen, through sound, or on the ground; from activist protests to seemingly quotidian tasks such as walking or conversing. While gender-consciousness lies at its heart, a transcultural feminist approach ultimately resonates across disciplines, spaces, and subject positions to demand a radically creative reassessment of how we can respond to forced migration. What, after all, would it mean to reconfigure border-crossing practices according to a transcultural feminist ethos? How might the asylum system be overhauled if rendered not just gender-sensitive but operational according to the non-biopolitical mentality of a transcultural feminist discourse? And how might concepts such as hospitality and community find themselves profoundly altered if rethought along the lines of a non-hierarchical, heterogeneous, open, and equal feminist society? By opening the door to questions such as this, the transcultural feminist imagination therefore invites a wealth of further scholarly exploration far beyond the specific examples charted within this volume.

When we mobilise creatively as transcultural feminists, then, we learn to move differently through the world. There are many directions in which we can choose to travel via the possibilities of the transcultural feminist imagination. But perhaps these alternative movements all ultimately lead us in the same direction: towards a world in which the act of journeying becomes an experience defined not by global disparity but by equality; not by pain but by joyful possibility.

\section{Notes}

1 Hayv Kahraman, Search, 2016, oil on linen, $96 \times 73$ inches $(243.8 \times 185.4 \mathrm{~cm})$.

2 There are a number of critical explorations of the cultural hybridity at stake in Kahraman's work. In particular, critics note the way in which Kahraman fuses references to 'Persian miniatures, Japanese woodcuts, and Italian Renaissance paintings' in a way that 'creat[es] a discourse between Eastern "otherness" and Western concepts of beauty'. Rebecca McGrew, 'Introduction - Hayv Kahraman: Weaving as Mending', in Rebecca McGrew, ed., Hayv Kahraman, Project Series 52 (Claremont, CA: Pomona College Museum of Art, 2018), pp.39-41; p.39.

3 Wassan Al-Khudhairi, 'Acts of Reparation', in Wassan Al-Khudhairi, ed., Acts of Reparation, Hayv Kahraman (St. Louis, MO: Contemporary Art Museum St Louis, 2017), pp.9-13; p.11.

4 Hayv Kahraman, 'Gendering Memories of Iraq - A Collective Performance', in Rebecca McGrew, ed., Hayv Kahraman, Project Series 52 (Claremont, CA: Pomona College Museum of Art, 2018), pp.81-88; p.83.

5 Hayv Kahraman, 'The Art of Mending', in Acts of Reparation, pp.15-16; p.15. 
6 Wenona Giles and Jennifer Hyndman, 'New Directions for Feminist Research and Politics', in Wenona Giles and Jennifer Hyndman, eds., Sites of Violence: Gender and Conflict Zones (Berkeley: University of California Press, 2004), pp.301-315; p.314.

7 Hayv Kahraman and Wassan Al-Khudhairi, 'Wassan Al-Khudairi Interviews Hayv Kahraman, Excerpted from an Email Exchange, July 5, 2017', in Hayv Kahraman, Hayv Kahraman (New York: Rizzoli Electra, 2018), pp.6-15; p.15.

8 Madalit Del Barco, 'Iraqi American Artist Hayv Kahraman is Building "An Army of Fierce Women"', NPR, 27th November 2019, https:/www.npr.org/ 2019/11/27/770452266/iraqi-american-artist-hayv-kahraman-is-building-anarmy-of-fierce-women?t=1603115114208 (last accessed 19th October 2020).

9 Maroussia Hajdukowski-Ahmed, 'A Dialogic Approach to Identity: Implications for Refugee Women', in Maroussia Hajdukowski-Ahmed, Nazilla Kanlou, and Helene Moussa, eds., Not Born a Refugee Woman: Contesting Identities, Rethinking Practices (New York: Berghan Books, 2008), pp.28-54; p.29.

10 Mohanty, “"Under Western Eyes” Revisited', pp.236-251.

11 Ella Shohat, 'Introduction', in Ella Shohat, ed., Talking Visions: Multicultural Feminism in a Transnational Age (Cambridge, MA: MIT Press, 2001), p.1.

12 See PAMOJA Women Together, 'Speaking With the River', in Ball and Reeve, eds., The World Is for Everyone, pp.31-41.

13 For more on sex trafficking as a specifically gendered mode of experience that has generated a significant amount of literary representation, see Laura Barberán Reinares, Sex Trafficking in Postcolonial Literature: Transnational Narratives from Joyce to Bolaño (Abingdon: Routledge, 2014). This work might be usefully extended to gendered and feminist scrutiny of other forms of trafficking and modern-day slavery, and to their cultural representation.

14 PAMOJA, 'Speaking With the River', p.34.

15 Ibid., pp.31-41.

16 See for instance Namrata Chindarkar, 'Gender and Climate Change-Induced Migration: Proposing a Framework for Analysis', Environmental Research Letters 7 (2012), pp.1-7. 


\section{Bibliography}

Aaftaab, Nahneed Gina, '(Re)Defining Public Spaces through Developmental Education for Afghan Women', in Ghazi-Walid Falah and Caroline Nagel, eds., Geographies of Muslim Women: Gender, Religion and Space (London: Guildford Press, 2005), pp.44-67.

Abdile, Hani, 'Hani, “Here I Am”, Bankstown Poetry Slam', 2nd March 2015, https://www.youtube.com/watch?v=sLkWpuj9Vqo (last accessed 10th April 2020).

—, I Will Rise (Victoria: Writing Through Fences, 2016).

, 'When I become Famous, I'll Give Tony Abbot a Job', in Michael Green and André Dao, eds., They Cannot Take the Sky: Stories from Detention (Sydney: Allen and Unwin, 2017), pp.29-47.

— 'Hani Abdile Live at QP2017', 17th December 2017, https://www.youtube. com/watch? v=-iFNvb-emPE\&t=58s (last accessed 10th April 2020).

Acer, Eleanor, Rebecca Gendelman, and Kennji Kizuka, 'Orders from Above: Massive Human Rights Abuses under Trump Administration Return to Mexico Policy', Human Rights First, October 2019, https://www.humanrightsfirst.org/sites/ default/files/hrfordersfromabove.pdf (last accessed 13th July 2020).

Achebe, Chinua, 'Refugee Mother and Child', Christmas in Biafra and Other Poems (New York: Doubleday, 1973).

Ado Ata Pictures, 'Another Dream', Queer in a Time of Forced Migration, 2019, animated documentary/virtual reality, 20 minutes.

Affan, Erkan, 'The Marginalisation of Transgender Refugee Women from UNHCR's Policies of Gender Mainstreaming', Jadaliyya, 27th May 2019, https:// www.jadaliyya.com/Details/38692 (last accessed 21st August 2020).

Agamben, Giorgio, Homo Sacer: Sovereign Power and Bare Life, trans. Daniel Heller-Roazen (Stanford, CA: Stanford University Press, 1995).

Ahmed, Leila, Women and Gender in Islam: Historical Roots of a Modern Debate (New Haven, CT: Yale University Press, 1992).

Ahmed, Sara, Strange Encounters: Embodied Others in Post-Coloniality (New York: Routledge, 2000).

- The Cultural Politics of Emotion, Second Edition (Edinburgh: Edinburgh University Press, 2014).

—, Living a Feminist Life (Durham, NC: Duke University Press, 2017).

Ahonen, Heidi and Antoinetta Mongillo Desideri, 'Heroines' Journey - Emerging Story by Refugee Women during Group Analytic Music Therapy', Voices: A World Forum for Music Therapy 14:1 (2014), pp.1-22. 
Ahonen, Pertti, 'Of Walls and Fences: Brexit and the History of Cross-Border Migration', Contemporary European History 28:1 (2018), pp.42-45.

Aizura, Aren, 'Transgender Travel Narratives', in Trystan T. Cotten, ed., Transgender Migrations: The Bodies, Borders and Politics of Transition (New York: Routledge, 2012), pp.139-156.

Akin, Fatih, dir., The Edge of Heaven (Germany, 2007).

Alexander, M. Jacqui, 'Erotic Autonomy as a Politics of Decolonization: An Anatomy of Feminist and State Practice in the Bahamas Tourist Economy', in M. Jacqui Alexander and Chandra Talpade Mohanty, eds., Feminist Genealogies, Colonial Legacies, Democratic Futures (New York: Routledge, 1997), pp.63-100.

— , 'Not Just (Any) Body Can Be a Citizen: The Politics of Law, Sexuality, and Postcoloniality in Trinidad and Tobago and the Bahamas', in Catherine Hall, ed., Cultures of Empire: A Reader (New York: Routledge, 2000), pp.359-376.

Al-Khudhairi, Wassan, 'Acts of Reparation', in Wassan Al-Khudhairi, ed., Acts of Reparation, Hayv Kahraman (St. Louis, MO: Contemporary Art Museum St Louis, 2017), pp.9-13.

Amnesty International, Afghanistan: Women Human Rights Defenders Continue to Struggle for Women's Rights (2008), https://www.amnesty.org/download/ Documents/52000/asa110032008eng.pdf (last accessed 23rd May 2019).

Anonymous, 'Debunked 300,000 Syrian Refugees Are Not Pregnant in Lebanon', The New Arab, 5th May 2017. https:/www.alaraby.co.uk/english/news/2017/5/5/ debunked-300-000-syrian-refugees-are-not-pregnant-in-lebanon (last accessed 7th December 2018).

Anzaldúa, Gloria, Borderlands/La Frontera: The New Mestiza (San Francisco, CA: Aunt Lute, 1999).

Appiah, Anthony Kwame, 'Cosmopolitan Patriots', in Pheng Cheah and Bruce Robbins, eds., Cosmopolitics: Thinking and Feeling beyond the Nation (Minneapolis: University of Minnesota Press, 1998), pp.91-133.

Ardener, Shirley, ed., Women and Space: Ground Rules and Social Maps (Oxford and Providence: Berg, 1993).

Ardia, C. A. Xuan Mai, 'Hear Her Singing: Taiwanese Artist Charwei Tsai and the Song of Women Refugees - in Conversation', Art Radar, 28th June 2017, http:// artradarjournal.com/2017/06/28/hear-her-singing-taiwanese-artist-charweitsai-and-the-song-of-women-refugees-in-conversation/ (last accessed 28th July 2020).

Arendt, Hannah, The Origins of Totalitarianism (San Diego, CA: Harcourt, 1994). Armstrong, John, Nations before Nationalism (Chapel Hill: University of North Carolina Press, 1982).

Assefa, F., M.Z. Jabarkhil, P. Salama, and P. Spiegel, 'Malnutrition and Mortality in Kohistan District, Afghanistan', JAMA 286:21 (2001), pp.2723-2728.

Atac, Ilker, Kim Rygiel, and Maurice Stierl, eds., The Contentious Politics of Refugee and Migrant Protest and Solidarity Movemements: Remaking Citizenship from the Margins (Abingdon: Routledge, 2017).

Atton, C., 'What Is “Alternative” Journalism?', Journalism 4:3 (2003), pp.267-272.

Baillot, Helen, Sharon Cowan, and Vanessa Munro, 'Seen But Not Heard? Parallels and Dissonances in the Treatment of Rape Narratives across the Asylum and Criminal Justice Contexts', Journal of Law and Society 36:2 (2009), pp.195-219. 
Baines, Erin, Vulnerable Bodies: Gender, the UN and the Global Refugee Crisis (Aldershot: Ashgate, 2004).

Baker, Aryn and Lynsey Addario, 'For Refugee Moms, Giving Birth Can Be Fraught with Danger', Time, 13th December 2017, http://time.com/5058722/refugeemothers-europe-greece-pregnant-prenatal/ (last accessed 14th December 2018).

Baker, Daniel, 'Regional Situation Report for Syria Crisis', UNFPA 27 (2014), https://syria.unfpa.org/sites/default/files/pub-pdf/UNFPA\%20Regional\%20 SitRep\%201\%20-\%2030\%20November\%202014\%20\%20\%23\%2027_0.pdf (last accessed 7th December 2018).

Baker Josephs, Kelly, 'Dissonant Desires: Staceyann Chin and the Queer Politics of a Jamaican Accent', Mosaic: An Interdisciplinary Critical Journal 42:2 (2009), pp.153-170.

Baksh, R. and W. Harcourt, 'Introduction: Rethinking Knowledge Power and Social Change', in R. Baksh and W. Harcourt, eds., The Oxford Handbook of Transnational Feminist Movements (Oxford: Oxford University Press, 2015), pp.1-47.

Ball, Anna, 'Biopolitical Landscapes of the "Small Human": Figuring the Child in the Contemporary Middle Eastern Refugee Crisis in Europe', in Anna Ball and Karim Mattar, eds., The Edinburgh Companion to the Postcolonial Middle East (Edinburgh: Edinburgh University Press, 2018), pp.446-468.

Ball, Anna and Karim Mattar, eds., The Edinburgh Companion to the Postcolonial Middle East (Edinburgh: Edinburgh University Press, 2018).

Ball, Anna and Camilla Reeve, eds., The World Is for Everyone: New Writing by PAMOJA Women Together (London: Palewell Press, 2019).

Banaszak, Lee Ann, The U.S. Women's Movement in Global Perspective: Issues and Strategies for the New Century (Lanham, MD: Rowman and Littlefield, 2005).

Barberán Reinares, Laura, Sex Trafficking in Postcolonial Literature: Transnational Narratives from Joyce to Bolaño (Abingdon: Routledge, 2014).

Barksy, Robert, Constructing a Productive Other: Discourse Theory and the Convention Refugee Hearing (Amsterdam: John Benjamins, 1994).

Basu, Amrita, ed., Women's Movements in the Global Era: The Power of Local Feminisms (Abingdon: Routledge, 2016).

Bauman, Zygmunt, Liquid Times: Living in an Age of Uncertainty (Cambridge: Polity Press, 2007).

Bauridl, Birgit M., 'Contemporary "Black"? Performance Poetry', Amerikastudien/American Studies 55:4 (2010), pp.715-724.

Berg, Lauri and Jenni Millbank, 'Constructing the Personal Narratives of Lesbian, Gay and Bisexual Asylum Claimants', Journal of Refugee Studies 22:1 (2007), pp.195-223.

Benjamin, Judy A., Post-Taliban Afghanistan: Changed Prospects for Women? UN Coordinator's Office, Afghanistan (Rawalpindi: The Army Press, February 2002).

Berlant, Laurent, 'Slow Death (Sovereignty, Obesity, Lateral Agency)', Critical Enquiry 33:4 (2007), pp.754-780.

Bernal, Victoria and Inderpal Grewal, eds., Theorizing NGOs: States, Feminisms, and Neoliberalisms (Durham, NC: Duke University Press, 2014).

Berry, Venise T., 'Feminine or Masculine: The Conflicting Nature of Female Images in Rap Music', in Susan Cook and Judy Tsou, eds., Cecilia Reclaimed: Feminist 
Perspectives on Gender and Music (Chicago, IL: The University of Illinois Press, 1994), pp.183-201.

Bhambra, Gurminder K., 'Postcolonial and Decolonial Reconstructions', in Gurminder K. Bhambra, Connected Sociologies (London: Bloomsbury Academic, 2004), pp.117-140.

Bhanji, Nael, 'TRANS/SCRIPTIONS: Homing Desires, (Trans)sexual Citizenship and Racialised Bodies', in Trystan T. Cotten, ed., Transgender Migrations: The Bodies, Borders and Politics of Transition (New York: Routledge, 2012), pp.157-175.

Bieksa, Lyra, Laurynas Jakuleviciene, and Egle Samuchovaite, 'Procedural Problems in LGBTQ Asylum Cases', Jurispudencija 19:1 (2012), pp. 195-207.

Bigo, Didier, 'Freedom and Speed in Enlarged Borderzones', in Vicki Squire, ed., The Contested Politics of Mobility: Borderzones and Irregularity (London: Routledge, 2011), pp.31-50.

Black, Shameem, Fiction across Borders: Imagining the Lives of Others in Late Twentieth-Century Novels (New York: Columbia University Press, 2010).

Bloch, Alice and Giorgia Dona, eds., Forced Migration: Current Issues and Debates (Abingdon: Routledge, 2018).

Bohmer, Carol and Amy Shuman, Political Asylum Deceptions: The Culture of Suspicion (Basingstoke: Palgrave Macmillan, 2018).

Boochani, Behrouz, No Friend but the Mountains: Writing from Manus Prison (London: Piccador, 2019).

Bosworth, Mary and Blerina Kellezi, 'Citizenship and Belonging in a Women's Immigration Centre', in Coretta Phillips and Colin Webster, eds., New Directions in Race, Ethnicity and Crime (Abingdon: Routledge, 2014), pp. 80-96.

Bouvard, Marguerite Guzman, Revolutionizing Motherhood: The Mothers of the Plaza de Mayo (Wilmington, DE: Scholarly Resources, 1994).

Boykin, Eboni, 'Sundance 2016 Women Directors: Meet Roksareh Ghaemmaghami "Sonita", Women and Hollywood, January 22nd 2016, http://womenandhollywood. com/sundance-2016-women-directors-meet-rokhsareh-ghaemmaghami-sonitacf42f1134948/ (last accessed 22nd May 2019).

Brady, Gabrielle, dir., Island of the Hungry Ghosts (Australia: Third Films, 2018).

Brané, Michelle and Lee Wang, 'Women: The Invisible Detainees', Forced Migration Research 44 (September 2013), pp.37-39.

Brigand, Alain, dir., 11.09.01, September 11th, A Film (France: Studio Canal Plus and Galatee Films, 2002).

Brigida, Anna-Catherine, 'El Salvador's Justice System Takes on a Historic Case', Foreign Policy, 9th March 2020, https:/foreignpolicy.com/2020/03/09/elsalvador-justice-system-historic-case-transgender-asylum-seeker/ (last accessed 21st September 2020).

Brodsky, Anne E., With All Our Strength: The Revolutionary Association of the Women of Afghanistan (London: Routledge, 2003).

Brooks, Daphne A., “'All that you can't leave behind”: Black Female Soul Singing and the Politics of Surrogation in the Age of Catastrophe', Meridians: Feminism, Race, Transnationalism 8:1 (2008), pp.180-204.

Brown, Janelle, “Fatima” Speaks: Resisting the Taliban', in Susan Hawthorne and Bronwyn Winter, eds., September 11, 2001: Feminist Perspectives (Melbourne: Spinifex Press, 2002), pp.70-75.

Brydon, Lynne and Sylvia Chant, Women in the Third World: Gender Issues in Rural and Urban Areas (Aldershot: Edward Elgar Publishing Ltd., 1993). 
Buckley-Zistel, Susanne and Ulrike Krause, eds., Gender, Violence, Refugees (New York: Berghahn Books, 2017).

Buist, Kevin, 'Meet the Jurors: Wanchegi Mutu', Artprize, 30th July 2015, https:// www.artprize.org/blog/wangechi (last accessed 19th June 2020).

Bulbeck, Chilla, Re-Orienting Western Feminisms: Women's Diversity in a Postcolonial World (Cambridge: Cambridge University Press, 1998).

Bulman, May, “'It's like hell”: Yarl's Wood Women Launch Hunger Strike against Their Indefinite Detention and Imminent Charter Flight', The Independent, 26th November 2018, https://www.independent.co.uk/news/uk/home-news/yarlswood-women-hunger-strike-detention-centre-home-office-flight-a8653111.html (last accessed 5th October 2020).

Bureau of Democracy, Human Rights and Labour, 'Jamaica: Country Reports on HumanRightsPracticesfor2011',USDepartmentofState, https://2009-2017.state. gov/j/drl/rls/hrrpt/humanrightsreport/index.htm?dlid=186525 (last accessed 21st September 2020).

Burnett, Jill, dir., This Way Out (U.S., 2004).

Bush, Laura, 'Radio Address by Mrs Bush,' The White House, 17th November 2001, http://www.whitehouse.gov/news/releases/2001/11/print/20011117.html (last accessed 4th January 2019).

Butler, Judith, Gender Trouble: Feminism and the Subversion of Identity (London: Routledge, 1999).

- 'Indefinite Detention', Precarious Life: The Powers of Mourning and Violence (London: Verso, 2004), pp.50-100.

Butler, Judith and Athena Athanasiou, Dispossession: The Performative in the Political (Malden, MA: Polity Press, 2013).

Butterwick, Shauna and Jan Selman, 'Deep Listening in a Feminist Popular Theatre Project: Upsetting the Position of Audience in Participatory Education', Adult Education Quarterly 54:1 (2003), pp.7-22.

Calvin, Kathy, 'Mothers around the World Are in Crisis. Here's How You Can Help', Time Magazine, 12th May 2018, http://time.com/5274229/mothers-daygift-donation-women-conflict-refugees/ (last accessed 3rd December 2018).

Caminero-Santangelo, Marta, 'Narrating the Non-Nation: Literary Journalism and "Illegal" Border-Crossings', Arizona Quarterly 68:3 (2012), pp.157-176.

Camminga, B., Transgender Refugees and the Imagined South Africa: Bodies over Borders and Borders over Bodies (Cham: Springer International, 2019).

Caroll, Sara Ann, The Desert Survival Series available online at Academia.edu, file:///Users/anna/Downloads/The_Desert_Survival_Series_La_serie_de.pdf (last accessed 14th July 2020).

Carroll, Aengus, State-Sponsored Homophobia 2016: A World Survey of Sexual Orientation Laws: Criminalisation, Protection and Recognition (Geneva: International Lesbian, Gay, Bisexual, Trans and Intersex Association, 2016).

Carpenter, R. Charli, “'Women, Children and Other Vulnerable Groups”: Gender, Strategic Frames and the Protection of Civilians as a Transnational Issue', International Studies Quarterly 49 (2005), pp.486-500.

Carruthers, Charlene, Unapologetic: A Black, Queer, and Feminist Mandate for Radical Movements (Boston, MA: Beacon Press, 2018).

Chambers, Iain, 'Art and the Refugee 'Crisis': Mediterranean Blues', Open Democracy, 10th July 2017, https://www.opendemocracy.net/5050/iain-chambers/ art-and-refugee-crisis-mediterranean-blues (last accessed 12th December 2018). 
Channel 4 News, 'Undercover in Yarl's Wood: Britain's Most Secretive and Notorious Immigration Removal Centre', Channel 4 Interactive, https://www.channel4. $\mathrm{com} /$ news/yarls-wood-immigration-detention-removal-centre-undercover (last accessed 6th January 2020).

Chaudhuri, Shohini and Howard Finn, 'The Open Image: Poetic Realism and the New Iranian Cinema', Screen 44:1 (spring 2003), pp.38-57.

Chevannes, Barry, 'Gender and Adult Sexuality', in Patricia Mohammed, ed., Gendered Realities: Essays in Caribbean Feminist Thought (Kingston: University of the West Indies Press, 2002), pp.486-494; p.488.

Childs, Simon, 'Yarl's Wood Detention Centre is at the Front Line of British State Racism', Vice, 15th May 2017, https://www.vice.com/en_uk/article/bmw5a8/ yarls-wood-detention-centre-is-at-the-front-line-of-british-state-racism (last accessed 11th June 2019).

Chin, Staceyann, Hands Afire (New York: Bleeker Theatre, 2000).

- Border/Clash: A Litany of Desires (New York: Bleeker Theatre, 2005).

- The Other Side of Paradise: A Memoir (New York: Scribner, 2009).

- Motherstruck (Chicago, DC and NYC, 2015-2016).

- Crossfire: A Litany for Survival (Chicago, IL: Haymarket, 2019).

Chindarkar, Namrata, 'Gender and Climate Change-Induced Migration: Proposing a Framework for Analysis', Environmental Research Letters 7 (2012), pp.1-7.

Christou, Anastasia, Adalgisa Giorgio, and Gill Rye, 'Mothering and Migration: Interdisciplinary Dialogues, European Perspectives and International Contexts', Women's Studies International Forum, 52 (2015), pp.49-52.

Cockburn, Cynthia, 'The Continuum of Violence: A Gender Perspective on War and Peace', in Wenona Giles and Jennifer Hyndman, eds., Sites of Violence: Gender and Conflict Zones (Berkeley: University of California Press, 2004), pp.24-44.

cooke, mirriam, 'Crusade! I Mean Democracy! You Know: Women!', The Middle East Women's Studies Review (fall-winter 2002), pp.14-16.

— Saving Brown Women', Signs 28:1 (2002), pp.468-470.

Cooper, Carolyn, Noises in the Blood: Orality, Gender and the 'Vulgar' Body of Jamaican Popular Culture (London: Macmillan, 1993).

Cox, Emma, 'Dialogue and Decentralisation in Australian Asylum Anthologies', Life Writing 7:3 (2010), pp.285-302.

Cox, Emma, Sam Durrant, David Farrier, Lyndsey Stonebridge, and Agnes Woolley, eds., Refugee Imaginaries: Research across the Humanities (Edinburgh: Edinburgh University Press, 2020).

Crawley, Heaven and Trine Lester, 'Comparative Analysis of Gender-Related Persecution in National Asylum Legislation and Practice in Europe', UNHCR, May 2004, https://www.unhcr.org/40c071354.pdf (last accessed 20th July 2020).

Crawley, Heaven, Refugees and Gender: Law and Process (Bristol: Jordan, 2001).

Crossley, Alison Dahl, Finding Feminism: Millennial Activists and the Unfinished Gender Revolution (New York: New York University Press, 2017).

Curtis, Sandra L., 'Feminist Music Therapy: Transforming Theory, Transforming Lives', in S. Hadley, ed., Feminist Perspectives in Music Therapy (New Haven: Barcelona Publishers, 2006), pp.227-244.

Dalilah, Zahra, 'Filmmaker Rokhsareh Ghaem Maghami on Afghan Rapper Sonita: "I Just Wanted Her and Myself to Win"', Gal-Dem, 1st November 2016, http://gal-dem.com/sonita-documentary-film/ (last accessed 25th June 2019). 
Dasgupta, Sudeep, 'Sexual and Gender-Based Asylum and the Queering of Global Space: Reading Desire, Writing Identity and the Unconventionality of Law', in Emma Cox, Sam Durrant, David Farrier, Lyndsey Stonebridge, and Agnes Woolley, eds., Refugee Imaginaries: Research across the Humanities (Edinburgh: Edinburgh University Press, 2020), pp.86-102.

De Genova, Nicholas and Martina Tazzioli, 'Crisis: New Keywords of "The Crisis” in and of "Europe", in Europe at a Crossroads: Managed Inhospitality (Zone Books Online, 2020), http://nearfuturesonline.org/europecrisis-new-keywordsof-crisis-in-andof-europe/ (last accessed 27th July 2020).

DeBano, Wendy S., 'Enveloping Music in Gender, Nation, and Islam: Women's Music Festivals in Post-Revolutionary Iran', Journal of Iranian Studies 38:3 (2005), pp.441-462.

Dechian, Sonja, Heather Millar, and Eva Sallis, eds., Dark Dreams: Australian Refugee Stories by Young Writers Aged 11-20 Years (Kent Town, SA: Wakefield, 2004).

DeGhett, Torie Rose, 'Afghanistan's First Female Rapper Tells the Stories that Might Otherwise Be Lost', The Guardian, 2nd November 2012, https:/www. theguardian.com/commentisfree/2012/nov/02/afghanistan-feamle-hip-hop (last accessed 26th June 2019).

De La Garza, Antonio Tomas, 'A Eulogy for Roxsana Hernández: Tracing the Relationship between Border Rhetoric and Queer Disability', QED: A Journal in GBLBTQ Worldmaking 6:3 (2019), pp.94-99.

Del Barco, Madalit, 'Iraqi American Artist Hayv Kahraman is Building "An Army of Fierce Women", NPR, 27th November 2019, https://www.npr. org/2019/11/27/770452266/iraqi-american-artist-hayv-kahraman-is-buildingan-army-of-fierce-women?t=1603115114208 (last accessed 19th October 2020).

Del Mundo, Fernando, '2001 Global Refugee Statistics', UNHCR, 18th June 2002, https://www.unhcr.org/en-lk/news/latest/2002/6/3d0f6dcb5/2001-globalrefugee-statistics.html (last accessed 25th June 2019).

Derrida, Jacques, 'Hostipitality', trans. Barry Stocker, Angelaki 5:3 (2000), pp.3-18.

_ ' 'Unconditionality or Sovereignty: The University at the Frontiers of Europe', Oxford Literary Review 31:2 (2009), pp.115-131.

Deylami, Shirin S., 'In the Face of the Machine: Westoxification, Cultural Globalization, and the Making of an Alternative Global Modernity', Polity 43:2 (2011), pp.242-263.

Dhamoon, Rita Kaur, 'A Feminist Approach to Decolonizing Antiracism: Rethinking Transnationalism, Intersectionality, and Settler Colonialism', Feral Feminisms 4 (2015), pp.20-38.

Dobbs, Leo, 'UNHCR Backs 16 Days of Opposition to Violence against Women', UNHCR, 25th November 2008, https:/www.unhcr.org/uk/news/ latest/2008/11/492c1eb74/unhcr-backs-16-days-opposition-violence-againstwomen.html (last accessed 13th July 2020).

Donato, Katharine, Donna Gabaccia, Jennifer Holdaway, Martin Manalansan, and Patricia Pessar, 'A Glass Half-Full? Gender in Migration Studies', International Migration Review 40:1 (2006), pp.3-26.

Doreen Indra, ed., Engendering Forced Migration: Theory and Practice (New York: Berghan Books, 1999), pp.1-22.

Dumper, Michael, Palestinian Refugee Repatriation: Global Perspectives (Abingdon: Routledge, 2006). 
Durham, Aisha, Brittney C. Cooper, and Susana M. Morris, 'The Stage Hip-Hop Feminisms: Built: A New Directions Essay', Signs 38:3 (2013), pp.721-737.

Edemariam, A., 'The Film Bush Asked to See', The Guardian, 26th October 2001, p.10.

Eisenstein, Zillah, Sexual Decoys: Gender, Race and War in Imperial Democracy (London: Zed Books, 2007).

Ellis, Deborah, Women of the Afghan War (London: Praeger, 2000).

Enloe, Cynthia, Bananas, Beaches, and Bases: Making Feminist Sense of International Politics, Second Edition (Berkeley: University of California Press, 2014).

Enright, Robert and Meeka Walsh, 'Reverberating Images: The Various Arts of Wangechi Mutu', Border Crossings 151 (2019), https://bordercrossingsmag.com/ article/reverberating-images (last accessed 19th June 2020).

Eschle, Catherine and Bice Maigushca, Making Feminist Sense of the Global Justice Movement (Lanham: Rowman and Littlefield, 2010).

Espiritu, Yến Lê and Lan Duong, 'Feminist Refugee Epistemology: Reading Displacement in Vietnamese and Syrian Refugee Art', Signs 43:3 (2018), pp.587-615.

Evans, Kate, Bump: How to Make, Grow and Birth a Baby (Brighton: Myriad, 2014).

— Red Rosa (London: Verso, 2015).

- Threads: From the Refugee Crisis (London: Verso, 2017).

Farley, Lesley and Alexis O'Hara, 'On the Road to Kandahar: Review', A Gathering of the Tribes, www.tribes.org (last accessed 11th April 2019).

Farr, Grant, 'Afghanistan: Displaced in a Devastated Country', in Marc Vincent and Birgitte Refslund Sorensen, eds., Caught between Borders: Response Strategies of the Internally Displaced, (London and Sterling: Pluto Press, in association with the Norwegian Refugee Council, 2001).

Farrier, David, Postcolonial Asylum: Seeking Sanctuary before the Law (Liverpool: Liverpool University Press, 2011).

Fassin, Didier and E. d'Halluin, 'The Truth from the Body: Medical Certificates as Ultimate Evidence for Asylum Seekers', American Anthropologist 107:4 (2005), pp.597-608.

Felman, Shoshana, The Scandal of the Speaking Body: Don Juan with J.L Austin, or A Scandal in Two Languages (Stanford, CA: Stanford University Press, 2002).

Fiddian-Qasmiyeh, Elena, 'Southern-led Responses to Displacement: Modes of South-South Cooperation?', in Elena Fiddian-Qasmiyeh and Patricia Daley, eds., Routledge Handbook of South-South Relations (London: Routledge, 2019), pp.239-256.

Fiddian-Qasmiyeh, Elena, Gil Loeschr, Katy Long, and Nando Sigona, eds., The Oxford Handbook of Refugee and Forced Migration Studies (Oxford: Oxford University Press, 2014).

Finlan, Alastair, Contemporary Military Strategy and the Global War on Terror: US and UK Armed Forces in Afghanistan and Iraq 2001-2012 (London: Bloomsbury Academic, 2014).

Flanders, Laura, 'Why Immigration Is a Feminist Issue', The Nation, 6th December 2011, https://www.thenation.com/article/archive/why-immigration-feministissue/ (last accessed 28th July 2020).

Fleming, Melissa, A Hope More Powerful than the Sea (New York: Flatiron Books, 2017).

Flynn, Michael, 'The Hidden Costs of Human Rights: The Case of Immigration Detention: Global Detention Project Working Paper No. 7', Global Detention 
Project, September 2013, https://www.globaldetentionproject.org/the-hiddencosts-of-human-rights-the-case-of-immigration-detention (last accessed 22nd July 2019).

Fobear, Katherine, 'Nesting Bodies: Exploration of the Body and Embodiment in LGBT Refugee Oral History and Participatory Photography', Social Alternatives 35:3 (2016), pp.33-43.

Foucault, Michel, 'Governmentality', in Graham Burchell, Colin Gordon, and Peter Miller, eds., The Foucault Effect: Studies in Governmentality (Chicago, IL: University of Chicago Press, 1991), pp.87-104.

Freedman, Jane, 'Who’s Responsible for Violence against Migrant Women?', Open Democracy, 28th August 2015, https://www.opendemocracy.net/en/beyondtrafficking-and-slavery/whos-responsible-for-violence-against-migrant-women/ (last accessed 13th July 2020).

- Gendering the International Asylum and Refugee Debate, Second Edition (Basingstoke: Palgrave Macmillan, 2015).

Funding and Donor Relations Services, UNHCR, 'UNHCR Global Appeal 1999 Refugee Women', UNHCR Online, 1st December 1998, https://www.unhcr. org/uk/publications/fundraising/3eaff442e/unhcr-global-appeal-1999-refugeewomen.html (last accessed 10th July 2020).

Gaskins Jr., Joseph, "Buggery" and the Commonwealth Caribbean: A Comparative Examination of the Bahamas, Jamaica, and Trinidad and Tobago', in Corinne Lennox and Matthew Waites, eds., Human Rights, Sexual Orientation and Gender Identity in the Commonwealth (London: Human Rights Consortium, 2013), pp.429-454.

Ghaem Maghami, Rokhsareh, dir., Going Up the Stairs (Iran/Netherlands: Women Make Movies, 2011).

— dir., Sonita (Germany/Switzerland/Iran: New Wave Films, 2015).

Ghobadi, Bahman, dir., A Time for Drunken Horses (Iran: Bahman Ghobadi Films, 2001).

Gibney, Matthew J., The Ethics and the Politics of Asylum: Liberal Democracy and the Response to Refugees (Cambridge: Cambridge University Press 2004).

Gibson, Ian, Federico Garcia Lorca: A Life (London: Faber and Faber, 1989).

Gibsone, Harriet, 'MIA's Borders: Artist Braves Boats and Barbed Wire in Video Crusade for Refugees', The Guardian, 27th November 2015, https://www. theguardian.com/music/2015/nov/27/mia-borders-video-refugee-crisis-europe (last accessed 28th July 2020).

Giles, Wenona and Jennifer Hyndman, 'New Directions for Feminist Research and Politics', in Wenona Giles and Jennifer Hyndman, eds., Sites of Violence: Gender and Conflict Zones (Berkeley: University of California Press, 2004), pp.301-315.

Gilligan, Carol, 'The Listening Guide Method of Psychological Enquiry' Qualitative Psychology 2:1 (2015), pp.69-77.

Giovanni, Janine di, The Morning They Came for Us: Dispatches from Syria (London: Bloomsbury, 2016).

Girma, Marchu, Sophie Radice, Natasha Tsangarides, and Natasha Walter, 'Detained', Women for Refugee Women, January 2014, https://www.refugeewomen. co.uk/wp-content/uploads/2019/01/women-for-refugee-women-reportsdetained.pdf (last accessed 13th November 2019).

Githens, Marianne, Contested Voices: Women Immigrants in Today's World (New York: Palgrave Macmillan, 2013). 


\section{Bibliography}

Gittlen, Ariela, 'In Her New Film, Wu Tsang Unveils the Queer History of One of China's Most Famous Poets', Artsy, 21st March 2016, https://www.artsy. net/article/artsy-editorial-wu-tsang-unveils-the-queer-history-of-one-of-china-smost-famous-poets (last accessed 30th September 2020).

Glissant, Édouard, Poetics of Relation, trans. Betsy Wing (Ann Arbor: University of Michigan Press, 1990).

Gopinath, Gayatri, Impossible Desires: Queer Diasporas and South Asian Public Cultures (Durham, NC: Duke University Press, 2005).

- Unruly Visions: The Aesthetic Practices of Queer Diaspora (Durham, NC: Duke University Press, 2018).

Gower, Melanie, 'Immigration Detention in the UK: An Overview', House of Commons Briefing Paper 7294 (September 2015), pp.1-26.

Green, Michael and André Dao, eds., They Cannot Take the Sky: Stories from Detention (Sydney: Allen and Unwin, 2017).

Greenberger, Alex, 'Take Me Apart: Wu Tsang's Art Questions Everything We Think We Know about Identity', ARTNews, 26th March 2019, https://www. artnews.com/art-news/artists/wu-tsang-12224/ (last accessed 30th September 2020).

Habib, Samar, Female Homosexuality in the Middle East: Histories and Representations (London: Routledge, 2007).

Hajdukowski-Ahmed, Maroussia, 'A Dialogic Approach to Identity: Implications for Refugee Women', in Maroussia Hajdukowski-Ahmed, Nazilla Kanlou, and Helene Moussa, eds., Not Born a Refugee Woman: Contesting Identities, Rethinking Practices (New York: Berghan Books, 2008), pp.28-54.

Halasa, Malu, Mother of All Pigs (Los Angeles, CA: Unnamed Press, 2017).

Hamid, Mohsin, Exit West (London: Penguin, 2018).

Haraway, Donna, Staying with the Trouble: Making Kin in the Chthulucene (Durham, NC: Duke University Press, 2016).

Hegazi, Sarah, 'A Year after "the Rainbow": A Regime Arrests, and the Islamists Applaud', Mada Masr, 24th September 2018, https://www.madamasr.com/ar/2018/ 09/24/opinion/u/\%d8\%b9\%d8\%a7\%d9\% 85-\%d8\%b9\%d9\% 84\%d9\% 89 \%d9\% $85 \%$ d9\% $88 \%$ d9\% $82 \%$ d8\%b9\%d8\%a9-\%d8\%a7\%d9\%84\%d8\%b1\%d9 \%8a\%d9\%86\%d8\%a8\%d9\%88-\%d9\%86\%d8\%b8\%d8\%a7\%d9\%85-\%d9\%8a $\%$ d $8 \%$ b9\%d8\%aa\%d9\%82\%d9\% 84\%d8\% 8c-\%d9\%88\%d8\%a5/?fbclid=IwAR 2BxGcS-3JhkU1ZRMrTidEazsiDQ1JjkPXcHIremRgDrU-tjyklqunEp20 (last accessed 20th August 2020).

Hill Collins, Patricia, 'On Violence, Intersectionality and Transversal Politics', Ethnic and Racial Studies 40:9 (2017), pp.1460-1473.

Hirschberg, Lynn, 'MIA's Agitprop Pop', The New York Times, 25th May 2010, https://archive.nytimes.com/www.nytimes.com/2010/05/30/magazine/30mia-t. html (last accessed 28th July 2020).

Hodge, Paul, '\#LetThemStay \#BringThemHere: Embodied Politics, Asylum Seeking, and Performativities of Protest Opposing Australia's Operation Sovereign Borders', EPC: Politics and Space 37:3 (2019), pp.386-406.

Hoerder, Dirk, Yvonne M. Hébert, and Irina Schmitt, eds., Negotiating Transcultural Lives: Belongings and Social Capital among Youth in Comparative Perspective (Toronto: University of Toronto Press, 2006).

Holland, Jack, Selling the War on Terror (Abingdon: Routledge, 2013). 
Home Office, 'National Statistics: How Many People Are Detained or Returned?', 22nd August 2019, https://www.gov.uk/government/publications/immigrationstatistics-year-ending-june-2019/how-many-people-are-detained-or-returned (last accessed 16th April 2020).

Horn, Denise M. and Serena Parekh, 'Introduction to "Displacement", Signs 43:3 (2018), pp.503-514.

Howe, Julia Ward, 'Appeal to Womanhood throughout the World, Boston', September 1870, Library of Congress, https://www.loc.gov/resource/rbpe. 07400300 (last accessed 11th December 2018).

https://www.jacobinmag.com/2017/05/immigration-donald-trump-muslimslatinos-no-ban-no-wall-no-raids (last accessed 13th July 2020).

Hudson, Valerie M. and Hilary Matfess, 'The Neglected Role of Brideprice in Catalyzing Instability and Violent Conflict', Military Review (January-February 2018), pp.34-47.

Human Rights Council, 'United Nations Office of the High Commissioner for Human rights - Report of the Detailed Findings of the Commission of Inquiry on Human Rights in Eritrea', OHCHR, 8th June 2016, https://www.ohchr.org/ Documents/HRBodies/HRCouncil/CoIEritrea/A_HRC_32_CRP.1_read-only. pdf (last accessed 15th December 2018).

Hyndman, Jennifer, 'Border Crossings', Antipode: A Journal of Radical Geography 29:2 (1997), pp.149-176.

- 'The (Geo)Politics of Mobility', in Lynn A. Straeheli, Eleonore Kofman, and Linda Peake, eds., Mapping Women, Making Politics: Feminist Perspectives on Political Geography (New York: Routledge, 2004), pp.169-184.

- ' 'Introduction: The Feminist Politics of Refugee Migration', Gender, Place and Culture 17:4 (2010), pp.453-459.

Issam Fares Institute for Public Policy and International Affairs, 'Syrian Refugee Crisis in Lebanon: Fatigue in Numbers', American University of Beirut, April 2018, https:/website.aub.edu.lb/ifi/publications/Documents/infographics/ 20180514_fatigue_in_numbers.pdf (last accessed 14th December 2018).

Itaborahy, Lucas Paoli, 'Jamaica', State-Sponsored Homophobia: A World Survey of Laws Criminalising Same-Sex Sexual Acts between Consenting Adults (Geneva: International Lesbian, Gay, Bisexual, Trans and Intersex Association, 2012).

Jackson, Gale P., Put Your Hands on Your Hips and Act Like a Woman: Song, Dance, Black History and Poetics in Performance (New York: AC Books, 2018). Jaffe, Sarah, 'The Collective Power of \#MeToo', Dissent 65:2 (2018), pp.80-87.

Jarrar, Nada Awar, A Good Land (London: Harper Collins, 2009).

- Somewhere, Home (London: Harper Collins, 2011).

- An Unsafe Haven (London: The Borough Press, 2016).

Johnson, Heather L., 'Click to Donate: Visual Images, Constructing Victims and Imagining the Female Refugee', Third World Quarterly 32:6 (2011), pp.1015-1037.

Joukhadar, Jennifer Zeynab, The Map of Salt and Stars (London: Weidenfeld and Nicolson, 2018)

Julius, Kenesha, "A "Universe of Possibilities": Taiwanese Artist Charwei Tsai - Interview', Art Radar, 6th November 2016, https://artradarjournal. com/2016/11/06/a-universe-of-possibilities-taiwanese-artist-charwei-tsaiinterview/ (last accessed 17th April 2020). 
Kahraman, Hayv, 'The Art of Mending' in Wassan Al-Khudhairi, ed., Acts of Reparation, Hayv Kahraman (St. Louis, MO: Contemporary Art Museum St Louis, 2017), pp.15-16.

— McGrew, ed., Hayv Kahraman, Project Series 52 (Claremont, CA: Pomona College Museum of Art, 2018), pp.81-88.

Kahraman, Hayv and Wassan Al-Khudhairi, 'Wassan Al-Khudairi Interviews Hayv Kahraman, Excerpted from an Email Exchange, July 5, 2017', in Hayv Kahraman, ed., Hayv Kahraman (New York: Rizzoli Electra, 2018), pp.6-15.

Kamalian, Zahra, ed., The Apple (International Reviews and Screenplay), trans. Minou Moshiri (Tehran: Rowzaneh Kar, 2000).

Kaplan, Caren, 'The Politics of Location as Transnational Feminist Critical Practice', in Inderpal Grewal and Caren Kaplan, eds., Scattered Hegemonies: Postmodernity and Transnational Feminist Practices (Minneapolis: University of Minnesota Press, 1994), pp.137-152.

Karabet, Anna, 'Refugee Women Share Their Heartbreaking Stories', Action Aid, 5th January 2016, https://www.actionaid.org.uk/blog/voices/2016/01/05/ refugee-women-share-their-heartbreaking-stories (last accessed 28th July 2020).

Karas, Tania, 'For Refugees in Lebanon, Giving Birth Comes at a High Price', NewsDeeply, 7th July 2017. https://www.newsdeeply.com/refugees/articles/ 2017/07/07/for-refugees-in-lebanon-giving-birth-comes-at-a-high-price (last accessed 24th October 2018).

Katz, Cindi, 'On the Grounds of Engagement: A Topography for Feminist Political Engagement', Signs 26:4 (2001), pp.1213-1234.

Keneally, Thomas and Rosie Scott, eds., Another Country: Writers in Detention (Broadway, NSW: Sydney PEN and Halstead Press, 2007).

Khalili, Homa, 'Sonita's Director: Why I Paid \$2000 to Stop a Rapper Being Sold into a Forced Marriage', The Guardian, 24th October 2016, https:// www.theguardian.com/film/2016/oct/24/sonita-director-interview-rokhsarehghaem-maghami (last accessed 26th June 2019).

Khattak, Saba Gul, 'Floating Upwards from History: Afghan Women's Experiences of Displacement', Development, 45:1 (2002), pp.105-110.

King, Rosamond S., 'More Notes on the Invisibility of Caribbean Lesbians', in Thomas Glave, ed., Our Caribbean: A Gathering of Lesbian and Gay Writing from the Antilles (Durham, NC: Duke University Press, 2008), pp.191-196.

Kingsley, Patrick, The New Odyssey: The Story of Europe's Refugee Crisis (London: Guardian Faber Publishing, 2017).

Kobayashi, Audrey, 'Colouring the Field: Gender, "Race”, and the Politics of Fieldwork', The Professional Geographer 46:1 (1994), pp.73-80.

Koyama, Emi, 'The Transfeminist Manifesto', in Rory Dicker and Alison Piepmeier, eds., Catching a Wave: Reclaiming Feminism for the Twenty-First Century (Lebanon, NH: Northeastern University Press, 2003), pp.244-262.

Kruks, Sonia, 'The Philosophy of Simone de Beauvoir: Ambiguity, Conversation, Resistance', Contemporary Political Theory 9:2 (2010), pp.256-258.

LaBelle, Brandon, 'Restless Acoustics, Emergent Publics', in Marcel Corbussen, Vincent Meelberg, and Barry Truax, eds., The Routledge Companion to Sounding Art (New York: Routledge, 2016), pp.275-286.

Lawler, Steph, 'Motherhood and identity', in Tess Cosslett, Alison Easton, and Penny Summerfield, eds., Women, Power and Resistance: An Introduction to Women's Studies (Buckingham: Open University Press, 1996), pp.153-164. 
Leake, Elisabeth, 'Spooks, Tribes and Holy Men: The Central Intelligence Agency and the Soviet Invasion of Afghanistan', Journal of Contemporary History 51:3 (2018), pp.240-262.

LeConté, Dill J., Jo Vearey, Elsa Oliveira, and Gabriela Martínez Castillo, “"Son of the Soil...Daughters of the Land": Poetry Writing as a Strategy of CitizenMaking for Lesbian, Gay, and Bisexual Migrants and Asylum Seekers in Johannesburg', Agenda 30:1 (2016), pp.85-95.

Lenette, Caroline, Donna Weston, Patricia Wise, Naomi Sunderland, and Helen Bristed, 'Where Words Fail, Music Speaks: The Impact of Participatory Music on the Mental Health and Wellbeing of Asylum Seekers', Art and Health 8:2 (2015), pp.1-15.

Lentin, Ronit, 'Pregnant Silence: (En)gendering Ireland's Asylum Space', Patterns of Prejudice 37:3 (2003), pp.301-322.

Liu M., A.T. Just, 'Now I See the Sunlight', Newsweek, 26th November (2001), p.46.

Locher, Birgit and Elisabeth Prügl, 'Feminism and Constructivism: Worlds Apart or Sharing the Middle Ground', International Studies Quarterly 45:1 (2001), pp.111-129.

Loescher, Gil, The UNHCR and World Politics: A Perilous Path (Oxford: Oxford University Press, 2001).

Lorca, Federico García, 'Lament for Ignacio Sanchez Mejias', trans. A.S. Kline, http://www.artofeurope.com/lorca/ (last accessed 25th June 2019).

Lorde, Audre, 'The Master's Tools Will Never Dismantle the Master's House', Sister Outsider: Essays and Speeches (Berkeley, CA: Crossing Press, 2007), pp.110-114.

Lousley, Gemma and Sarah Cope, 'We Are Still Here: The Continued Detention of Women Seeking Asylum in Yarl's Wood', Women for Refugee Women (October 2017), https://www.refugeewomen.co.uk/wp-content/uploads/2019/01/womenfor-refugee-women-reports-we-are-still-here.pdf (last accessed 5th October 2020).

Loveridge, Steve, dir., Matangi/Maya/M.I.A (U.K./U.S./Sri Lanka: Dogwoof Films, 2018).

Lubkemann, Stephen C., Culture in Chaos: An Anthropology of the Social Condition of War (Chicago, IL: University of Chicago Press, 2008).

Maccarone, Angelina, dir., Unveiled (Germany/Austria, 2005).

Macnab, Geoffrey, 'A Women's Place', The Guardian, 19th May 2003, https:// www.theguardian.com/film/2003/may/19/cannes2003.cannesfilmfestival (last accessed 25th June 2019).

Magner, T., 'A Less Than "Pacific" Solution for Asylum-Seekers in Australia', International Journal of Refugee Law 16:1 (2004), pp. 53-90.

Majidi, Majid, dir., Baran (Iran: Mirimax Films, 2001).

Makhmalbaf, Hana, dir., The Joy of Madness (Iran/France: Makhmalbaf Film House, 2005).

Makhmalbaf, Samira, dir., Blackboards (Iran/Italy: Makhmbalbaf Film House, 2000).

- dir., At Five in the Afternoon (Iran/France: Makhmalbaf Film House, 2002).

Malkki, Liisa H., 'Purity and Exile: Violence, Memory and National Cosmology among Hutu Refugees in Tanzania (Chicago, IL: University of Chicago Press, 1995). 
, 'Speechless Emissaries: Refugees, Humanitarianism and Dehistoricization', Cultural Anthropology, 11:3 (1996), pp.377-404.

—_, 'News and Culture: Transitory Phenomena and the Fieldwork Tradition', in James Ferguson and Akhil Gupta, eds., Anthropological Locations: Boundaries and Grounds of a Field Science (Los Angeles: University of California Press, 1997), pp.86-101.

Manchanda, Rita, 'Gender Conflict and Displacement: Contesting "Infantalisation” of Forced Migrant Women', Economic and Political Weekly 39:37 (2004), pp.4179-4186.

Mares, P., Borderline (Sydney: UNSW Press, 2002).

Marouf, Fatma E., 'The Emerging Importance of "Social Visibility" in Defining "a Particular Social Group" and its Potential Impact on Asylum Claims Related to Sexual Orientation and Gender', Yale Law and Policy Review 27:1 (2008), pp.47-106.

Martin, Craig, 'Turbulent Stillness: The Politics of Uncertainty and the Undocumented Migrant', in David Bissell and Gillian Fuller, eds., Stillness in a Mobile World (New York: Routledge, 2011), pp.192-208.

Martin, Susan, 'Global Migration Trends and Asylum', UNHCR New Issues in Refugee Research Working Paper Series 41 (2001), pp.1-27.

Massad, Joseph, 'Re-Orienting Desire: The Gay International and the Arab World', Public Culture 14:2 (2002), pp.361-385.

Massey, Doreen, 'Power-Geometry and a Progressive Sense of Place', in J. Bird, B. Curtis, G. Robertson, and L. Tickner, eds., Mapping the Futures: Local Culture, Global Change (London: Routledge, 1993), pp.59-69.

Masson, Charles, Droit du Sol (Brussels: Casterman, 2009).

McCormack, Donna, Queer Postcolonial Narratives and the Ethics of Witnessing (New York: Bloomsbury Academic, 2014).

McDonald-Gibson, Charlotte, 'Moms of Young Muslims Enlist in the Fight against ISIS', TIME Magazine, 15th September 2016, http://time.com/4489886/ isis-mothers-schools-edit-schlaffer-islamic-state/ (last accessed 14th December 2018).

McDonald-Gibson, Charlotte, Cast Away: Stories of Survival from Europe's Refugee Crisis (London: Portobello, 2016).

Mcginley, Ali, 'Detention of Women: Principles of Equality and NonDiscrimination', Forced Migration Review 44 (September 2013), p.3.

McGrew, Rebecca, 'Introduction - Hayv Kahraman: Weaving as Mending', in Rebecca McGrew, ed., Hayv Kahraman, Project Series 52 (Claremont, CA: Pomona College Museum of Art, 2018), pp.39-41.

McLaren, Margaret A., 'Introduction: Decolonizing Feminism', in Margaret A. McLaren, ed., Decolonizing Feminism: Transnational Feminism and Globalization (London: Rowman and Littlefield, 2017), pp.1-18.

McWilliams, Susan, Travelling Back: Toward a Global Political Theory (Oxford: Oxford University Press, 2014).

Mernissi, Fatima, Beyond the Veil: Male-Female Dynamics in Modern Muslim Society (Bloomington: Indiana University Press, 1987).

Meshkini, Marzieh, dir., Stray Dogs (Iran/France: Makhmalbaf Productions, 2006).

Messing, Arietta, Rachel E. Fabi and Joanne Rosen, 'Reproductive Injustice at the US Border', American Journal of Public Health 110:3 (2020), pp.339-344. 
Metzger, Sean, 'Concerning the Queer Refugee: Staceyann Chin's Transient Performance', Cultural Dynamics 0:0 (2020), pp.1-16.

Middlekoop, Louis, 'Normativity and Credibility of Sexual Orientation in Asylum Decision Making', in Thomas Spijkerboer, ed., Fleeing Homophobia: Sexual Orientation, Gender Identity and Asylum (New York: Routledge, 2013), pp.154-175.

Minh-ha, Trinh T., When the Moon Waxes Red: Representation, Gender and Cultural Politics (London and New York: Routledge, 1991).

Mirapuri, Dawn, 'Meditations on Memory and Belonging: Nada Awar Jarrar's Somewhere, Home', in Layla Al Maleh, ed., Arab Voices in Diaspora: Critical Perspectives on Arab Anglophone Literature (Amsterdam: Rodopi, 2009), pp.463-485.

miriam cooke, War's Other Voices: Women Writers on the Lebanese Civil War (Cambridge: Cambridge University Press, 1988).

Moghadam, Valentine, 'Afghan Women and Transnational Feminism', The Middle East Women's Studies Review (fall 2001), pp.1-7.

- 'Patriarchy, the Taliban, and Politics of Public Space in Afghanistan', Women's Studies International Forum 25:1 (2002), pp.19-31.

Mohanty, Chandra Talpade and M. Jacqui Alexander, 'Cartographies of Knowledge and Power: Transnational Feminism as Racial Praxis', in Amanda Lock Swarr and Richa Nagar, eds., Critical Transnational Feminist Praxis (Albany, NY: SUNY Press, 2010), pp.23-45.

Mohanty, Chandra Talpade, 'Introduction: Cartographies of Struggle: Third World Women and the Politics of Feminism', in Chandra Talpade Mohanty, Ann Russo, and Lourdes Torres, eds., Third World Women and the Politics of Feminism (Bloomington: Indiana University Press, 1991), pp.1-50.

_- "Under Western Eyes: Feminism and Colonial Discourse', in Chandra Talpade Mohanty, Ann Russo, and Lisa Torres, eds., Third World Women and the Politics of Feminism (Bloomington: Indiana, 1991), pp.51-80.

_ ist Structures', in Chandra Talpade Mohanty, ed., Feminism without Borders: Decolonizing Theory, Practicing Solidarity (Durham, NC: Duke University Press, 2003), pp.221-252.

— , 'Preface: Toward a Decolonial Feminism for the 99 Percent', in Margaret A. McLaren, ed., Decolonizing Feminism: Transnational Feminism and Globalization (London: Rowman and Littlefield, 2017), pp.vii-xi.

- Feminism without Borders: Decolonizing Theory, Practicing Solidarity (Durham, NC: Duke University Press, 2003).

Moore, Lindsey, 'Women in a Widening Frame: (Cross-)Cultural Projection, Spectatorship, and Iranian Cinema', Camera Obscura 20:2(59) (2005), pp.1-33.

Moreno, Karina, 'A Politics of Solidarity', Jacobin, 11th May 2017.

Morton, Lindsay, 'Evaluating the Effects of Epistemic Location in Literary Journalism', Journalism 17:2 (2016), pp.244-259.

Motta, Carlos, The Crossing, Stedelijk Museum, Amsterdam, 16th September 2017-21st January 2018, https://www.stedelijk.nl/en/exhibitions/carlos-mottathe-crossing (last accessed 24th August 2020).

Mulvarine, A., 'Unveiled Threat: The Taliban is Relentless in its Oppression of Afghan Women', US News and World Report, 15th October (2001), pp.33-34.

Mulvey, Laura, 'Visual Pleasure and Narrative Cinema', Screen 16:3 (1975), pp.6-18. 
Muñoz, José Esteban, Cruising Utopia: The Then and There of Queer Futurity, 10th Edition (New York: New York Universty Press, 2019).

Murray, David A. B., 'The Homonational Archive: Sexual Orientation and Gendered Identity Refugee Documentation in Canada and the US', Ethnos 82:3 (2017), pp.520-544.

Murray-Román, Jeannine, 'Multimedia Staceyann Chin: Performing and Blogging "Cyberjournal"', Extensions: The Online Journal of Embodiment and Technology 3 (2006), http://www.performancestudies.ucla.edu/extensionsjournal/ roman.htm (last accessed 21st September 2020).

Mutu, Wangechi, The End of carrying All (2015). Video installation (three screens); 10 mins 40 s video in loop.

Myrivilis, Stratis, The Mermaid Madonna (London: Hutchinson, 1959).

Nancy, Jean-Luc, Listening, trans. Charlotte Mandell (New York: Fordham University Press, 2007).

Nayeri, Dina, The Ungrateful Refugee (Edinburgh: Canongate, 2019).

New Wave Films, 'Sonita', New Wave Films, http://newwavefilms.co.uk/view-filmdetail.html/?viewListing=MTU1\&cat=2 (last accessed 26th June 2019).

Nichols, Bill, 'What to Do about Documentary Distortion? Toward a Code of Ethics', International Documentary Association, 30th April 2006, https://www. documentary.org/feature/what-do-about-documentary-distortion-toward-codeethics (last accessed 26th June 2019).

Nolan, Catherine, Transnational Ruptures: Gender and Forced Migration (Abingdon: Routledge, 2016).

Norwegian Refugee Council/Internal Displacement Monitoring Centre, Internal Displacement: Global Overview of Trends and Developments in 2009 Afghanistan, 17th May 2010, https://www.refworld.org/cgi-bin/texis/vtx/ rwmain ? page $=$ search $\&$ docid $=4$ bf $252560 \&$ skip $=0 \&$ query $=$ internal $\% 20$ displacement\%202001\&coi=AFG (last accessed 4th June 2019).

Okparanta, Chinelo, Under the Udala Trees (London: Granta, 2017).

O'Neill, Maggie, Asylum, Migration and Community (Bristol: Policy Press, 2010).

O’Neill, Xana and Rym Momtaz, 'Madaya Mom', ABC News, 3rd October 2016, https://abcnews.go.com/International/deepdive/madaya-mom-mother-strugglesurvival-syria-civil-war-42362213 (last accessed 12th December 2017).

Oliver, Kelly, 'The Special Plight of Women Refugees', in Margaret A. McLaren, ed., Decolonizing Feminism: Transnational Feminism and Globalization (London: Rowman and Littlefield, 2017), pp.177-200.

Oliviero, Katie E., 'Sensational Nation and the Minutemen: Gendered Citizenship and Moral Vulnerabilities', Signs: Journal of Women in Culture and Society 36:3 (2011), pp.679-706.

Ong, Aihwa, Buddha Is Hiding: Refugees, Citizenship, the New America (Berkeley: University of California Press, 2003).

Operario, Don and Tooru Nemoto, 'On Being Transnational and Transgender: Human Rights and Public Health Considerations', American Journal of Public Health 107:10 (2017), pp.1537-1538.

O'Regan, Kathryn, 'How Collaboration Is the Driving Force Behind Wu Tsang's Mesmerising New Film on the Migrant Crisis', Sleek Magazine, 10th October 2019, https://www.sleek-mag.com/article/wu-tsang-migrant-crisis/ (last accessed 5th October 2020). 
Oxford English Dictionary, 'trans-, prefix', Oxford English Dictionary Online, June 2020, https://www.oed.com/view/Entry/204575? result=4\&rskey=JS0R8f\& (last accessed August 14, 2020).

Palladino, Mariangela and Agnes Woolley, 'Migration, Humanitarianism, and the Politics of Salvation', LIT: Literature Interpretation Theory 29:2 (2018), pp.129-144.

Palmer-Mehta, Valerie, 'Subversive Maternities: Staceyann Chin's Contemplative Voice', QED: A Journal in GLBTQ Worldmaking 3:1 (2016), pp.34-60.

Passarlay, Gulwali with Nadene Ghouri, The Lightless Sky: My Journey to Safety as a Child Refugee (London: Atlantic, 2015).

Pedwell, Carolyn, 'Mediated Habits: Images, Networked Affect and Social Change', Subjectivity, 10:2 (2017), pp.1-23.

Perera, Suvendrini, 'Oceanic Corpo-Geographies, Refugee Bodies and the Making and Unmaking of Waters', Feminist Review 103 (2013), pp.59-79.

Peterson, V. Spike and Anne Sisson Runyan, Global Gender Issues (Westview: Colorado, 1993).

- Global Gender Issues in the New Millennium, Third Edition (Philadelphia, PA: Westview Press, 2010).

Phillips, Tom, “This Is Our Feminist Spring”: Millions of Mexican Women Prepare to Strike over Femicides', The Guardian, 7th March 2020, https://www. theguardian.com/world/2020/mar/07/mexico-femicides-protest-women-strike (last accessed 28th July 2020).

Pillay, Navanethem, 'Opening Remarks at the Panel Discussion on Human Rights of Migrants in Detention Centres', UN Human Rights Council, 17th September 2009, http://www2.ohchr.org/english/issues/migration/taskforce/docs/ HCStatementPanelMigrants.pdf (last accessed 22nd July 2019).

Portes, Jonathan, What Do We Know and What Should We Do about Immigration? (London: Sage, 2019).

Pouilly, Cécile, 'Refugee Women and Children Face Heightened Risk of Sexual Violence Amid Tensions and Overcrowding at Reception Facilities on Greek Island', UNHCR, 9th February 2018, https:/www.unhcr.org/uk/news/ briefing/2018/2/5a7d67c4b/refugee-women-children-face-heightened-risksexual-violence-amid-tensions.html (last accessed 13th July 2020).

Power, Jill, 'Lesbian, Gay, Bisexual and Trans People and Persecution: Experiences of LGBT People and the UK Asylum System', in Oreet Ashery, ed., Staying: Dream, Bin, Soft Stud and Other Stories, available as PDF via Artangel, https://www. artangel.org.uk/project/staying/ (last accessed 24th August 2020), pp.8-13.

Prosser, Jay, Second Skins: The Body Narratives of Transsexuality (New York: Columbia University Press, 1998).

Pruitt, Lesley, Helen Berents, and Gayle Munro, 'Gender and Age in the Construction of Male Youth in the European Migration “Crisis”, Signs 43:3 (2018), pp.687-709.

Puar, Jasbir, Terrorist Assemblages: Homonationalism in Queer Times (Durham, NC: Duke University Press, 2017).

Raboin, Thibaut, Discourses on LGBT Asylum in the UK: Constructing a Queer Haven (Manchester: Manchester University Press, 2017).

Raj, Anita, Charlemagne S. Gomez, and Jay G. Silverman, 'Multisectoral Afghan Perspectives on Girl Child Marriage: Foundations for Change Do Exist in Afghanistan', Violence against Women 20:2 (2014), pp.1489-1505. 
Rajan, Nithya, 'What Do Refugees Want? Reading Refugee Lip-Sewing Protests through a Critical Lens', International Feminist Journal of Politics 21:4 (2019), pp. 527-543.

Ramrayka, Liza, 'The Quiet Crisis of Europe's Pregnant Refugees', The Huffington Post, 13th June 2016, https://www.huffingtonpost.com/entry/europe-pregnantrefugees_us_575eba7ce4b0ced23ca88e5e (last accessed 14th December 2018).

Refugee Council, The Vulnerable Women's Project: Refugee and Asylum Seeking Women Affected by Rape or Sexual Violence - Literature Review (London: Refugee Council, 2009).

Research Directorate, Immigration and Refugee Board of Canada, 'Jamaica: Treatment of Sexual Minorities, Including Legislation, State Protection and Support Services', IRB: Immigration and Refugee Board of Canada, January 2013, http://www.irb-cisr.gc.ca:8080/RIR_RDI/RIR_RDI.aspx?id=454341\&l=e (last accessed 21st September 2020).

Rettberg, Jill Walker and Radhika Gajjala, 'Terrorists or Cowards: Negative Portrayals of Male Syrian Refugees in Social Media', Feminist Media Studies 16:1 (2016), pp.178-181.

Reynolds, Rhon, Rebecca Schiefler, and Neela Ghoshal, 'Not Safe at Home: Violence and Discrimination against LGBT People in Jamaica', Human Rights Watch, 21st October 2014, https://www.hrw.org/report/2014/10/21/not-safehome/violence-and-discrimination-against-lgbt-people-jamaica (last accessed 21st September 2020).

Rich, Adrienne, Of Woman Born: Motherhood as Experience and Institution (New York: Norton, 1976).

Riphenburg, Carol J., 'Gender Relations and Development in a Weak State: The Rebuilding of Afghanistan', Central Asian Survey 22:2/3 (2003), pp.187-207.

Rivers, Nicola, Postfeminism(s) and the Arrival of the Fourth Wave: Turning Tides (Basingstoke: Palgrave Macmillan, 2017).

Rose, Jacqueline, Mothers: An Essay on Love and Cruelty (London: Faber \& Faber, 2018).

Rosenberg, Lauren and Emma Howes, 'Listening to Research as a Feminist Ethos of Representation', in Kristine L. Blair and Lee Nickoson, eds., Composing Feminist Interventions: Activism, Engagement, Praxis (Boulder: University of Boulder, Colorado Press, 2019), pp.75-91.

Rostami-Povey, Elaheh, Afghan Women: Identity and Invasion (London: Zed Books, 2007).

Rousseau, Cécile, François Crépeau, Patricia Foxen, and France Houle, 'The Complexity of Determining Refugeehood: A Multidisciplinary Analysis of the Decision-Making Process of the Canadian Immigration and Refugee Board, Journal of Refugee Studies 15:1 (2002), pp.43-70.

Rowell, Melody, 'Inside the Harrowing Journeys of Refugee Mothers', National Geographic, 10th January 2017, https:/www.nationalgeographic.com/ photography/proof/2017/01/syria-greece-refugees-mothers-pregnancy/ (last accessed 12th December 2018).

Roy, Arundhati, War Talk (Cambridge, MA: South End Press, 2003).

Rubin, Barnett R., Afghanistan from the Cold War through the War on Terror (Oxford: Oxford University Press, 2015).

Ruiz, Hiram A., 'Afghanistan: Conflict and Displacement 1978 to 2001', Forced Migration Review 13 (2001), pp.8-13. 
Runyan, Anne Sisson, Amy Lind, Patricia McDermott, and Harriet H. Marchand, Feminist (Im)Mobilities in Fortress(ing) North America: Rights, Citizenships, and Identities in Transnational Perspective (New York: Routledge, 2013).

Russo, Ann, 'The Feminist Foundation's Campaign to Stop Gender Apartheid: The Intersections of Feminism and Imperialism in the United States', International Feminist Journal of Politics 8:6 (2006), pp.557-580.

Rygiel, Kim, 'Governing Borderzones of Mobility through E-Borders', in Vicki Squire, ed., The Contested Politics of Mobility: Borderzones and Irregularity (London: Routledge, 2011), pp.143-168.

Said, Edward, 'Reflections on Exile', Granta 13 (1984), pp.157-172.

- Reflections on Exile: And Other Literary and Cultural Essays (London: Granta, 2012).

Salsbury, Eleanor and Emma Encinas, 'We Will Be Judged for This: Feminist Lawmakers and Activists Protest Trump's Immigration Policies outside Otay Meda Detention Centre', Ms. Magazine, 26th June 2018, https://msmagazine. com/2018/06/26/will-judged-feminist-lawmakers-activists-protest-trumpsimmigration-policies-outside-otay-mesa-detention-center/ (last accessed 27th July 2020).

Samari, Goleen, 'The Response to Syrian Refugee Women's Health Needs in Lebanon, Turkey and Jordan and Recommendations for Improved Practice', Humanity in Action, https:/www.humanityinaction.org/knowledgebase/583the-response-to-syrian-refugee-women-s-health-needs-in-lebanon-turkeyand-jordan-and-recommendations-for-improved-practice (last accessed 7th December 2018).

Sayej, Nadja, 'It's about Finding a Place': Stunning Portraits of Women Affected by the Refugee Crisis', The Guardian, 1st September 2020, https://www. theguardian.com/artanddesign/2020/sep/01/its-about-finding-a-place-stunningportraits-of-women-affected-by-the-refugee-crisis (last accessed 14th October 2020).

Scagliotti, John, dir., Dangerous Living: Coming Out in the Developing World (U.S., 2003).

Schiff, Jade Larissa, 'Welcoming Refugees: Mindful Citizenship and the Political Responsibility of Hospitality', Signs 43:3 (2018), pp.737-762.

Sedgwick, Eve Kosofsky, Tendencies (Durham, NC: Duke University Press, 1993). Sekaran, Shanthi, Lucky Boy (New York: G.P. Putnam's Sons, 2016).

Shakhsari, Sima, 'The Queer Time of Death: Temporality, Geopolitics, and Refugee Rights', Sexualities 17:8 (2014), pp.998-1015.

Shalhoub-Kevorkian, Nadera, Militarization and Violence against Women in Conflict Zones in the Middle East: A Palestinian Case-Study (Cambridge: Cambridge University Press, 2009).

Sharifi, Niloo, 'How Wu Tsang is Rejecting the Confines of Gender and Language', Sleek, 14th November 2017, https://www.sleek-mag.com/article/wu-tsanginterview-identity-fact/ (last accessed 30th September 2020).

Sheibani, Khatereh, Aesthetics, Modernity and Film after the Revolution (London: IB Tauris, 2011).

Shire, Warsan, Teaching My Mother How to Give Birth (London: Mouthmark Poetry, 2011).

Shohat, Ella, 'Gender in Hollywood's Orient', Middle East Report (JanuaryFebruary 1990), pp.40-42. 


\section{Bibliography}

ed., Talking Visions: Multicultural Feminism in a Transnational Age (Cambridge, MA: MIT Press, 2001).

Shukla, Nikesh, ed., The Good Immigrant (London: Unbound, 2017).

Silvera, Makeda, 'Man Royals and Sodomites: Some Thoughts in the Invisibility of Afro-Caribbean Lesbians', Feminist Studies 18:3 (1992), pp.521-532.

Silverman, Stephanie J., 'Immigration Detention in the UK', Migration Observatory briefing, COMPAS, September 2016, http://www.aviddetention.org.uk/ sites/default/files/images/Briefing-Immigration_Detention-1.pdf (last accessed 15th November 2019).

Sinno, Hamed, 'Hamed Sinno on Pride and Mourning in the Middle East', Frieze, 26th June 2020, https://www.frieze.com/article/hamed-sinno-pride-andmourning-middle-east (last accessed 20th August 2020).

Sisters Not Strangers Coalition, 'Hear Us: The Experiences of Refugee and AsylumSeeking Women during the Pandemic', Sisters Not Strangers, July 2020, https:// www.refugeewomen.co.uk/wp-content/uploads/2020/08/Hear-us-Sisters-NotStrangers.pdf (last accessed 13th October 2020).

Sisters Uncut, 'Yarl's Wood Demonstration: A Statement of Solidarity', Sisters Uncut, http://www.sistersuncut.org/2018/03/19/yarls-wood-demonstration-astatement-of-solidarity/ (last accessed 13th November 2019).

Smith, Ali, 'The Detainee's Tale', in David Herd and Anna Pincus, eds., Refugee Tales (Manchester: Comma Press, 2016), pp.49-62.

- Spring (London: Penguin, 2019).

Smith, Caroline, The Immigration Handbook (Bridgend: Seren Press, 2016).

Smith, Kate, 'Stories Told by, for, and about Women Refugees: Engendering Resistance', ACME: An International E-Journal for Critical Geography 14:2 (2015), pp.461-469.

Smith, Sidonie and Julia Watson, Reading Autobiography: A Guide for Interpreting Life Narratives (Minneapolis: University of Minnesota Press, 2001).

Solomon, Patrick, 'Two Years after Egypt's "Rainbow Flag Arrests”, LGBTIQ People Face an Ongoing Security Crackdown', Open Democracy, 22nd September 2019, https:/www.opendemocracy.net/en/5050/two-years-after-egyptsrainbow-flag-arrests-lgbtiq-people-face-an-ongoing-security-crackdown/ (last accessed 21st September 2020).

Sontag, Susan, Regarding the Pain of Others (London: Penguin, 2003).

Speyer, John, 'For Music. Education Zone', Music in Detention, 2008, http://www. musicindetention.org.uk/aboutmid.htm (last accessed 15th April 2020).

Spivak, Gayatri Chakravorty, 'Can the subaltern speak?', in C. Nelson and L. Grossberg, eds., Marxism and the Interpretation of Culture (Urbana: University of Illinois Press, 1988), pp. 271-316.

Squire, Vicki, The Exclusionary Politics of Asylum (Basingstoke: Palgrave Macmillan, 2009).

Stabile, Carol A. and Deepa Kumar, 'Unveiling Imperialism: Media, Gender and the War on Afghanistan', Media, Culture and Society 27:5 (2005), pp.765-783.

Statovci, Pajtim, Crossing (London: Pushkin Press, 2019).

Stewart, Catriona, 'Mercy Baguma: Home Office Facing Legal Action', The Herald, 8th October 2020, https://www.heraldscotland.com/news/18777917.mercybaguma-home-office-facing-legal-action/ (last accessed 13th October 2020).

Stone, Michel, The Iguana Tree: A Novel (Spartanburg: Hub City Press, 2012). 
Stonebridge, Lindsey, Placeless People: Writing, Rights, and Refugees (Oxford: Oxford University Press, 2018).

Stromberg, Matt, 'For Artists, the U.S.-Mexico Border Is Fertile Territory', Artsy, 6th March 2017, https://www.artsy.net/article/artsy-editorial-mexican-artiststhreat-trumps-wall-fuel-inspiration (last accessed 16th July 2020).

Strongheart Foundation, 'The Impact of Child Marriages: Refugees', Sonita.org, https://static1.squarespace.com/static/59b6f61cf14aa1d3e46429eb/t/5a0cf58ae 4966bbd235c6016/1510798730306/CM+Impact+Refugees+PDF_Nov_15.pdf (last accessed 23rd May 2019).

Stryker, Susan, 'The Transgender Issue: An Introduction', GLQ: A Journal of Gay and Lesbian Studies 4:2 (1998), pp.145-158.

Stryker, Susan, Paisley Currah, and Lisa Jean Moore, 'Introduction: Trans-, Trans, or Transgender?', WSQ: Women's Studies Quarterly 36:3 (2008), pp.11-22.

Tapper, Richard, ed., The New Iranian Cinema: Politics, Representation and Identity (London: IB Tauris, 2006).

Tazzioli, Martina and William Walters, 'The Sight of Migration: Governmentality, Visibility and Europe's Contested Borders', Global Society 30:3 (2016), pp.445-464.

The World, 'Remembering Sarah Hegazi, the Egyptian LGBTQ Activist Arrested for Unfurling the Rainbow Flag', The World, 16th June 2020, https:/www. pri.org/stories/2020-06-16/remembering-sarah-hegazi-egyptian-lgbtq-activistarrested-unfurling-rainbow-flag (last accessed 20th August 2020).

Thomas Morgan, dir., Soufra (USA/Lebanon: Rebelhouse Studios, 2017).

Tickner, J. Ann, 'What Is Your Research Program? Some Feminist Answers to International Relations Methodological Questions', International Studies Quarterly 49:1 (2005), pp.1-21.

Ticktin, Miriam, 'A World without Innocence', American Ethnologist 44:4 (2017), pp.577-590.

Tinti, Peter and Tuesday Reitano, Migrant, Refugee, Smuggler, Saviour (London: C Hurst and Co., 2018).

Tondo, Lorenzo and Maurice Stierl, 'Banksy Funds Refugee Rescue Boat Operating in Mediterranean', The Guardian, 27th August 2020, https://www. theguardian.com/world/2020/aug/27/banksy-funds-refugee-rescue-boatoperating-in-mediterranean (last accessed 13th October 2020).

Torres, Rebecca Maria, 'A Crisis of Rights and Responsibility: Feminist Geopolitical Perspectives on Latin American Refugees and Migrants', Gender, Place and Culture 25:1 (2018), pp.13-36.

Townsend, Mark, 'Women Fight to Help Families Torn Apart by 'Racist' Deportation Policy', The Guardian, 3rd January 2020, https://www.theguardian. com/uk-news/2021/jan/03/women-fight-to-help-families-torn-apart-by-racistdeportation-policy (last accessed 1st February 2021).

- 'Revealed: Priti Patel U-Turn on End to Detention for Refugee Women', The Guardian, 27th February 2021, https://www.theguardian.com/world/2021/ feb/27/revealed-priti-patel-u-turn-on-end-to-detention-for-refugee-women (last accessed 5th March 2021).

Transnational Feminists, 'Transnational Feminist Practices against War. October 2001. A Statement by Paola Bacchetta, Tina Campt, Inderpal Grewal, Caren Kaplan, Minoo Moallem, and Jennifer Terry', in Susan Hawthorne and Bronwyn 


\section{Bibliography}

Winter, eds., September 11, 2001: Feminist Perspectives (Melbourne: Spinifex Press, 2002), pp.58-63.

Trilling, Daniel, Lights in the Distance: Exile and Refuge at the Borders of Europe (London: Picador, 2018).

Tsai, Charwei and Tsering Tashi Gyalthang, Hear Her Singing, 2017 Video with Sound and Colour, 16 minutes 28 seconds, https://www.youtube.com/ watch? $v=$ SfaFCrQcWjo\&t=15s (last accessed 4th May 2020).

Tsai, Charwei, 'Conversation between Stephanie Rosenthal and Charwei Tsai', hearhersinging.info, http://hearhersinging.info/ (last accessed 12th June 2019).

Tsang, Wu, dir., Wildness (U.S., 2012).

$\longrightarrow$, dir., Duilian (Hong Kong: Spring Workshop, 2016).

- One Emerging from a Point of View, 2-channel Overlapping Projections, 43 minutes, 2019.

- One Emerging from a Point of View, Sharjah Art Foundation, http:// sharjahart.org/sharjah-art-foundation/projects/one-emerging-from-a-point-ofview-2019 (last accessed 5th October 2020).

Tyler, Imogen, 'Naked Protest: The Maternal Politics of Citizenship and Revolt', Citizenship Studies 17:2 (2013), pp.211-226.

UN Women, 'Displacement and Resilience: Five Women, Five Stories', UN Women, 17th June 2019, https://www.unwomen.org/en/digital-library/ multimedia/2019/6/photo-essay-cameroon-displacement-and-resilience-stories (last accessed 5th October 2020).

UNHCR, 'Convention and Protocol Relating to the Status of Refugees', UNHCR, December 2010, https://www.unhcr.org/uk/3b66c2aa10 (last accessed 13th July 2020).

_- 'Guidelines on International Protection Number 9: Claims to Refugee Status based on Sexual Orientation and/or Gender Identity within the Context of Article 1A(2) of the 1951 Convention and/or its 1967 Protocol Relating to the Status of Refugees', UNHCR, 12th October 2012, https://www.unhcr. org/publications/legal/509136ca9/unhcr-guidelines-international-protection-9claims-refugee-status-based.html (last accessed 16th September 2020).

— , '2014-2019. Beyond Detention: A Global Strategy to Support Governments to End the Detention of Asylum-Seekers and Refugees', UNHCR, 2014, https://www.unhcr.org/53aa929f6 (last accessed 5th October 2020).

- 'Global Trends 2013', UNHCR, 2014, https://www.unhcr.org/uk/ statistics/country/5399a14f9/unhcr-global-trends-2013.html (last accessed 5th October 2020).

- ' 'Operation: Islamic Republic of Iran, 2014 Year-End Report', UNHCR, 2014, http://reporting.unhcr.org/sites/default/files/pdfsummaries/GR2014IslamicRepublicofIran-eng.pdf (last accessed 25th June 2019).

_ _ 'Global Trends 2018', UNHCR, 2019, https://www.unhcr.org/uk/statistics/ unhcrstats/5d08d7ee7/unhcr-global-trends-2018.html (last accessed 5th October 2020).

- 'Seven Years On: Timeline of the Syrian Crisis', UNHCR Philippines, 7th March 2018, https://www.unhcr.org/ph/13427-seven-years-timeline-syria-crisis. html (last accessed 12th December 2018).

— 'Women on the Run: First-Hand Accounts of Women Fleeing El Salvador, Guatamala, Honduras, and Mexico', UNHCR, October 2015, https:// www.unhcr.org/uk/publications/operations/5630f24c6/women-run.html (last accessed 13th July 2020). 
- 'Global Trends in Forced Displacement in 2019', UNHCR, June 2020, https://www.unhcr.org/5ee200e37.pdf (last accessed 27th July 2020).

Unknown author, 'Charwei Tsai', Ocula, https://ocula.com/artists/charwei-tsai/ (last accessed 17th April 2020).

Unknown author, 'Hani Abdile', Word Travels, http://www.wordtravels.info/ hani-abdile-sf (last accessed 10th April 2020).

Unknown author, 'Hani Abdile', Writing through Fences, http:// writingthroughfences.org/writers/hani-abdile/ (last accessed 10th April 2020).

Valji, Nahla, 'Women and the 1951 Refugee Convention: Fifty Years of Seeking Visibility', Refuge 19:5 (2001), pp.25-35.

Various Authors, 'Feminist Resources for \#TheResistance', Signs: Journal of Women in Culture and Society, http://signsjournal.org/features/virtual-issues/ feminist-resources-for-theresistance/\#noban (last accessed 5th October 2020).

Various Authors, Frontiers: A Journal of Women's Studies 39:3 (2018).

Virilio, Paul, Speed and Politics, trans. Semiotext(e) and Mark Polizzotti (Los Angeles, CA: Semiotext(e), 2006).

Voegelin, Salomé, Sonic Possible Worlds: Hearing the Continuum of Sound (New York: Bloomsbury Academic, 2014).

Von Welser, Maria, No Refuge for Women: The Tragic Fate of Syrian Refugees (Vancouver: Greystone Books, 2017).

Vourloumis, Eirini, 'The Mermaid Madonna', Eirini Vourloumis Photography, http://www.eiriniphoto.com/the-mermaid-madonna/ (last accessed 5th October 2020).

Wali, Sima, 'Afghan Women: Recovering, Rebuilding', Ethics and International Affairs 16:2 (2002), pp.15-21.

Wamariya, Clementine and Elizabeth Weil, The Girl Who Smiled Beads: A Story of War and What Comes After (London: Windmill Books, 2019).

Weir, Lorna, Pregnancy, Risk and Biopolitics: On the Threshold of the Living Subject (Abingdon: Routledge, 2006).

Weiwei, Ai, dir., Human Flow (Germany/USA/China/Palestine/France: 24 Media, 2017.

Welldon, Estella, Mother, Madonna, Whore: The Idealization and Denigration of Motherhood (London: Karvac, 1988).

Western, Tom, 'Aural Borders, Audible Migrations: Sound and Citizenship in Athens', British Forum for Ethnomusicology Conference, Newcastle, April 2018, https://www.academia.edu/36416837/Aural_Borders_Audible_Migrations_ Sound_and_Citizenship_in_Athens (last accessed 5th October 2020).

_- "Refugee Voices" in the Sonopolis: Ethics and Aesthetics of Collaborative Field Recording in Athens', British Forum for Ethnomusicology Conference (April 2019), file:///Users/anna/Downloads/Refugee_Voices_in_the_Sonopolis_ Ethics_a.pdf (last accessed 15th November 2019).

Whitlock, Gillian, 'The Skin of the Burqa: Recent Life Narratives from Afghanistan', Biography 28:1 (2005), pp.54-76.

- Postcolonial Life Narratives: Testimonial Transactions (Oxford: Oxford University Press, 2015).

Wilsher, Daniel, Immigration Detention: Law, History, Politics (Cambridge: Cambridge University Press, 2014).

Women for Refugee Women, 'Set Her Free: Five Years of Campaigning against Immigration Detention', Women for Refugee Women, 28th January 2019, 


\section{Bibliography}

https:/www.refugeewomen.co.uk/set-her-free-5-years-of-campaigning-againstimmigration-detention/ (last accessed 13th November 2013).

_ https://www.gov.uk/government/publications/immigration-statistics-yearending-june-2019/how-many-people-are-detained-or-returned (last accessed 16th April 2020).

Wong, Ilyn, 'Between Opacity and Transparency: Wu Tsang at Gropius Bau', Berlin Art Link, 29th November 2019, https://www.berlinartlink.com/2019/11/29/ between-opacity-and-transparency-wu-tsang-at-gropius-bau/ (last accessed 2nd October 2020).

Wong, Jill, 'Charwei Tsai: The Art of Change', MutualArt, July/August 2009, https://www.mutualart.com/Article/Charwei-Tsai--The-Art-of-Change/951052 D8A9F26195 (last accessed 17th April 2020).

Woolley, Agnes, Contemporary Asylum Narratives: Representing Refugees in the Twenty-First Century (Basingstoke: Palgrave Macmillan, 2014).

_ - 'Narrating the "Asylum Story": Between Literary and Legal Storytelling', Interventions 19:3 (2017), pp.376-394.

Wright, Terence, 'Moving Images: The Media Representation of Refugees', Visual Studies 17:1 (2002), pp.53-66.

Yazbek, Samar, The Crossing: My Journey to the Shattered Heart of Syria, trans. Nashwa Gowanlock and Ruth Ahmedzai Kemp (London: Rider, 2015).

Yousafzai, Malala, We Are Displaced: My Journey and Stories from Refugee Girls around the World (London: Weidenfeld and Nicholson, 2019).

Žižek, Slavoj, The Plague of Fantasies (London: Verso, 2008).

— A Aainst the Double Blackmail: Refugees, Terror and Other Troubles with the Neighbours (London: Penguin, 2016).

Zurek, Yvette, 'The Experiences of Women in Australian Immigration Detention Centres', Forced Migration Research 20 (May 2004), pp.37-38. 


\section{Index}

Note: Page numbers followed by " $\mathrm{n}$ " denote endnotes.

Abdile, Hani 105-114, 122

Adshead, Kay 104

Agamben, Giorgio 23

Ahmed, Sara 48-50, 57-58, 108, 157

Angelou, Maya 60

Anthropocene 152

Anzaldúa, Gloria 134-135, 140-144, 147,148

Arendt, Hannah 23, 49

Ashery, Oreet 138

asylum: androcentrism of 9, 107, 115-116; anthology 107, 113-114; credibility of claim to $10,107-108$, 115-116; interview 9, 105, 107-108, 111; see also voice: testimony autobiography see life-narrative

Baguma, Mercy xvi

Behind the Wire 107; see also immigration detention: Australian biopolitics 40, 43, 46, 101-102, 105, 109, 110-111, 113-116, 121-122, $147,166-167,171$

body / embodiment 9, 14, 22, 77, $87-88,105,115,119,121,132,133$, $135,155,165-167$; as 'proof' of asylum claim 115; racialized 145148; sexed and gendered 133-134, 144, 150; as situation 80 ; speaking through 104, 110, 115, 118, 138; see also trans

borders xv, 15-16, 90, 135, 141-142, 148; border-guard 21; borderland 134-135, 140-141, 144; crossing, politics / poetics of 133-135, 139-150, 152-157; Operation Sovereign Borders 106; securitization of xvii, 40, 110; see also biopolitics; immigration detention

Butler, Judith 88, 111, 133; and Anthanasiou 88-89

camp, refugee xvi, 7, 9, 12, 54, 56, 67n85, 110; Za'atari 39

campaigns: Families for Justice xvi; humanitarian 41; \#MeToo 40, 62n11, 147; \#NoBanNoWallNoRaids 12; \#SetHerFree 102-103; see also feminism/t: activism / protest; women's groups

Campsfeld Nine 105

Canada 74, 131

capitalism/t 84-86, 88-91, 93, 120; Capitalocene 152

care, politics of 2, 42, 47-48, 50-51, 53-54, 56-59

Caribbean 141-148; Jamaica 27, 141, 143-146, 148

Central America 11-13, 102; Circulo Violeta 12; Mexico 11-14, 134, 141; see also Anzaldúa, Gloria; feminism/t: activism

child 7, 45, 54, 56; Aylan Kurdi 42; bride $81-82,85$; infantilization of refugee woman 57; in utero 43,45 (see also pregnancy); women with children 7, 25, 49

Chin, Staceyann 27, 140-148, 157

climate change $1,117,170-171$; see also Anthropocene

Cockburn, Cynthia 59-60

colonial/ism 15-16, 45, 54, 90-91, 113, 134, 145, 165, 168, 171; Europeanderived colonial laws on sexuality 
145; see also decolonial; imperialism; postcolonial; slave/ry

community: 'accidental' 120; of aporia 104; cross-cultural alliance 12 , 50, 117; feminist xviii, 167, 170; of listeners 106, 112; national 21; queer 27, 131-132, 135, 147, 149, 156-157; refugee 49, 74; writing workshops $67 \mathrm{n} 87$

conflict: ideological 69-71, 73, 78, 80-81, 89, 91-93, 136; military 26, 69-70, 75, 89-93; national 56, 75, 86 ; zones 59,71

conversation xvii, 25, 58-61, 80, 107, $121,123,169$

COVID-19 $\mathrm{xv}-\mathrm{xvi}, 124 \mathrm{n} 3$; see also lockdown

cruel optimism 148

decolonial xv, 4, 16, 23, 26, 29n8, 92-93, 167; see also feminism/t: decolonized; postcolonial

Derrida, Jacques 23, 48, 65n41

destitution xvi, 76

dispossession 88-89

education $19,22,49,69,71,74,77,79$, $81-83,86,107,170$

Eritrea 46-47

ethics: of feminist engagement with refugees 13, 41, 49-50, 58-59, 81; of representation $21,40,81,84,104$, 108, 122 (see also representation of forced migrants / refugees)

Europe xv-xvi, 20, 25, 43-50, 52, 58-59, 70; Germany 139; Greece 42, 44, 48, 140, 149-153; Netherlands 137; U.K. xv-xvi, 22, 26, 60, 101-106, 114-116, 138; see also refugee crisis

Evans, Kate 40-41

feminisation of migration $4,6-7$, 11,71 ; see also forced migration: gendering of

feminism/t: activism 12 (see also feminism/t: protest); alliance xviii, 12, 19, 26, 39, 50, 72, 89, 93, 111, 142, 146-147, 151, 152, 154, 156, 170; black and woman-of-colour 4, 85, 146; coalition xvi, 4, 59, 61, 93, 120, 147; collaboration xviii, 19 , 26, 90, 103, 106; and colonialism / imperialism 72, 81, 90; community xviii; decolonised 15, 80, 91-93; definition of 24, 168; figureheads 22 ; fourth wave 4,13 ; as movement $4,157-158,171$; protest $11-12$, 17, 25-26, 101-105, 111, 119, 122; postcolonial 4, 72, 96n26, 107, 112-113; queer 135, 140, 144, 148, 150, 156, 158; scholarship 18-19; solidarity 57 (see also feminism/t: alliance); South-South model 90-91; transnational 15 (see also transcultural feminism); see also intersectionality: intersectional feminism; queer/ness: queer feminism

Fernández, Ana Teresa 14

forced marriage 9, 53, 73, 82-83, 85, 136, 144; pishkesh (bride price) 71, 83-84, 86-88; see also child bride forced migrant women: image of 3, 20-21, 53, 165-167; as NGO figureheads 4, 20; within the media 4, 20, 167; as agents 13, 19, 168; see also representation of forced migrants / refugees: self-representation forced migration: feminist approach to 7-14 (see also transcultural feminism); gendering of 4, 7-9, 10 (see also feminisation of migration); as term 18; see also forced migrant women

Forced Migration Studies 6-8, 13, 136

gaze $69,72-73,77,81,91-92,134$, $165,167,170$

Gender and Development Studies 6-7, $42,45-46$

gender mainstreaming 4, 30n11, 137

gender persecution $9,45,82,108$

Geneva Convention see 1951 Convention Relating to the Status of Refugees

Ghaem Maghami, Rokhsareh $73,81-92$

Glissant, Édouard 54

Gopinath, Gayatri 133-134, 137

Greece see Europe: Greece

Haraway, Donna 140, 150, 152-154, 156

Hegazi, Sarah 131-133, 140

Home Office xvi

honour 55-56, 83; killing 136 
hospitality $19,23,25,48,51,91,109$, $136,154,171$

hostile environment 120, 170

humanitarian/ism 4, 26, 39-43, 54, 56, $73,82,88,90,92,104,108,111-$ $112,123,167$

immigration detention: Australian 106-114; centre 7, 9, 24, 26, 114121,159 n11; gendering of / feminist response to 102-103, 106, 115-116, 122; of pregnant women 103; protest against / within 101-104; system 101-102, 121-122; U.K. 114-121 (see also Yarl's Wood); U.S. 11-12, 102, 159n11

immigration removal centre see immigration detention: centre imperialism 3, 15-16, 26, 72-73, 84, $86,92,134,137,148,171$; see also colonialism; decolonial; feminism/t: and colonialism / imperialism; postcolonial

internal displacement 18, 24, 25, 69-92

intersectionality $27,80,82,84,92,135$, $141,146,147-148$; intersectional feminism xvii, 1, 4, 30n12, 157, 169

Iranian cinema 72-74, 76, 79, 81, 91-92; see also Ghaem Maghami; Makhmalbaf

Jarrar, Nada Awar 51-58

journalism 3-4, 20, 40, 51-52, 57, 74, 77, 86, 105, 137-138, 140, 149; literary 44-50; Nada El-Kouny 138; see also representation of forced migrants / refugees: in photography / photojournalism

Kahraman, Hayv 166-168

Klemp, Pia xvii

lesbian 136-141, 144-147; see also LGBTQ+; queer/ness

LGBTQ+ 101, 131, 133, 136-138, 142$143,147,158 \mathrm{n} 1$; gay international 142-143, 148; Hamid Sinno 131; see also colonial/ism: European-derived laws on sexuality; lesbian; queer

life-narrative 21, 107-108, 138; testimonio 42, 44, 46, 50, 59; see also oral history; voice: testimony listening, politics of $17,19,61,87,101$, 103, 105-106, 108-114, 117-118, 120-123; deep listening 27, 108, 114, 118, 122-123; see also voice

lockdown $\mathrm{xv}-\mathrm{xvii}$

Lorde, Audre 83

Maccarone, Angelina 139

Makhmalbaf: film house 74, 96n28;

Samira 70, 72-81, 91-92

Malkki, Liisa 4, 120

masculinity $8,11-12,43,45,55,71-73$, 77, 84, 109, 150; men 4; Minutemen 11; see also patriarchy

McDonald-Gibson, Charlotte 43-51

Mediterranean xvi, 43, 149, 153

M.I.A 22

Middle East xv; Afghanistan 25, 69-93; Egypt 131-132, 138; Iran 70, 72-91

(see also Iranian cinema); Iraq 165-167; Lebanon 51-53, 55-56;

Morocco 149, 151; queerness within 131-132, 138, 158n2; Syria xv, 4, 39-43, 51-55, 67n85

migrant crisis see refugee crisis

mobility: as embodied 2, 7,110; as queer metaphor 155 ; social 74-81; unequal politics of xvii, 7-8, 15, 18, 52; see also borders; forced migration

Mohanty, Chandra Talpade 15-16, 80, 84, 90, 168

mother/s 39-68, 123, 148; and child 48-49, 53; and child separation policy 102; healthcare for 39, 41-42, $50,54,75$; image of 43-49, 51, 53-54, 56, 58, 167-168; maternity as driver of forced migration 45-46; political alliance of $39,40,47,57$; see also pregnancy

Motta, Carlos 137

music: contrapuntality 109; in detention 106, 114-121, 123; hip-hop 85; rap 81, 85-90 (see also Sonita); see also M.I.A; therapy: music; voice: singing

Mutu, Wangechi 2-5

1951 UN Convention Relating to the Status of Refugees 9, 10, 31n34, 69, 132-133; see also asylum

oddkin 150, 152, 155-157, 140

Okparanta, Chinelo 138 
opacity 54-55

oral history 107-108, 122; see also asylum: anthology; life-narrative

patriarchy: and detention 10,121; and kinship structures 55-56, 84; as limiting factor in mobility 71, 75-76, 78; of militarism 92; of nation-state $10,18,46,56,134-135,144$; as system 48, 58, 82-83, 150; see also masculinity

performativity 86-89, 136, 139, 168

postcolonial $\mathrm{xv}, 4,16-17,29 \mathrm{n} 8$, 37n99, 52, 58, 88-89, 103, 108; see also decolonial; feminism/t: postcolonial

poverty $1,71,73,75,82$; see also destitution

pregnancy 9, 11, 43 (see also child; mother/s); forced 56

protest see feminism/t: protest; immigration detention: protest against/within

purdah 78; burqa 77-79; 'lifting the veil' 77

queer/ness 27, 131-158; 'queer diaspora' 134; 'queer liberal' 136137; 'queer refugee' 142, 145, 148; see also feminism/t: queer; lesbian; LGBTQ+; sexual orientation; trans; women*

\section{racism $85,145-147$}

rape $10-12,55-56,108,116,136,143-$ 144,147 ; see also sexual violence refugee crisis $\mathrm{xv}, 20,25,29 \mathrm{n} 7,40-44$, $51,58,70,149,170$; gendering of 4, 42

representation of forced migrants / refugees: in art xvii, 140-156, 165-167; in culture 3-4, 20-21; in documentary 26, 40; in film 3, 20, 70, 72, 84, 138-139 (see also Iranian cinema); in the Humanities 23; in literature 20-21, 39-67, 107-138 (see also life-narrative); in poetry 112-114, 141-148; in photography / photojournalism xvii, xviii, 20, 66n63, 116, 131, 136-137, 140, 149, 153; self-representation xv, xviii, 2 , 19, 35n82, 73, 84-90, 104, 137, 168 rescue: colonial rescue fantasy 71 ; politics of $21,41,86,168$; of refugees xvi, 44-45, 149, 153, 155; see also feminism/t: alliance / coalition / collaboration / community river xvii-xviii, 28, 169-170 Roy, Arundhati 80-81

\section{Sedgwick, Eve Kosofsky 134}

September 11th, 2001 69, 71-72, 77, 93 sexual orientation: claim to asylum on the basis of 133; persecution on the basis of 131-133

sexual violence $9,56,71,82,102-103$, $136,144,147$; see also rape

Shogaolu, Tamara 138

slave/ry 108, 145, 148, 170

Smith, Ali 104

Sonita 73, 81-92; see also rape; representation of forced migrants / refugees: self-representation

Sontag, Susan 86

sound, politics of 79, 101-103, 105-106, 109-111, 113-114, 117, 120, 122-123, 165, 171; 'refugee feedback' 111; 'sonic cosmopolitanism' 117-119; see also listening; voice: singing

Spivak, Gayatri Chakravorty 71, 104, 111; see also subaltern

'stranger fetishism' 59

subaltern 4, 91-92, 104, 108, 111, 167; see also Spivak, Gayatri Chakravorty

Taliban 22, 69, 74-75, 78-79, 81-82, 94

therapy 104, 107, 117; music 114-116

trafficking 7, 9, 18, 170

trans 131, 137, 139-140, 149-156; asylum claim on basis of persecution against 133, 137; trans feminism 151; transgender 9, 132-133, 139, 146, 151-152, 155

transcultural feminism 2, 5, 170-171; feminist imagination $2,6,14-15$, 167-171; see also feminism/t

trauma xvi, 9-11, 51, 56, 61, 102, 104, 106, 108, 117, 131, 135, 155, 170; see also therapy

Tsai, Charwei 114, 116-121

Tsang, Wu 140, 149-157

twenty-first century: asylum policy 106 ; cultural imagination 3-5, 20-21, 24, 169; numbers of displaced in 3,7 
U.S. 40; activism in 12, 102; border 11, 14, 141 (see also Anzaldúa, Gloria; borders: borderland; immigration detention: U.S.); government 39; home / host nation $81,86,90,92$, 140-148; hostile environment 41; militarism 25-26, 71, 75, 165-167

voice $21,113,168$; conversation xviii, 59-60; poetic $28,60-61,112-114$, 141-148, 170-171; silence /

silencing 104 (see also subaltern); singing 85, 105, 109, 114-121, 131 (see also music); testimony 105 , 107-108, 111-112, 115; see also asylum: interview; life-narrative; representation of forced migrants / refugees: self-representation widow 71,76

women* 27, 38n107, 132-133, 159n6; see also queer/ness; trans

women's groups: Circulo Violeta 12;

Georgia Latino Alliance for Human Rights 12; National Domestic Worker's Alliance 12; PAMOJA Women Together Group xvii-xviii, 18-19, 28, 35n82, 60-61, 67n87, 123, 169-170; Sisters Not Strangers xvi; Women for Refugee Women 26, 102, 106, 114, 116-119; see also feminism/t: alliance / coalition / collaboration / community

Yarl's Wood 101-103, 114-123; see also immigration detention

Yousafzai, Malala 22 


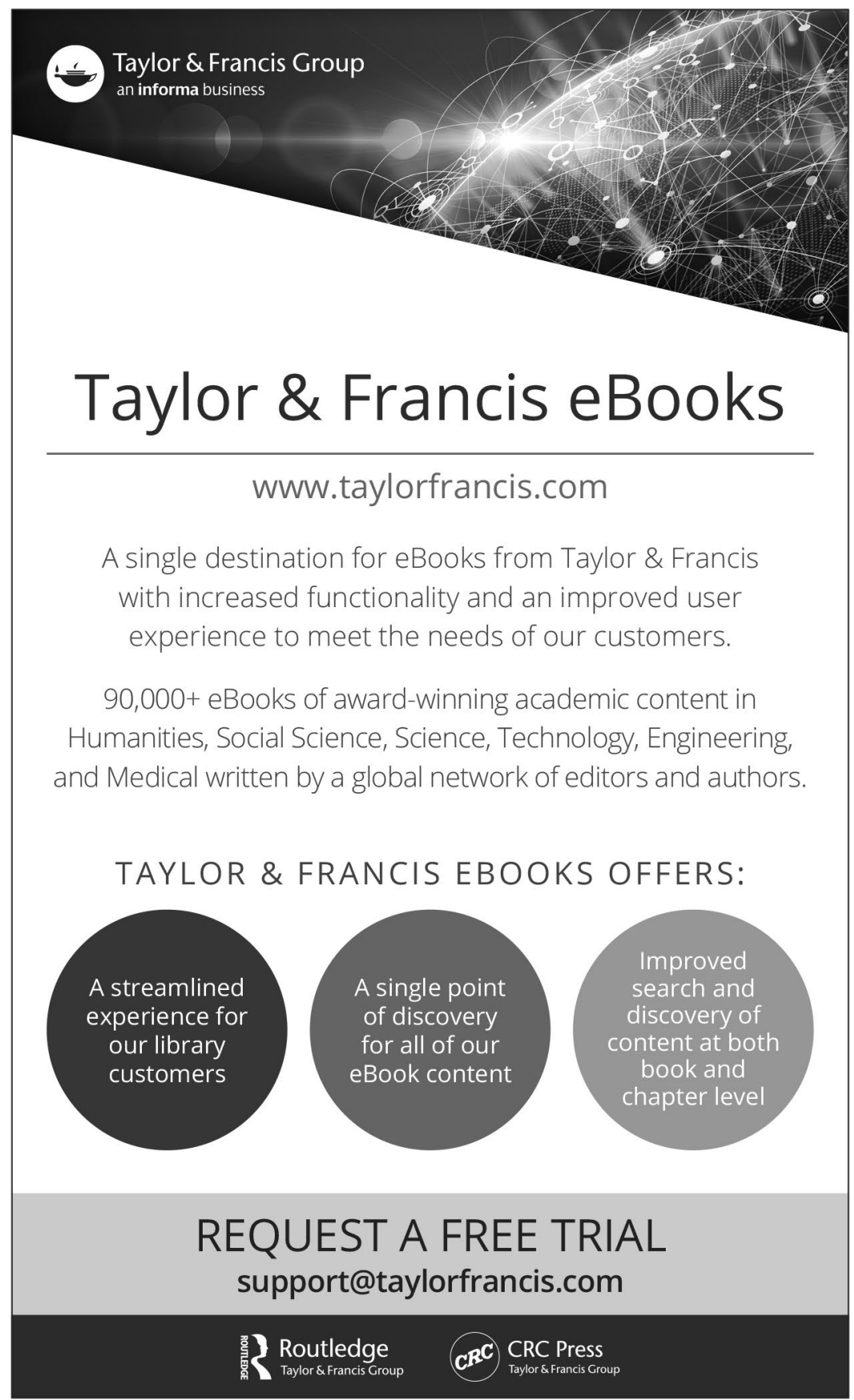

